\title{
Markus Wolf
}

\section{Freimaurertum bei Puškin}

\section{Einführung in die russische Freimaurerei und ihre Bedeutung für Puškins literarisches Werk}

Verlag Otto Sagner München · Berlin · Washington D.C.

Digitalisiert im Rahmen der Kooperation mit dem DFG-Projekt „Digi20“

der Bayerischen Staatsbibliothek, München. OCR-Bearbeitung und Erstellung des eBooks durch den Verlag Otto Sagner:

http://verlag.kubon-sagner.de

( $)$ bei Verlag Otto Sagner. Eine Verwertung oder Weitergabe der Texte und Abbildungen, insbesondere durch Vervielfältigung, ist ohne vorherige schriftliche Genehmigung des Verlages unzulässig. 


\title{
SLAVISTISCHE BEITRÄGE \\ Begründet von \\ Alois Schmaus
}

Herausgegeben von

Peter Rehder

\author{
Beirat: \\ Tilman Berger - Walter Breu - Johanna Renate Döring-Smirnov \\ Wilfried Fiedler · Walter Koschmal · Ulrich Schweier - Miloš Sedmidubský · Klaus Steinke
}

BAND 355

\section{VERLAG OTTO SAGNER \\ MÜNCHEN 1998}


Markus Wolf

\section{Freimaurertum bei Puškin}

Einführung in die russische Freimaurerei und ihre Bedeutung für Puškins literarisches Werk

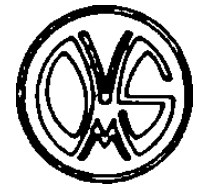

\section{Verlag OtTo SAGNeR}

MÜNCHEN 1998 
Die Tusche-Interpretation .. Puškin mit Zulinder. Stock und Blick nach links unten" ist das Werk von Pavel L'vovič Bumin und aus:

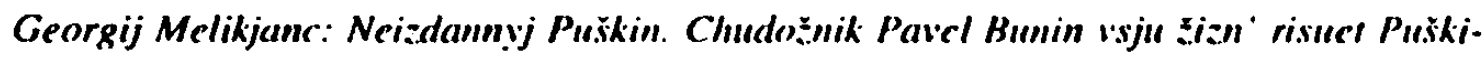
na. no izdat' al'bom s étimi rabotami ne mošet. In: Isvestija. $N^{\circ} 222$. 22. nojabrja 1997. S. 6.

Der Zirkel mit dem Winkeldreieck ist ein russisches Unikat und aus:

T. O. Sokolovskaja: Vozroždenie masonstva pri Aleksandre I. In: S. I. Mel'gunov / N. I. Sidorov: Masonstvo v ego prošlom i nastojaščcom II. Moskva 1915. 184. (alz sobranija PatekaN)

ISBN 3-87690-692-X

(C) Verlag Otto Sagner, München 1998 Abteilung der Firma Kubon \& Sagner D-80328 München 
Bei dem, was in Symbolle versteckt, verborgen ist, liegt nichts dahinter. So steckt das ganze Geheimnis der Freimaurerei daurin, daß man meint, es sei was dahinter.

GEORG F. WIIIEM HEGEL (1770-1831)

Einst führte mich mein Vater ins Lesekabinett einer der $\Delta$ oder $\mathscr{O}$-Logen, wo er ofi soupierte, Kaffee trank. Karten spielie und sonstige Freimaurerarbeiten verrichiete.

HEINRICH HEINE (1797-1856)

\section{O R W O R T}

Zu einem erstaunlich einhelligen Urteil über die 'masonistische Bündelei' kommen Hegel und Heine, zwei Zeitgenossen Puskkins, wie sie verschiedener nicht sein könnten: Eigentlich hätten die Freimaurer nichts Besonderes an sich, die, uniform kostümiert, sich regelmäßig an entlegenen Orten zusammenfinden und dabei in furchteinflößender Weise geheimnisvolle Utensilien zu ihrem Mittelpunkt machen. Die Doppeldeutigkeit der freimaurerischen Sprache, die Verschwiegenheit allen 'Nichteingeweihten' gegenüber - glaubt man dem Tenor Hegels und Heines, so wäre das Freimaurertum allein aus seiner geheimniskrämerischen Fassade zu erklären, und man könnte sich spannenderen Themen zuwenden. Doch Hegels pointiert vernichtendes Urteil und Heines aphoristischer Spott bezeugen zugleich das Gegenteil ihrer Botschaft: Die Einzigartigkeit einer weltbürgerlichen Bewegung, die es vermochte, so bedeutende Europäer wie Friedrich den Großen, Goethe, Fichte oder Mozart und russische Dichter wie Sumarokov, Radišcev, Glinka und Ryleev an sich zu binden.

Es war der Geheimniskult der Logen, der so viele anlockte, manche auch enttäuschte (wie beispielsweise Goethe) und insbesondere in den Augen der herrschenden Ordnung die Freimaurer verdächtig erscheinen lieB. Bis heute sind die Folgen dieses erfolgreich bewahrten Geheimnisses zu spüren, weshalb Neugierige vor allem auf zwei Quellen verwiesen sind: Entweder entschließt man sich wie Pierre Bezuchov in Lev Tolstojs «Vojna i min», selbst dazuzugehören, oder bleibt auf die zahlreichen „Verräterschriften“ ehemaliger Freimaurer angewiesen. Arbeiten zum Freimaurertum jenseits dieser engen Verbundenheit oder starken Distanzierung zu ihrem Thema sind leider immer noch selten. Mit meiner Arbeit hoffe ich, zu dieser 'dritten Gattung' freimaurerischer Literatur etwas beitragen zu können. Sie geht auf eine Untersuchung zuriick, die als Magisterarbeit im August 1989 am Münchner Institut für slavische Philologie entstand. Seither ist sie mehrfach überarbeitet, mit einer aktualisierten Literaturliste versehen und um einen dreiteiligen Index erweitert worden. Die Idee für dieses waghalsige Unternehmen geht auf meinen Lehrer Prof. Dr. Aage A. Hansen-Löve, zurück, für dessen zahlreiche und wertvolle Impulse ich an dieser Stelle danken möchte. Der Durchsicht der Erstfassung nahm sich Sebastian Ranft (Berlin) an, von dessen Fähigkeit, das jeweils Erreichte mit immer neuen Fragen zu konfrontieren, diese Arbeit sehr profitiert hat. Für die Endkorrekturen standen mir Uta Engelmann (München) und Julia Brauch (Berlin) zur Seite und waren mir eine unersetzliche Hilfe. Schließlich gilt mein Dank Herm Prof. Dr. Peter Rehder, ohne dessen Einsatzbereitschaft, Großzügigkeit und Erfahrung dieses Buch so nicht möglich gewesen wäre.

München, im Dezember 1997

Markus Wolf

Wolfmark@cip.ub.uni-muenchen de 


\section{A B K ÜRZUNG EN}

BSE

B. A. Vvedenskij/A. M. Prochorov (Hrsg.): Bol'šaja sovetskaja énciklopedija [BSE, Moskva, 3. Auflage, tom 1-30/31 (1969-78/81)]

ÉS

Brokgauz, F. A./Efron, I. A. (Hrsg.): Énciklopedičeskij slovar', [S.-Peterburg, tom 1-82 (1891-1904) \& Supplementbd. 1/D-4/D. (1905-07)]

KLL Kindlers Literatur Lexikon im dtv, Bde. 1-14, München 1986.

LÉS V. M. Koževnikov/P. A. Nikolaev (Hrsg.): Literatumyj énciklopedičeskij slovar', Moskva 1987.

PSS $\quad$ A.S. Puškin: Polnoe sobranie sočinenii v desjati tomach, 2. izdanie, Moskva 1956-58.

RA P. I. Bartenev (Hrsg.): Russkij archiv. [Žumal izdannij pri Certovskoj Biblioteke Petrom Bartenevym s 1863, Moskva, 1863-1917]

RS M. I. Semevskij (Hrsg.): Russkaja starina. [S.-Peterburg 1870-1918]

SEEJ

The Slavic and East European Journal. [De Kalb/lL., Bd. 1ff., 1957ff.]

SIÉ E. M. Žukov (Hrsg.): Sovetskaja istoričeskaja ènciklopedija. [Moskva, tom 1-16 (1961-76]

SJaP Slovar' jazyka Puškina. [Moskva, tom 1-4 \& Supplementband (1956-61)]

SSRLJa Slovar' sovremennogo russkogo literaturnogo jazyka. [tom 1-17, Moskva (1948-65)]

VE Vestnik Evropy. [1. Moskva (1802-30); 2. S.-Peterburg (1866-1918)]

VI Voprosy istorii. [Moskva, tom 1ff., (1926ff.)]

ŽMNP Žumal' Ministerstva narodnogo prosvěščenija. [S.-Peterburg (1834-1917)] 


\section{EINLEITUNG}

1. Das Freimaurertum - einführende Aspekte der Forschung................... 9

2. Freimaurertum bei Puškin - zum Forschungsstand ............................. 12

3. Ansatz und Ziel dieser Untersuchung .......................................... 16

\section{ERSTER TEIL: METHODIK}

KAPITEL I FREIMAURERISCHE SYMBOLIK UND KÜNSTLERISCHER TEXT

4. Symbolbegriff und freimaurerische Symbolik .................................. 18

5. Freimaurerische Symbolik und Geheimbund-Allusionen ................... 21

KAPITEL II AUSGANGSPUNKTE UND BEZUGSRAHMEN DER FREIMAURERISCHEN GEHEIMGESELLSCHAFTEN

6. Die „Alten Pflichten“ des James Anderson (1717/23) ........................ 22

7. Die Initiation und die Grade (Männerbundtradition) ......................... 23

8. Grundzüge des Rituals - „nichtverkörperte Symbolik“" ..................... 27

9. Beständige Zeichen - „verkörperte Symbolik“ .................................. 35

\section{ZWEITER TEIL: HISTORIE}

KAPITEL III GRUNDZUGE DER GESCHICHTE NICHTPOLITISCHER GEHEIMGESELLSCHAFTEN IN RUSSLAND (1730-1821/7)

10. Umstrittene Anfänge (1730er Jahre) ............................................. 41

11. Blütezeit und Verfall unter Ekaterina II. und Pavel I. (-1801) ............ 45

12. Anfängliche Unterstützung und späteres Verbot unter Aleksandr I.

a) Erste Logentätigkeit (1802) und Protektion (1810) ......................... 54

b) Reform des Großlogensystems (Provinzialloge/«Astraea») ........... 56

c) Puškins Loge «Ovidij» in Kisinev .............................................. 58

d) Gründe für das Ende aller Logen/Dekabristenaufstand .................60

KAPITEL IV

FREIMAURERISCHES IDEENGUT - EIN IDENTIFIZIERUNGSPROBLEM

13. Aspekte der Freimaurerdichtung und -literatur ................................. 64

14. Literatur mit Geheimbund-Allusionen ............................................ 67 


\section{DRITTER TEIL: ANALYSE}

\section{KAPITEL V ALLUSIONEN ZUR GESCHICHTE UND ZEICHENWELT NICHTPOLITISCHER GEHEIMBÜNDE IN PUŠKINS WERK}

Geheimbund-Allusionen in Puskins Lyrik

15. Lyrisches Schaffen vor 1821 (4. Mai) ...................................................6 68

16. Verbannungslyrik (1821-1826) .................................................. 70

17. Lyrik der Nachverbannungszeit (1826-1836) .................................... 75

Geheimbund-Allusionen in Puskins prosaischen Gattungen

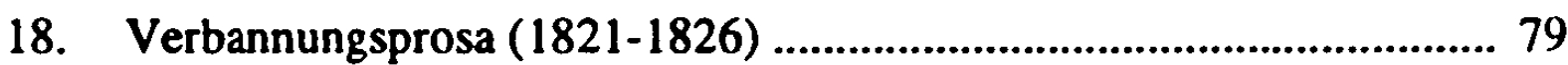

19. Prosa nach emeutem Verbot der Geheimbünde (1826-1836) ............ 82

Geheimbund-Allusionen in Puskkins Aufsätzen, Tagebüchern und Briefen

20. Puškins kritische Schriften und Aufsätze ........................................ 104

21. Puškins Tagebücher und autobiographische Schriften ....................... 107

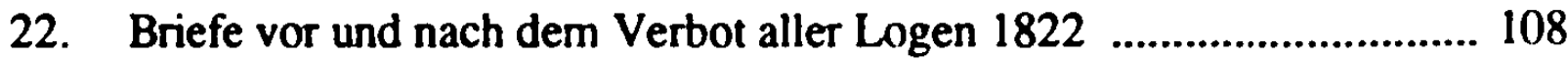

23. Briefe nach Puß̌kins Kenntnis vom Dekabristenaufstand (1826-) ........ 108

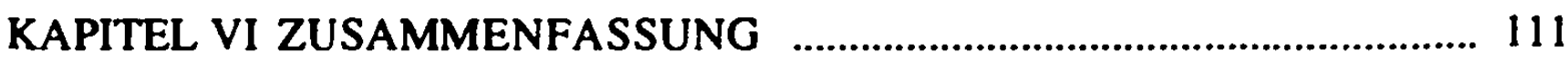

\section{LITERATURÜBERSICHT}

I. NACHSCHLAGEWERKE ZUM FREIMAURERTUM .................................... I

II. GENESE UND EXPANSION DES FREIMAURERTUMS ................................ III

III. FREIMAUREREI IN GESCHICHTE UND LITERATUR RUBLANDS .................. VIII

IV. MOTIVE DER FREIMAURERLITERATUR ............................................... XXIV

V. MOTIVE DES FREIMAURERTUMS BEI PUSKIN ......................................... XXIX

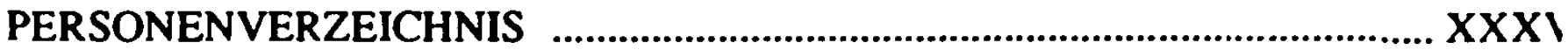

DEUTSCHES MOTIV - UND SACHREGISTER ........................................... XLV

RUSSISCHER MOTIVINDEX DES FREIMAURERTUMS ......................... LXIV 


\section{Das Freimaurertum - einführende Aspekte der Forschung}

Die Beschäftigung mit dem Freimaurertum öffnet den Blick in eine Männerbundtradition. die besonders im 18. und 19. Jahrhundert in weiten Bereichen des öffentlichen Lebens deutliche Spuren hinterlassen hat. Das Freimaurertum und die mit ihm verwandten okkultistischen und politischen Geheimbünde sind ein gesamteuropäisches Phänomen,' auf das verschiedene geisteswissenschaftliche Disziplinen in den letzten Jahren vermehr aufmerksam geworden sind. Es hat zwar bisher keinen Mangel an Publikationen über das Freimaurertum gegeben; doch sofern diese, wie es die Regel ist, von Freimaurem (den sogenannten „Eingeweihten") verfaBt worden sind, richten sie ihr Augenmerk überwiegend auf die Logenintema und die Entwicklung der verschiedenen Systeme. Weiterfuihrende Fragestellungen beispielsweise nach dem Einfluß der freimaurerischen Bewegung auf Artefakte aller Künste, treten dabei nur allzu oft in den Hintergrund. Die „nichteingeweihte" Forschung dagegen, soweit sie über entsprechende Kenntnisse verfügt, erwähnt nur in einzelnen Fällen, welche Persönlichkeiten aus Geschichte und Kunst dem Bund angehört haben. Ferner bildet die seit 250 Jahren von den Freimaurem in Deutschland betriebene Historiographie des Männerbundes in den grundlegenden Fragen ein völlig kontroverses Bild. So ist sogar bis heute unter den Angehörigen des Bundes strittig, ob der Freimaurerbund von den kirchenbauenden Steinmetzbruderschaften abstammt oder ursprünglich nur eine Genossenschaftsbildung der aufklärerischen Zeit darstellt. ${ }^{3}$

Um einen Zugang zu dieser entlegenen Thematik zu finden, müßte ein erstes Interesse darin bestehen, die Freimaurerbewegung von allen sonstigen Geheimbünden unterscheiden zu lernen. Eine wichtige Orientierung bietet hierfür der Münchner Historiker Ludwig Hammermayer. Um zu einer „Standortbestimmung von Loge und Geheimgesellschaft innerhalb der bürgerlich-adligen Organisationsformen des 18. Jahrhunderts“ zu kommen, so fordert er, müsse die Erforschung „multiperspektivisch angelegt (...), interdisziplinär

' GEYER, D.: Der Aufgeklärte Absolutismus in RuBland. Bemerkungen zur Forschungslage, in: Jahrbücher für die Geschichte Osteuropas 30 (1982), 176-89, hier 188.

2

Besonders auffällig ist das bei den länderbezogenen Darstellungen zum Freimaurertum. Neben den umfassenden Arbeiten des Nichtfreimaurers Aleksandr N. Pypin gehören die Publikationen von Emst Friedrichs für die Forschung über die Geschichte det Freimaurerei in RuBland zu den Standardwerken. Doch obwohl die Abhandlungen des ehemaligen Professors am Berliner Kadettenkorps von Pypin in dessen Spätwerk gewürdigt werden, finden sie keine entsprechende Beachtung in der wissenschafilichen Literatur. Friedrichs kommt besonders zugute, daB et um die Jahthundertwende ..Quellenmaterial der GroBen Landesloge zu Berlin sowie der Petersburget und Moskauer Bibliotheken" verwenden konnte. Trotzdem enthält seine 1921 erschienene „Russische Literaturgeschichte" nicht einmal Konturen einer russischen Freimaurerdichtung, ganz zu schweigen von freimaurerischen Anspielungen in einzelnen Werken.

${ }^{3}$ So R. HORN: Studien zur deutschen Freimaurerischen Historiographie des 19. Jahrhunderts, München 1980. Bis heute ist diese Frage nicht nur unter Anhängem des Bundes strittig geblieben. (I FNNHOFF/POSNER (1932), 127/134/598 (siehe unter „Bauhüttenbruderschafien“, „Geschichtstheorien der Freimaurerei ${ }^{\text {(N)}}$. Die unter Freimaurem seltener vertretene Genossenschaftsthese dominien H. BOOS: Geschichte der Freimaurerei. Ein Beitrag zur Kultur und Literatur-Geschichte des 18. Jahmunderts (1906), Wiesbaden 1969. 
durchgeführ" und „übernational“ betrieben werden. Grundsätzlich gelte, daß Freimaurerlogen allesamt Geheimgesellschaften, umgekehrt aber nicht alle Geheimgesellschaften Freimaurerlogen seien. Zweitens muß genau zwischen ,regulär-orthodoxalem Freimaurertum und den paar- und pseudomaurerischen Geheimbünden, von den Gold- und Rosenkreuzern bis zu den Illuminaten genau differenziert" werden."

Dabei ergeben sich folgende Schwierigkeiten: Da die Mitglieder des Bundes offiziell zur Verschwiegenheit über das „Gebrauchtum, die Erkennungszeichen und die inneren Angelegenheiten ${ }^{\text {“5 }}$ der Freimaurerlogen verpflichtet sind, bleibt der "profanen ${ }^{\text {“6 }}$ Forschung nur die Lektüre der sogenannten „Verräterschriften“, um zu einem Grundmuster der Symbolik und Rituale der Freimaurer zu kommen. Von seiten der Freimaurer wird seit langem beteuert, daß das Geheimnis unzählige Male „verraten“ worden sei.' Mittlerweile ist die auch Nichtfreimaurem offenstehende Literatur kaum mehr zu überblicken.

Dennoch ist ein Großteil aller Schriften, die das Freimaurertum zum Gegenstand hat, von „Nichteingeweihten“" geschrieben worden, deren Beweggründe meist politisch motiviert waren und einer sachlichen Aufklärung daher oft nicht dienlich sind. Die Hauptangriffe ihrer Schriften zielen vor allem auf das Geheimnis der Freimaurer. Seit den ersten päpstlichen Bullen' kehrt dieser Vorwurf immer wieder. Zwar ist das Geheimnis das Moment, welches das Freimaurertum auch mit den politischen Geheimbünden verbindet, dennoch hat es damit bei den Freimaurern eine völlig andere Bewandtnis: Dem „Nichteingeweihten" bleibt das persönliche Erlebnis einer zeremoniellen Kulthandlung verborgen, während der Kult in politischen Geheimbünden nur ein Mittel für einen Zweck dar-

'HAMMERMAYER, L.: Zur Geschichte der europäischen Freimaurerei, in: BÁLAZS, E. H./HAMMERMAYER, L./... (Hrsg.): Befirderer der Aufklïrung in Osteuropa. Freimaurer, Gesellschaften, Clubs, in: Studien zur Geschichte der Kulturbeziehungen in Mittel- und Osteuropa 5 (1979), 13/33.

'Das ,Internationale Freimaurerlexikon“ (1932) von E. LENNHOFF/O. POSNER betont in Anlehnung an die „Alten Pflichten“ des Konstitutionenbuches (1723) von Reverend James Anderson, welche dort auch auf den ersten Seiten übersetzt abgedruckt sind, daB das freimaurerische Geheimnis in den Gelöbnisworten ruhe, die der Lehrling bei seiner Aufnahme dem Meister vom Stuhl nachspreche. Darin gelobt der Kandidat „über das Gebrauchtum, die Erkennungszeichen und die inneren Angelegenheiten unverbrïchliche Verschwiegenheir” zu bewahren. (Siehe unter „Geheimnis“", 575)

6.

Als ,profan“ gilt die ganze uneingeweihte Umwelt außerhalb der Freimaurerei.

LENNHOFF/POSNER (1932), 1642-47. Die Verfasser des Lexikons haben den sogenannten Verräterschriften einen eigenen Eintrag gewidmet. Darin werden zahireiche Publikationen chronologisch aufgeführ, die eine Enthüllung des freimaurerischen Geheimnisses beanspruchen. Das Aufkommen der Freimaurerei habe anfänglich eine Flut von Privatdrucken mit sich gebracht; diese hätten zunächst allein dem "Sensationsbedürfnis der Zeir" und erst später ,religions- oder parteipolitischen Zwecken“ gedient.

Mehrere Bücher könnten allein mit Gerüchten und Anfeindungen gefüllt werden, denen sich die Freimaurerei seit ihren Anfägen im 18. Jahrhundert ausgesetzt sieht.

'In der ersten Bulle von Papst Clemens XII. (28.4.1738) wurde eine „Vermischung der Katholiken“ mit dieser "religiösen Sekte" verboten und zum ersten Mal die ..Staatsgefährlichkeit der Freimaurerei" festgeschrieben. (LENNHOFF/POSNER (1932), 235/36) 
stellt, bei dem es nicht um die Vervollkommnung der Tugenden des einzelnen Mitgliedes geht. Das freimaurerische Geheimnis liegt demnach im „Wesen des Mysterien-Männerbundes", das nur durch den Akt der freimaurerischen Einweihung (,Initiation") offenbart werden kann.

Andererseits hat gerade die Betonung des Geheimnisses als Merkmal des freimaurerischen Selbstverständnisses in der „profanen“ Welt zu allerhand Spekulationen und neben politischen Verleumdungen sogar zu einer Reihe abergläubischer Vorstellungen geführt. Das „Handwörterbuch zum Deutschen Aberglauben“ (1931) vermerkt eine Reihe abwegiger "Vorstellungen des Volksglaubens" über angebliche Besonderheiten des Bundes." Die Freimaurerei wird jedoch nicht mehr allein abergläubischen Spekulationen überlassen. Neben Historikern interessieren sich zunehmend Theater- und Musikwissenschaftler für den Einfluß von Brauchtum und Symbolik des Freimaurertums auf Kunstwerke namhafter Künstler.'

Bei den genannten Hindernissen kann eine Untersuchung künstlerischer Texte auf ihre freimaurerischen Aspekte sich auf verschiedene Quellen stützen: Neben dem symbolischen Brauchtum, den rituell-stereotypen Dialogen und der Geschichte des Freimaurertums können auch abergläubische Vorstellungen über den Männerbund nicht aus dem Blick verloren werden.

10

LENNHOFF/POSNER (1932), 575.

11

Als ein immer wiederkehrendes Beispiel sei an dieser Stelle auf die Vorstellung des sogenannten 'Jahresopfers' hingewiesen. Jedes Jahr, so sagt die Uberlieferung, losen die Freimaurer einen unter sich aus, der noch im selben Jahre sterben muB. In die gleiche Richtung geht der Vorwurf des Ritualmordes. Nach BÄCHTOLD-STÄUBLI spielt bei diesem Aberglauben der Inhalt der maurerischen Lehren und die humanitäre Grundidee keine Rolle, sondern zielt vor allem auf die geheimnisvolle Kultemystik. Das sei dadurch begünstigt worden, daB der Bund zwar seine Ideen habe bekannt werden lassen, das Ritual aber geheimhalie. (BÄCHTOLD-STÄUBLI, H./HOFFMANN-KRAYER, E.: Handwörterbuch des deutschen Aberglaubens, Bd. 3, Berin/Leipzig 1931, 23-45)

${ }^{12}$ DaB Wolfgang Amadeus Mozart dem Freimaurerbund angehört hat, ist nicht jedem bekannt. Dabei ist der freimaurerische Einfluß auf seine Musik nicht zu unterschätzen. Er hat sogar Werke komponiert, die unmittelbar als musikalische Umrahmung des Rituals gedacht waren. Es ist das Verdienst des Prager Musikwissenschaftlers PAUL NETTL, auf Elemente der ,königlichen Kunst“" in Mozarts „Zauberflöte“" im „Hohelied“ und anderen Werken hingewiesen zu haben. Daneben gibe es von GROSSEGGER (1981) eine Untersuchung zu Freimaurerdramen in Österreich, für die Zeit 1770-1880, in denen Mozarts Oper ebenfalls eine grobe Rolle spielt. Interessant für die weitere Untersuchung ist in diesem Beitrag der Versuch, zu einem Paradigma der freimaurerischen Symbolik und des Brauchtums zu kommen, was erst eine systematische Analyse der Dramen nach freimaurerischen Aspekten ermöglichen würde. In diesem Bemühen ist die Arbeit von Grobegger im Bereich der Theaterwissenschaften die einzige ihrer Art. (GROSSEGGER, E.: Freimaurerei und Theater 1770-1880. Freimaurendramen an den k.u.k. privilegierten Theatem in Wien 1981) 


\section{Freimaurertum bei Puškin - Zum Stand der Forschung}

Zum Anlaß des 100. Todesjahres Puškins schreibt der Schriftsteller Michail A. Osorgin in der Pariser Emigrantenzeitung «Poslednyja novosti» (1937) einen Artikel über den Aspekt des Freimaurertums bei Puškin. Darin beklagt er, daß - gemessen an der Menge von Veröffentlichungen - seit dem Tod des Dichters die Gemeinsamkeiten zwischen Puškin und dem Freimaurerbund nur geringes Interesse gezeitigt hätten.'

In der Tat ist der Aspekt des Freimaurertums sowohl in bezug auf das Leben Puškins wie auch auf sein Werk deutlich vernachlässigt worden. Dies hat vor allem zwei Gründe. Zum einen konnte P. V. Annenkov erst 1855 die sechsbändige Ausgabe von Puškins Werken durchsetzen. Fünfzehn Jahre später wurde dann der breiten russischen Öffentlichkeit zum ersten Mal der Brief Puškins zugänglich gemacht, in dem er seinem Freund V. A. Žukovskij seine einstige Zugehörigkeit zu einer Loge in Kiß̌inev gesteht. " Schwer wog, daß Zar Aleksandr I. 1822 alle Geheimgesellschaften einschließlich der offiziell angemeldeten Freimaurerlogen in Rußland verbieten ließ. Fünf Jahre später wurde in Folge des Dekabristenaufstandes dieses Verbot emeut bestätigt. Die somit erzwungene Tabuisierung der Freimaurerei blieb daher nicht ohne Auswirkungen auf die Geschichtswissenschaft und die künstlerische Literatur. Erst in der zweiten Hälfte des 19. Jahrhunderts avancierte die Freimaurerei erstmals $\mathrm{zu}$ einem eigenen Thema in amtlichen und wissenschaftlichen Publikationen der zaristischen Zeit." Weit folgenreicher als diese Veröffentlichungen, die nur in einem kleinen Kreis ihre Wirkung entfalten konnten, war Tolstojs Roman «Vojna i min, in dem in aller Ausführlichkeit das freimaurerische Aufnahmeritual geschildert wird. Bis heute ist das Bild vieler Russen von der Freimaurerei ausschließlich durch diesen Roman geprägt. ${ }^{10}$

13

OSORGIN, M. A.: Puškin - vol'nyj kamenšxiik, in: Postednyja novosti, 10.2.1937, 1-6. Im gleichen Jahr erschien sein Roman, der einen Freimaurer porträtierte *Vol'nyj kamenšzikn.

${ }^{14}$ PUŠKIN, A. S.: Novye pis'ma Puškina k V. A. Žukovskomu, in: RA 8 (1870), 1176777. 15

Die Gründe für die plötzlich aufkeimende Publikationstätigkeit ab 1865 hängen mit der am 6. April von Aleksandr II. in Kraft gesetziten Neuregelung des russischen Presse- und Publikationswesens und der damit verbundenen Aufhebung der Präventivzensurbestimmungen zusammen. Der Literaturhistoriker und Freimaurerexperte Aleksandr Pypin bringt 1867 seine erste Schrift über den Männerbund heraus: PYPIN, A. N.: Russkoe masonstvo, in: Vestnik Evropy 12 (1867), 42-48. Eine amtliche Kommentierung der Ereignisse von 1822 leistet KUŠELEV, E. A.: Uničtoženie masonskich łož v Rossii v 1822 g., in: RS 18 (1877), 455-79, 641 -54 mit einem Kapitel über den «Arzamas» (655/56). Literaturwissenschaftliche Arbeiten, die den Bund direkt behandeln, erscheinen ab 1867 und betreffen zunächst nur die Ekaterinische Zeit: LONGINOV, M. N.: Novikov i moskovskie Martinisty, Moskva 1867, 85-87. (Siehe auch seine Rezension in: Vestnik Evropy $6 / 7$ (1867)); NEZELENOV, A. I.: Nikolaj I. Novikov, izdatel' zurnalov, S.-Peterburg 1875; PEKARSKIJ, P. P.: Dopolnenija $\mathbf{k}$ istorii masonstva v Rossii XVIII ago stoletija (1780-1792gg.), in: Sbornik stat'ej, citannych $v$ otdelenii russkago jazyka i slovesnusti Imp. Akad. nauk 7 (1870), No. 4, 1-224.

16

In Tolstojs «Vojna i mir» (1868/69) wird Pierre Bezuchovs Eintrit in den Bund beschrieben und auch das freimaurerische Aufnahmeritual wiedergegeben. (TOLSTOJ, L. N.: Vojna i mir, tom II, cast' 2. gl. $2(2-4 ; 10 ; 12) ;$ gl. 3 (7; 8; 10). Bis heute sind in RuBland Ziele und Riten des Bundes überwiegend 
Von einer zunehmenden Aufmerksamkeit durch die Geschichts- und Literaturwissenschaft kann erst ab 1905/06 gesprochen werden, als die Freimaurerei wieder aufkeimte, und auch Veröffentlichungen sich wieder vermehrt der Bewegung widmen." Da in sowjetischer Zeit das Verbot des Männerbundes erneuert wird - ohne daß nach dem letzten Verbot 1826 eine ausdrückliche Erlaubnis zu seiner Wiedereinführung bestanden hätte wird die Erforschung dieses kulturgeschichtlichen Phänomens Anfang der zwanziger Jahre wieder eingestellt." Ebenso wie in der Zeit davor, stand das emeute Verbot aller Geheimgesellschaften einer eingehenden Erforschung des Verhältnisses von Puškins und

nur durch Tolstojs Roman bekannt. „Eingeweiht" wurde Tolstoj jedoch nicht. Dennoch ist seine persönliche Einstellung zu dern Männerbund belegt. Am 7/20. März 1905 schrieb er aus Jasnaja Poljana einem deutschen freimaurerischen Schriftsteller, daB er sich über das zugesandte freimaurerische Buch bedanke, und dab es ihn freue, ohne es zu wissen, seiner „Gesinnung nach ein Freimaurer" zu sein. Uberdies versicherte er, bereits seit seiner Kindheit zu wissen, daB die "Freimaurerei viel Gutes für die Menschheit" ge$\tan$ habe. (LENNHOFF/POSNER (1932), 1586)

17 LENNHOFF/POSNER (1932: 1355-63). Siehe auch in der Literaturübersicht unter III. „Freimaurerei als Phänomen in Geschichte und Literatur RuBlands". Als vorrevolutionäre Freimaurerei-Experten sind hervorgetreten: M. V. Dovnar-Zapol'skij, S. P. Mel'gunov, A. N. Pypin, V. I. Semevskij, T. O. Sokolovskaja und G. V. Vernadskij.

$1 "$

Auffallend ist, daB sowjetische Historiker die freimaurerische Geheimbundthematik nicht behandeln. Der Aufsatz in der *Sovetskaja istoriceskaja enciklopedija» 9 (1966). 167-69) über die Freimaurerei ((frank-) masonstvo) wurde nicht von einem Historiker geschrieben, sondem von dem Tartuer Strukturalisten Ju. M. LOTMAN (1966). Die angefuihnte Literaturliste vermerkt nicht eine historische Arbeit aus sowjetischer Zeit. Von den vorrevolutionären Publikationen und zwei späteren philosophischen Aufsätzen abgesehen (E. G. PLIMAK (1957); B. S. SOLODKIJ (1974)), hat sich nur die nichtsowjetische Forschung um Zugänge zur Geschichte der freimaurerischen Geheimblinde in RuBland bemüht (siehe auch GEYER, D.: Der Aufgeklärte Absolutismus in RuBland, in: Jahrbucher für die Geschichte Osteuropas 30 (1982), 188/89). Seit 1966 hat sich daran kaum etwas geändert. Neben Ju. M. LOTMAN haben unter den sowjetischen Literaturwissenschafilern P. N. SAKULIN (1915; 1928), N. K. PIKSANOV (1947), G. P. MAKOGONENKO (1976), N. D. KOČETKOVA (1975; 1987) ein literaturhistorisches Interesse an der Thematik erkennen lassen, wobei die zuletzt genannte Forscherin in der neuen einbändigen Literaturenzyklopädie (LES (1987), 212/13) nicht nur den gesamteuropäischen Aspekt, sondern erstmals auch die Bedeutung der Freimaurerei für die russische Literatur herausstellt. Nach 1917 ist auberhalb der Sowjetunion dem gröBten internationalen Geheimbund sowohl in der historischen Forschung wie auch als Motiv in der künstlerischen Literatur mehr Beachtung geschenkt worden. Neben einigen ausländischen Schriften der letzten zwanzig Jahre kann die russische Emigration insgesamt auf eine lebhafiere Publikationstätigkeit zurickblicken. Namentlich hervorzuheben sind insbesondere T. A. BAKOUNINE [BAKUNINA] (1935; 1967; 1967) und P. BOURYCHKINE (1967), die zusammen die einzige Bibliographie von der "Freimaurerei in RuBland" (1967) erstellt haben. T. A. Bakunina hat überdies in französischer Sprache ein Freimaurerverzeichnis mit über 3.000 namhaften Personen herausgegeben, die bis 1822 dem Bund angehört haben. Die jedem Portrait sich anschließenden Titelverweise sind sehr hilfreich. Tat'jana A. BAKIJNINAS (1935) erste Schrift über die russischen Freimaurer stellt dreizehn ihrer Anhänger vor und dokumentiert ihre einzelnen Verbindungen, wobei sie auch A. S. Puskin berücksichtigt. In der überwiegend historiographisch motivierten Forschung treten die Emigranten B. TELEPNEV (1923; 1925; 1926; 1929), D. TSCHIŽEWWSKIJ (1935), E. ELKIN (1965/66), G. V. VERNADSKIJ $(1923 ; 1927)$ und N. N. BERBEROVA (1986) hervor. 
seinem Werk zum Freimaurerbund entgegen."

Ein breiter Rahmen wird unter den sowjetischen Literaturwissenschaftlern dagegen dem Kontakt Puškins mit den Dekabristen eingeräumt. Da viele der Dekabristen Freimaurer waren, ${ }^{\text {D }}$ enthalten auch Monographien zu diesem Thema Hinweise auf den Bund, die das Verständnis von Puškins künstlerischen Texten vertiefen.

Abgesehen von wenigen Stellen bei Puskkin, die einen direkten Hinweis auf das Frei-• maurertum erkennen lassen, fält auf, daß es vornehmlich nichtmuttersprachliche Slavisten gewesen sind, die unscheinbare Bezüge auf Freimaurerei gezielt enthüllt und Verbindungen herzustellen versucht haben. ${ }^{22}$ Diese Arbeiten betreffen einzelne Werke Puškins und beziehen sich nur auf ausgesuchte Teile einer freimaurerischer Symbolik. Eine umfassende Klassifikation freimaurerischer Symbole und Rituale ist jedoch bisher ausgeblieben, von der Frage, wie Puškin Freimaurerlogen-Interna für seine Texte poetisch nutzbar macht, ganz zu schweigen.

Was für die Symbolik und Ritualistik zutrifft, gilt auch für die freimaurerische Historie bei Puškin. Da die Geschichte des Freimaurertums nur wenigen bekannt - unter ihren Anhängem aber umso deutlicher präsent - ist, ist ihre Kenntnis bei Puškin nicht nur vorauszusetzen, sondern es ist sogar damit zu rechnen, daß Puškin unter den Bedingungen einer aufmerksamen Zensur verdeckte Anspielungen macht. Demnach sind drei Elemente des Freimaurertums Quellen einer möglichen Auseinandersetzung Puškins mit einem

19

Soweit nicht anders vermerkt, beziehen sich alle Datierungen auf den Gregorianischen Kalender.

20

LENNHOFF/POSNER (1932), 329/30 basiert auf FRIEDRICHS (1904), 160/61. Die Führer des Aufstandes und besonders jene, die mit Puškin in Verbindung standen, gehörten überwiegend den nichtpolitischen Freimaurergesellschaften an. (F. N. Glinka, P. I. Pestel', V. F. Raevskij u.a.)

21

Das betrifft beispielsweise die Beiträge der Autoren V. A. MJAKOTIN (1923), M. B. NEČKINA (1949), N. Ja. EJDEL 'MAN (1979; 1984) und V. G. BAŽANOV (1950). Schwierig bleibt die Unterscheidung zwischen den Dekabristenbünden und den nichtpolitisch-freimaurerischen Verbänden, da hierzu keinerlei Quellen vorliegen.

$\boldsymbol{2}$

Das Literaturverzeichnis beinhaltet im Teil V. Titel zu freimaurerischen Symbolen, Ritualen und Allusionen bei Puškin. Die wichtigsten davon sind von den Slavisten H. B. WEBER (1968), L. G. LEIGHTON (1977;1982;1983) und E. NERRE (1986). Abgesehen von früh erkannten Bezügen in Puß̌kins Widmungsgedicht aGeneralu Pušxinu» (1821) für den Chef der Kišinever Freimaurerloge "Ovidij», von Parallelen zu der Eidesformel des freimaurerischen Initiationsrituals im Gedicht «Prorok» (1826), die schon in zaristischer Zeit verbreitet worden sind, glauben 0.g. Autoren freimaurerische Anspielungen (Allusionen) in Puskkins «Pikovaja damas (1834) [H. B. WEBER; L. G. LEIGHTON] und sogar parodistische Stilisienungen des Freimaurertums im «Grobovకcik» (1830) [E. NERRE] ausmachen zu können. Eine Ausnahme stellen auch nicht die Veröffentlichungen zweier Emigranten zum Thema «Puskin i masonstvo» dar. Ihre Publikationen (1940); o.J.) behandeln vornehmlich das Leben Puskins und sehen in seinem Duelltod die Machenschaften einer Freimaurerei, die sich als zarenfeindlicher Verschwörungsbund an Puskins Distanzierung gegenüber den Dekabristen gerächt hat. Diese Mutmaßungen sind aber weder mit Puskins Briefwechsel noch mit seinem autobiographischen Schrifttum belegbar. Die zitierten Bezüge Puškins auf die Geheimbünde finden sich übrigens bei ihnen nicht im Original, sondern gehen auf die vorrevolutionäre Forschung zurück. (IVANOV, V. F.: A. S. Puškin i masonstvo, Charbin 1940; BAŠlLOV, B.: Puškin i masonstvo, in: Istorija russkogo masonstva 7, Buenos Aires o. J.) 
Männerbund (die Symbol- und die Ritualwelt wie seine Geschichte), welcher in seiner wichtigsten Schaffensperiode verboten, dem er aber noch vor seinem Verbot beigetreten war. 


\section{Ansatz und Ziel dieser Untersuchung}

«4 Мая был я принят в масоны», schreibt Puškin in seinem Tagebuch im Jahre 1821 im bessarabischen KiY̌inev, genau ein Jahr nachdem er Petersburg hatte verlassen müssen. ${ }^{23}$ In einem Brief an seinen Freund V. A. Žukovskij schreibt Puškin fünf Jahre später, ${ }^{21}$ daß er Mitglied einer KiSinever Loge gewesen sei. Ohne den Namen der fraglichen Loge zu erwähnen, fügt er hinzu, es sei die Loge, wegen der in Rußland alle anderen geschlossen worden seien. Nur an diesen beiden Stellen bekennt er seine Zugehörigkeit zum Freimaurerbund. Hingegen wird in den amtlichen vorrevolutionären Untersuchungen seine Mitgliedschaft in der Loge «Ovidij» in Kišinev bezweifelt.

Sicher ist jedenfalls, daß sein Vater und sein Onkel Freimaurer gewesen sind. ${ }^{26}$ So wäre es nicht verwunderlich, hätte Puškin bereits vor der autobiographisch belegten Aufnahme in den Freimaurerbund in Kišinev (4.5.1821) Elemente freimaurerischer Logeninterna poetisch verarbeitet. Insofern gehört auch Puškins frühe „voreingeweihte“ Schaffensperiode (Lyzeumslyrik und sonstige Werke vor 1821) mit zum Gegenstand der Untersuchung. Weitere Eckpfeiler der Freimaurerhistorie bilden die gegen den Bund erlassenen Verbote vor und nach dem Dekabristenaufstand $(1822 ; 1826)$, so daß sich die Analyse der Werke Puškins mit Blick auf geheimbundhistorische Ereignisse in drei Abschnitte gliedern läßt:

1. Poetisches Schaffen vor Puškins angeblicher Aufnahme (4.5.1821);

2. Zeit nach dem ersten Verbot des Freimaurertums und aller anderen $\mathrm{Ge}$ heimbünde (1.8.1822) bis zum Dekabristenaufstand (25.12.1825);

3. Werke der Periode nach dem emeuerten Verbot des Freimaurertums (21.4.1826).

Diese Perioden werden jeweils getrennt nach den Gattungsformen (Lyrik, prosaische

23

Dieser Arbeit liegt die zehnbändige Ausgabe von Puskkins Gesamtwerk zugrunde. (PUŠKIN, A. S.: Polnoe sobranie soxinenij, tom I-10, Moskva 1956-58. (im folgenden zitiert: „PSS“)) PSS VIII, 18.

${ }^{24}$ PSS X, 198/99. (Pis'mo k V. A. Zukovskomu 20.1.1826)

KUL'MAN, N. K.: K istorii masonstva $v$ Rossii. Kišinevskaja loð̌a, in: Zumal Ministerstva narodnago prosvěšcenija 11 (1907), 343-73, hier 355. Zur Loge «Ovidij» siehe Kap. III, 12c.

26

Der Vater Sergej L'vovix (1770-1848) tritt in St. Petersburg 1817 der Loge «Alexandre (du Lion d'Or)» bei. Dessen Bruder (und Onkel von Aleksandr) Vasilij L'vovix Puß̌kin (1770-1830), der wie Aleksandr auch zu dem Dichterkueis «Arzamas» gehört hat, ist schon seit 1810 Mitglied der Petersburger Loge «Les Amis Réunis». Mitglied ist zur selben Zeit der spïtere Führer der Dekabristen P. I. Pestel’. In den Jahren 1819/20 wird er in den Mitgliederlisten der Loge «Elisabeth a la Vertu et Chercheurs de la Mannen als Steward ersten Grades geführt. (BAKOUNINE, T.: Repertoire biografique des francs-macons russes, (XVIIle et XIXe sizcles), Paris 1967, 429) Die engagierte Anhängerschaft des zeit seines Lebens Puškin sehr z.ugetanen Onkels und Dichters Vasilij läBt die Annahme zu. daB A. S. Puskin Logeninterna schon vor seinem Eintritt in den Bund bekannt gewesen sind. Unklar ist trotzdem, ob Puskin auch formell Freimaurer war, was nach dem Verbot bis zu seinem Tod nicht ausgesprochen oder aufgeschrieben werden konnte. Eine jede Beschäftigung mit freimaurerischem Gedankengut geht jedoch zwangsläufig mit einer Verbundenheit zur Bewegung einher. 
Gattungen sowie Aufsätze, Tagebücher und Briefe) ${ }^{27}$ nach freimaurerischen Inhalten untersucht. Die Berücksichtigung aller überlieferten Texte sowie die gewählte Einteilung erlaubt danach abschließende Aussagen, die den Stellenwert freimaurerischer Elemente und Anspielungen im Gesamtwerk Puskins beurteilen lassen. (Kap. IV)

Im dritten analytischen Teil (Kap. V) werden die „Geheimbund-Allusionen“ zur Geschichte und Zeichenwelt nichtpolitischer Geheimbünde im Werk Puškins" behandelt. Die Bezeichnung "nichtpolitischer Geheimbund" wird dabei aus Gründen gewählt, die in der Problematik der Identifizierbarkeit des Freimaurerbundes liegen."

Diese Untersuchung wird von den ersten beiden Teilen METHODIK und HISTORIE vorbereitet. Im ersten Teil der METHODIK (Kap. I) wird das Verhältnis 'künstlerischer Text und freimaurerische Symbole' - als erste Voraussetzung für die Analyse des künstlerischen Textes - dargestellt. Der Bezug des künstlerischen Textes auf Bund und Symbol wird mit Hilfe des systematisierenden Oberbegriffs der Allusion hergestellt. Eine zweite Aufgabe des methodischen Teils wird es sein, den inhaltlichen freimaurerischen Bezugsrahmen nach außen (Freimaurertum als 'korporatives Phänomen') wie nach innen (,Alte Pflichten“, „Hiram-Sage“, "Steinmetzzunft-Brauchtum“ usw.) abzustecken. Die Erarbeitung dieses internen Bezugsrahmens bietet die Möglichkeit, aus den der freimaurerischen Literatur entnommenen Schlüsselwörtem ein Glossarium für den russischen Logenbetrieb zu erstellen. Ein russisches Motivregister im Anhang dieser Arbeit erschließt dieses Material (Brauchtumsutensilien. Tugenden, Wendungen des freimaurerischen Frage-und-Antwort-Spiels) erstmals systematisch, das heißt sowohl in seiner Bedeutung während des 'maurerischen' Logenbetriebs wie auch im Werk Puškins.

Die methodische Grundlegung eines begrifflichen und inhaltlichen Bezugsrahmens (ERSTER TEIL) sowie ihre Einordnung in den historischen Kontext (ZWETER TEIL) bilden diz Voraussetzungen für die Analyse des Puškinschen Werkes. Die Analyse (DRITTER TEIL) veranschaulicht als Herzstück dieser Studie die Einbettung freimaurerischer Motive in Puškins Werk und gibt Aufschluß, inwieweit Puskin - unter den Bedingungen des Verbots der Geheimgesellschaften - seinem Bund literarisch treu geblieben ist. Ziel sind Erkenntnisse, welche freimaurerischen Quellen (Symbolik, Ritualistik oder Geschichte) er in welchen Genres künstlerisch eingesetzt hat.

${ }^{n}$ Die Bezeichnung „prosaische Gattung" ist provisorischer Natur. Sie vermag jene Werke Pußkkins au vereinen, die nicht ausschlieBlich lyrisch oder autobiographisch genannt werden können. Den ansonsten in der Analyse künstlerischer Texte eher zurückhaltend behandelien Aufsätzen, Tagebuichern und Briefen soll hier besondere Aufmerksamkeit geschenkt werden. Denn unter den Bedingungen des Verbots freimaurerischer Gesellschaften kann auf der Basis sogenannter "freimaurerischer Erkennungszeichen" gerade in der Kommunikation mit anderen Freimaurem (Briefe) ein 'Code' vorliegen, der nur für "Eingeweihte" verständlich ist. (LENNHOFF/POSNER (1932), 446)

x

Hierbei wurde HAMMERMAYERS (1979) Differenzierung von politischen und nichtpolitischen Geheimbinden zugrunde gelegt. (Siehe 10/11) 


\section{ERSTER TEIL: METHODIK}

\section{KAPITEL I KÜNSTLERISCHER TEXT UND FREIMAURERISCHE SYMBOLE}

\section{Symbolbegriff und freimaurerische Symbolik}

Schon in der Androgynensage in Platons Dialog "Symposion» kommt die Bezeich-, nung Symbol ${ }^{29}$ zur Bezeichnung eines Teils von einem Ganzen vor. Unter «"Hxađto oǔv

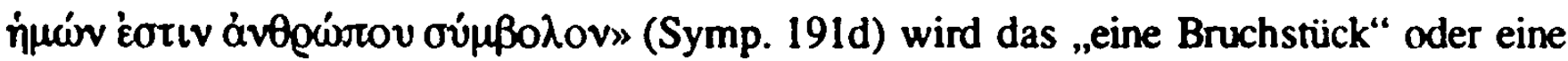
„Hälfte“ des Menschen (Geschlecht der Männer) verstanden, die in tiefster Sehnsucht nach ihrer „verlorenen“" anderen Hälfte (Geschlecht der Frauen) ein gedachtes Ganzes, nämlich den Menschen, darstellt. Das Symbol deckt sich somit bei Platon mit der "Idee“ des Menschen überhaupt. Vor ihm war die Bezeichnung «tò oú $\mu ß 0 \lambda o v »$ in der Bedeutung „Erkennungszeichen" verbreitet.

Nach LURKER (1988) gebrauchten die alten Griechen „Symbol“ zunächst unter dem Aspekt.einer materiellen Beschaffenheit des Bezeichneten, als „Symbol aus etwas (die beiden zusammenzufuigenden Teile)", während in der heutigen Bedeutung "Symbol" eher nichtmateriell gedacht wird, als „Symbol von etwas ... (die Freundschaft der Besitzer der Bruchstiicke)“."

Kaum eine Veröffentlichung über das Freimaurertum hat bisher den Versuch unterlassen, die Bedeutung der Symbole für den Bund zu bestimmen. ${ }^{32}$ Dennoch bleiben die mei-

29

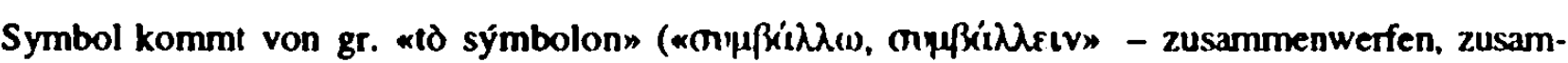
menbringen, zusammenfuigen).

30

Sowohl bei Pindar (Ol. 12,7) wie Sophokles (Phil. 401), Aischylos (Ag. 8) und Euripides (Hel. 298) ist «тò oíußohov» belegt als ein Zeichen, aus dem man etwas erkennt (Kennzeichen, Merkmal). Daneben hat es Bedeutungen als Wiedererkennungszeichen (.tessera hospitalis“", als Marke für die Bezahlung der Richter in der Antike), als Parole. Sinnbild, Ubereinkunft, Vertrag sowie als Empfehlungsbrief. (PAPE, W.: Griechisch-Deutsches Wörterbuch in drei Bänden, Braunschweig 1914, Bd. 2, 979/80) Der Symbolforscher Manfred Lurker beschreibt in seinem "Wïrterbuch der Symbolik" unter dem Stichwort „Symbol” den Gebrauch dieses Erkennungszeichens anschaulich: „Wenn zwei Freunde für längere Zeit oder für immer voneinander schieden, so zerbrachen sie eine Münze, ein Tontäfelchen oder einen Ring; kam nach Jahren jemand von der befreundeten Familie zurück, so konnten die zusammengefügten Teile

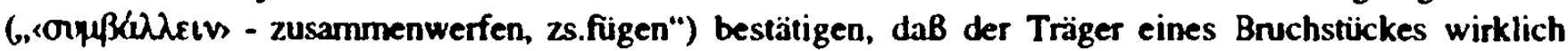
Anspruch auf die Gastfreundschafi besaB. Das Symbolon ist also ein ,Zusammengefügtes', in dem ein sonst nicht wahmehmbarer Sinninhalt manifestiert wird." (LURKER, M.: Symbol, in: LURKER, M. (Hrsg.): Wörterbuch der Symbolik, Stuttgart 1988, 698)

31

LURKER (1988), 698.

32

LENNHOFF/POSNER (1932), 940-42; 1541-46. („Literatur der Freimaurerei“; „Symbol“) Siehe die Publikationen in den Rubriken des Literaturübersicht II. „Genese und Expansion des Freimaurertums" und IV. „Motive der Freimaurerliteratur." Stellvertretend für viele sei an dieser Stelle die Definition des Freimaurers Goethe genannt. Für ihn sei „wahre“ Symbolik überall dort, wo „das Besondere das Allgemeine repräsentier, nicht als Traum und Schatten, sondem als lebendig augenblickliche Offenbanung des Unerforschlichen". (GOETHE, J. W. v.: Maximen und Reflexionen, in: GOETHE, J. W. v.: Werke, Bd. 1-24, Zürich 1949, hier: 9, 532, Nr. 314) 
sten Bemühungen unbefriedigend, weil die Vielfalt der freimaurerischen Symbole systematisch unerfaßt bleibt. Angefangen bei den Logenutensilien des freimaurerischen Rituals, über Erkennungszeichen, Losungen, Eidesformeln bis hin zu Schritten, Handbewegungen, Klopfzeichen sowie anderen logenintern festgelegten Zeremonien.

Eine sinnvolle Kategorisienung all dieser verschiedenen Symbole läßt sich von ihrer Beschaffenheit her, in Anlehnung an LURKERS (1988) Unterscheidung zwischen einem „Symbol aus etwas" und einem „Symbol von etwas"," vomehmen. Verkörperte (das heißt materialisierte) Symbole sind vor allem die Logenutensilien, zu den nichtverkörperten Symbolen zählen unter anderem die Losungen, Handbewegungen, Klopfzeichen und die logeninternen rituellen Zeremonien.

Das freimaurerische Symbol entfaltet sich in einem sich zum Ritual versammelnden, traditionsbewußten Personenkreis. In dem Rahmen erst wird der Bezug (des Symbols) zu metaphysischen Inhalten hergestellt, so daß mit Recht von einem freimaurerischen „System der Sittlichkeit, eingehüllt in Allegorien und erleuchtet in Sinnbilder ${ }^{\text {"4 }}$ gesprochen werden kann. Vor diesem Hintergrund sprechen Freimaurer von der Symbolik als einem Bindeglied und „Mittel der inneren Organisation“. Das (eingeweihte) „Internationale Freimaurerlexikon" (LENNHOFF/POSNER (1932)) betont darüber hinaus, daß das Symbol die ,geistige Arbeit der Loge durch seine Anschaulichkeit" etleichtem solle und zudem eine Gleichartigkeit des Denkens schaffe.

Mit der Funktion des freimaurerischen Symbolsystems als Bindeglied der Logenorganisation geht zugleich auch eine Abgrenzung gegenüber Nichtmitgliedem einher. Die Symbolik ist auch in engem Zusammenhang mit dem freimaurerischen Geheimcharakter zu sehen, der auf die nichteingeweihte „profane" Welt schon immer eine Faszination ausübte. Diese Attraktivität, die sich aus der Vermutung speiste, daß hinter der Organisation mehr steckt, als man auch nur spekulieren könne, bescherte dem Bund im 18. und 19. Jahrhundert einen erstaunlichen Mitgliederzulauf in ganz Europa. ${ }^{36}$ Dabei kommen sich 'Erwartung der Neophyten' und 'freimaurerische Historiographie' in dem Anspruch entgegen, durch die rituelle .Arbeit" ein aus vergangenen Epochen der Menschheit herrïhrendes, aber bislang verborgenes Wissen zu erlangen. ${ }^{37}$ Diese rituelle „Arbeit" schließt die Debatte über das Geheimnis ${ }^{38}$ und über die einzelnen Bedeutungen der Symbole und

33

LURKER (1988), 698.

LURKER (1988), 210.

33

LENNHOFF/POSNER (1932), 1545.

${ }^{36}$ BIEDERMANN, H.: Das verlorene Meisterwort, München 1986, 53-56.

37 BIEDERMANN (1986) sieht die Suche der Freimaurer nach dem höchsten Wissen in seiner "Kultur- und Geistesgeschichte des Freimaurertums" in Analogie zu esoterischen Traditionen aller Epochen, die eine "Kultur des höchsten Wissens" wiederzufinden suchen. (53-56)

Das von den Freimaurem seit Anbeginn thematisierte Geheimnis erregte nicht nur stets die Aufmerksamkeit Neugieriger, sondern auch die Neugierde. HAMMERMA YER (1979) abezeichnet dies, 4 , 
Riten mit ein, was selbst ein wichtiger Bestandteil freimaurerischer Logenarbeit ist.

Die Suche freimaurerischer Historiker und Symbolforscher nach den Bedeutungen für die der Steinmetzzunft entlehnte Bausymbolik kennt keineriei Grenzen. ${ }^{39}$ Auch wenn der freimaurerische Symbolbestand, der auf kabbalistische, christliche, alchemistische und baugenossenschaftliche Traditionen zurückgeht, begrenzt ist, so ist doch die Bedeutungsvielfalt, die sich damit auf dem weiten Feld der Tugenden und der Sittlichkeit ausdrücken' läßt, unerschöpflich. Die freimaurerische Symbolforschung zeugt von diesem Reichtum ${ }^{* 0}$ wie auch diverse Handbücher, die den Neuaufgenommenen eine Einführung in das Brauchtum geben sollen, es deswegen aber nur allzu oft an Klarheit und Übersichtlichkeit fehlen lassen." Eine Ausnahme bildet die unter heutigen Freimaurem in Vergessenheit geratene kurze Darstellung von HENNE AM RHYN (1906), die sich um einen systematischen Zugang zur Symbolik bemüht. Dennoch vermeidet auch HENNE AM RHYN eine allgemeine Definition der Symbolik. Er betont den unauflöslichen Bezug zwischen den Symbolen und dem Personenkreis, in dem sie ihren Sinn entfalten. Symbole und Sinnbilder sind für ihn einfach „Merkmale der Zusammengehörigkeit menschlicher Kreise“."

Wichtig bleibt, daß das Bezeichnete (,signifié") der freimaurerischen Symbolik vor allem aus einem System zur sittlichen Läuterung besteht, um die sich die Mitglieder des Bundes im Ritual bemühen. Dieses Vorhaben bringt es jedoch mit sich, daß die verwendeten Symbole über keine similaren Bezüge zu dem Signifikat (,signifié“) verfügen. Dieses arbiträre Moment ${ }^{3}$ der Verbindung zwischen den Symbolen und einem sittlichabstrakten Bedeutungsinhalt darf als ein wichtiges Charakteristikum der freimaurerischen Zeichenwelt gelten.

stehung und Entfaltung der regulären Freimauerei als ein „bedeutendes Phänomen des 18. Jahrhunderts“. Dennoch lagen die Interessen der meisten Neophyten nicht ausschlieBlich in der Befordenung der Sittlichkeit, als sie in den Bund eintraten. Wahrscheinlicher ist, daB die Mehrheit hinter dem Geheimnis handfeste weltliche Vorteile vermutete.

39 Zum Streit der freimaurerischen Historiographie, der für den Bund charakteristisch ist, siehe: LENNHOFF/POSNER (1932), 598-601.

to

Die Freimaurer J. SCHAUBERG (1861-63), A. WOLFSTIEG (1922), F. C. ENDRES (1930), A. HORNEFFER (1916), C. F. W. DYER (1983) stehen für viele andere in der Rubrik IV. „Freimaureristhe Elemente der Freimaurerliteratur", deren Arbeiten über die Symbolik eher dem Bestreben der Vollsändigkeit denn einer die Einzelheiten aussparenden Systematik folgen.

11

SCHROEDER, W.: Handbüchlein für die Brr. Lehrlinge, Berlin 1909; ders.: Handbüchlein für die Brr. Gesellen (...) für die unter der Grob-National-Mutterloge, ,Zu den drei Weltkugeln" arbeitenden Logen von Wilhelm Schroeder, Berlin 1910; ders.: Handbüchlein für die Brr. Meister, Berlin 1909.

12 HENNE AM RHYN, O.: Kurzgefabte Symbolik der Freimaurerei, Berlin 1906, in: Bücherei fuir Freimaurer $11 / 12$ (1906), 5/6.

${ }^{13}$ Den Begriff ,.Arbitraritär" verwendet Ferdinand DE SAUSSURE in „Cours de linguistique genérale", Genève 1915. DE SAUSSURE (1965: 97-102) unterstreicht darin die besondere Natur des sprachlichen Zeichens, dessen Teile (.,Bezeichnendes" (,signifiant”) - „Bezeichnetes“ (,signifie“)) sich im willkirlich-nichtmotivierten Verhältnis (,immotivé") zueinander befinden. 
5. Freimaurerische Symbolik und Geheimbund-Allusionen

Mit dem Begriff der „Geheimbund-Allusion“ werden personenkreisgebundene Geheimbund-Mitteilungen, logenintern-rituelle Vorgänge, stereotype Dialog-Wendungen eines Frage-und-Antwort-Spiels, Logenutensilien, Anspielungen auf die Freimaurer-Historie wie auch die Phantasien des Aberglaubens erfaßt. Anspielungen oder Allusionen («nameki», «alljuzii») implizieren immer ein spezielles Vorwissen, da sie an etwas bereits Bekanntes anknüpfen.

Puß̌kins Freimaurermitgliedschaft stellt in diesem Zusammenhang einen besonderen Fall dar. Die traditionell nichtpolitischen Männerbünde waren ab 1822 in Rußland verboten. Das heißt, in den entscheidenden Schaffensjahren war die Poetisierung der Freimaurerei für Puškin ein Tabu, das nur durch die Wahl von Mitteln literarisch überwunden werden konnte, die sich einer Entschlüsselung von profaner Seite entziehen. Allusionen, Anspielungen oder versteckte Hinweise, die sich als literarische Verfahren eines für jeden dechiffrierbaren Codes nur an bestimmte Adressaten mit speziellem Vorwissen richten, sind von daher bei Puškin in bezug auf die verbotene Freimaurerei anzunehmen. Zu seiner Zeit war nicht abzusehen, ob der Freimaurerei nicht eine baldige Wiedergeburt beschieden sein würde. Von daher ist eine Versuchung bei Puškin vorauszusetzen, mit freimaurerischen Inhalten literarisch zu spielen. Der Begriff der „Geheimbund-Allusion“ ist der Versuch, diesem möglichen literarischen Versteckspiel Puškins mit der Freimaurerthematik einen provisorischen Namen zu geben. 


\section{KAPITEL II AUSGANGSPUNKTE UND BEZUGSRAHMEN DER FREIMAU- RERISCHEN GEHEIMGESELLSCHAFTEN ${ }^{\mu}$}

\section{Die „Alten Pflichten“ des James Anderson (1717/23)}

Was das orthodoxale ,reguläre Freimaurertum" («(frank-)masonstvo», "orden svobodnych kamenšcikov») ${ }^{45}$ von den „pseudomaurerischen Geheimbünden “46 («tajnye obščestva») unterscheidet, ist das Andersonsche Konstitutionenbuch von 1723 («kniga konstitucij»). "James Anderson (1680-1739) war Reverend an der schottischen Presbyterianerkirche in London und gab der ersten „Großloge von London und Westminster" im Auftrag des Großmeisters Herzog John von Montagu sechs Jahre nach ihrer Gründung mit seinen „Constitutions" eine Verfassung. Die erste Auflage war, wie fälschlicherweise behauptet wird, keinesfalls nur für Mitglieder bestimmt, sondern ging direkt in den Buchhandel. ${ }^{48}$ Die erste, 1717 gegründete englischen Großloge ${ }^{49}$ erkannte das vom Großmeister bestellte Konstitionenbuch an, das bis heute den Logenbetrieb teilweise regelt und die Grundlage der freimaurerischen Weltanschauung bildet. Bis heute sind die darin festgelegten Pflichten (die sogenannten „Alten Pflichten“ („Old Charges“)) für alle Maurer grundlegend, die das Primat der Großloge von England anerkennen und daher Wert auf den Nachweis legen, ihr anzugehören. ${ }^{50}$ Das auch als „Grundgesetz der Freimaurer" bekannte Manuskript Andersons führt gleich im ersten Hauptstück „Von Gott und der Religion“ das „berufliche“ Gebot für die „spekulativen Maurer" an: „Der Maurer ist durch seinen Beruf verbunden, dem Sittengesetz. zu gehorchen, und wenn er seine Kunst recht versteht, wird er weder ein dummer Gottesleugner noch ein Wüstling ohne Religion sein"." Jeder wird im Konstitutionenbuch dazu angehalten, die freimaurerische, sittliche

4

In diesem Kapitel wird mit der Erstellung des freimaurerischen Glossariums begonnen, das über ein deutsches und ein russisches Motivregister [ausgewiesen und sprachlich unterschieden durch («...») und (.....")] am SchluB der Arbeit erschlieBbar ist.

45 Die bevorzugte russische Eigenbezeichnung der 'orthodoxalen Freimaurer' ist: «orden svobodnych kamenscikov».

46

HAMMERMAYER, L.: Zur Geschichte der europäischen Freimaurerei, 13. Siehe oben 9/10.

47

Der Originaltitel des Konstitutionenbuches lautet "The Constitutions of the Free-Masons, containing the History, Charges, Regulations etc. of that most Ancient and Right Worshipful Fratemity (for the use of the Lodges)"; LENNHOFF/POSNER (1932), 13. Die nussische Version findet sich bei: PYPIN, A. N.: Russkoe masonstvo XVIII i pervaja cetvert' XIX v., Petrograd 1916, 18/19.

Die 1738 erschienene, zweite Auflage hatte im Gegensatz zur Erstausgabe eine weniger stark deistische Tendenz. Zu Andersons EinfluB auf die Freimaurerei siehe auch KUESS, G. G.: Die Vorgeschichte der Freimaurerei im Lichte der englischen Forschung, Hamburg 1960 oder BEGEMANN, W.: Vorgeschichte und Anfänge der Freimaurerei in England, Bu. 1-2, Berlin 1909/10.

\section{9}

\$

Mehrere Logen mit gleichem Ritual schließen sich bisweilen zu einer Grobloge zusammen.

S1

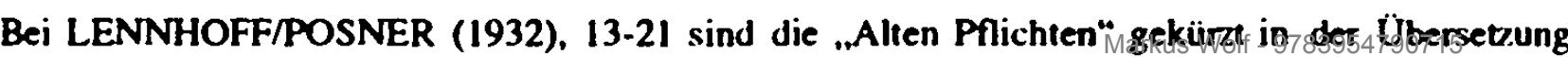


Kunst («iskusstvo») anzustreben. In ähnlicher Weise wird von der „königlichen Kunst“ («korolevskoe remeslo») im Zusammenhang mit den rituellen Tătigkeiten in der „Loge“ / im „Tempel“ («vnutrennij chram») und während der „Logenarbeit" («remeslennyj trud v lože») gesprochen.

Eine Besonderheit der "Alten Pflichten“ («starye objazannosti»), ${ }^{52}$ in deren Zentrum die Tugenden und die Männerbundtradition stehen, ist die Allegorisierung ihrer Anweisungen durch die Gepflogenheiten und Vorschriften der Steinmetzbruderschaften. In diesem Sinne wird gemeinhin unter den Anhängern zwischen der operativen und spekulativen Freimaurerei ${ }^{\text {“s3 }}$ unterschieden. Das nur schwer übersetzbare "speculative" legt dabei den Unterschied zwischen der in den Bauhütten der Steinmetzbruderschaften geleisteten (operativen) Werkarbeit und der in den Logen der Freimaurer üblichen geistigen und symbolischen (spekulativen) Arbeit fest. Arbeitsanweisungen, Chargen und Werkzeuge der Baukunst können sowohl für Pflichten der Werkmaurerei stehen als auch für Verhaltensmaßregeln einer spekulativen Maurerei, die sich an der Kunst der guten Sitten übt. Die profane Baukunst der Steinmetze («remeslennye bratstva»/«kamenotesy») zur tugendhaften „königlichen Kunst“ der spekulativen Maurerei, deren Arbeit in „Allegorien eingehüllt" und durch "Sinnbilder erleuchtet" ist."

\section{Die Initiation und die Grade (Männerbundtradition)}

Seit ihrem Bestehen haben die „Alten Pflichten“ («starye objazannosti») und die Schriften James Andersons das freimaurerische Symbolsystem der spekulativen Maurerei bestimmt. Der Text der „Alten Pflichten“ schreibt zwar Regeln für die wirkliche Arbeit der Steinmetzzunft («bratstvo kamenotescov») vor, regelt aber de facto die „ethische Arbeit" («nravstvennaja rabota») einer Gesinnungsgemeinschaft («(so)bratstvo», «tovarišcestvo»), die neben ihrer sitdich-metaphysischen Gesinnung auch noch über eine Gemeinschaftspflege verfügt, die an die Ausdrucksformen der weit verbreiteten Männerbünde, insbesondere der Bauzinfte erinnert."

Als allgemeine Ausdrucksformen des Geheimbundwesens sind Formen der organi-

der Ausgabe von 1723 abgedruckt. Eine kritische Bearbeitung der verschiedenen Ausgaben bietet: FISCHER, R.: Die Alten Pflichten. Das Grundgesetz der Freimaurerei, Berlin 1919.

32 PYPIN (1916), 19.

S3

LENNHOFF/POSNER (1932), $1487 / 88$.

'4 CHERASKOV, I. M.: Proischożdenie masonstva i ego razvitie v Anglii XVIII i XIX v., in: MEL'GUNOV, S. I./SIDOROV, N. P.: Masonstvo v ego prošlom i nastojašcem, Moskva 1915, tom I, $3 / 4$.

ss So der Wortlaut der Verfassung der ersten Grobloge von England. (OLIVER, G.: Signs and Symbols Illustrated and Explained in a Course of Twelve Lectures on Freemasonry, London 1857, 1/2)

so

PYPIN (1916), 16, 24, 33. 
sierten Geselligkeit auch bei religiös-esoterischen Gruppen und Strömungen der Antike (Gnostiker, Mysterien) und auch bei Kulten und Bräuchen der sogenannten 'Dritten Welt' zu finden." Der Vollzug von Einweihungs- oder Initiationsriten («posveščenie», «obrjady priema») hat bei schriftlosen und traditionsgebunden Naturvölkern, wie auch in den entwickelten Industrieländern seinen Platz." Verglichen mit anderen Geheimbünden spielen bei den Freimaurem ((«frank-)masony», "vol'nye kamenščiki») die antiken My- • sterien («starye misterii») eine herausragende Rolle. Sie gehören zu den alten Geheimkulten («tajnye kul'ty»), mit denen eine stufenweise Einweihung in neue Lehren durch Initiationsriten vollzogen wird. Das Aufnahmezeremoniell der Mysterien, ${ }^{50}$ das den $\mathrm{Zu}$ gang zu den Lehren der Priester eröffnete, bedeutete für den Initianten («kandidat») Wanderungen, Reisen und schwere Prüfungen. ${ }^{\infty}$ Ganz ähnlich verläuft die freimaurerische Initiation («posvešcenie», «obrjady priema»), das heißt die Aufnahme des Neophyten in den Männerbund." Das esoterische Wissen wird entlang bestimmter "Altersklassen“ strukturiert, mit denen jeweils besondere Rechte und Pflichten einhergehen. Die Gruppierung nach dem Lebensalter (,Jüngling“, „Mann“, „Greis“) entspricht einer langen Tradition, die sich auch bei Naturvölkem findet. ${ }^{62}$ Die auf das jeweilige Lebensalter bezogenen

37

LURKER (1988), 228/29.

st

Bei den Naturvölkern wird die häufigste Form der Initiation mit der Geschlechtsreife markien. In diesen Übergangsriten übt sich bekanntermaßen die männliche Jugend, wobei sie sich oft erheblichen psychischen und physischen Belastungen ausgesetzt sieht. Absonderung von der bisherigen Lebensgemeinschaft (Deposition), Fastenübungen, Enthaltung von Schlaf, religiös-kultische wie sexuelke Unterweisungen, Úberprüfung des Wissens und sonstige Mutproben sind Merkmale dieser Übergangsriten, die jungen Männem den Eintritt in eine für sie neue, weil abgesonderte, männliche Gerneinschaft eröffnen. In einer nach festgelegten Formen (Riten) ablaufenden feierichen Handlung wird die Weihe in Form einer Beschneidung, Maskierung, Zahnverstümmelung oder Tätowierung vollzogen. (JENSEN, A. E.: Beschneidung und Reifezeremonien bei Naturvölkem. Stuttgart 1933) Eine säkularisierte Form des Eintritts in einen Bund oder Stand stellt der „Ritterschlag" dar. In der industriell entwickelten Gesellschaft finden sich Reifeerklärungen in den Glaubens- oder Gesinnungsgemeinschaften (Kirche, Staat, Schule, Sekten, Burschenschaften, andere Vereine), in beruflichen Verbänden (Handwerker, Soldaten, Seeleute) und bei Jugendlichen (Gangs, Clique, Mutprobe, Einstand).

so

Zu den antiken Mysterien, die in so mancher Loge zur historisch-geistigen Autorität erhoben worden sind, gehören zum Beispiel die Ägyptischen, die Orphischen und die Eleusinischen Mysterien und der Mithraskult. (LENNHOFF/POSNER (1932), 1080-87)

${ }^{60}$ An dieser Stelle sei daran erinnert, daB im 4./5. Jahrhundert kirchliche Bräuche (Tauf- und Abendmahlsfeiern) - genauso wie bei den Freimaurem später - vor Uneingeweihten geheimgehalten wurcken. Eine Theorie dafür ist, daB das antike Mysterienwesen auf die frühen Christen EinfluB ausgeübt hat. (BERTHOLET, A.: Wörterbuch der Religionen, Stuttgart 1976, 30. (..Arkandisziplin“)

${ }^{61}$ In der Regel wird die Erlangung höherer Grade nicht mit der Bezeichnung „Initiation” belegt.

${ }^{02}$ Der Ubertritt von einer in die nächst böhere Stufe ist in der Regel mit einem Zeremoniell ("'rires de passages") verbunden. Die Anzahl dieser Altersklassen ist bei den Naturvölkem ebenso unterschiedlich wie die Menge der durch die Grade bezeichneten ethischen Wissensstufen bei den Freimaurern oder Hierarchien in andem Geheimbünden. Naheliegend ist daher auch die Theorie, daß die Männerbünde aus der

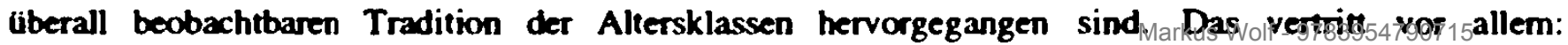


Erkenntnisstufen werden in ein System von Rängen oder Graden («stepeni»; «grad(us)y») gefaßt und nach den ihnen entsprechenden ethischen Inhalten symbolisch benannt («simvoličeski-nravstvennye stepeni»). Das Wissen um diese Inhalte («nravstvennosti») steht bei den drei Johannisgraden („Lehrling“" («učenik»), „Geselle“ («tovarišč), „Meister" («masten )) nur denen offen, die schon die jeweilige Stufe erreicht haben. Die drei Grade entfalten daneben auf zwei weiteren Ebenen ihre Bedeutung: So können sie als Altersklassen ("Jüngling“ - „Mann" - „Greis“) und auch als Lebensetappen (,Geburt" „Leben“ - „Tod") gedeutet werden. ${ }^{63}$ Hinzu kommt die allgemeine rangübergreifende Bezeichnung "Bruder" («brat»), die die Bundzugehörigkeit und damit auch die prinzipielle Gleichheit der Ränge vor dem Gesetz ausdrückt. Bei den Johannisgraden werden ethische Inhalte kodifiziert, die nur denen bekannt sind, die auch schon die jeweilige Stufe erreicht haben; nebenher können sie auch für die Altersklassen oder für die Etappen des Lebens

SCHURTZ, H.: Altersklassen und Männerbünde, Berlin 1902.

63

PYPIN (1916), 22. SCHAUBERG (1861-63) sieht in dieser Benennungsform nicht nur einen Berührungspunkt mit mittelalterlichen Zünften und Gemeinschaften, die in den geistlichen oder klösterlichen Bruderschaften ihren Ursprung haben, sondern will sie sogar bis auf das Alte Ägypten zurückgeführt wissen. (Vergleichendes Handbuch der Symbolik (1861-63), 1: 86) Neben den Johannisgraden (Lehrling" - „Geselle" - „Meister"), die sich an den Lehrberufen der Handwerker orientieren, entstanden früh weitere Ränge, die unter Freimaurern auch unter dem Begriff „Hochgrade“ bekannt sind. Es liegt zwar in ihrem Wesen, daB sie die drei symbolischen Grade (der Johlunnismaurer) voraussethen, im Unterschiod an denen aber diese nur als Vorbereitung zu ihrer eigentlichen Hochgradfreimaurerei ansehen. Das auf Vollständigkeit der ethischen Inhalte bezogene Johannismaurersystem geriet mit dem Aufkommen der Hochgrade in Bedrängnis, weshalb es denn auch gegen die Hochgradvertreter polemisierte: „Ein höherer Grad ist eine aus verschiedenen Zeremonien, symbolischen Formeln und hieroglyphischen Bildern in nevem Zeiten zusammengesetzte Mysterie, in welcher Zeremonien, Formeln und Hieroglyphen moralisch gedeutet, die Enthüllung ihres eigentlichen Sinns aber und die völligen Aufschlüsse erst in einem noch höhem Grade verheissen werden (...), wekches denn so lange von Grade zu Grade fortgeht, als in diesem oder jenem Logensysteme notwendig scheint, seine letzten und höchsten Aufschlüsse, durch mehr oder weniger höhere Grade symbolisch vorzubilden, welche sodann den SchluBstein des ganzen Logensystems ausmachen, sind selbst nichts anderes, als eine erdichtete, aller Zeit und Menschengeschichte widersprechende, jede Prufung und Kritik scheuende Historie des Ordens, von denjenigen erfunden, welche die immer höher steigende Wissbegierde der Brüder nicht anders zu befriedigen wussten oder von der traurigen Uberzeugung gekeitet wurden; dass die Menschen überall die Täuschung mehr lieben könnten, als die Wahrheit, und selbst das Gute nur durch die Hülle der Täuschung sehen wollen". (FESSLER, I. A.: Eleusinien des 19. Jahrhunderts, Bd. I, Berlin 1802/03, 172 zitiert in: ALLGEMEINES HANDBUCH DER FREIMAUREREI (1900), Bd. 1, 458) Weniger kämpferisch verteidigt M. ERLER (1964) den Ursprünglichkeitsanspruch der Johannisgrade: Wichtiger als ihre Anzahl sei die Frage, ob für jene Grade, die über die fundamentalen Ränge der sogenannten blauen Freimaurerei - Blau gemäB der Tradition der englischen Bawhüttenbruderschaften - hinausgehen, eine Berechtigung vorliege. (ERLER, M.: Der modeme Mensch und das Ritual, München 1964, 25) Ähnlich äußert sich HENNE AM RHYN (1906: 39): Was Hochgrade bieten, gehe durchweg uber die Freimaurerei hinaus und stamme aus den traurigsten Zeiten ihrer Verimungen. (LENNHOFF/POSNER, 188) Die Hochgrade waren innerhalb der Freimaurerei immer umstritten. Auf die Freimaurerhistorie hatten sie insbesondere in RuBland entscheidenden EinfluB. Die "symbolischen“ Johannisgrade müssen hingegert in einem engen Zusammenhang mit der Entwicklung der Werkmaurerei der Bauhüttenbruderschaften des Mittelalters zur Geistesmaurerei kerstander 
stehen. ${ }^{4}$ Die verschiedenen Bedeutungsebenen der Johannisgrade («juannovskie stepeni», «pervyja tri stepeni») $)^{\text {ss }}$ verwerfen die Annahme eines vornehmlich sittlichen Bezugsrahmens innerhalb des freimaurerischen Symbolsystems. Es ist nicht allein im gleichwohl breiten Rahmen der Ethik zu suchen, sondern erstreckt sich auch auf das traditionelle Männerbundbrauchtum, mit dem ebenfalls die politischen Männerbünde («tajnye obščestva») verwandt sind. ${ }^{\infty}$ Die ersten drei Grade der Johannismaurerei («učenik», («tovarišx»/«diakon"), "mastem) verbinden alle freimaurerischen Gemeinschaften." Abweichungen und Ergänzungen (wie sie zum Beispiel die Hochgrade darstellen) machen den besonderen Charakter der einzelnen Lehrarten und Systeme aus. Johannisstufen («juannovskie stepeni») wie Hochgrade («vyš̌ija stepeni», «novye grad(us)y») verfügen über ihr eigenes Zeichen («znak»), ihr eigenes Wort («slovo»)/Parole («parol'») und ihre

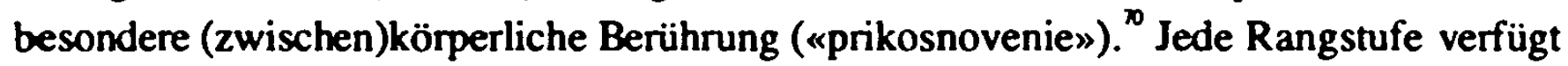
damit über ein eigenes System zur Veranschaulichung metaphysischer Inhalte.

Die Initiation markiert den Übergang in eine neue Welt - „mitten in der alten verborgenen Welt". "Ist dieser Schritt erst einmal geschafft, stellt sich aus dem Erlebnis und Wissen der Teilhabe ein Gefuhl der Mitwisserschaft und Überlegenheit ein. Die Abstufung der Arkandisziplinen ("arcana") - die strenge Geheimhaltung der Kultbräuche sind in den Hochgraden besonders ausgeprägt. Diese "disciplini arcani" wecken besonders unter Hochgradmitgliedem das Bedürnis aufzusteigen. Doch diesem Drang nachzukommen heiBt zunächst, sich unterzuordnen.

a

LENNHOFF/POSNER (1932), 629.

os PYPIN (1916), 46.

os PYPIN (1916), 41.

67 LENNHOFF/POSNER (1932), 1547; SOKOLOVSKAJA, T. O.: Obrjadnost' vol'nych kamensxikov, in: MEL GUNOV, S. I./SIDOROV, N. P.: Masonstvo v ego prostom i nastojašcem, Moskva 1915, tom II, 80-117, hier 84.

PYPIN (1916), 34.

क

PYLAEV, M. I.: Staraja Moskva. Razskazy iz byloj Žizni pervoprestol'noj stolicy, S.-Peterburg 1891, 85.

${ }^{\text {T}}$ SOKOLOVSKAJA, T. O.: Obrjadnost' (1915), 110. Siehe auch PYPIN (1916), 53.

" Nach REINHARD KOSELLECK (1959) kann an der Maurerei eine neue Form der freiwilligen Unterordnung, die „Pathogenese der alten bürgerlichen Welt" beobachtet werden: „Das Geheimnis trennte die Brider von der übrigen Außenwelt, und so entwickelte sich durch die Abweisung aller bestehenden sozialen, religiösen und staatlichen Ordnungen die neue Elite, die Elite als ,Menschheit'. Die Teilnahme am Geheimnis hielt ein bestimmtes MiBtrauen und Vorsicht gegen die AuBenstehenden wach; die ständig beschworene Sorge vor ,Verrat' trug immer mit dazu bei, das BewuBtsein der eigenen, der neuen Welt zu steigem und damit die Verpflichtung, ihr zu dienen." (KOSELLECK, R.: Kritik und Krise. Ein Beitrag zur Pathogenese der bürgerlichen Welt, Freiburg i. Br./München 1959, 61/62)

$n$

Die Beteuerungen der Freimauret, unpolitisch zu sein, sind nicht haltbar. KOSELLECK (1959) zIfolge fungiert das Geheimnis vielmehr als Herrschaftsinstrument, indem es/aine innefgessellischafiliche 


\section{Grundzüge des freimaurerischen Rituals - „nichtverkörperte Symbolik“}

Initiationsriten haben ihre eigene Ästhetik und lassen sich in ihren stereotypen Abläufen beschreiben. In der normalen sittlich-rituellen Logenarbeit («nravstvennaja rabotas) ${ }^{\text {B }}$ haben Symbole und die zeremoniellen Bewegungen autorisierter Mitglieder ihren vorgesehenen Platz. Dazu kommen die festgelegten Redewendungen des freimaurerischen Frageund-Antwort-Spiels zwischen dem der Loge vorsitzenden "Meister" («mastern), den "Aufsehem" («nadzirateli») und dem „Initianten“ («kandidat»)." Die verschiedenen freimaurerischen Systeme unterscheiden sich zwar durchaus im Wortlaut ihrer Rituale, immer ist jedoch von besonderer Bedeutung, daß das jeweilige Ritual mit peinlicher Genauigkeit durchgeführt wird, um seine Wirkung zu entfalten. All dies macht die 'nichtverkörperte freimaurerische Symbolik' aus.

Die Abläufe des Aufnahmerituals («ceremonija priema») ${ }^{75}$ und der alltäglichen Zeremonien können schematisch rekonstruiert werden. Es gibt einen unverletzbaren „rituellen Duktus “" $^{\text {“6 }}$ der freimaurerischen Ritual-Ästhetik, eine Art Kern, der durch eine im zeitlichen sich ereignende Hauptattraktion gekennzeichnet ist, um nach dieser Kulmination in einen abfallenden Ritus-Teil überzuleiten, der reziprok dem Nullpunkt wieder zustrebt. Das von ERLER (1964) entworfene Schema zum Ritusverlauf, das an dieser Stelle übernommen wird, veranschaulicht diese nichtverkörperten symbolischen Bewegungsabläufe, die sowohl in der Aufnahme eines Neophyten als auch in der Meistererhebung kulminieren können. "Die in dem Schema hinzugefügten Klammem haben folgende Bedeutung:

"Trennumg zwischen weltlichem Außenraum und moralischem Innenraum" bewirkt. Gerade in der „Ablehnung der Politik“ innerhalb des Logenbetriebes etablierten sich die Maurer selbst als besseres "Gewissen der Politik“. Auch entstand mit der Freimaurerei eine neue Form der ständevereinenden Gemeinschaft - und zwar innerhalb und doch neben der Gesellschaft. Vergessen wenden darf indessen nicht der kosmopolitische Charakter der neuen Bewegung. Insbesondere dor, wo - wie allen voran in RuBland - die Grenzen als drickend empfunden wurden, und die Reisebedingungen sich durch Mitgliedschaftszertifikate erleichtern ließen, war die Freimaurerei attraktiv. Denn mit Vollzug der Aufnahme in den Bund ist der Neophyt ungeachtet seines adeligen oder nichtadeligen Standes allen Mitgliedem wie ein Bruder gleichgestellt. (KOSELLECK (1959), 63, 66/67; WAGNER, H.: Die politische und kulturelle Bedeutung der Freimaurer im 18. Jahhundert, in: BÁLAZS, E. H./: Beförderer der Aufklärung in Osteuropa, 68-86, hier 71/72)

$n$

PYPIN (1916), 33.

4

MIERS, H. E.: Lexikon des Geheimwissens, München 1979, 345.

75

PYPIN (1916), 53.

76

ERLER (1964), 24/25.

"ERLER (1964), 24/25. Siehe auch MIERS (1976), 345. Das Schema Erlers wurde auch von der Darstellung her übernommen. Auf die Darstellung der rituellen Beförderung zurn Gesellen («tovarišx, «diakon") wird verzichtet, da sie für das Werk Puskins nicht von Interesse ist. Soweit nicht anders vermerkt, sind die russischen Begriffe an PYPIN (1916), 42ff. angelehnt. Wie ELKE NERRE (1989) 7agef 
a. Runde (...) Klammern mit deutschem Text enthalten Anmerkungen ERLERS (1964). b. Eckige [...] Klammem geben die von ERLER (1964) angeführten russischen Bezeichnungen und Redewendungen für die jeweiligen Ritual-Teile wieder. c. Geschweifte $\{\ldots\}$ Klammern enthalten Ergänzungen des Verfassers.

STUFE 0 Einführung der Brüder in den Tempel. [«brat'ja vo chram»]

\section{AUFSTEIGENDER RITUS}

STUFE I \{a\} Sicherung und Reinigung. (Deckung außen und innen.)

\{,Deckung" steht allegorisch für 'gesichert vor dem Eintritt Unbefugter'.\}

(b) Eintritt in den Ritus. (Feststellung der Zeit, Eröffnung der Vorloge.

[\{a\} Диалог: «Мастеръ спрашиваетъ младшаго діакона:

- Какая первая обязанность масона?

- Смотрђть, чтобы ложа была покрыта.

- Исполните свою должность.

(6) Младшій діаконъ ударяетъ три раза въ дверь, и п о к р ы в а т е л ь (...) одинъ изъ братьевъ, состоящій на стражђ у дверей) отвђчаетъ $\mathrm{Cb}$ другой стороны также тремя ударами. Діаконъ доноситъ объ этомъ мастеру: «Достопочтенный, ложа открыTa.» PYPIN (1916), 48]

STUFE II

1. Incantatio. (Das Licht erleuchte diesen Tempel); Darstellung dieses Vorhabens. (Ein Bruder (...) legt uns den Arbeitsplan auf!)

STUFE III Hereinrufen des Lichtes. (Entzünden der Lichter.)

STUFE IV Übertragung auf die höhere Ebene, (Festlegung des rituellen Ortes.) Tempel [«chram»] als Symbol des Weltalls - Frage: Wo hat (...) seinen Platz?) - [«Мастеръ: Скажите, гдъ мъсто младшаго діакона /младшаго надзирателя/старшаго надзирателя/мастера въ ложе? Qтветь: Позади старшаго надзирателя на юr $/$ на запады/ на востокь. Мастеръ; Въ чемъ состоитъ ваша обязанность? Ответъ: Передавать порученія оть старшаго надзирателя младщему/Чтобы можно было лучше наблюдать солнце/Какъ солнце заходитъ на западђ, чтобы окончить день, такъ и старшій надзиратель стоить на западђ, чтобы закрывать ложу, платить людямъ ихъ заработокъ и отпускать ихъ съ работы/

merkt, sind die russischen Begriffe an PYPIN (1916), 42ff. angelehnt. Wie ELKE NERRE (1984) zutreffend bemerkt, greift Pypin in seiner Darstellung des Rituals hauptsächlich auf die englische Fachliteratur zurück und bezieht sich nur vereinzelt auf ältere russiscthe Titel.

$n$

Die Feststellung der Zeit wird immer mit den Ausdrücken „Hochmittag“ oder „Hochmitternachr” gekennzeichnet, und markiert Anfang oder Ende der rituellen Handlung.

9

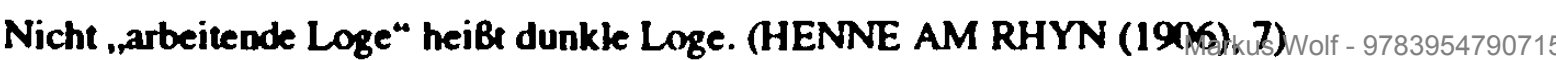


Какъ солнце всходить на востокъ, чтобы открытъ денъ, такъ мастеръ стоитъ на востокь, чтобы открыть свою ложу и поставить людей на работу.» PYPIN (1916), 48/49]

Konfessio (Frage: Warum nennen wir uns Freimaurer?)

2. Incantatio (GroBer BAW ...) \{.BAW“ steht verkürzt für „Baumeister aller Welten".\}

Eröffnung der „Arbeit“. (Hoch- und Hauptritus)

[«Затьмъ мастеръ снимаетъ шляпу и объявляеть ложу открытой, сльдующими словами: Эта ложа открыта во имя св. Іоанна; я запрещаю всякую брань, клятвы или шопотъ, и всь профанные разговоры, хакого бы рода ни было, подъ неменьшимъ штрафомъ, чьмъ какой положить большинство. Мастеръ ударяетъ три раза о столъ деревяннымъ молоткомъ и надеваетъ шляпу; остальные братья остаются безъ шляпъ. Онъ спрашиваеть потомъ, готовъ-ли къ принятию д же н т л ь м е н ъ, предложенный въ прошлой разъ?) PYPIN (1916), 49] \{Der Gentleman ist der ehrbare Bürger, der unbedingt in den Bund aufgenommen werden möchte. Das Aufnahmebrauchtum wird an dieser Stelle nur auszugsweise wiedergegeben.\}

\section{\{Schematischer Ablaur des Initiationsritus nach PYPIN\}}

[«Обряды приема: Кандидат оставляется \{въ особой комнать\} одинъ. Оттуда его приводятъ въ другую комнату, совершенно темную. Здъсь спрашиваютъ его: имъетъ-ли он истинное желаніе быть принятым? (...) у него спрашиваютъ его имя и званіе; (...) потомъ обнажають ему правое кольно, на ле-

"Die Himmelsrichtungen haben im "Freimaurertempel” auch symbolische Bedeutung. Von Osten aus leitet der "Meister vom Stuhl“" die Loge, über ihm leuchtet in vielen Maurertempeln die ,strahlende Sonne" und von hier aus empfängt der Suchende das ,maurerische Licht". Der Osten oder Orient [ «vostok»] bezeichnet oft die Örtlichkeit einer Loge. (LENNHOFF/POSNER (1932), 1167) LURKER (1988: 304) nennt den Osten sogar ein freimaurerisches Symbol. Siehe auch FISCHER, R.: Ritual und Symbol. Unterrichtsvorträge, Leipzig 1878, 103; HENNE AM RHYN (1906), 120 und SCHAUBERG (1861-63), 392-433. Die Ostung der Kultbauten und Gräber, die schon in der Antike bevorzugte Wendung Richtung Osten während des Gebets, und auch die Bauart des Salomonischen Tempels nehmen indes dem freimaurerischen Osten seine Originalität, stellen ihn aber in eine kultische Tradition.

11

Es entspricht dem ,maurerischen Gebrauch", die Loge grundsätzlich vor dem Sonnenlicht verschlossen zu halten. Selbst am hellsten Tag wird der "Tempel“ nur künstlich beleuchtet. SCHAUBERG (1861-63) schreibt in seinem Werk zur freimaurerischen Symbolik, daB die Einführung des künftigen Maurerlehrings in die dunkle Kammer des stillen Nachdenkens ältesten Traditionen entstamme und sich gar eine Verwandtschaft zu den "Mithrashöhlen“ feststellen lasse. Er sieht im "dunklen Vorbereitungszimmer" (für den Neuaufzunehmenden) ein Anzeichen dafür, daB ,uralte Hiram-Mysterien an dunklen Orten (Höhlen) in Rom gefeiert und dann nach England gebrachr" wonden sind. SCHAUBERG geht bei den freimaurerischen Ritualen wie Symbolen von einer bis zu den antiken Mysterien zurückreichenden Tradition aus. (Bd. 1, 56). 
вую обутую ногу надђвають туфлю, завязываютъ плакатомъ глаза и предоставляютъ его на ньсколько времени его размышленіямъ. Комната охраняется братъями (...) Въ ложђ мастер стоитъ на востокъ, на груди виситъ у него наугольникъ; библія открыта на евангеліи отъ Іоанна, и три горяшія свьчи ставятся въ чертежђ на полу, въ видђ треугольника (...)»] «(...) Когда всъ приготовленія кончены, предлагающій стучить три раза въ дверь ложи; мастеръ отвђчаетъ тремя ударами молотка, и младшій надзиратель спрашиваетъ: «Кто тамъ? ${ }^{82}$ Кандидатъ (научаемый провожатимъ) отвђчаетъ: «Человъкъ, который желаетъ имђть и просить участія въ благах этой достопочтенной ложи, посвященной св. Іоанну, какъ это сделали до меня многіе братья и товарищи)] \{Посль вопроса мастера к кандидату, он приказал:\} [«Покажите ему свђтъ.» Посль того кандидата подъводятъ, тремя особенными масонскими шагами, к скамейкђ, стоящей передъ упомянутымъ чертежемъ.» PYPIN (1916), 50/51]

\{Charakteristisch für die Initiation sind die rituellen, von den Himmelsrichtungen geleiteten Wanderungen [«Пути съ востока на западъ.)"] und die Lichtsymbolik. [«Покажите ему свъть.»]]

[«Мастеръ спрашиваетъ его: Объшаетъ ли онъ никому и никакимъ образомъ не выдавать масонской тайны, кромъ брата въ ложђ и въ присутствіи великаго мастера? - и когда кандидатъ даеть его объщаніе, ему растегиваютъ жилетъ и къ обнаженной львой груди приставляютъ остріе циркуля, который онъ самъ держитъ въ лђвой рукъ. Кандидатъ кладетъ правую руку на евангеліе, развернутое на чтеніи отъ св. Іоанна, и при этомъ произноситъ за мастеромъ присягу.» PYPIN (1916), 52]

"Das rituelle, dreimalige ,An-die-Tür-Klopfen" ist außerdem zweck- und gradspezifisch unterschieden. In jedem Fall versinnbildlicht es das Bevorstehen eines brüderlichen Besuchs. (HENNE AM RHYN (1906), 45)

83

STEPANOV, A. P.: Prinjatie v masony v 1815 godu, in: RS 1 (1870), 225.

"In der rituell zu entblößenden „Brust” und der "Freilegung des rechten Knies“, die auch vorkommt, sieht der Freimaurer DEITERS (1963: 124) eine Maßnahme, die ursprünglich die heimliche Aufnahme von Frauen vermeiden helfen sollte.

is

In der schottischen Maurerei geht es bei den Einweihungen anders zu, wie G. SCHWARTZBOSTUNITSCH (1928) detailliert ausführt. Viel werde mit der schwarzen Farbe schon bei der Aufnahme in den Bund operiert. AuBerdem sei der Dolch [«kinžalı] ständiges Befördenungsrequisit in den Zeremonien der schortischen Maurerei und symbolisiere die Rache gegenüber den Feinden des Ordens. Das Hauptgewicht der schottischen Maurerei liege in der Schulung der Selbstbeherrschung. Der zur Beförderung zugelassene Geselle sagt sich von eigensüchtigen Prinzipien los, die auch ihre besonderen Symbole haben. (SCHWARTZ-BOSTUNITSCH, G.: Die Freimaurerei. Ihr Ursprung, ihre Geheimnisse, ihr Wirken, Weimar 1928, 212) Nach HENNE AM RHYN (19)6: 37) treten besonders hervor. Goldmünze (Habsucht), Bronzemedaille (Ruhmsucht), Dolch (Rachsucht). Soweit die Eigenheiten des 33 Grade umfassenden schottischen Hochgradsystems. 


\section{\{Freimaurerische Eidesformel («kljatva», «prisjagar)\}}

[«Присяга состоить въ обышаніи хранить и не выдавать ни подъ какимъ видомъ жикакой изъ тайныхъ мистерій свободнаго каменьщичества) - any of the secret Mysteries of Free-Masonry; далье въ обещаніи, что новопринятый не будеть изображать этой тайны никакимъ вообразимымъ способомъ, - кни писать, ни печатать, ни вырђзывать, ни рисовать, ни красить или гравировать, ни подавать повода къ тому, чтобы это случилось, ни на хакой вещи подъ небесами, подвижной или неподвижной, на который бы она могла быть прочитана или понятна), - для того, чтобы тайна не могла быть пріобрђтена къмънибудь незаконно. Все это обьщается безъ всякаго колебанія, внутренняго умолчанія и какой бы ни было увертки, и подъ страхомъ такого наказанія: пусть мнь будетъ перерђзана шея, языкъ вырванъ съ корнемъ и зарытъ в морскомъ пескь при низкой водъ, за кабельтовъ разстоянія отъ берега, гдь приливъ и отливъ проходять дважды въ двадцать четыре часа.» (PYPIN $(1916), 52)]^{60}$

\{Nach Aufsagen der Eidesformel [«kljatva», «prisjaga»] wird der Neuaufgenommene [«novoprinjatyj»] mit dem besagten Erkennungszeichen [«znak»], der besonderen zwischenkörperlichen Berührung [«prikosnoven'e»] ${ }^{\text {un }}$ und dem spezifischen Wort des ersten Ranges [««slovo učenika»] vertraut gemacht. Nachdem er sich traditionell zur Rechten des Meisters [«master»] gesetzt hat, bekommt er die obligatorische Schürze [«zapon», «perednik»"] und das persönliche Mitgliederverzeichnis der Loge [«spisok lož»], die ihn aufgenommen hat. PYPIN (1916), 533

25

Die freimaurerische Eidesformel gehört zu den umstrittensten Bestandteilen des Ritualtextes. Schwerste Strafen werden dem Freimaurer angedroht, sollte er das "Geheimnis“ preisgeben. Der Kandidat muB die vorgesehenen Bestrafungsformen (,Durchschneiden des Halses“, „Herausreißen der Zunge an der Wurzel", „Vergraben der Zunge am Seestrand bei Niedrigwasser $\left.(. . .)^{\omega}\right)$ aufsagen. Dies hat auf profaner Seite dazu geführt, die Eidesformel nicht in ihrem übertragenen Sinn, sondern wörtlich zu nehmen. Siehe auch LENNHOFF/POSNER (1932), 404-05. (,Eid")

87

,Zwischenkörperliche Berilihrung“" heißt: es sind mehrere Akteure beteiligt.

8

Das Wort, das dem Neuaufgenommenen in russischen Logen gegeben wird, lautet nach T. O. SOKOLOVSKAJA (in lat. Schrifi) ,Nekaman“. Weitere Einzelheiten zu den Zeichen und den Berührungen finden sich bei SOKOLOVSKAJA, T. O.: Obrjadnost' vol'nych kamensxikov (1915), 110/11, andere Worte für das Aufnahmeritual bei: STEPANOV, A. P.: Prinjatie v masony v 1815 godu (1870), 226.

"Die Schürze symbolisiert die ,sittliche“ Arbeit. (RUSSKIJ VOL'NYJ KAMENŠČIK. Franc-maçon russe. Bjulletin russkich lož, Bde. 1-2, Paris 1946, hier Bd. 1, 12-14)

$\mathfrak{\infty}$

Am Ende des streng festgelegten Rituals beglückwünschen die Mitglieder den neuen „Bruder”, und det Meister bringt seinen "Toast" [ $\alpha$ tost»] aus, der in ein freimaurerisches Gastmahl [«masonskij pim»] mündet, das unter Freimaurem allegorisch unter dem Namen ,Feversalve" [«pal 'bas] bekannt ist. Freimaurerische Trinksitten und -sprüche können verschiedene Formen annehmen. Eine kleine Entwicklungsgeschichte der Trinksitten und -spriche gibt das „Intemationale Freimaurerlexikon“ (1932), 1593. 95. „Man trank auf die heiligen Schutzpatrone, den König und die Kunst ("the King and the Craft"), auf die Grobbeamten, den Grobmeister und die Grobloge, auf alle Brüder, man gedachte der Schwestern, (...) an vaterländische Gedenktage, auch der Armee und der Flotte usw. Zwischen den Trinksprüchen wurden passende Lieder gesungen, die Maurerlieder und die Nationalhymne u.a.m." AENNHOFFIPOSAER 
\{Neben dem Initiationsritus findet auch die Meistererhebung vor Ende des aufsteigenden Ritus-Teils statt. Beide Ereignisse haben einen besonders festlichen Charakter, da sie nicht immer Teil des freimaurerischen Rituals sind. Aufnahme- und Beförderungszeremoniell sind neben dem Johannistag" die höchsten Feste, die die Freimaurer begehen." Die Meistererhebung knüpft an eine alte Erzählung aus der Bausagentradition, die HiramLegende, an. Sie bildet neben dem „Andersonschen Konstitutionenbuch“ das Kernstück der Freimaurertradition. Die „Hiram-Legende" ist in ihrer von den Freimaurem überlieferten Version sowohl "Grundlage für die Arbeit der Meister" als auch für einen Teil der Hochgrade bestimmend." Bei der zeremoniellen Aufnahme in den Stand der Meister können nur die Angehörigen des Meistergrades [ «mastery»] und die zu befördernden Gesellen [«tovariš̌i», «diakony»] anwesend sein. Die maurerische Meisteraufnahme wird mit den sie begleitenden Gebräuchen von SCHAUBERG (1861-63) als "höchstes Mysterium" bezeichnet, das die Tradition der antiken Mysterienbuinde fortsetzt." In dieser Beförderung wird zunächst symbolisch das Begräbnis des irdischen Menschen vollzogen, wobei erst in dessen Folge der Eintritt in ein reines und vollkommenes Leben (Licht) stattfinden kann. Die Aufnahme soll eine zweite (symbolische) Geburt für den Kandidaten sein (Goethes 'Stirb-und-Werde'-Gedanke mutmaßlich in Anlehnung an das

(1932), 1594; siehe auch SCHAUBERG (1861-63), 646-49).

91

Das Johannisfest fällt auf den 24. Juni, das Geburtsfest Johannes des Taüfers. Interessant ist, daB Johannes der Evangelist der Schutzpatron vieler Steinmetzgilden war. (LENNHOFF/POSNER (1932), 780-84)

$\boldsymbol{q}$ ${ }^{9}$ HENNE AM RHYN, O.: Kurzgefabie Symbolik (19)6), 26.

Nach Einschätzungen des Freimaurers ERLER (1969) hat die freimaurerische Tradition der HiramLegende ihren Ursprung in a) der biblischen Uberlieferung, b) in auBerbiblisch-historischen und c) auBerbiblisch-magischen Quellen. Die biblischen Bezüge sind vor allem im Buch der Könige (1Kön. 4, 6; 5, 15-32) und den Chroniken (2Chronik 2, 13/14) zu finden, wo Hiram als der König von Tyrus beim Tode Davids an Salomo zunächst eine Trauergesandtschaft und später Bauholz schickt. Er sendet Salorno zu Hiram und lieB ihn um einen weisen Mann bitten, der versteht, zu arbeiten in Gold, Silber, Erz, Eisen, Steinen. Holz, Scharlach, gelber Seide, Leinwand rosinrot und zu graben alkerlei, und allerlei künstlich zu machen, was man inm vorgibr". (LENNHOFF/POSNER (1932), 699) Es fehlen aber direkte rituelle Bezüge, wie z.B. der Tod des Baumeisters. In den frühen englischen Manuskripten taucht der Name Hirams als Meister der Steinmetze erst nach 1700 auf, und auch erst zu dieser Zeit ist von den beiden Säulen 'Jachin und Boas' die Rede. In der "Groben Legende vom Tempelbau" sieht ERLER eine auBerbiblische Quelle der Hiram-Legende der Freimaurer. Ebenso seien Auszüge aus dem "Testament Salomonis", die „Osiris-Legende“" Plutarchs und ,altägyptische Statuenbildhauer-Rituale“ in der Bausage verarbeitet. Auffallend sind die von ERLER (1969) dargestellten Parallelen der Hiram- zu der Osiris-Legende. (M. ERLER: Die grobe Legende vom Tempelbau. Ein Vergleich mit alten Quellen, (Handschr. f. Brt. Frmr.), München 1969, S. 17-44) Der genaue Wortlaut der Hiram-Legende ist bei ERLER (1969) wiedergegeben und im Rahmen seines rituelien Ablaufs nur stellenweise von Belang. Kürzer und mit zahlreichen Bezügen zum Meisterritual ist die Legende Hirams bei BINDER (1988) nachlesbar. (BINDER, D.: Die diskrete Gesellschaft. Geschichte und Symbolik der Freimaurer, Graz 1988, 198-202) Als .Arbeitsanweisung" für Brüder-Meister dient T. STENTZ: Die Hiram-Sage, Handschrift für Brr. Meister, Berlin 1871.

ar

PYPIN (1916), 47.

95

Für SCHAUBERG (1861-63), Bd. 1, 631 ist die Meisterweihe das „grosse sirtliche Drama und Epos", das „vom Menschengeschlecht schon seit langen Jahrtausenden“" ausgeführt werde 
Paulinische Diktum vom 'neuen Menschen' und dem 'Tod des alten Menschen') mit ihr ein Abstreifen aller menschlichen Gebrechen und Irtümer einhergehen."

Der Vorsitzende des Geschehens ist der Meister vom Stuhl [«master stula»], der als 'Primus inter pares' begriffen wird. Vor der Arbeit haben sich die anwesenden Inhaber des dritten Grades bereits in eine Anwesenheitsliste eingetragen, nachdem sie schon zuvor im Tempel gewesen waren, um den „Tempel" [«chram»] für die "Arbeit" [ «trud», «rabota»] zu erleuchten. Danach wird der Tempel für die. Aufnahmehandlung umdekoriert und einige „Beamte“ legen besondere Kleidung an. Die zu befördernden Gesellen werden hereingeführ, und man verlangt ihnen das eben erlernte $\mathrm{PaBwort}$ und die $\mathrm{zwi}$ schenkörperliche Berührung (,Griff") ab. schürzen [«zapon», «perednik»] abgenommen. Dann folgen die Reisen [«putesestvija masterov»]. Nach Ablegung des Meistergelöbnisses wird die Hiram-Legende vorgetragen, die mit dem Gesellen [ «tovariṧ», «diakon»] symbolisch nachgespielt wird.'

Der zweite Aufseher [ «vtoroj nadziratel'»] legt dann dem Gesellen [«tovariš̌̌ ", «diakon»] seinen Hammer [«molotok»] auf den Kopf. Es folgt ihm darin der erste Aufseher ["pervyj nadziratel'»], darauf der Meister, und zugleich fassen die beiden Aufseher den Meisterkandidaten von hinten und werfen ihn in den Sarg, der sofort mit einer Leinwand bedeckt wird. ${ }^{101}$ Dem Neumeister streckt man die linke Hand der Länge nach der Seite aus, die rechte Hand wird mit dem Schurzfell umwickelt und der rechte Fuß auf das linke Knie gestellt, um ein Winkelmaß [«naugol'nik»] zu formieren. In dieser Stellung muB er bleiben, bis das verlorene Wort wiedergefunden wird. Dabei wird die Loge hell erleuchtet und ein Choral gesungen. Darauf sagt der Meister vom Stuhl: „Meine Brüder, das Wort der Meister ist verloren gegangen; laßt uns reisen, um es wiederzufinden!" Man begeht nun um den (an die Hiram-Legende angelehnten und für das Ritual gestellten, Anm. d. Verf.\} .Toten" drei Reisen [«putešestvija masterov»] im sogenannten Meisterschritt [«masterskij šag»]. ${ }^{102}$ Nach diesen schlägt der Meister vom Stuhl auf seinen Tisch [«ma-

9

LENNHOFF/POSNER (1932), 1018.

97

SCHAUBERG (1861-63), 633.

9.

SOKOLOVSKAJA, T. O.: Masonskija sistemy, in: MEL'GUNOV, S. P./SIDOROV, N. I.: Masonstvo (...) (1915), tom II, 52-79, hier 56.

9

HAACK, F.-W.: Freimaurer, München 1988, 17.

100

HAACK (1988), 17. Bei HAACK (1988) lautet der genaue Wortlaut: „Ich gelobe auf Maurerwort: Mich der Bruderschaft in unauflöslicher Gemeinschaft zu verbinden; verschwiegen zu sein wie der Tod; an mein vergängliches Leben fortan den Maßstab des Ewigen anzulegen.”

101

SCHWARTZ-BOSTUNITSCH, G.: Die Freimaurerei. Ihr Ursprung, ihre Geheimnisse, ihr Wirken. Weimar 1928, 212. In diesem Moment wird auch noch ein anderes wichtiges Symbol der Freimaurer ins Ritual eingeführ. Die Rose tritt neben ihrer Verwendung beim Johannisfest, das auch Rosenfest genannt wird (SCHAUBERG (1861-63), Bd. 1, 180), fermer bei der „Grablegung“ eines Bruders in Erscheinung. (LENNHOFF/POSNER (1932), 1329/30) Diesem werden drei Rosen mit ins Grab mitgegeben. (Siehe auch JUNKER, H.: Die Rose als Wiedergeburtssymbol, Leipzig 1929)

102

SCHWARTZ-BOSTUNITSCH (1928: 212) bemerkt hierzu, daB der sogenannte "Meisterschritt" darin bestehe, daB bei jedem Schritt so getan werde, als ob man über einen Sarg steigen müBte. Das veranlasse den "Neumeister", immer an den Tod zu denken (212). Hinzu kommt, daB der Geselle einen Totenschädel [«ర̌erep»] überreicht bekornmt, bevor et auf die "Reise“ geschickt wird; und während der Ubergabe wird ihm gesagt: „Der, dessen Schädel du trägst, mein Bruder, war einst, ein Mensch, 
sterskij stol»] oder den Altar [«altar'»] und sagt: „Meine Brïder, das erste Wort, so man unter uns hören wird, soll dasjenige sein, welches uns zum Meisterworte dienen wird".

"Er hebt jetzt das Leinentuch, wickelt dem im Sarge Liegenden die rechte Hand aus dem Schurzfell [«zapon»; «perednik»] und nimmt sie schweigend am Zeige- und Mittelfinger, worauf die Brüder, die mit den niedergelassenen Händen eine Kette bilden [«cep'»], näherrücken“. Nachdem der Meister vom Stuhl das Meisterwort 'Mac-Benac' dem ersten Aufseher ins Ohr geflüstert und es weiter die Runde gemacht hat, wird der im Sarge [«grob»] liegende Kandidat [«kandidat»] vom ersten Aufseher mit den Worten aufgerichtet: „Die Haut verläßt das Fleisch“. Der zweite Aufseher faßt ihn bei der anderen Hand und sagt: „Das Fleisch verläßt die Knochen“. Der Meister vom Stuhl tritt hinzu, faBt den Liegenden mit der linken Hand hinter die rechte Schulter, mit der Rechten die rechte Hand, die der zweite Aufseher unterdessen freigegeben hat, macht den Meistergriff, drückt sein rechtes Knie auf das linke des Liegenden und sagt: „So will ich versuchen, ihn aufzurichten". Dann hebt er ihn auf ${ }^{103}$ und sagt ins rechte Ohr: „Mac" und ins linke: „Benac“. Das heiBt nach „Sarsena“: Mac-Putrefaktion, „Fäulnis" als erster Ausruf des Erstaunens, und „Benac“ - „im Scheine“ als zweiter. ${ }^{104}$ Darauf muß der neue Meister die Reise um die Loge herum machen, den Brüdem den Meistergruß und das Meisterwort geben. Ein Freudenlied und ein neuer Eid, gegen Profane und Brüder niederer Grade verschwiegen zu sein, beschließt die Zeremonie". Soweit diese Details zum Meisteraufnahme-Rituals bei SCHWARTZ-BOSTUNITSCH (1928).

In der Zusammenfassung der wesentlichen Punkte der Meistererhebung können letztlich fün Schritte unterschieden werden:

1. In Anlehnung an die Hiram-Legende gerät der Geselle in Verdacht, Komplize der verbrecherischen Gesellen zu sein. Daher wird ihm der Gesellenschurz. abgerissen. (Symbolisiert den Ausstoß aus der alten Gesellengemeinschaft.)

2. Vorbereitung auf den Tod durch drei „Reisen“. Dabei das erschüttemde Ereignis, in drei Schritten über das „Abbild seiner letzten Ruhestätte“ gehen zu müssen.

Die drei Meisterreisen sind in ihrer Form den Reisen der niederen Grade ähnlich, gewandelt hat sich indes, wofür diese Reisen stehen sollen. Im Norden der Loge wird er auf die Vergänglichkeit alles Irdischen hingewiesen; im Osten erhält er Zuspruch, indem ihm Uberirdisches prophezeit wird; im Süden endlich wird er aufgefordert, ein Leben in steter Rücksicht auf das Ende zu führen. Der Westen erinnert den Meisterkandidaten resümierend daran, daB der Tod eine Herausforderung für das Leben ist. Die Vorwegnahme des Todeseriebnisses soll dem künftigen Meister eine möglichst frühzeitige Erlangung der geistigen Freiheit bescheren. (BINDER, D.: Die diskrete Gesellschaft, Graz, 1988, 193/4)

103

Die Erhebung ist ein wichtiges Ereignis in der Meisteraufnahme. Die fünf Punkte der Meisterschaft (.,FuB gegen FuB", .Knie gegen Knie“, ,.Hand in Hand". ..Brust gegen Brust“ und die ,.linke Hard um den Nacken ${ }^{\omega}$ ) bilden eine notwendige Hilfestellung, damit der Tote nicht wieder zusammenbricht.

104

Der neue Meister erwacht erst „zum Leben“, nachiem der ,Meister vom Stuhl“ dem Erhobenen das Meisterwort ins linke und rechte Ohr geflüstert hat. Unter der einsetzenden Musik wird der junge Bruder Meister an den Meistertisch geführt.

ros

SCHWARTZ-BOSTUNITSCH (1928), 213.

106

$\mathrm{Zu}$ den maurerisch-symbolischen Schritten sei noch angemerkt, daB in den Johannisgraden die Schritte stufenweise gelehrt werden. Der Lehrling ersteigt mit 3, der Geselle mit 5 und der Meister mit $_{7}$ 
3. Der Geselle erlebt „Identifikation“ mit Baumeister Hiram, dem vorbildlichen Menschen.

4. Im Grabe erfolgt die Läuterung: Vorbereitung auf den Wandel. Geburt des neuen Menschen.

5. Erhebung zum neuen Leben im Geiste des Meisters (.,Meta noeite!"), um zu begreifen, was es heißt: „Er lebt im Sohne“.

\section{ABSTEIGENDER RITUS}

STUFE VI Schließung der eigentlichen Arbeit [«okončanie raboty», «truda»], Bestimmung der Zeit. (,Welche Zeit ist es?"), 1. Danksagung: (meist nur noch sehr verstümmelt oder verändert erhalten, als Lied oder Spruch)

\section{STUFE VII Entlassen des Lichtes. (Löschen der Lichter.)}

STUFE VIII Darstellung der vollendeten Arbeit (Kettenbildung) [«cep'»]; 2. Danksagung (meist auch als Kettenspruch oder Lied).

STUFE IX

Übertragung des Ergebnisses auf die profane Ebene. (Gezeigt wird dies auch an einem profanen Beispiel.) Schließung der Loge [«loža»].

STUFE 0

Entlassung der Brüder [«brat’ja»] aus dem Tempel [«chram»].

9. Beständige freimaurerische Zeichen - „verkörperte Symbolik“

In seinem Werk über die „Symbolik der Freimaurerei“ hat HENNE AM RHYN (1906) die „Freimaurerloge“ [«masonskaja loža»] als die „Grundlage der Symbolik“ bezeichnet. ${ }^{108}$ Die rituellen Abläufe sind im Bereich der nichtverkörperten Symbolik - gepaart mit der freimaurerischen Allegorik jedoch durch die vorherige rituelle „Absicherung der Loge" bedingt. Diese „Deckung“ sichert sowohl das Ritual wie die einzelnen systemspezifisch-rituell verwendeten beständigen Symbole vor unbefugten Einblicken. Die beständig-verkörperten Symbole gehören ausschließlich zum Logeninventar und können daher nur über die Lektüre der freimaurerischen Veröffentlichungen oder der sogenannten Verräterschriften erschlossen werden. Einige „Logenrequisiten“" [«prinadležnosti»] sind in der Beschreibung der rituellen Abläufe bereits vorgestellt worden. Grundlage der Symbolik ist bekanntlich die "Arbeit der Handwerker" [«remeslenniki»] insbesondere der

Stufen den Altar. Für das Ritual ist entscheidend, daB der Maurer alles in der geraden Linie nach Muster eines rechtwinkligen Dreiecks abschreitet. Auch die Hand soll der Maurer im rechten Winkel bewegen. (.WinkelmaB*) (SCHAUBERG (1861-63), Bd. 1, 433/34; LENNHOFF/POSNER (1932), 1417)

107

Die nochmals erfolgte Untergliederung der Meisteraufnahme ist an SCHERPE (BINDER (1988), 204) angelehnt. 
„Steinmetzen“ [«kamenotesy»]. Ihre Werkzeuge stellen die bekanntesten Symbole der Freimaurer. Das „Winkelmaß" [«naugol'nik»] wie auch der „Zirkel“ [«cirkul'»] finden im Aufnahmeritual Verwendung. ${ }^{109}$ Zusammen mit der während der „Tempelarbeit“" auf dem „Altar" [«altar'»] liegenden aufgeschlagenen „Bibel“ [«biblija»] gehören sie zu den 'Drei Großen Lichtem' der Freimaurerei [«tri velikie svetil'nika masonstva»]. Die 'Drei Kleinen Lichter' [«tri menšie svetil'nika»] brennen als „Kerzen“ [«sveči»] auf den „drei . Säulen“ [«tri stolba»] ${ }^{110}$ der „Weisheit“, „Schönheit“, „Stärke“ [«mudrost'», «krasota», «sila»] und symbolisieren die „Sonne“ [«solnce»], den „Mond“ [«luna»] und den „Meister vom Stuhl" [«master stula»]." Als Lichtquellen für die Loge gelten die Gestime als Inkamation der schöpferischen Urkräfte und der Logenvorsitzende („Stuhlmeister") als "Sohn“, der in Anlehnung an den „Logos“ das geistige Licht ausstrahlt."

Neben dem „Stuhlmeister" sind auch noch die genannten „Aufseher" [«pervyj i vtoroj nadziratel'»] berechtigt, den „Hammer" [«molotok»] zu fuhren. Er dient als Schlaginstrument für gradspezifische „Klopfzeichen“, mit denen einzelne Szenen des Rituals begleitet werden." ${ }^{13}$ Bei den Freimaurern versinnbildlicht er in Form eines Steinmetzschlegels die Macht, den Willen, die Befugnis, aber auch die Gewalt des operativen Maurers."

109

Das „WinkelmaB“" wird stets vom „Stuhlmeister” [ «master stula»] als Zeichen seiner Würde getragen. Es steht als Symbol für das Gewissen und die Gerechtigkeit. (SOKOLOVSKAJA, T. O.: Masonskija sistemy, in: MEL'GUNOV, S. P./SIDOROV, N. I.: Masonstvo (...) (1915), tom II, 52-79, hier 56). Der Zirkel symbolisiert bei den Freimaurem die Liebe zu den Menschen und die Menschlichkeit in dem Bild, daB eine Spitze dem rituellen Ablauf getreu, ,in dem Herz des Aufzunehmenden symbolisch verankert" sei und der andere Schenkel diesen mit den anderen Brüdem verbinde; neben der weiteren Vorstellung als Bild der kosmischen Ordnung verkörpem die beiden gleichseitigen Schenkel des Zirkels noch das Gleichgewicht zwischen Recht und Pflicht. (HENNE AM RHYN, O.: Kurzgefaßte Symbolik der Freimaurerei, 64)

${ }^{110}$ In allen Logen stehen fünf Säulen. Drei tragen die .Lichter” und sind um den „Teppich“ oder „Tapis" ["tapii»] angeordnet, auf dem, wie auf einer .J.ehrtafel“, Symbole dargestellt sind. (Siehe auch POLAK, M. S.: Die Tapis in ihrer historisch-paedagogischen, wissenschaftlichen und moralischen Bedeutung oder Geschichte der Urreligion als Basis der Freimaurerei, Amsterdam 1855). Die beiden freistehenden oder einen Portikus tragenden Säulen ,Jachin und Boas“ gehen auf die Bibel (IKön. 7,15-22) zurück und figurieren als Grundpfeiler für die Humanität. (Gerechtigkeit und Wohlwollen) (LURKER (1988), 212; PYPIN (1916), 63 und SCHAUBERG (1861-63), Bd. 1, 205-40, über den Stellenwert der Bibel Bd. 1, 280-92)

III

Die Sonne regiere nämlich den Tag, die Nacht werde vom Mond beherrscht. Ebenso führe der Meister die Loge an. (PYPIN (1916), 59; SCHAUBERG (1861-63), 205-39)

112

LURKER (1988), 211. (,Osten“)

113

Den Ursprung für den freimaurerischen Hammer sieht Schauberg wie fast alles andere auch im antiken Ägypten. (SCHAUBERG (1861-63), 136-49, hier 139; BINDER (1988), 216)

114

HENNE AM RHYN (1906), 25. Siehe auch LENNHOFF/POSNER (1932), 664/65. Eine Ge schichte der symbolischen Bedeutung des Hammers bis zur Entstehung des Bundes versucht der Freimaurer G. SCHULZ (1825) nachzuzeichnen. Er geht aber über die konventionellen Bedeutungen nicht hinaus. (SCHULZ, G.: Der Harnmer in seiner symbolischen Bedeutung. Für Jedermann insonderheit für Maurer und die es werden wollen, Naumburg/Saale 1825). Eine Abbildung eines freimaurerischen Ham- 
Von den rituellen Abläufen während der Initiation ist bereits bekannt, daß für die schottische Lehrart der "Dolch" [«kinžal»] als zeremonielles Utensil wichtig ist." gezogene „Schwert“ [(«obnažennyj) mex»] bzw. der „Degen“ [«špaga»] hat ebenfalls in der Hochgrad-Freimaurerei seinen Platz und ist von verschiedenen Maurern als abwegige Neuerung beklagt worden.

In Anlehnung an die handwerkliche Arbeit der Maurerzünfte vertergen die Freimaurer noch die „beweglichen" und „unbeweglichen Kleinodien“ [ $\ll$ tri podvižnych i tri nepodvižnych klejnody»]. Die beweglichen werden von dem „Winkelmaß" [«naugol'nik»], dem Lineal [«linejka»] sowie dem „Lot" oder dem „Senkblei“ [kotves'»] gebildet; und die sind seine wichtigsten Werkzeuge." ${ }^{116}$ Beweglich nennt er sie deshalb, weil das „Winkelmaß" unter anderem auf der „Brust des Meisters“ oder der „Aufseher" hängt und nicht einen festen Platz in der Loge einnimmt. Die unbeweglichen Kleinodien der rituellen Arbeit sind das „Reißbrett" des Meisters [«čertež», «čertežnaja doska»], der „rauhe Stein“ des Lehrlings [«dikij kamen' dlja učenika»] und der vollendete oder „kubische Stein“ [«soveršennyj, kubičeskij kamen'»], der dem erfahrenen „Maurer" dazu dient, sich mit seinen Kleinodien an ihm zu versuchen." Ebenfalls zum "Logeninventar" [«vnutrennost' loži»] gehört der bunte „Baldachin“ [«mnogocvetnyj baldachin»], der bei den Freimaurem die „Jakobsche Himmelsleiter" [«lestnica Iakova»] symbolisiert." Während der Baldachin auch den Himmel verkörpert, kommt die "Jakobsleiter" als freimaurerisches Symbol in der schottischen Lehrart vor." verkörpertes Symbol verwendet, während et im „orthodoxalen System“ der Johannismaurer allenfalls als allegorische Bezeichnung für die „Zunge“ bekannt ist, die Geheim-

mers nebst anderen typischen Gebrauchsgegenstünden findet sich unter den russischen Quellen bei SOKOLOVSKAJA, T. O.: Obrjadnost' vol'nych kamenšxikov, in: MEL'GUNOV, S. P.SIDOROV, N. P.: Masonstvo (...) (1915), tom II, 83.

11 s

Siche Anmerkung 85.

${ }^{116}$ Für den Maurer bilden sie die Grundwerte: „WinkelmaB** (,Beförderung der Sittlichkeit"), das "Lineal" (Gleichheit) und das „Lot". (,Aufrichtigkeit”, „Gradheir" und „Offenherzigkeit für das ganze Leben") (PYPIN (1916), 65)

II)

PYPIN (1916), 66. In diesem Sinn weist die Allegorie „Behauen des Steines“ auf die soziale Selbsterziehung des Menschen hin. Die "Harmonisierung der Steinform erinnert an die Notwendigkeit von sittlichen Maßstäben, ohne die eine sittliche Germeinschaft undenkbar ist", so der Eintrag im "Internationalen Freimaurerlexikon" (1932). ENDRES (1930) führt die Allegorie mit dem Hinweis weiter, dab auch der „Tempel nicht einfach aus rohen Steinen entstehen“ könne. (LENNHOFF/POSNER (1932), 1504. (-,Stein, kubischer")

${ }^{118}$ Die von Jakob im Traum erblickte „Himmelsleiter” (1Mos. 28,12f) stellt eine Verbindung zwischen Erde und Himmel her. Auf ihr steigen die Engel Gones auf und nieder. (PYPIN (1916), 65)

119

Und zwar im 30. Grad (Ritter Kadosch). Sie hat sieben Sprossen. Auf der einen Seite tragen diese die Namen der sieben frejen Künste auf der anderen die sieben Kardinaltugenden. Die drei Hauptsprossen stehen für den Glauben, die Liebe und die Hoffnung. (SCHAUBERG (1861 -63), 657/58) 
nisse bewahren soll. [«ključ'»] ${ }^{120}$

Auch an Bekleidungsstücken machen Freimaurer metaphysische Inhalte fest. Da diese einheitlich sein muß, ist eine Umkleidung vor Betreten des 'Salomonischen Tempels' [«chram Solomonovas] - auch 'Tempel der Humanität' [«chram gumannosti»] ${ }^{121}$ genannt - unerläBlich. Die Mitglieder des Bundes sind bei 'gedeckter Loge' einfach mit einem Frack [«odetyj prosto vo frak»], ${ }^{122}$ bisweilen mit einem Zylinder [«cilind»; «kruglaja šljapa»] $^{123}$ und weißen Handschuhen [«belye perčatki»] ${ }^{124}$ bekleidet. Diese sollen zeigen, daß die Hände während der 'Arbeit' sauber bleiben müssen. Zumeist ebenfalls in weißer Farbe gehalten sind die graduell zu unterscheidenden 'Bundeskleider' oder 'Schurzfelle' [«zapon», «perednik»], die als Sinnbild der Arbeit auch für die „Unschuld“" stehen. ${ }^{125}$ Der Gebrauch freimaurerischer Abzeichen [«masonskie znaki»] als Zeichen der Logenzugehörigkeit („Bijou"/,Kleinod") ist zwar nicht allgemein verbreitet, dennoch haben andere Abzeichen (überreicht aus Anlaß von Jubiläen) immer zur rituellen Bekleidung gehört. ${ }^{126}$

Metaphysische Bedeutung haben die Freimaurer auch Farben und Zahlen gegeben. Ohne sicheren Bezug auf die verkörperte Symbolik finden hier die Spekulationen allerdings kein Ende. Das alte Zunftwappen der englischen Maurerei hatte einen „blauen Grund"; wahrscheinlich steht die freimaurerische „Hauptfarbe Blau" in dieser Tradition. Dennoch ist die Assoziation mit der Farbe des Himmels keinesfalls nur bei den Männerbünden verbreitet. ${ }^{12}$ Die freimaurerisch betriebene Zahlensymbolik ist ein eigenes Kapitel. Grundsätzlich hat neben der Drei und den durch sie teilbaren Zahlen auch die Sieben

120

LENNHOFF/POSNER (1932), $1396 / 97$.

121

PYPIN (1916), 62,71. (LENNHOFF/POSNER (1932), 77273).

122

STEPANOV, A.P.: Prinjatic v masony v 1815 godu, 221.

123

IVANOV, V. F.: O Petra pervago, 38.

124

SCHAUBERG (1861-63), Bd. 1, 81/82

125

LURKER (1988), 212. SCHAUBERG (1861-63) nennt die Schürze auch ,das orientalische Urkleid der Menschheir und erkennt in diesem Kleidungsstück sogar die ..spätere Gestaltung des biblischen Feigenblattes von Adam und Eva". Auch knüpft er an die alten Ägypter an und kommt zu dem SchluB, daB die Maurer die Schürze nicht als Maurermeister tragen, sondern als „Symbol des Umenschen und als die Geweihten des lichten und reinen Himmelsgortes". (Bd. 1, 71-74)

126

LENNHOFF/POSNER (1932), 9 (.,Abzeichen“). Abbildungen von Logenabzeichen, Emblemen und Maurerschürzen des Dekabristenführers P. I. Pestel' sind in einem Sammelband des Moskauer Revolutions-Museums (1929) abgedruckt. (DRUŽININ, N. M.: Masonskie znaki dekabrista P. I. Pestelja, in: Muzej Revoljucii Sojuza SSR, sb. 2, Moskva 1929, 12-47) Maurerische Anstecknadeln kommen als Element der Porträtmalerei von berïhmten eingeweihten Staatsmännem häufig vor. (Z.B. bei Friedrich dem Großen und Zar Pavel I.)

${ }^{127}$ LENNHOFF/POSNER (1932), 460/61 (.,Farben“). Neben dem „Blau“ des Johannismaurers spielt die Farbenordnung der Bänder auch eine Rolle. Nach Desaguliers wurde 1731 in der englischen Farbenordmung folgendes beschlossen: Grobbeamte tragen das blaue, Stewards das rote, und Stuhlmeister und die Brüder das weiße Band. Bei einigen Schurzfellen taucht die gelbe Farbe auf arkus Wolf - 9783954790715 
sowohl in der verkörperten wie in der nichtverkörperten Symbolik ein erhebliches Gewicht. $^{12}$ Ein wenig beachtetes Symbol der Freimauret ist der „Spiegel“" [«zerkalo», «zerkal'ce»], der in der - hier nicht weiter ausgeführten - Beförderung zum Gesellen vorkommt. Der „Spiegel“ ist auf Selbsterkenntnis und nicht auf Eitelkeit gerichtet und bildet eine andere Gestaltung des kubischen Steins mit dem darauf liegenden WinkelmaB. ${ }^{120}$

Von den Pflanzen gilt neben der erwähnten "Rose“ auch die "Akazie“ als ein typisches Symbol der maurerischen Bewegung. ${ }^{130}$ Mit einem "Akazienzweig" [«vetv' akacii»] wurde in der Hiram-Legende der Ort des "getöteten Hiram“ gekennzeichnet. ${ }^{\text {'3! }}$ Daher sind oft Darstellungen zu finden, die den "Akazienzweig auf einem Grabhügel" zeigen. Die Akazie ist auch ein Bestandteil des Meistererhebungsrituals. Aber auch bei realen freimaurerischen Begräbnissen werden ihre Zweige mit ins Grab geworfen. ${ }^{132}$ Als einzige Vertreterin des Tierreiches bildet die „Biene“ [«pčela»] das Identifikationsmerkmal für das Freimaurertum überhaupt. Das emsige Insekt wie auch seine Behausung als „Bienenkorb“ («ulej») deutet auf die für alle Männerbünde wichtige Gemeinschaftsarbeit hin.

Die Symbole wie auch das Schema für die Initiations- und Beförderungsrituale bestätigen die Worte des Freimaurers und Spezialisten für die freimaurerische Symbolik $O$. HENNE AM RHYN (1906): Die Freimaurerei sei „geistige Hauptkunst" und „ein System für sich". Zweifellos bestehen Ähnlichkeiten mit ihrer größten Widersacherin (der Katholischen Kirche); doch über die konkreten Differenzen hält sich HENNE AM RHYN (1906) bedeckt. ${ }^{133}$ Während Religionen und Konfessionen auf Lehrsätzen und Prinzipien gründen, die, obgleich unbeweisbar, eine geschlossene Lehre bilden, fehle den

128

LENNHOFF/POSNER (1932), 1733-1741. Während „Dreizahl” und ,Dreieck“ Grundsymbole des "Lchrlingsgrades" darstellen, korrespondieren die Fünf und das Pentagramm mit dem Gesellengrad. Verwunderlich ist dann nicht, daB die Sieben als herausragende (,heilige") Zahl dem Meister zukommt. Mehr als alk anderen steht sie für die Vollkommenheit der Weltschöpfung (7 Planeten mit Sonne und Mond), abgesehen von den biblischen Vorgaben. (Der siebte Tag ist Gott zu weihen. Sieben Bitten des Vaterunser, siebenarmiger Leuchter, sieben Augen Jahwes u.s.w. (LURKER (1988), 660) Siehe auch ENDRES, F. K.SCHIMMEL, A.: Das Mysterium der Zahl. Zahlensymbolik im Kulturvergleich, Köln 1984. Endlos sind die Verbindungen die SCHAUBERG (1861-63) zu den freimaurerischen Bedeutungen herstellt. (Bd. 2, 325-480)

129

Nach SCHAUBERG (1861-63) solle sich det Geselle selbst zum kubischen Stein, d.h. zum brauchbaren Stein in dem groben Bau der Menschheit durch Ablegung und Entfernung seiner Fehler und Gebrechen formen (Bd. 1, 104). Das Lehrbild der Selbstbeschau im Spiegel besaB schon der altschottische Ritus in Form eines Spiegels mit dem in der Mitte eingegrabenen Wort 'Jehova' (LENNHOFF/ POSNER (1932), 1489. (.,Spieger"))

${ }^{130}$ Uber die Rose, Siche oben Anmerkung 101.

131

IVANOV, V. F.: O Petra pervago, 38. Siche auch 28-32. (Hinweise auf die „Hiram-Legende")

${ }^{132}$ Die einzige Darstellung einet freimaurerischen Begräbnisprozession bietet: FARINA, S.: II libro dei rituali del rito scozzese antico ed accettato, Roma 1946, $138 f$.

133

HENNE AM RHYN (1906), 12-21. 
Freimaurem nahezu jede Dogmatik. ${ }^{13 x}$ Die Symbole, Allegorien und Rituale der Freimaurer beziehen sich neben der 'bauzunftgebundenen Gemeinschaftspflege' zwar auch auf ethisch-metaphysische Inhalte; da aber eine Dogmatik im Sinne einer einheitlichen Glaubenslehre von der Bewegung im grundlegenden „Konstitutionenbuch" abgelehnt wird, ${ }^{135}$ ist die These einer einheitlich aufgebauten und, womöglich nach politischen Gesichtspunkten operierenden "Weltmaurerei“" nicht zu halten. ${ }^{136}$

Für die Analyse eines künstlerischen Textes nach freimaurerischen Zusammenhängen müßte aufgrund dieser Vielfalt zunächst der Typ des Logensystems bekannt sein, der der entsprechende Autor im Einzelfall angehörte. Doch ist solches Quellenmaterial nur in seltensten Fällen zugänglich. Ein weiteres Moment muß also hinzutreten, um Freimaurerisches bei einem als Freimaurer bekannten russischen Autor als solches identifizierbar zu machen. Es ist dies die bislang kaum wahrgenommene, dabei aber nicht unerforschte Personen- und Institutionengeschichte freimaurerischer Geheimbünde in Rußland. Von daher müssen logeninterne Symbolwelten nicht die alleinige Folie für die Analyse künstlerischer Texte nach maurerisch-allusiven Elementen bilden. Mit den Daten und Namen einer russischen Freimaurerhistorie gesellt sich vielmehr eine chronologische und damit gesicherte unabhängige Kategorie dem Symbolisch-Unbegrenzten hinzu, und kann so Quellendefizite dort überbrücken helfen, wo diese die gesicherte Analyse im einzelnen zu verunmöglichen scheinen.

134

Eine Dogmatik wird von der Freimaurerei grundsätzlich abgelehnt und zwar mit der Begrïndung, daB sich diese am Beispiel der Geschichte der Katholischen Kirche als eine abzulehnende Institution entpuppt habe, (LENNHOFF/POSNER (1932), 374)

Die Mauret werden nach Anderson zu der Religion verpflichtet, in der, ,alle Menschen übereinstimmen und jedem seine besondere Meinung“" gelassen wird. (LENNHOFF/POSNER (1932), 15) 


\section{KAPITEL III GRUNDZUGE DER GESCHICHTE DER NICHTPOLITISCHEN GEHEIMGESELLSCHAFTEN IN RUBLAND (ca. 1730-1821/7)}

\section{Umstrittene Anfänge (1731-62)}

„In der Geschichte der russischen Kultur gibt es, wie es scheint, keine Frage, die umstrittener und schwieriger ist, als diejenige nach der Herkunft und Entwicklung der Maurerei in Rußland". Mit diesen Worten leitet SEMEKA (1914) seine Abhandlung *Russkoe masonstvo v XVIII v.» ein. ${ }^{13}$ Weitreichender äußert sich zwei Jahre später G. V. VERNADSKIJ in seinem Vorwort zu dem schon zitierten Spätwerk PYPINS (1916), das den Schlußstein einer fast 50jährigen Beschäftigung mit dem Thema bildet. Kaum ein Thema der „Geschichte der russische Intelligenz" oder der „Geschichte der russischen Geisteslebens" sei, Vernadskij zufolge, so wenig beobachtet worden wie die Frage nach dem Einfluß der Freimaurer. ${ }^{130}$ Insbesondere für das erste Viertel des 19. Jahrhunderts hält der Historiker Vemadskij in seinem Vorspann fest, daß „die freimaurerische Organisation" eine "interessante Erscheinung" in Rußland sei. Erst sie habe einem wichtigen Teil der Gesellschaft einen fertigen Rahmen für religiöse und philosophische Ansichten, literarische Geschmäcker und politische Sympathien gegeben. ${ }^{19} \mathrm{Um}$ die Anfänge des Freimaurertums in Rußland ranken sich jedoch hartnäckige Legenden, die selbst kleinste Anzeichen von Authentizität in den Archivdokumenten in den russischen Nationalbibliotheken schuldig bleiben. ${ }^{100}$

137

SEMEKA, A. V.: Russkoe masonstvo v XVIII v., in: MEL'GUNOV, S. P./SIDOROV, N. P.: Masonsivo (...) (1914), tom I, 124-174.

130

PYPIN (1916), V.

139

PYPIN (1916), V. Erste Anzeichen einer Entstehung von Freimauretlogen sind zweifelsfrei in St. Petersburg aufzufinden (RAUCH, G. v.: Johann Georg Schwarz und die Freimaurer in Moskau, in: BÁLAZS, E. HJ(...): Beförderer der Aufklärung in Osteuropa, 213).

140

Der größte Teil des freimaurerischen Handschriftenmaterials - überwiegend aus dem 18. Jahrhumdert - befand sich nach SEMEKA (1914: 125) in der Bibliothek des ehemaligen Moskauer RumjancevMuseums, dem Vorgänger und Nachfolger der Lenin-Bibliothek, für die der Badeker-Reisefuihrer "Russland" von 1912 noch zugängliche "Archive russischer Freimaurerlogen und Insignien" verzeichnete. [BAEDEKER, K.: Russland (1912), 290] Nach LEIGHTON (1987: 41) soll seinerzeit auch Tolstoj (siehe oben Anmerkung 16) auf dieses Material zuriickgegriffen haben. Bekanntlich sind diese Bestände bis heute nur schwer zugänglich. Dennoch ist dieser MiBstand noch in der späten Sowjetunion beklagt worden. (SOLOV'EV, O. F.: Masonstvo v Rossii, in: VI 10 (1988), 3) Ein umfassendes Bild der vorrevolutionären Archivbestände nicht nur für das 18., sondern auch für das 19. Jahrhundert gibt: VERNAD. SKIJ, G. V.: Russkoe masonstvo v Carstvovanie Ekateriny II, Petrograd 1917, in: Zapiski Istoriko-filologiceskago fakul'teta Petrogradskago Universiteta 37 (1917), VII-XXIV. Hinweise auf den heutigen Standort verschiedener russischer Bestände an Freimaurerliteratur (18./19. Jahrhundert) finden sich bei: LEIGHTON, L. G.: Freemasonry in Russia: The Grand Lodge of Astraea (1815-1822), in: The Slavonic and East European Review 60 (1982), No. 2, 244-61, hier 245-47 und bei JENA (1992), der in der Archivar-Fachzeitschrift auch auf Bestände zur deutschen Freimaurerei im Moskaver Sonderarchiv hinweist. 
In den Bereich der Sage gehört zweifellos die Annahme, Peter der Große (Petr I.) sei bereits während seines Aufenthaltes in den Niederlanden (1697/98) eingeweiht worden, daß das Freimaurertum schon mit Petrs I. Rückkehr im Zarenreich Eingang gefunden habe und die Stiftung des schottischen Andreasordens (1698) mit der Freimaurerei schottischen Ursprungs zusammenhänge. ${ }^{141}$ Gleichwohl haben erste Zirkel bereits unter Anna Ioanovna (1730-40) bestanden. Diesen Standpunkt vertreten vor allem die russischen . Untersuchungen der zaristischen Zeit. Von der Legende über Petr I. einmal abgesehen, datieren sie die frühesten Logengründungen nach $1731{ }^{142}$ während Friedrichs mehr durch idealistische Vorstellungen geprägt von einer „echten Freimaurerei“ erst ab 1771/76 spricht und vorherige maurerische Tendenzen als ,Zweigarten" oder allenfalls "Schattierungen“" eines orthodoxalen Freimaurertums begreift. ${ }^{143}$ Unterschiede sieht der ehemalige Professor am Berliner Kadettenkorps vor allem in der zielgerichteten Erfas-

141

LENNING (1901), Bd. 2, 270. FRIEDRICHS, E.: Geschichte der einstigen Maurerei in RuBland, Berlin 1904, 1-2. Eine andere Uberlieferung besagh, daB Peter der Grobe von dem Estauer der St. PaulsKathedrale Christopher Wren (1632-1723) aufgenommen worden sei, obgleich schon dessen Bundeszugehörigkeit sehr umstritten ist. Demnach soll bereits Ende des 17. Jahrhunderts eine Loge in RuBland bestanden haben. Der Stuhlmeister sei F. Ja. Lefort (1656-99), der erste Aufseher P. Gordon (1635-99), und der zweite solle sogar Peter selbst gewesen sein. (In chronologischer Reihenfolge: LENNING (1901), Bd. 2, 555/56; LENNHOFF/POSNER (1932), 1724/25; SOKOLOVSKAJA, T. O.: Russkoe masonstvo i ego znaxenie $v$ istorii obščestvennago dviženija (XVIII i pervaja đetvert' XIX stoletija), S.Peterburg 1907. 6; PYPIN, Russkoe masonstvo (1916), 88; VERNADSKU (1917), 2/3 (V. verweist auch an dieser Stelle auf Archivmaterial); HENNINGS, P.: Zur Geschichte der Freimaurerei im zaristischen RuBland, in: Quatuor coronati Hefte 2 (1965), 25-36, hier 25-27. Siehe auch den Titel der spekulativen und allein bekannte Ergebnisse referierende Arbeit von IVANOV, V. F.: Ot Petra pervago do nasich dnej. Russkaja intelligencija i masonstvo, Charbin 1934, 81/82. Auch wird erzählt, daß Peter in Kronstadt selbst eine Freimaurerloge ins Leben gerufen habe, nachdem er von seiner zweiten Reise (1717) ein freimaurerisches Statut nach RuBland mitgebracht habe. Freilich fehlen auch dafür die Quellen (LONGINOV (1867), 92; PYPIN (1916), 88). Verehrung genieße der Name Peters des GroBen unter anderem deshalb bei den russischen Freimaurern, weil mit seiner Person die Öffnung zum Westen und auch die Akzeptanz dieser westlichen Bewegung verbunden ist. Vielleicht war es auch das freimaurerische Lied G. R. DERŻA VINS (1743-1816) «Pesn' Petru Velikomu», das als literarischer Lobgesang Petrinischer Reformen eine Grundlage für die Legende bildete, Petr I. als Begründer der russischen Freimaurerei anzusehen (PYPIN (1916), 88/89). Siche auch PYPIN, A. N.: Russkoe masonstvo do Novikova, in: VE 6 (1868), 546-80, hier 548. IVANINA, N. S.: Masonstvo v Rossii v XVIII i XIX vekov, in: RS 35 (1882), 533-560; 36 (1882), 61-76, hier 534 (L-RA: Zapiska o masonstve, in: RS 35 (1882), 533-560). Daruber hinaus ist die Erzählung, daB ein gewisser Kapitïn J. Phillips von der Grobloge in London zum Provinzial-Grobmeister von RuBland bestimmt (24.6.1737) und dann wenige Jahre später von dem späteren preuBischen Feldmarschall Friedrichs des Groben, Jakob Keith (1696-1758), abgelöst worden sei, nur durch eine kleine Notiz im Konstitutionenbuch (dt. Ausg. 1738, 536) belegt (FRIEDRICHS (1904), 3/4). Siehe auch ALLGEMEINES HANDBUCH DER FREIMAUREREI (1901), Bd. 2, 270; PEKARSKIJ, P. P.: Dopolnenija $k$ istorii masonstva $v$ Rossii XVIllago stoletija (1780-1792) gg, in: Sbomik stat' ${ }^{\prime} j$, Citannych $v$ otdelenii russkago jazyka i slovesnosti Imp. Akad. nauk 7 (1870), No. 4, 1224, hier 2; SEMEKA (1914), 126.

142

PYPIN, Russkoe masonstvo (1916), 87; SEMEKA (1914), 125/26.

143

FRIEDRICHS, E.: Geschichte der einstigen Maurerei, 19. (Siehe Anmerkung 2) 
sung des sittlichen Gedankens, die er als einzige Richtschnur einer „wahren Freimaurerei" zugestehen will. In der Tat wird auch von SEMEKA (1914) die erste Periode der russischen Freimaurerei (1731-1762) als eine höchst unvollkommene, sich ausschlieBlich den Launen der Mode hingebende Erscheinung verstanden, weil sie vom Westen kritiklos übernommen worden sei, ohne überhaupt ,Merkmale gesunder gesellschaftlicher Bedürnisse" $\mathrm{zu}$ berücksichtigen.

Obwohl das Konstitutionenbuch für 1731 einen von England aus geweihten GroBlogenmeister für ganz Rußland vermerkt, der "über die See gesandt worden" sei," fehlen weitere Quellen für die 30er Jahre, so daB auch die russische Forschung eine einsetzende Ausbreitung der Logentätigkeit erst für die 40er Jahre ansetzt. Vomehmlich seien es in Rußland ansässige Ausländer (Engländer, Franzosen, Deutsche) gewesen, unter denen sich anfangs eine Ausbreitung der Freimaurerei vollzog. ${ }^{146}$ Englische wie französische Einflüsse treten dabei hinter den deutschen noch bis 1771 zurick, wobei Logen mit zuvorderst russischen Mitgliedem als Träger der Entwicklung noch die Ausnahme blieben. Für die Zeit unter Elizaveta (1741-62) kann A. N. Pypin nur wenige Petersburger Logen nennen. Gleiches gilt für die allein mit dieser Zeit in Verbindung zu bringenden maurerischen Vertreter, ${ }^{197}$ die - obgleich nicht unerheblich für die Geschichte der freimaureri-

144 SEMEKA (1914), 125. Obwohl sich Semeka auf ältere Arbeiten A. N. Pypins stützt (siehe auch PYPIN, A. N.: Russkoe masonstvo do Novikova, in: VE 6 (1868), 548), kommt er dennoch zu anderen Ergebnissen. Für die Anfänge eine noch unvollkommene und mit den Gedanken des Konstitutionenbuchs nicht in Einklang stehende Freimaurerei zu konstatieren, bedeutet, daB auch Semeka eine Vorstellung von einer "wahren Maurerei" haben muB. Die fehlende Dogmatik der Freimaurerei im Unterschied zu anderen religiösen Gesinnungsgemeinschaften macht sich auf seiten der Forschung negativ bemerkbar. Einerseits wird von einer wahren, weil vor allem sittlich-orientierten Freimaurerei gesprochen, die sich erst später entwickle; andererseits divergieren die späteren Einschätzungen stark, wekches System oder welche Loge dem sittlichen Ideal am nächsten komme. In dieser an einer Textanalyse ausgerichten Geschichte der russischen Maurerei kann es daher nicht darum gehen, von e i n e $r$ "wahren" Maurerei auszugehen, sondem (soweit als eben für die Texte Puskins erforderlich), auch die verwanden Spielarten einer zuvorderst sittlichen Freimaurerei darzulegen.

${ }^{145}$ NETTELBLADT, Br. v. (?): Geschichte der Freimaurerey in RuBland, in: Kalender für die Provinzialloge von Mecklenburg 1835, 36. (Zitiert bei LENNING (1901), Bd. 2, 270)

146

SEMEKA (1914), 128; LENNHOFF/POSNER (1932), 1355. G. V. Vernadskij stellt in seinem Werk zur Ekaterinischen Freimaurerei die praktischen Vorteile der Anhängerschaft heraus: Freimaurerische Diplome dienten unter den Ausländern als hervorragende Empfehlungspapiere für den Eintritt in die deutsche Kolonie in St. Petersburg. Im Besitz dieser Diplome brauchten ankommende Ausländer nicht eben „spezielle Freunde“ für den EinlaB; uberall konnte man feststellen, daB dieses Dokument Türen öffnete - anfangs für ankommende Händler, und dank dieser Leute später auch für die russischen Kaufleute und Magnaten. (VERNADSKIJ (1917), 3)

147

Unter den bekannteren russischen Namen, die Semeka ein erstes Mal fir das Jahr 1756 hervorhebt, steht auch derjenige A. P. Sumarokovs (1718-77). (Siche auch LENNHOFF/POSNER (1932), 1769/1770; VERNADSKIJ (1917), 216 zitiert Panin mit den Worten, daB Sumarokov die literarische Kraft der noch jungen russischen Maurerei sei. Obwohl Sumarokov in seinen letzten 20 Lebensjahren uberzeugter Freimaurer gewesen sein soll, könne nach Ansicht von PIKSANOV (1947) nicht von einem

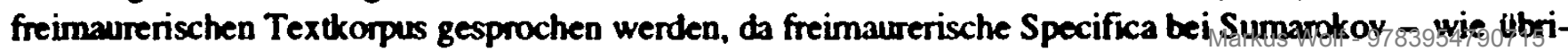


schen Bewegung, ${ }^{14}$ - den Gang dieser Untersuchung aber nicht weiter interessieren dürfen.

Resümierend läßt sich feststellen, daß - abgesehen von den Legenden, die die reiferen Herrscher der männlichen Linie (Petr I. wie Petr III.) betreffen - mit Blick auf die Quellenlage für die vorkaterinische Zeit nur wenig gesichert ist. ${ }^{149}$ Das gilt zu dieser Zeit sowohl für die Geschichte wie auch die Historiographie der russischen Freimaurerei, wobei letztere nicht zuletzt wegen der nur geringzähligen Logen in RuBland noch nicht existierte. ${ }^{150}$ Somit ist die erste Periode der Freimaurerei in Rußland durch das Fehlen der ,nationalen Farben" und einer erst wenig den idealistisch-sittlichen Forderungen des Konstitutionenbuches entsprechenden Haltung gekennzeichnet. ${ }^{\text {'st }}$ Dabei muß betont werden, daß freimaurerische Systeme in Rußland auch später nie zu einer programmatisch-ideologischen Einheit finden ${ }^{132}$ und bisweilen stark miteinander rivalisierende Verbände unter

gens bei fast allen Freimaurer-Poeten des 18. Jahrhunderts - kaum erkennbar seien. (PIKSANOV, N. K.: Masonskaja literatura, in: Istorija russkoj literatury, tom IV, cast' 2, Moskva/Leningrad 1947, 51-84, hier 68) Als Freimaurer-Poeten dieser Zeit werden auch V. I. Majkov und I. F. Bogdanoviz, besonders aber M. M. Cheraskov hervorgehoben: PIKSANOV (1947), 73; KOCETKOVA (1987), 212. Die Mitgliedschaft von über 30 ehrbaren russischen Herrschafien bezeugt nach Ansicht Semekas, daB am Ende der Herrschaft Elisabeths die Maurerei im russischen Boden Wurzeln zu schlagen begann, und sie von da an die Formen für idealistische Strömungen vorgab. (SEMEKA (1914), 131/32) Dennoch habe man sich am Anfang nur selten und zudem in der Stille von Dachkammern entlegener Häuser getroffen, so die Tagebuchaufzeichnungen Böbers. (PYPIN (1868), 556)

148

SEMEKA (1914), 124-32. PYPIN, Russkoe masonstvo (1916), 95-100. G. V. Vernadskjj verweist als Experte des maurerischen 18. Jahrhunderts auf die für die Anfänge der Freimaurerei unter Elisabeth zuverlässigen Angaben A. N. Pypins (VERNADSKIJ (1917), 5). Darüber hinausgehende Angaben finden sich bei PEKARSKIJ, P. P.: Dopolnenija $k$ istorii masonstvá v Rossii XVIIlago stoletija (1780)1792 gg.), in: Sbomik stat'ej, Citannych $v$ otdelenii russkago jazyka i slovesnosti Imp. Akad. nauk 7 (1870), No. 4, 1-224, 127.

149

Nach seinem Grobvater Petr l. ist in der russischen freimnurerischen Historiographie auch für die nur halbjährige Regierungszeit Petrs III. (1762) überliefert, dab et als zweiter im „reifen Mannesalter" regierender männlicher Herrscher nach Erscheinen des Konstitutionenbuches dem Bund angehört habe. Uberdies habe er der Petersburger Loge, Zur Beständigkeir" in Oranienbaum ein Haus zum Geschenk gemacht und - wie auch bei Peter dem Groben - selbst "freimaurerische Arbeiten" verrichtet. Auch dies muB in das ,Reich der Fabel" verwiesen werden, solange sich nichts Authentisches in den Archiven finden läßt. (PYPIN, Russkoe masonstvo (1916), 100, siehe auch FRIEDRICHS (1904), 3/18 und TELEPNEV, B.: An Outline of the History of Russian Freemasonry. Some Aspects of Russian Freemasonry during the Reign of the Emperor Alexander I, in: Ars Quatuor Coronatorum (38) 1925, 6-9).

Der einzige sowjethistorische Beitrag ist der des Tartuer Literaturwissenschaftlers Ju. M. Lotman, Darin datiert er eine erste Periode russischer Freimaurerei auf die Jahre 1730-70, ohne näheres Quellenmaterial beizubringen, Daneben stellt er fest: „Gebräuche und Fragen des Rituals ziehen zu dieser Zeit noch keine besondere Aufmerksamkeit auf sich." (LOTMAN, Ju. M.: Masonstvo, in: Sovetskaja istoriceskaja énciklopedija tom IX (1966), 168/69).

1S1

SEMEKA (1914), 132-35.

IS2 TSCHIĽEWSKIJ, D.: Rußland zwischen Ost und West. Russische Geistesgeschichte II. 18. bis 20. Jahrhundert, Hamburg 1961, 50/51. 
dem Begriff „Freimaurer" geführt werden.

Russische Freimaurer aus dem frühen 18. Jahrhundert als Persönlichkeiten von Rang und Namen, auf die Puskkin in seinen Werken anspielen könnte, bilden in dieser ersten Periode der russischen Freimaurerei noch die Ausnahme; auBerdem sind nur wenige Logenbezeichnungen aus dieser Zeit erhaiten. ${ }^{\text {15 }}$ Im Zusammenhang mit dem Namen der mutmaßlich Puškinschen Loge in KiŠinev «Ovidij» wird die Frage des Entlehnungsmusters für die Logennamen noch von Interesse sein.

\section{Blütezeit und Verfall unter Ekaterina II. und Pavel I. (-1801)}

Es wäre für den Beginn dieser zweiten Periode verfehlt anzunehmen, daB mit dem Regierungsantritt Ekaterinas II. besondere Gesetze erlassen worden wären, die den Männerbünden in RuBland eine besondere Stellung eingeräumt hätten. Noch war es nicht an der Zeit, daB Freimaurer im ,aufgeklärten Absolutismus“ Ekaterinas II. ${ }^{\text {144 }}$ mit der weltlichen Gewalt einen Dialog pflegten, geschweige denn auf die „specielle Protection der Kaiserin $^{\text {" hoffen konnten. }}{ }^{135}$ Deutlich ist allendings, daß nach Ekaterinas II. Thronbesteigung das „Leben der Freimaurer bemerkbarer" wurde.

Ernst Friedrichs" ${ }^{17}$ sieht in der Frühphase (1771-76) zunächst ein Ringen der englischen und der deutschen Landesloge um die jurisdiktionelle Vorherrschaft der Systeme, die an eine ausländische Landesloge gebunden sind. ${ }^{\text {ss }}$ Die Vereinigung der beiden Lan-

153

Der Freimaurer P. Hennings nennt in der einzigen wissenschafulichen historischen Zeitschrift der Freimaurer "Ars quatuor coronatorum" (mit dem deutschen Ableger "Quatuor coronati Hefte") für die Zeit um 1750 nur zwei existente nussische Logen (in St. Petersburg und Riga) mit Namen und bezieht sich dabei auf die Angaben NETTELBLADTS (1835), 36-43, (Siche Anmerkung 145; HENNINGS $(1965,27) \mathrm{Zu}$ weiteren Veröffentlichungen der Londoner Forscherloge: LENNHOFF/POSNER (1932), 94.

154

GEYER (1982), 176-189 (Siche Anmerkung 1).

155

NETTELBLADT (1835), 38.

156

NETTELBLADT (1835), 38.

157

Er war Mitglied der Groben Berliner Landesloge.

158

FRIEDRICHS (1904) nennt den Direktor der Wissenschaften des Adeligen Landkadettenkorps Baron v. Reichell. Im Jahre 1769 von dem Begründer des Schwedischen Hochgradsystems in Deutschland, J. W. K. v. Zinnendorf (1753-82), in dessen neungradigem, in der christlichen Lehre verankerten System eingewiesen, habe er diese neue (Zinnendorfsche) Lehrart in RuBland eingeführt. Im Jahre 1769 solle Reichell bei seiner Abreise von Berlin nach St. Petersburg von dem darnaligen "wortführenden Meister" der Loge , Zu den drei goldenen Schlüsseln", Baron von Zinnendorf, den Auftrag erhalten haben, „dass er alles zur Ehre und zur Aufnahme unseres Königlichen Ordens in dortigen Gegenden versuchen sollte“. Die Grobloge von England hatte die Zinnendorfsche Grobe Landesloge bereits 1773 anerkannt. Während zwei Jahre vorher die Grobe Landesloge in Deutschland das Protektorium Friedrichs des Groben erlangte, grïndete Reichell in St. Petersburg die Loge "Apollo" mit der Mutterloge in Berlin (23). Unter den 14

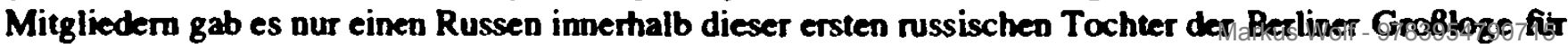


deslogen brachte zunächst ein Rückgang der Anzahl der Logen der Elagin-Reichellschen Union. ${ }^{199}$ Nach 1776 existierte dieses Schwedische System Zinnendorfscher, d.h. Berliner Lehrart ${ }^{160}$ in Rußland noch neun Jahre bis es zerfiel. Von allen Hochgradsystemen ist die vier Grade umfassende schottische Lehrart den russischen Freimaurem wahrscheinlich am längsten bekannt. ${ }^{161}$

Dennoch haben auch zahlreiche andere Hochgradsysteme, die, zumeist umstritten, von einem an die englische wie deutsche Landesloge angeschlossenen 'orthodoxalen Freimaurertum' angefeindet worden sind, in RuBland früh Eingang gefunden. ${ }^{162}$ Bindeglied all dieser Systeme und Orden war die freilich noch nicht legalisierte aber geduldete freimaurerische Organisationsform, die ihrerseits im Europa des 18. Jahrhunderts eine völlig neue Institution darstellte. Früh breitete sich die sogenannte „Strikte Observanz“ («Strogaja nabljudenija») und das „Klerikat der Tempelherren“ («Tamplierskij klerikat») aus.

Deutschland. FRIEDRICHS (1904, 24/25) nennt Namen von „Brïder-Beamten“. Der jurisdiktionelle Konflikt begann, als im Juni gleichen Jahres von seiten Englands die Loge, Zur vollkommenen Einigkeit" eröffnet und der Günstling der Zarin, I. P. Elagin (1725-94), zum Provinzial-GroBmeister erklärt wurde. Zwar rief 1773 Reichell die Loge "Harpokrates“ ins Leben, nachdem „Apollo" die Arbeit aus finanziellen Gründen einstellen muBte. Dennoch hatte er kaum Aussicht, die deutsche Mutterloge gegenüber der englischen Tradition (d.i. Elagin) durchzusetz.en. Im Jahr 1774 gründeten die Engländer weitere Logenkonstituierung anderer Logen in der ganzen Welt zumindest zur Diskussion. Jedenfalls gelingt es Reichell mit der Hilfe des russischen Fürsten und „Bruders“ N. N. Trubeckoj (1744-1821) dann 1776 doch, den im Dienste Ekaterinas II. stehenden Elagin für sich und sein System zu gewinnen. Später tritt det russische Gesandte in Schweden, N. 1. Panin (1718-83), als Stellvertretender Grobmeister der Provinzialloge hinzu, der das schwedische System dort schon kennengelemt hat. (PYPIN (1916), 133) Mit den übergetretenen Logen Elagins zählt FRIEDRICHS (1904) fast 20 Logen, von denen die meisten Anfang der 70er Jahre gegründet worden sind und nach 1776 der schwedisch-berlinischen Jurisdiktion angehören. (FRIEDRICHS (1904), 39-64) Buchstäblich aus erster Hand berichtet: FISCHER, J. K. A.: Die Maurerei im Orient von Rußland unter der Regienung der Kaiserin Ekaterina II. (1806), in: Zeitschrift fuir Freimaurer. Als Manuskripl gedruckt für Brüder, Altenburg 1 (1823), S. 1-43. Auf weiterführende Literatur zu den genannten Freimaurem wird bei: BAKOUNINE, T.: Repertoire biographique (1967), $135 / 36$ (Elagin), 390/91 (Panin), $437 / 38$ (Reichel), 565/66 (Trubeckoj) und LENNHOFF/POSNER (1932) verwiesen.

is9

Im Spiegel der nussischen Quellen unterstanden Mitte der 1770er Jahre 13 Logen dem von England aus eingesetzten späteren Kabinettssekretär I. P. Elagin, wïhrend Reichell nur acht hinter sich wuBte. Nach der Vereinigung der Landeslogen blieben 18 Logen der Elagin-Reichellschen Union übrig. (VERNADSKIJ (1917), 84)

160

LENNHOFF/POSNER (1932), 1355.

${ }^{161}$ PYPIN (1916), 107/108. Wegen einer Notiz im Konstitutionenbuch über den Provinziallogenmeister Jakob Keith gilt es als wahrscheinlich, daB die franzïsischen Grade des schotischen Systems in Rubland schon seit den 1730er Jahren bekannt sind. (Siehe auch Anmerkung 141)

162

Das AusmaB des Einflusses der französischen Freimaurerei in dieser frühen Phase liegt vollkommen im dunkeln. Bekannt ist nur, daB 1773 Graf A. S. Stroganov schon am freimaurerischen Konvent teilgenommen hat, welcher in Paris für die Organisation des französischen Grob-Orients einberufen worden war. (PYPIN (1916), 117)

163

Beide Organisationen hielten sich für berechtigte Nachfahren der alten, Tempelritger stagden aber 
Namen einiger aktiver russischer Tempelherren dieser Zeit waren auch schon unter Elizaveta bekannt. $^{\text {164 }}$

Bedeutender waren im RuBland des ausgehenden 18. Jahrhunderts die Rosenkreuzer («rozenkrejcery»), über deren historische Hintergründe allein vieles zu sagen wäre. ${ }^{165}$ Ein für diese Untersuchung wichtiges Kapitel ihrer Geschichte ist der Fall N. I. Novikov, auf den Puskkin in seinen autobiographischen Schriften trotz strengster Zensurbestimmungen Bezug nimmt. Vernadskij nennt den in einschlägigen Handbüchern und Literaturgeschichten als frührealistischen Aufklärer und Begründer der russischen Joumalistik ${ }^{160}$ bekannten Novikov einen „Patriarchen der Jekatherinischen Rosenkreuzer"; ${ }^{167}$ er brachte jedoch nicht als erster das Rosenkreuzertum («rozenkrejcerstvon) nach Rußland. ${ }^{166}$ Wäh-

im Ruf eines Kryptokatholizismus“. Die stark katholische Färbung der beiden nicht mit den Grundlagen des Konstitutionenbuchs zu vereinbarenden Lehrarten lieB den Gedanken aufkommen, ob ,nicht von weitblickenden Instanzen des Papsttums der Versuch einer Missionstätigkeit im evangelischen Deutschland" versucht wurde, die später auch in RuBland FuB faBte. (LENNHOFF/POSNER (1932), 842, 1501/02) Vorreiter des, ,nussischen Klerikats" war der Geistliche J. A. Star(c)k (1741-1816), der 1768 in St. Petersburg seine erste Loge gründete. Vorher war er schon Anhänger des siebenstufigen russischen Systems, das von dem russischen General griechischer Herkunft Peter Melissino (1726-97) gestiftet worden war. (TELEPNEV, B.: Johann August Starck and his Rite of Spiritual Masonry, in: Ars Quatuor Coronatorum 41 (1929), 238-84) Es umfaBte mystische Lehren mit kabbalistischern und magischem Einschlag; 1777 trat Melissino jedoch dem System der Berliner Landesloge bei, noch bevor seine russischen Logen auf Geheiß Ekaterinas II. ihre Pforten schlieBen muBten. (FRIEDRICHS (1904), 8/9, LENNHOFF/POSNER (1932), 1022 (,Melissino“), PYPIN (1916), 103, 118/19

104

Nicht wenige zähiten zu den bekanntesten Russen ihrer Zeit: Fürst Ju. M. Dolgorukij, Oberpro kuror des Heiligen Synods, Fürst G. P. Gagarin, Kammerhen Fürst A. B. Kurakin, Vize-Direktor der Akademie der Wissenschaften, A. A. Rževskij, Senator und Dichter Fürst M. M. Šcerbatov, Graf A. K. Razumovskij, Graf A. S. Stroganov gehörten alle der ersten Gründung des Templerischen Systems durch Starck an.

165

Wie bei den 0.g. Hochgradsystemen verbindet die Rosenkreuzer mit der an eine orthodoxale Landesloge gebundenen Freimaurerei vorwiegend die Form ihrer Organisation.

106

DUWEL, W. (Hrsg.): Geschichte der klassischen russischen Literatur, Berlin/Weimar 1973, 71; SIE (1966), 307108; LENNHOFF/POSNER (1932), 1134. Als Herausgeber von Zeitschriften («Pustomelja* (1770), «Koselek» (1774), «Moskovskie vedomosti* (1779-89), «Utrennij svet» (1777-80) trat Novikov darin vor allem als Schriftsteller mit dem Genre des satirischen Briefes hervor.

167

VERNADSKIJ (1917), 244.

160

Soweit bekannt gehen die ersten russischen Rosenkreuzer-Logen auf den Professor für deutsche Sprache und Philosophie, J. G. Schwar(t)z (Švarc), zurlick, obgleich die Bewegung auf eine über das 17. Jahrhundert aurijckreichende Tradition verweisen kann. Als Leiter des pädagogischen Universitätsinstituts in Moskau war Schwarz mit Novikov Mitglied der Moskauer Loge „Eintrache” («Garmonija» 1779) bis er in Mitau (1781) Einführungen in das Berliner Gold- und Rosenkreuzersystem erhielt. Mit Novikov befreundet sah Schwarz die Schriften Jakob Böhmes und Saint-Martins als geeignetes Mittel an, dem Geheimnis in der Natur mit der Magie als "göttlicher Wissenschaft" näher zu kommen. Eigenen Vorstellungen zufolge stammen die „R.C.“ von den Gnostikern des 2. und 3. Jahrhunderts ab und verfolgten auf der Suche nach dem Geheimnis Gottes - einen mutmaBlich aus dem 16./17. Jahrhundent stammenden, hermetisch-pansophisch-alchemistischen Mystizismus, der den orthodoxalen Prinzipien des Konstitutionenbuches eher fernstand. (VERNADSKUJ (1917), 65; VERNADSKL (1928) 163; 54 ThKA- 
rend der Wilhelmsbader Freimaurerkonvent $(1782)^{169}$ für Europa das Ende vieler mystischer Hochgradsysteme bedeutete, konnten die Rosenkreuzer in RuBland nicht nur fortbestehen, sondern sich sogar erst richtig ausbreiten. Dagegen ist die Behauptung Tukalevskijs übertrieben, daß das Schottische System von da an nur noch offiziell weiterexistierte und Rosenkreuzer-Bewegung von da an mehr und mehr Anhänger gewann. ${ }^{170}$ Die Dominanz der Rosenkreuzer im Ekaterinischen Rußland ist nach ihrer Emanzipation von den ausländischen GroBlogen indessen unverkennbar, und sie dauerte bis zum ersten Verbot der Männerbünde.

Namhafte Personen gehörten nach Angaben Novikovs dem Orden der Rosenkreuzer an." Novikov betätigte sich mit seinem Kreis aber nicht nur hinter „verschlossenen Tempeltüren". 1779 nach Moskau berufen, übernahm er dort die Universitätsdruckerei, wobei der Ukas vom 15.1.1783 der „Gesellschaft Gelehrter Freunde“ («Družeskoe učenoe obšcestvo") ermöglichte, weitere unabhängige Druckereien zu gründen, deren Publikationen nicht nur für die Logenmitglieder gedacht waren. ${ }^{12}$ Durch diese Gesellschaft wurden

LEVSKIJ, V. N.: N. I. Novikov i I. G. Švarc, in: MEL'GUNOV, S: PJSIDOROV, N. I.: Masonstvo (...) (1914), tom I, 175-226, hier 213/14). Dennoch verband sie mit den Freimaurem die Organisationsform des Männerbundes, welcher im absolutistischen Staat der weltlichen wie der geistlichen Macht allein gegenüberstand. Auffallend ist für RuBland, daB viele namhafte sowohl den Freimaurerlogen im inund Ausland als auch Rosenkreuzerverbindungen angehiörten.

169

HAMMERMAYER, L.: Der Wilhelmsbader Freimaurer-Konvent von 1782. Ein Höhe- und Wendepunkt in der Geschichte der deutschen und europäischen Geheimgesellschaften, in: Wolfenbuittler Studien zur Aufklärung 5/2, Heidelberg 1980.

170

TUKALEVSKJ (1914), 214. Letzalich hat es in ganz RuBland nie mehr als 20 HöchstgradRosenkreuzer gegeben.

171

I. P. Turgenev, P. P. Turgenev, A. M. Kutuzov, S. I. Gamaleja, V. V. Culkov, A. I. Novikov, I. V. Lopuchin (LONGINOV (1867), 88, siehe auch VERNADSKIJ (1917), 73). Nach dem Tode von Schwarz (1784) wurden laut Novikov noch aufgenommen: N. N. Trubeckoj, Ju. N. Trubeckoj, A. A. Cerkasskij, M. M. Cheraskov, K. Mongal'cev, I. I. Frenkel', O. A. Pozdeev. Nach Novikov waren $7 \mathbf{\text { - }}$ mindest Teilnehmer: Ch. A. Cebotarev, M. I. Bagrjanskij. Aufnahme-Petitionen reichten 1784 ein: A. Lodyzenskij, P. V. Lopuchin, A. Verevkin, V. Ja. Kolokol'nikov, M. I. Nevzorov, V. I. Bazenov (PIKSANOV (1914), 227-55; PYPIN (1916), 352; VERNADSKIJ (1917), 73).

172

Uber diese Gesellschaft existient nur eine einzige Schrift, die zuverlässige Aussagen über Arbeitsprogramm und Ziele der Gemeinschaft erlaubt. (Siehe RA $3 / 4$ (1863). Von einer Gruppe begeisterter Aufklärer um N. I. Novikov und J. G. Schwar(t)z gegründet, gehörte dieser neuen Institution neben Cheraskov und dem Freund Radiševs, A. M. Kutuzov, und in seinen letzten Lebensjahren auch der deutsche Dichter J. M. R. Lenz an. Auch konnte sich in diesem Kreis der künftige Schriftsteller und Historiograph N. M. Karamzin bilden (BAKUNINA (1934), 64-70; siehe HARDER, H.-B.: Nikolaj Karamzin und die philosophisch-literarischen Kreise in Königsberg, Berlin. Weimar und Zürich, in: BÁLAZS, E. H./ (...): Beförderer der Aufklärung in Osteuropa, 304-19). Der Kreis um Novikov scharte sich nach der Ubersiedlung von St. Petersburg nach Moskau vor allem um den Schriftsteller und Universitätskuratoren M. M. Cheraskov (siehe auch ROTHE, H.: Zu Cheraskovs Dichtungsauffassung, in: ROTHE, H./HARDER, H.-B.: Studien zur Literatur und Aufklänng in Osteuropa GieBen 1978, in: Bausteine zur Geschichte der Literatur bei den Slawen, 94-109; ROZANOV, I. N.: Michail Matveevix

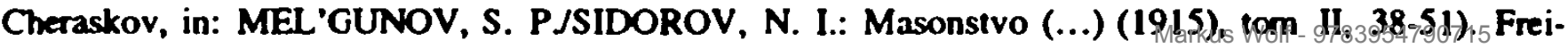


zum ersten Mal ausländische Schriften von Voltaire, Rousseau, Montesquieu und Hume in Massenauflagen der russischen Öffentlichkeit zugänglich gemacht. Inwieweit Novikovs aufklärerische Arbeit (satirische Zeitschriften, Buchübersetzangen in hohen Auflagen, frei zugängliche überregionale Leihbibliotheken in den Logen, unterstützte Neugründungen von Buchhandlungen, Armenspeisungen usw.) nur aus seiner MännerbundAnhängerschaft zu verstehen ist, kann nicht festgestellt werden. ${ }^{\text {'n }}$ GEYER (1982) schliebt jedoch zurecht: „Wer Novikov als Aufklärer ernstzunehmen wünscht, wird auch sein Rosenkreuzertum emstnehmen müssen". ${ }^{174}$ Das betrifft vor allem die Frage nach dem Einfluß dieser rosenkreuzerisch-freimaurerischen Organisationsform (als Geheimbund) ${ }^{175}$ auf die aktive Rolle und die Poetik Novikovs (Aufklärung), die ohne die erstaunliche Ausbreitung des Bundes im Ekaterinischen Rußland nicht denkbar gewesen

maurerische Traditionen im Werk Cheraskovs analysiert: PIKSANOV, N. K.: Masonskaja literatura, in: Istorija russkoj literatury, tom IV, Cast' 2, Moskva/Leningrad 1947, 51-84, hier 73-80). Diese Stellung Cheraskovs trug maBgeblich dazu bei, daB Novikov die Universitätsdruckerei 1779 ubernehmen konnte (TUKALEVSKIJ (1914), 190/198; PYPIN (1916), 182/83; KRASNOBAEV (1979), 257. Den Kreis um Novikov im Rahmen det aufklärerischen Freimaurerei behandelt unter Bericksichtigung der modernen sowjetischen Forschung: KRASNOBAEV, B. I.: Eine Gesellschaft gelehrter Freunde am Ende des 18. Jahhunderts. «Družeskoe ułenoe obšzestvo», in: BÁlAZS, E. HJ(...): Befönderer der Aufluärung in Osteuropa. Freimaurer, Gesellschaften, Klubs, 257-70. (Siehe auch den dortigen Anmerkungsapparat aur Novikov-Forschung); darin nicht berücksichtigt sind die Schriften von KOCETKOVA (1964; 1975; 1987), die von der westlichen Forschung wegen der neuen Beurteilung des Stellenwerts der Freimaurerei in der Aufklänugsepoche mit wachsendem Interesse wahrgenommen wenden: MACARTHUR, G. H.: Freemasonry and Enlightenment in Russia. The Views of N. I. Novikov, in: Canadian Slavic Studies 14 (1980), 370 71; MACARTHUR, G. H.: Catherine II and the Masonic Circle of N. I. Novikov, in: Canadian Slavic Studies 4 (1970), 529-46; LEIGHTON (1982), 244-61, hier 245. Krasnobaev betont in seinem Aufsatz abschliebend, daB der Verband keinesfalls nur auf den persönlichen Einfall von Novikov und Schwarz zurikckgehe. Vielmehr habe es in den Jahren 1773/74 schon eine „Gesellschaft zur Befördzrung des Buchdrucks" gegeben, 1777-80 dann eine "Gesellschaft zur Errichtung von Lehranstalten" («Utrennyj svet $x$ ), 1781 die Moskaver Ausgabe (mit entsprechender Gesellschaft) bis dann 1782 die „Gesellschaft Gelehrter Freunde" entstand. Einem anderen aber dennoch der Gesellschaft verwandten Kreis gehörten die Dichter N. A. L'vov, 1. I. Chemnicer, V. V. Kapnist und auch G. R. Derłavin an. Von letzterem ist zwar bekannt, daB er Novikov Literatur über Freimaurerei abkaufte und ein später von Freimaurern verwendeten und zur Freimaurerliteratur zählenden Lobgesang auf Petr I. schrieb, dennoch ist seine Anhängerschaft zum Bund nicht gesichert. (BAKOUNINE (1967), 116)

173

LENNHOFF/POSNER (1932), 1135.

174

Nur wenige sowjetische Arbeiten úber Novikov berücksichtigen ubberhaupt den Aspekt des Männerbundes, wobei diese die aktuellen westlichen Debatten über den Zusammenhang von Auflärung und Geheimbundwesen - mit Ausnahme von KOCETKOVA - bisher nicht aufgegriffen haben (GEYER (1982), 188/89): (MAKOGONENKO (1951; 1976); ZAPADOV (1968); MARTYNOV (1981)). Dagegen hat sich die vorrevolutionäre Forschung dieses Problems geradezu rege angenommen: LONGINOV (1867); NEZELENOV (1875); TARASOV (1908); TUKALEVSKIJ (1914); BOGOLJUBOV (1916); PYPIN (1868, 1916). Eng an die vorrevolutionären Arbeiten lehnt sich die Exilforschung an: BAKUNINA (1934), 32-39; BAKOUNINE (1967), 371-73; BOURYCHKINE/BAKOUNINE (1967), 93-95.

175

IN-HO, L. RYU: Moscow Freemasons and the Rosicrucian Order. A Study in Organization and Control, in: GARRARD, J. G. (Hrsg.): The Eighteenth Century in Russia, Oxford 1973, 198-233. Siehe auch GEYER (1982), 188/89. (Anmerkung 1) 
wäre. ${ }^{176}$

Die wachsende Akzeptanz dieser von Ekaterina II. zumindest bisher geduldeten Männerbünde erfuhr einen ersten Rückfall mit dem Ausbruch der Französischen Revolution 1789. Hatte die erste (vorkaterinische) Phase (1731-62) eine Freimaurerei ausgebildet, die noch eine fremde "Maurerei in Rußland" war, und es eine unabhängige russische Bewegung noch nicht gab, ${ }^{17}$ kam es während der zweiten Entwicklungsstufe (1762-81/2) zu einer erstmals russischen Maurerei, die - verschiedene Systeme ausbildend - sich stark differenzierte. Die dritte Phase (1781-92) ist gekennzeichnet von der Ausprägung verschiedener Hochgradsysteme, wobei unter ihnen die Rosenkreuzer, obwohl in Westeuropa durch den Wilhelmsbader-Freimaurerkonvent zurückgedrängt, in Rußland letztlich obsiegten. ${ }^{13 n}$ Andererseits hatten die Wirmisse der Französischen Revolution Stimmen laut werden lassen, die auch in den Freimaurem die Anstifter sahen. ${ }^{179}$ Ekaterina II. lieB 5 Jahre später durch ihre Staatsbeamte verkünden, daB sie die Zusammenkünfte der Freimaurer nicht gerne sehe. ${ }^{100}$ Diesem Entschlu $B$ zu einem vorzeitigen Ende aller "Logenarbeit" gingen indes weitere Entscheidungen voraus, die aus der Geschichte der russischen Freimaurerei nicht wegzudenken sind. Ekaterina II. nahm im Laufe ihrer gesamten Regienungszeit keine wohlwollende Haltung gegenüber mystischen Tendenzen ein. Dennoch verbreiteten sich unter ihr Männerbünde nicht nur offiziell; ${ }^{18 !}$ als mystische Hochgrad-Maurerei trieb „Scharlatanerie" («šarlatanstvo») und "Obskurantismus" («obskurantizm») wilde Blüten. In ganz Europa bekannt gewordene Hochstapler wie

176

Dennoch waren die Rosenkreuzer nach dem Tod von Schwarz (1784) keine einheitliche Bewegung mehr. Es entwickelten sich drei Richtungen mit besonderen Schwerpunkten: 1) sittlich-religiöse Richtung (Novikov); 2) asketische Verfolgung des Lebenswegs Christi (Gamaleja); 3) Betonung der RosenJueuzerischen Theorien; (so Schwarz' nachgelassene Schriften (über Magie, Kabbalistik, Theosophie) (TUKALEVSKL (1914), 215/16).

in

FISCHER, J. K. A.: Die Maurerei im Orient von RuBland unter der Regienung der Kaiserin Katharina II., Altenburg 1806, 4.

${ }^{i n}$ Zu dieser Einteilung der russischen Freimaurerei des 18. Jahhunderts kommt SEMEKA (1914), 124-74.

${ }^{179}$ Es war die Zeit der Verdächtigungen A. Barruels und J. Robinsons, die die Enzyklopädisten, Inluminaten und nicht zuletzt Freimaurer für die Französische Revolution verantwortlich machten. Seitdem gehören die Freimaurer in eine Galerie jener Gruppen, die als Verursacher von Weltverschwönungen verdächtigt werden. (LENNHOFF/POSNER (1932), 1694/95).

100

FRIEDRICHS (1904), 90. Nach den Angaben des württembergischen Hofrats G. Reinbeck informierte Ekterina II. gerade die Staatsdiener, von denen sie wuBte, daB sie zur Gesellschaft gehörten und diese empfahlen ihren Bridern, ihre Arbeit einstweilen einzustellen. (REINBECK, G.: Flüchtige Bemerkungen auf einer Reise von St. Petersburg über Moskwa, Grodno, Warschau, Breslau nach Deutschland im Jahre 1805, Leipzig 1806, 177 (LENNING (1901), 273).

181

MEZIER, A. V.: V poiskach pravdy i smysla Żizni. Ozerk iz istorii russkago masonstva, in: Istorija i obscestvennye voprosy 112, S.-Peterburg 1906, 53. 
Cagliostro $^{122}$ und Graf Saint-Germain ${ }^{123}$ kamen nach Rußland, gaben sich als Freimaurer, Magier, Heilkünstler und Propheten aus und zogen Leichtgläubige der sogenannten guten Gesellschaft in ihren Bann. '" Obwohl von dem orthodoxalen Freimaurertum entschieden abgelehnt, sind diese Vertreter jedoch aus keiner historischen Darstellung der europäischen Männerbünde wegzudenken. Fkaterinas Vorstellungen von den russischen Männerbünden ranken um das Phänomen der Hochstapelei wie auch dem Schicksal Aleksandr Nikolaevið Radišcevs (1749-1802). ${ }^{\text {1as }}$ Ein Jahr nach der französischen Revolution veröffentlichte der sein gegen die Leibeigenschaft gerichtetes Buch «Putesestvie iz Peterburga v Moskvu» (1790), nachdem in Novikovs Zeitschrift KŽivopisec» (1772) ein Vorläufer dieses bedeutendsten Werkes erschienen war. Obwohl Radišcev in seinem Buch über den freimaurerischen Mystizismus spottete, hielt die Zarin den Autor für einen Anhänger der „Martinisten“ («martinisty») mit den sich angeblich notwendig aus diesem Vorwurf ergebenden aufrührerischen Absichten und verurteilte ihn zum Tode. ${ }^{106}$ Später

182

Ob Cagliostro (eigtl. Joseph Balsamo; 1743-95) uberhaupt in eine Freimaurerloge aufgenommen wurde, ist fraglich. $\mathrm{Zu}$ eigennützigen $\mathrm{Zwecken}$ erfunden ist dagegen die 1781 von dem eingeweihten Goethe im „Großkophta“ (1792) beschriebene Ordensgründung, die um 1782 zuerst auftauchte und mit Cagliostro wieder verschwand. Ein Versuch, auch in St. Petersburg unter dem Schutz von Ekaterina II. sein System zu verbreiten, miBlang, offenbar weil die Gräfin von der Recke - in Mitau 1779 mit ihm zusammengetroffen - die Zarin erfolgreich vorgewarnt hatte (PYPIN (1916), 283-85, 287; LENNHOFF/ POSNER (1932), 29, 246-51 (Ägyptische Maurerei, Cagliostro); FRIEDRICHS (1904), 78-81; FRIEDRICHS (1907), 42/43).

133

Saint-Germain war für orthodoxale Freimaurer ein Abenteurer unbekannter Herkunft. Er gab vor, tausend Jahre alt zu sein, über Zauberkräfte zu verfügen und in höchste freimaurerische Grade eingeweiht zu sein. Cagliostro bezeichnete sich als dessen Schüler. Zu Beginn der Ekaterinischen Ära (1762) bereiste Saint-Germain auch RuBland. (PYPIN (1916), 40; LENNHOFF/POSNER (1932), 1372/73; SCHMID (1998: 153-60)

is

Ekaterina II. hatte die Schwindeleien Cagliostros, freimaurerische Inhalte vorzuschieben, durchschaut und ihn in ihrer Trilogie ( cherlich gemacht. Später wähnte sie in Cagliostro einen Illuminaten. (PYPIN (1916) 309/10).

ius

IVANOV-RAZUMNIK: Russkaja literatura of 70-ych godov do nasich mej, Berlin 1923, 333/34.

126

PYPIN (1916), 310. Ekaterina II. hatte von den Martinisten falsche Vorstellungen. Saint-Martin (Spitznarme durch Cagliostro: kJehovar) (1743-1803) hatte das theosophische Werk "Des Erreurs et de la Vérite ou les hommes rappelés au principe universel de la science" (1775) verfaßh, das kabbalistische Ziige aufwies und von Jakob Böhme und Emanuel Swedenborg beeinfluBe war. Das System stand den Rosenkreuzern nahe. In jedem Fall kann aber nicht davon gesprochen werden, daB die Martinisten ein Geheimbund mit politischen Zielen waren. Diese hatten ihre Anhänger nur in den Vorstellungen der Zarin. (PYPIN (1916), 286; LENNHOFF/POSNER (1932), 999/ 1000) Dennoch darf das politische Gewicht der nichtoffiziellen Verbindungen in einem absolutistischen Stant trotz all ihrer anderweitigen Beteuerungen nicht unterschätzt werden. Das Bekenntnis zur politischen und religiösen kosmopolitischen Uberparteilichkeit war nicht zulett eine Bedingung itrer Existenz und somit bei manchen Verbindungen of nicht mehr als ein blobes Lippenbekenntnis. Da der Novikover Kreis auch den Ansichten Saint-Martins zuneigte, galten sie eben auch als Martinisten (LONGINOV (1867), 85-87). Teile des Briefwechsels der Moskaver Freimauret (eigentl. Rosenkreuzer, die sich für die wahren Freimaurer hielten und mit SaintMartin sympathisierten) wird zusammengefabt bei: BARSKOV, Ja. L.: Perepiska moxkoyskich massopgv 
wandelte die Zarin diese Strafe in eine lebenslängliche Verbannung um.

Gegen die nichtoffiziellen Männerverbindungen war noch deutlicher die Maßnahme gerichtet, die Ekaterina II. zwei Jahre später gegenüber Novikov, dem „Patriarchen der russischen Rosenkreuzer" verfügte, obgleich man diesem auch nicht das geringste Vergehen nachweisen konnte. ${ }^{\text {lu }}$ Sie beauftragte den Metropoliten Platon, Novikov auf seine Glaubensfestigkeit zu prüfen. Das Urteil des Kirchenfürsten war zwar für Novikov überaus glänzend, trotzdem wurde Novikov $1792 \mathrm{zu} 15$ Jahren Schlüsselburg verurteilt." Diese Ereignisse sprechen durchaus für die Einschätzung, daß in den Augen Ekaterinas II. kein wesentlicher Unterschied zwischen Freimaurem, Theosophen, Illuminaten, ${ }^{100}$ religiösen Schwärmern, Abenteurem und Schwindlern bestand. ${ }^{191}$ Ein an das Konstitutionenbuch Andersons angelehntes Freimaurertum konnte sich mit der Bewegung der Rosenkreuzer nicht einverstanden erklären; dennoch wird Novikov (R.C.) in den meisten Darstellungen als ein der 'echten Aufklärung' verbundener Freimaurer weniger wegen seiner Einstellung zur freimaurerischen Arkanpraxis («Poznanie samogo sebja») sondern seiner humanitären und bildenden Kulturarbeit wegen gewürdigt. ${ }^{12}$ Mit dem Fall Novikov endet im Jahr 1794 auch die erste Phase der russischen Freimaurerei bis zum ersten

XVIII-go veka (1780-1792 gg.), Petrograd 1915.

187

MYL'NIKOV (1979) zitiert sowjetische Forscher, wonach in Radiscevs Schrifien zu einem ,schonungslosen Kampf gegen die Freimaurer" aufgefordert wurde. (MYL'NIKOV, A. S.: Die Rolle nichtoffizieller Vereinigungen im geistigen Leben und in den internationalen Beziehungen RuBlands während der Aufklärungsepoche, in: BÁLAZS, E. H./(...): Beförderer der Aufklärung in Osteuropa, 197-212, hier 198; siehe auch PLIMAK, E. G.: Masonskaja reakcija protiv materializma v Rossii (70-90-e gody XVIII veka), in: Voprosy filosofii 1 (1957), 51-62 und ROGOV, I. M.: K voprosu o *masonstvex A. N. Radisceva, in: Vestnik Leningradskogo gosudarstvennogo universiteta 20 (1958), 153f.)

18:

So wenig überschaubar die sowjetische Literatur über Novikov auch sein mag, so wenig berücksichtigen die Studien nach 1917 den sozialen Aspekt und die Gebrüuche der freimaurerischen Arkanpraxis bei dem russischen Aufklärer. (Anmerkungen 168/171) (GEYER (1982), 187; RYU (1973), 199-232)

109

Seine Schöpfungen gingen mitsamt Bibliothek und Bücherlager zugnunde. Erst nach dem Tod Ekaterinas II. (1796) bekam Novikov auf GeheiB Pavels I. seine Freiheit zurick. (LENNHOFF/POSNER (1932), 1136) Dea Fall Novikov zog nicht nur unter Freimaurem breite Kreise. (DOVNAR-ZAPOL:SKIJ, M. V.: Pravitel'stvennyja gonenija na masonov, in: MEL'GUNOV, S. P./SIDOROV, N. I.: Masonstvo (...) (1915), tom II, 118-34)

190

Es sind in den russischen Archiven offenbar keine Dokumente vorhanden, die belegen, ob es Anhänger des durch den Jesuitenzögling Adam Weishaupt 1776 gegründeten und 1785 durch den bayerischen Kurfuirsten Karl Theodor wieder verbotenen Illuminatenordens in RuBland gab. (VASJUTINSKIJ, A. M.: Orden illjuminatov (1914), 112-23; PYPIN (1916), 307)

191

STENDER-PETERSEN, A.: Geschichte der russischen Literatur, München 1986, 423; SEMEKA, A. V.: Russkie roeenkrejcery i socinenija Imperatricy Ekateriny II protiv masonstva, in: Zumal' Ministerstva narodnago prosvescenija 2 (1902), 343-400.

192

FRIEDRICHS (1907), 43/44; LENNHOFF/POSNER (1932), 1134-36. DaB die Freimaurerei auf Novikov einen schlectiten EinfluB ausgeübe habe, kann jedoch nur als eine Entstellung der wirklichen Sachverhalte beurteilt werden (NEZELENOV (1875), 99); dennoch wird angenommen, daB Novikov sich lediglich am Rande für das Gebrauchtum und das Ritual interessierte. (LOTMAN (1966); 1639) 
Verbot jeder „Logenarbeit“. In den zu seinen Lebzeiten nichtveröffentlichten Aufsätzen lehnen sich Puškins Bezüge auf die Verurteilung Radiš̌evs wie auf den Fall Novikov eng an die nichtoffiziellen Männerbünde an; und das trotz der für ihn in diesem Bereich besonders geltenden Zensurbestimmungen.

$\mathrm{DaB}$ der Sohn von Ekaterina II., Pavel I., auf einigen Bildnissen als Regent mit freimauretischen Emblemen und Symbolen abgebildet ist, ist kein Beweis für seine Zugehörigkeit zum Freimaurerbund. ${ }^{\text {is }}$ Dennoch wird bei ihm - wie zuvor auch bei den Zaren Petr I. und Petr III. - angenommen, daß er auf einer Auslandsreise eingeweiht wurde. ${ }^{\text {'t }}$ Interessant ist, daß es nicht nur zu seinen ersten Amtshandlungen gehörte, Novikov die Freiheit wiederzugeben und Radiščv die Rückkehr aus der Verbannung zu erlauben; Pavels I. erste Schritte drückten auch in anderer Hinsicht ein gewisses Wohlwollen gegenüber den Freimaurem aus. ${ }^{195}$ Zwischenzeitlich gab es gar die Hoffnung, daB die "Logenarbeit" in Rußland wieder zugelassen werden würde, zumal überliefert ist, daß Pavel I. verschiedenen Vertretern eine Audienz gewährte, sich ihnen dabei als einer der ihren («pišite ko mne prosto, po-bratski i bez vsjakich komplimentov») vorstellte und sie anwies, vor weiteren Logengründungen zunächst seine Befehle abzuwarten. ${ }^{196}$ Indirekte Hinweise auf freimaurerische Bünde und ihre Mitglieder befinden sich auch in Pavels $I$. nachgelassenen Briefen.'

Dennoch kam es nicht zu einer offiziellen Akzeptanz der bisher immer noch nichtoffiziellen Verbindungen durch den allgewaltigen Staat, geschweige denn durch die orthodoxe Schultheologie. Aus politischen Erwägungen wurde Pavel I. 1798 'Großmeister des Katholischen Souveränen Malteserordens' und konnte schon allein deshalb nicht

193

Die von SOKOLOVSKAJA (1907) untersuchten Bilder Pavels I. hingen bis vor der Revolution im Šcukin-Museum («Malaja gruzinskaja 21»). Siche auch BAEDEKER (1912), 295); bis heute ist ein weiteres Exemplar in det freimaurerischen Porträtgalerie in Stockholm zu sehen.

194

In den Jahren der gröbien Verbreitung der Männerbünde im Rußland des 18. Jahrhunderts (177682) soll Pavel I. noch als Thronfolger auf einer Auslandsreise durch Empfehlung seines Erziehers Graf $N$. I. Panin (1718-83) und in Begleitung von Fürst A. B. Kurakin (1752-1818) im Jahr 1776 einer Loge in Riga beigetreten sein. (FRIEDRICHS (1907), 44; BAKUNINA (1934), 51/52) Eine andere Version besagt, daB die Einweihung durch den Senator I. P. Elagin in RuBland geheim vollzogen wurde. (ŠUMIGORSKIJ, E. S.: Imperator Pavel I. i masonstvo (1915), 135-52, hier 141/42)

195

Der Schriftsteller M. M. Cheraskov erhielt bald den Grad eines Geheimen Rates, I. P. Turgenev wurde Direktor der Moskauer Universität und N. V. Repnin alsbald zum Feldmarschall ernannt. Diese und noch weitere Ereignisse geben AnlaB, Pavels I. Maßnahmen nicht nur in automatischer Opposition zu der Politik seiner ihm nicht wohlgesonnenen Mutter, sondern durchaus als Wiedergutmachung gegenüber den Männerbünden zu beurteilen. (BAKUNINA (1934), 54)

196

BAKUNINA (1934), 55; siehe auch ŠUMIGORSKIJ (1915), $142 / 43$.

197

Siehe dazu die einzige auf den russischen Kulturraum bezogene Freimaurerbibliographic: BAKOUNINE, T./BOURYCHKINE, P.: La franc-maçonnerie en Russie, in: Etudes sur l'histoire, l'economie et la sociologie des pays slaves 11, Paris/La Haye 1967, 98/99; VERNADSKU, G. V.: Le césarevitch Paul et les francs-maçons de Moscou, in: Révue des études slaves 3 (1923), 268-86. Weitere Angaben zur vorrevolutionären Forschung finden sich auch bei BAKOUNINE (1967), $394 / 95$. 
auch Patron der Freimaurerbewegung sein. ${ }^{100}$ Aus der Sicht der Freimaurer ist es daher durchaus angebracht, von einer „Blütezeit", wie auch von einem „Verfall“, sowohl unter Ekaterina II. wie auch unter Pavel I. zu sprechen. Eine Entwicklung, die unter Aleksandr I. anhalten sollte.

\section{Anfängliche Unterstützung und späteres Verbot unter Aleksandr I.}

a) Erste Logentätigkeit (1800/02) und offizielle Protektion (1810)

DaB sowohl nach dem ersten offiziellen Verbot der Freimaurerei (1797) wie im Anschluß an die vorläufige Erneuerung dieser Anordnung in Aleksandrs ersten Regierungsmonaten $(1801)^{199}$ einige Logen in St. Petersburg neu gegründet wurden, steht auBer Zweifel. ${ }^{200}$ Erste Absprachen zwischen den zumeist namhaften Logengründern und den zaristischen Aufsichtsorganen dürfen daher angenommen werden. Inwieweit die verordnete Untätigkeit der Maurerei nicht nur in Kreisen ihrer Anhänger spürbar war, ${ }^{201}$ und daher trotz Verbots stellenweise eine karitativen Zwecken geschuldete Ausnahme gemacht wurde, läßt sich auch nach Prüfung des veröffentlichten Archivmaterials nicht klären. Ebenso wenig erkennbar sind die Gründe für die Erneuerung des Verbots, zumal 1803 eine völlige Kehrtwendung eingetreten sein soll. ${ }^{202}$ Die deutsche wie die vorrevolutionäre Forschung stimmen aber darin überein, daß schon vor 1807 einige Logen gearbeitet haben. ${ }^{203}$ Unter ihnen trat die Loge «Les Amis Réunis»" schon allein wegen der

19

FRIEDRICHS (1904), 45/46.

$19 \%$

Nach der Verhaftung Novikovs, die übrigens ohne genaue Begründung erfolgte, sprach Ekaterina II. kein offizielles Verbot gegen die Freimaurerei aus, wohl aber erlieB sie einen Ukas gegen Novikov und seine Freunde. Dieser Ukas vom 1.8.1792 findet sich bei: LONGINOV (1867), 114. Ein erstmaliges amtliches Interdikt soll nach ausländischen Aufzeichnungen 1797 durch Pavel I. ausgesprochen und bei Antritt Aleksandrs 1. bekräftigt worden sein. (ACTA LATOMORUM (1815/16), Bd. 1, 199; 210/11; siehe auch PYPIN (1916), 522)

soo

In seinem „Chronologischen Verzeichnis aller Logen in RuBland“ vermerkt Pypin sowohl für das letzte Jahr unter Pavel $I$. als auch für die ersten Monate unter Aleksandr I. nach der Emeuerung des Versammlungsverbots eine Logengründung (PYPIN (1916), 522). Dennoch darf nicht vergessen werden, daB es allein eine ausländische (deutsche) Freimaurer-Zeitschrift war, die von beiden Anordnungen wissen will. (SOKOLOVSKAJA, T. O.: Vozrożdenie masonstva pri Imperatore Aleksandre I. (1915), 154.

m)

FRIEDRICHS (1907), $47 / 48$.

202

Nicht nur, daB der neue Zar das Verbot aufgehoben haben soll. Durch das maurerische Engagement eines um eine Audienz bittenden Freimaurers umgestimmt, soll Aleksandr I. sogar selbst "eingeweiht" worden sein. Danach war es der Staatsrat und Direktor des Petersburger Kadettenkorps J. Bïber ( $\propto B 2$ berw), der die Aufhebung des Verbots bei Aleksandr I. erreichte. Doch diese Angaben finden sich nur in der genannten deutschen Freimaurerzeitschrift, so daB sowohl das Datum der neuerlichen amtlichen Akzeptanz des Bundes wie die Anhängerschaft Aleksandrs I. bezweifelt werden muB. (FRIEDRICHS (1904), 100/1; BAKUNINA (1934), 77-81).

203

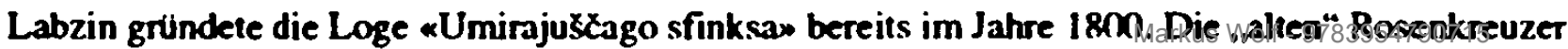


Mitgliederliste besonders hervor. Großfürst Konstantin Pavlovið stand an der Spitze, General A. A. Žerebcov war einer der Gründer und brachte das System aus Frankreich mit. ${ }^{205}$ Ebenfalls zu den Anhängem der jüngsten Stunde gehörten: Herzog A. v. Württemberg, ${ }^{200}$ Graf S. K. Potockij, ${ }^{207}$ Graf A. Osterman-Tolstoj, General N. M. Borozdin, K. O. Audé-de-Sion, Graf I. A. Naryłkin, ${ }^{20}$ Graf A. Ch. Benkendorf, ${ }^{209}$ A. D. Balašov ${ }^{210}$ und andere. 211

Aus dem Jahr 1805 ist die deutschsprachige Loge „Alexander zum gekrönten Pelikan $^{\text {“212 }}$ belegt, die infolge der stark anwachsenden Mitgliederzahlen 1809 geteilt werden mußte. ${ }^{213}$ Seit diesem Jahr existieren neben anderen die Logen «Elisabeth zur Tugend» (russischsprachig, unter A. S. Sergeev) ${ }^{214}$ und „Peter zur Wahrheir ${ }^{2215}$ (französisch- und deutschsprachig, unter G. H. Ellisen). ${ }^{216}$ Diese drei Verbände formierten sich 1809 zur Großen Direktorialloge «Vladimir zur Ordnung» unter der Leitung von Böber. ${ }^{217}$ Noch

Novikov, Pozdeev und Gamaleja waren ihr gegenüber wohlgesonnen. 1803 entstand die geheime Loge «Neptunaw, die der Senatsvorsitzende M. I. Golenišev-Kutuzov ins Leben rief. Auch soll die Loge, det Vasilij L'vovið Puškin und Pestel' später beitraten «Soedinennych druzej («-brat'ev»)» (,Les Amis Reunis") bereits 1802 entstanden sein. Sie arbeitete auf der Grundlage des 7-gradigen französischen Systems, das in Frankreich vor 1789 verbreitet war. (FRIEDRICHS (1904), 10203; PYPIN (1916), 522)

204

Von dieser renommierten Loge existieren unveröffentlichte Freimaurerlieder und Logenreden in französischer Sprache aus den Jahren 1810/11, und es ist anzunehmen, daB in dieser Literatur A. S. Puskins Onkel Sergej L'vovið oder auch ein Pavel I. Pestel' hervorgetreten ist. (PYPIN (1916), 522/23)

ms

BAKOUNINE (1967), 623. Dort weitere bibliographische Angaben auch für im folgenden aufgezähiten Logenbriider.

206

Generalgouvemeur in WeißruBland.

207

Später Minister für Konfessionen und Volksaufklärung in Polen.

20

Zeremonienmeister am Hof des Zaren.

${ }^{2009}$ Polizeichef unter Nikolaj I., persönlicher Vertrauter Aleksandrs I. und nach dem Dekabristenaufstand mit der persönlichen Zensur der Schriften und Briefe A. S. Puskins beauftragt.

210

Polizeiminister unter Aleksandr I.

211

Das Mitgliederverzeichnis aus dem Jahr 1810 beziffert die Zahl der „Brüder" auf 79, wobei zwischen 50 aktiven und 29 Ehrenmitgliedern unterschieden wird. (FRIEDRICHS (1904), 105) Unter den ständigen Besuchern ist der bekannte Freimaurerei-Reformator Professor I. A. Fessler (1756-1839) hervorzuheben. (SOKOLOVSKAJA (1915), 159)

212

*Aleksandra Blagotvoritel'nosti k koronovannomu Pelikanu». (BAKOUNINE (1967), 625)

213

Auch von ihr lagen bis vor der Revolution Protokolle im damaligen Moskauer Museum vor.

214

«Elizavetu k Dobrodetelix. (BAKOUNINE $(1967), 630)$

215

«Petra $k$ istinen. (PYPIN (1916), 524)

${ }^{216}$ Russische Schreibweise: E. E. Ellisen.

${ }^{217}$ \&Vladimira k porjadku», (BAKOUNINE (1967), 638; FRIEDRICHS (1904), 106; PYPIN (1916), 525). 
vor der offiziellen Anerkennung des Freimaurertums kam es zur Gründung der Petersburger Loge «de la Palestine»."

Mit der erstmaligen Erteilung einer amtlichen Erlaubnis zur Wiedereröffnung der Logen in Rußland (1810) ${ }^{219}$ verbreitete sich die Freimaurerei für den Zeitraum von zehn Jahren in einem zuvor nicht erreichten AusmaB. War die Freimaurerei bisher nur geduldet, erlangte sie nach 1810 zum ersten Mal einen eigenen Status: sie trat zum ersten Mal als offiziell anerkannte Körperschaft in einen Dialog mit den zaristischen Behörden. 200

\section{b) Reform des Großlogensystems («Große Provinzialloge» und Großloge «Astraea»)}

War das Verhältnis des Staates zu den neuen Körperschaften in seinen Grundzügen neu geregelt, so stand die Reform der erst nach 1810 verstärkt aktiv werdenden Freimaurerverbände erst noch bevor. Die russischen Freimaurer hatten sich nach dem Wilhelmsbader Freimaurerkonvent von den ausländischen Landeslogen gelöst. Seitdem dominierte in Rußland die Hochgrad-Freimaurerei (Rosenkreuzer, Martinisten), während in Westeuropa diese stark an Anhängem verlor.

218

«Palestiny», (BAKOUNINE (1967), 633). Der Meister vom Stuhl der 75 Mitglieder zahlenden Loge war von 1810-1814 der Kammerter M. Ju. Wielhorsky («Viel'gorskij») (1787/88-1856) (SOKOLOVSKAJA, T. O.: Iz zapiskach knižek masonov grafa M. Ju. Viel'gorskogo i F. N. Glinki, in: RA 45 (1907), 136-38). Aus der Fassung des über sie angefertigten Polizeiberichts geht hervor, daB sie .nach dem System von Zerebcov" arbeitete und kein besonderes Reglement hatte. Unter ihren Mitgliedem ist auch der spätere Vorkämpfer für die Befreiung Griechenlands, General Fürst Alexander Ypsilanti («Ipsilantix), verzeichnet. Nach 1820 erscheint sein Name jedoch nicht mehr in den Verzeichnissen (FRIEDRICHS (1904), 108; PYPIN (1916), 387, 427). Mit A. Ypsilanti wie auch seinem Bruder Dmitrij stand A. S. Puskkin in seiner Kisinever Zeit in persiinlichem Kontakt. Dort das erste Mal uberhaupt Zeuge kriegerischer Auseinandersetzungen, verehrte Puškin zunächst Ypsilanti. In seiner über zwanzig Jahre später verfaBten Erzählung «Kirdłali» (18.34) würdigte er zwar dessen Tapferkeit im Kampf, sprach ihm dann jedoch Führerqualitäten ab.

219

Der genaue Monat und Tag ist bei Friedrichs wie bei Pypin nicht angegeben. PYPIN (1896), 56; (1916), 380; FRIEDRICHS (1904), 108, (1907), 108. In das gleiche Jahr fält auch die Gründung des Kaiserlichen Lyzeums in Carskoe Selo durch M. M. Speranskij und A. K. Razumovskij, die auch Mitglieder in Freimaurerlogen waren.

20

Aus einem bei FRIEDRICHS (1904) ahgedruckten Zirkularschreiben (im ehemaligen Moskauer Archiv) des Polizeiministers an die Vorsteher der einzelnen Logen (??.08.1810) geht hervor, daB die Regierung bisher keinen Grund hatte, die Zusammenkünfte der Freimaurerlogen zu verhindern, weil diese sich bisher nicht das Geringste hatten zu Schulden kommen lassen. Die Prüfung der freimaurerischen Reglements habe ergeben, daB das Ziel niemandem tadelnswert erscheinen könne. Daher wurde den Freimaurem angeboten, mit besonders ausgesuchten Vertrauensleuten eine Uberprüungskommission einzuberufen, die die Beziehungen zwischen den einzelnen Logen und dem Minister für Volksaufklärung herstellen sollten. Im Laufe dieses Überprïfungsverfahrens, das der Minister für Volksaufklärung Graf A. K. Razumovskij, Polizeiminister A. D. Balałov, Graf M. M. Speranskij und Professor I. A. Fessler vornahmen, sollte es zunächst keine neuen Logen geben. Im gleichen Jahr wurde det neue Status festgeschrieben: Die alten Logen durfien fortbestehen, und die Grïndung never Logen wurde erlaubt, sofem sie angemeldet werden. (PYPIN (1896), 59/60; FRIEDRICHS (1904), 109-11) Markus Wolf- 9783954790715 
Nach der offiziellen Zulassung der Freimaurerei in Rußland sah es zunächst so aus, als wuirde die Dominanz der Hochgrad-Freimaurerei ungehindert fortbestand. ${ }^{221}$ Ein Brief des Stuhlmeisters Ellisen an Böber leitete dann aber die Wende von der HochgradFreimaurerei zu den orthodoxalen, die aus dem Konstitutionenbuch bekannten Traditionen ein. ${ }^{2 m}$ Dieses Schreiben ist das Dokument einer Freimaurerei, die sich erneut an ausländische (englische und deutsche) Traditionen anzulehnen sucht. ${ }^{23}$ Ellisens Forderung nach der alleinigen Anerkennung der drei Johannisgrade ist ein Grund für die Reform des bisherigen an die Hochgrad-Freimaurerei festhaltenden Großlogensystems, an deren Ende die Bildung der GroBloge «Astraea» (,Asträa“, „Astreja“) steht. ${ }^{22}$ Ihr in französischer Sprache abgefaBter Grundvertrag beinhaltet neben dem einleitenden Treuebekenntnis zur zaristischen Staatlichkeit die Absage gegenüber jeder "Geheimniskrämerei“. Ebenfalls unvereinbar mit der Verfassung wurden die „Grundsätze der sogenannten "Illuminaten und Mystiker" wie schon gar "Alchemie“ angesehen. Zweck ihrer Arbeiten sei ausschließlich, die menschliche Glückseligkeit durch „Beförderung der Moralität, der Tugend, der Religiösität, der treuesten Ergebenheit des Landesherrn und die strengste Be-

21

Böber stand seit 1809 der Großen Direktorialloge «Vladimir zur Ordnung* vor und gewann mehr EinfluB, als sich 1811/12 auch die beiden Logen «Les Amis Reunis» und «De la Palestine» unter seine Oberthoheit begaben. Uberdies war Böber Präfekt des Kapitels ,Zum Phönix“ und Obermeister det schottischen Andreasloge „Zum St. Georg" und gehörte somit zu den exponiertesten Hochgrad-Freimaurern seiner Zeit.

22

Das historische Dokument ist sowohl bei Pypin wie bei Friedrichs abgedruckt. E. E. Ellisen gebraucht gegenüber Böber den Terminus der „ursprïnglich reinen Freimaurerei“ («pervonaxal'noe Cistoe svobodnoe kamensxixestvo»), die, im vorigen Jahrhundert zum zweiten Mal aus England gekommen, nur drei symbolische Grade kannte. Die englische wie die deutsche Maurerei hätte die HochgradFreimaurerei als schädlich angesehen, und nach seiner Einschätzung seien die Stifter der Hochgrade sowieso die Jesuiten gewesen. Zu den „Aposteln der Jesuiten“ Zählt Ellisen auch die genannten russischen Systemgrindet Star(c)k und Zinnendorf. (PYPIN (1872, dt. 1896) und PYPIN (1916), 400-406; ausführlich auch bei FRIEDRICHS (19(4), 117-23)

223

«Астрея стремилась къ достиженію цћли истиннаго масонства, основанной на святомъ Евангеліи (...)» (KUL'MAN, N. K.: K istorii masonstva v Rossii. Kišinevskaja loža, in: Ž̉umal Ministerstva narodnago prosvěšxenija, (nov. ser.) II (1907), 345).

24 Sehr viele Logen, die Böber unterstanden, schlossen sich in kurzer Zeit Ellisen und seiner Loge «Peter zur Wahrheit» an. Da Böber keine Lösung sah, demissionierte er schon ein Jahr nach Erhalt des Briefes von Ellisen. An seine Stelle trat später der Namensvetter A. S. Puskins Graf V. V. MusinPuskin-Brjus, der später zum GroBlogenmeister der GroBloge «Astraea» avancierte. (BAKUNINA (1967), 354/55) Zunächst noch reformbestrebt sah Graf Musin-Pułkin-Brjus trotz. des Widerstandes der Hochgrad-Logen die alte Grobe Direktorialloge «Vladimir» seit dem 11.8.1815 für aufgelöst an. Ungeachtet dessen blieben einige Logen dieser Grobloge treu, da ihrer Ansicht nach nur der Zar die Auflösungsbefugnis fir sie inne hatte. Mit Erlaubnis der Regierung konnte sich am 30.8.1815 die Grobloge «Astraea» konstituieren, während die Direktorialloge noch bis 19.9.1816 fortbestand. (FRIEDRICHS (1904), 12527) An ihre Stelle trat die Grobe Provinzialloge, die den sich neu formenden Verbänden eine neue Verfassung gab. Bis zum Verbot allet Freimaurerlogen im Jahr 1821 existierten in RuBland diese beiden Groblogen, deren Verfassung sich nur in beider Akzeptanz der Hochgrade unterschiadus Wolf -9783954790715 
folgung der Gesetze des Staates" zu erhöhen (\$ 6). ${ }^{23}$ Zwar verbietet die Verfassung nicht generell den Eintritt von Hochgrad-Logensystemen, das Schwergewicht liegt aber eindeutig auf den drei symbolischen, in der Tradition des Konstitutionenbuches stehenden Johannisgraden. Zurecht kann darauf hingewiesen werden, daß allein die Namen der obersten Logenbeamten imstande waren, so manchen "Suchenden" anzuziehen. ${ }^{26}$

Signifikant ist, da $B$ in den ersten zwei Jahren nach der Gründung der exakt sieben Jah- . re existierenden Großloge, allein sechs der insgesamt zwölf registrierten Logen in St. Petersburg lokalisiert waren, während in dem verbleibenden Zeitraum nur 3 in der Hauptstadt, dagegen die verbleibenden 13 in weiter entfernten Städten gegründet wurden. ${ }^{27}$ Enorm ist der Zulauf der Großloge «Astraea» zu nennen, die in den ersten vier Jahren (1815-18/19) bereits 1.320 Mitglieder verzeichnete.

\section{c) Puß̌kins Loge «Ovidij» in Kišinev}

In einer späteren Fassung dieses Gesamtverzeichnisses aller der GroBloge «Astraea» zugeschriebenen Bünde ist mit der Nummer 25 auch die Loge «Ovidij» aufgeführt. ${ }^{27}$ Dennoch wird von amtlichen Stellen bezweifelt, daß eine vollständige und für eine geregelte Logenarbeit zwingende Registrierung der angeblich nach schottischem Ritus arbeitenden Gesellschaft überhaupt je vorgenommen wurde. ${ }^{230}$ Wenngleich eine regierungsamtliche

as

Gesetzes-Passagen der Verfassung der Grobloge *Astraea* finden sich bei FRIEDRICHS (1904), $128-31$.

208

FRIEDRICHS (19)4), 132. Neben den genannten Mitgliedem spielten eine aktive Rolle: Fürst A. Ja. Lobanov-Rostovskij, F. P. Tolstoj, Baron H. v. Korff, 1819 übemahm A. L. Naryłkin das GroBmeisteramt von V. V. Musin-Puß̌kin-Brjus', sogar Bïber schloB sich später der GroBloge an.

27

LEIGHTON (1982), $25(1) / 259$.

2

Friedrichs wie auch Leighton kommen beide $2 u$ demselben Ergebnis auf det Grundlage der schon in der zaristischen Zeit veröffentlichten Quellen (RA 3 (1865), 495-5(X)), (FRIEDRICHS (1904), 135; LEIGHTON (1982), 259). 1404 Mitglieder zählt nach nochmaliger Prüfung der regierungsamtlichen Unterlagen der Senator Kušelev: KUŠLLEV, E. A.: Uničtoženie masonskich lož v Rossii v 1822 g, in: RS 18 (1877), 664. In der Zeit seit ihrem Bestehen bis 1822 betrug die Mitgliederanzahl der Freimaurer in russischen Logen (samt Ausländem) über 3.250 (BAKOUNINE (1967), XXIII; siehe auch CLARKE, J. E.: Freemnsonry in Russia, in: The Modern Encyclopedia of Russian and Soviet History 12 (1979), 16). 20

SOKOLOVSKAJA erweitert die Zählung Pypins (24 Logen) um den Hinweis auf eine Mitteilung des Puskin-Biographen Nikolaj O. Lemer, so daB anzunehmen ist, daB ihr das Orginaldokument von 1820/21 moch nicht vorlag. Darin ist die Loge in Kisinev unter der Nummer 25 aufgeführt. SO. KOLOVSKAJA, T. O.: Dvadcat' pjataja masonskaja loł̌a sojuza Astrei, in: RS 129 (1907), 642.

230

Auf amtliches Material kann sich Semevskij berufen. Danach gab die GroBloge der Kiłinever Loge *Ovidij» die Nummer 25, nachdem sie ihren Grobmeister angewiesen hatte, ihr das Patent («masonskaja gramota», Abb. siehe DOVNAR-ZAPOL'SKIJ (1915), 118) zukommen zu lassen. Doch in dieser Eigenschaft verweigerte der beauftragte Kuselev aus nicht erfindlichen Grinden die Unterschrift unter die schon fertiggestellte Logenurkunde (SEMEVSKIJ, V. I.: Masonskaja loła v KißineVe in: SEMEYSKII. V. I.: 
Mitgliederliste nicht vorliegt und eine (nach den zwischen der Großloge «Astraea» und Regierung getroffenen Vereinbarungen) entsprechend ,geregelte Annahme und Installierung" der Loge «Ovidij» womöglich nicht erfolgte," ist dennoch (neben den Angaben Pußkins) aus verschiedenen Memoiren und Biographien bekannt, welche Personen sich selbst zu Mitgliedem einer oder mehrerer Logen zählten: ${ }^{22}$ Neben dem nicht mit I. I. Puščin zu verwechselnden General P. S. Pušxin (Stuhlmeister) und General M. F. Orlov gehörten weitere zwölf Personen ${ }^{23}$ dazu: Major V. F. Raevskij, der General S. A. Tuckov, Major M. Maksimovic, Oberstleutnant A. I. Barocci (Barozzi), der Oberstleutnant (?) Kjurto, der Naturforscher L. S. Tardan, der Schriftsteller I. Brankovic, der Chirurg R. Girljanda, der Advokat P. Fleri (Fleury), der ehemalige frz. Offizier Baron S. Sambonno (Ch. Chambonneau), der Bojar M. Bernardo, det Kaufmann M. Draguševič und der ehem. frz. Oberst Baron L. Treska. ${ }^{24}$ Die Zusammensetzung der Mitglieder läßt den Schluß zu, daß die französische Sprache für den Logenbetrieb vorgesehen war. Auffallend ist neben der dominant vertretenen Berufsgruppe der Soldaten die Tatsache, daß der Name Puß̌kins in den veröffentlichten logeninternen Schriften, die die genannten 13 Namen wiedergeben, nicht vorkommt. ${ }^{23}$

Puškin vermerkt in seinem Kišinever Tagebuch, daß er am 4. 5.1821 aufgenommen wurde; doch erst am 7.7.1821 wenden sich die Kiß̌never Freimaurer mit der Bitte an die Leitung der Großloge «Astraea», ihrer Loge eine Verfassung zu geben. Daraufhin erst bildete sich die Loge rOvidij» in KiY̌inev, wobei eine erforderliche Gründungsurkunde

Politiceskaja i obšcestvennaja idei dekabristov, S.-Peterburg 1909, 314). Siehe auch die friheren Arbeiten KUL'MAN, N. K.: $K$ istorii masonstva v Rossii. Kisinevskaja loža, in: Zumal Ministerstva narodnago prosvešenija, (nov. ser.) 11 (1907), 343-73; Ц̌̌EGOLEV, P. E.: K istorii Puskinskoj masonskoj ložy, in: Minuvšie gody $5 / 6$ (1908), (=Zurnal posvjašennyj istorii i literature, =Slavistic Printings and Reprintings 120 (Bd. 1-3)), The Hague 1973, 517-20.

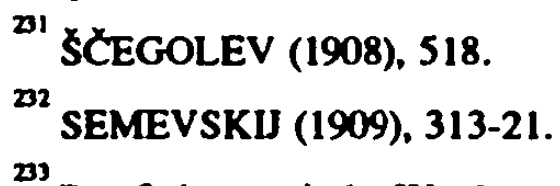

Der freimaurerische Wendegang fast aller Mitglieder samt weiterführender Literatur findet sich in dem freimaurerisch-biographischen Lexikon von BAKOUNINE (1967), 427/28 (Pušxin), $382 / 383$ (Orlov).

${ }^{24}$ Weitere Beteiligte an der Logenarbeit in KiYinev nennt Suller: so den Gutsbesizer N. S. Alekseev und den Apotheker Majgler. Kul'man ist überdies noch der Schweizer Mitterhofer und Graf M. Sucoo bekannt (KUL'MAN (ŽMNP, 1907), 353/365). An weitere Mitglieder habe sich Suller nicht mehr erinnem können. Ziel der Loge sei es nur gewesen, für wohltätige Zwecke Geld zu sammeln (SEMEVSKU (1909), 314/15. In den Veröffentlichungen des KiSinever Puskin-Museums findet sich noch der Name eines weiteren Logenmitglieds: K. A. Ochornikov (TRUBECKOJ, B. A.: „Tvoej molvoj napolnen sej predel (...)“. Stranicy Zizai Pußkina v Moldavii, Kił̌inev 1973, 19; weitere Namen, die im Zusarnmenhang mit der Kixinever Loge zu nennen sind finden sich bei CHAZIN (1979), 159-62 und TYMČIŠIN, V. V.: Puskin yo Moldova, Kišinéu 1979). 
von seiten der Großloge mutmaßlich nie ausgestellt wurde. ${ }^{26}$ Demnach betrachtete sich Puskkin zu einem Zeitpunkt als aufgenommener und eingeweihter Freimaurer, als die „Brider" in Kišinev noch keine Verfassung besaßen. Fest steht allendings, daß Puskin sich zeitweilig als Anhänger der einzigen Kišinever Freimaurerloge begriff (seit 4.5.1821), ${ }^{23}$ mit deren aktivsten Mitgliedern (Raevskij, Pušcin, Orlov ${ }^{23}$ ) er in dieser Zeit befreundet war. $^{239}$

\section{d) Gründe für das Ende aller Logen und der Dekabristenaufstand}

Uber die Frage, wie es zur plötzlichen Schließung der Logen in Rußland kommen konnte, ist viel spekuliert worden. Ob es nun wirklich der Freimaurer Graf C. A. H. Haugwitz («Chaugvic») war, der Aleksandr I. das Verbot der vielen angeblich nur karitative Zwekke verfolgenden Geheimgesellschaften mit Blick auf die Entwicklung in anderen Länder empfahl, ${ }^{200}$ oder ob wirklich, wie auch Puskin behauptet, die Gründe ausschließlich in den politischen Ambitionen der Mitglieder der letzten offiziell anerkannten Loge «Ovidij» zu suchen sind, ${ }^{211}$ muß offen bleiben. Jedenfalls kam die Anweisung des Zaren auch für die Leitung der Großloge überraschend.

In Kiß̌inev wurde der bessarabische Gouverneur, Vorgesetzte und väterlicher Freund Puskins, General 1. N. Inzov, ${ }^{212}$ von Fürst P. M. Volkonskij am 19.11.1821 von der be-

20

KUL'MAN (ŽMNP, 1907), 343-73; PYPIN (1916), 532.

237

PSS VIII, 18. («1821, 4 Мая был я принят в масонын).

236

Einschränkend muB zu General M. F. Orlov gesagt werden, daB seine Mitgliedschaft nur durch Puskkin belegt ist. (PYPIN (1916), 532 und BAKOUNINE (1967), 382/83)

209

PSS X, 198/99. (Žukovskomu, 20.01.1826)

200

FRIEDRICHS (1904), 157; (1907), 52

241

Semevskij betont, daB der Name des späteren Dekabristen V. F. Raxvskij ausgereicht habe, um die angeblich karitative Bestimmung der Loge anzuzweifeln. Ebenfalls ein Grund dafii ist die Skepsis des Zaren gegenüber dem General und Logenstuhlmeister P. S. Pušxin. AnlaB dazu gab, so vermutet Sernevskij, eine Berichterstattung über die Kiß̌never Neuigkeiten («Kiß̌nevskie novosti»), die von geheimen Agenten zusammengestellt und dem Zaren zugeleitet wurden. Darin wird auch von General Orlov berichtet, der wie ein Vater viele erieuchtet habe; daneben ist auch von Puskin die Rede, der öffentlich und in Kaffechäusem nicht nur über die Armeeführung, sondem auch über die Regierung geschimpft ha ben solle. Wichtig ist fir Semevskij, daB sich dieses Anklagedokument zusammen mit den Logenunterlagen in derselben amtlichen Mappe befunden habe. Abgesehen von diesem Aktenstück soll vor allem die unsichere politische Lage in Bessarabien der Grund für die SchlieBung gewesen sein, die wegen der Logenmitgliedschaft kommandierender Generäle Verschwönungstheorien Nahrung gab. (SEMEVSKU (1909), 315/16)

212

Erzogen im Hanse von dem Reichellschen Logenbruder und Fürsten N. N. Trubeckoj war I. N. Inzov (1768-1845) auch mit dem Weggefährten Novikovs und Kuratoren der Moskauer Universität $\mathbf{M}$. $\mathbf{M}$. Cheraskov verwandt (CHAZIN, M.: «Tvoej molvoj napolnen sej predel...», Kißinev 1979, 117). Die Bekanntschaft Inzovs, der sich aktiv in den geduldeten Männerbünden engagierte, blieb nicht ohpe Ein- 
vorstehenden SchlieBung der bessarabischen Logen in Kenntnis gesetzt. Inzov wurden in diesem Zusammenhang von Volkonskij wegen des Umgangs des 22jährigen Puškin Vorhaltungen gemacht: „Warum wurde nicht verhindert, da $B$ er sich mit Freimaurerlogen abgebe", wurde der Freimaurer Inzov in dieser Eingabe gefragt. ${ }^{2.3}$ In seinem Antwortschreiben bestritt er zunächst - mögliche Befüchtungen der Regienung vorwegnehmend - die denkbaren Absichten Puškins, selbst Logengründungen vornehmen zu wollen, nicht aber, daß Puškin ihm gegenüber seinerzeit das Interesse bekundet habe, mehr über die Freimaurerlogen zu erfahren. ${ }^{2 \mu}$

Bis zum offiziellen Verbot verstrichen noch acht weitere Monate, doch nach dem Rechenschaftsbericht Inzovs an Volkonskij ist kaum davon auszugehen, daß in dieser Zeit der Logenbetrieb aufrecht erhalten wurde. ${ }^{215}$ Wahrscheinlicher ist, daB Inzov seit Mitte November 1821 versuchte, Puškin (trotz aller Sympathie für die Bewegung) von diesen Kreisen fernzuhalten und Puškin sich sporadisch nicht länget als ein halbes Jahr mit dem Freimaurertum auseinandersetzte. Es ist nur schwer vorstellbar, daß diese Ereignisse an dem späteren Verbot vom 1. August 1822 keinen entscheidenden Anteil hatten. ${ }^{216}$ Die späteren regierungsamulichen Begründungen für die „Abschaffung der Freimaurerlogen in RuBland im Jahr 1822" (1877) geben in dieser Frage auch keine weiteren Anhaltspunkte. $^{2 n}$ Kaum zufällig erfolgte der Erlaß Aleksandrs I. auf den Tag genau (1.8.1822)

fluB auf Puskins Persönlichkeitsentwicklung. Wichtiger aber ist, daB Inzov als Eingeweihter - er war Mitglied der Loge. Zur goldenen Kugel" in Hamburg - und Kenner einiger der beríhmtesten Freimaurer und Rosenkreuzer aus der Ekaterinischen Zeit (Cheraskov, Trubeckoj) auch Kenntnisse über Sinn und Zweck des Freimaurertums wie uber die Arkanpraxis und Systeme verfügte. (BAKOUNINE (1967), 219).

${ }^{213}$ Knjaz' Vol'konskij - generalu Inzovu (19.11.1821), in: Imperatory Aleksandr I. i Nikolaj I. i ich epochi 1812-1855, in: RS 40 (1883), 654.

24

«Относнтельно же занятія его по масонской ложь, то не по открытію таковоһ, не можетъ быть онымъ, хотя бы и желаніс его къ тому было". (General Inzov - knjazju Volkonskomu (1.12.1821), ebd., 657.

213

Inzov informierte sofort den als Stuhlmeister der Loge «Ovidij» vorgesehenen General P. S. Puscin. der ihm zur Rechtfertigung ein Papier vorlegte, das er von der Grobloge *Astraea erhalten hatte. wonach es ihm angeblich, „mit Wissen des Innenministeriums“ erlaubt war, eine symbolische Loge anf der Grundlage der dem Staat bekannten Vereinbarungen zu gründen. Die Befürchtung Volkonskijs, da's neben der Loge in Kiß̌nev General S. A. Tuckov in der strategisch ebenfalls wichtigen Stadt Izmail eine Loge gegründet hatte, konnte Inzov verwerfen. Denn Tuckov war auch der Loge *Ovidij» beigetretem (BAKOUNINE (1967), 568/69). Dennoch wird die spätere Anweisung des Zaren an die Offiziere (16.12.), neben dem Beamteneid keine weiteren Schwüre auf sich zu nehmen, seine Wirkung vor allerm in der 'Soldatenloge' «Ovidij» nicht verfehlt haben. (SEMEVSKIJ (1909), 317/18)

246

Bei det Frage nach den Gründen für die LogenschlieBungen sind die Ausführungen von Friedrichss irrefuhrend, der - auf Pypins Arbeiten bezugnehmend - den Fehler begeht, den Schriftsteller Puskkin mint dem Groblogenmeister Musin-Puskin(-Brjus') zu verwechseln, der keinesfalls der Kišinever Loge angehörte. In seiner später verfaßten , Russischen Literaturgeschichte“ (1921) bringt er Puškin mit dem Bund nicht in Verbindung, würdigt aber die literaturhistorische Bedeutung der Bewegung in 18. Jahrtundert

24

KUŠELEV, E. A.: Unǐ̌toženie masonskich lož v Rossii v 1822g., in: RS 18 (18779.9455-79. 
30 Jahre nach der durch Ekaterina II. verfügten Inhaftierung Novikovs (1.8.1792). ${ }^{24}$ Dem bei Kušelev abgedruckten Begründungsschreiben des Innenministers Kočubej an die beiden Großlogenmeister ist zu entnehmen, daß die Regienung nicht mehr in der Lage war, zwischen einer orthodoxalen Freimaurerei und den sich bisweilen dahinter verbergenden, weil politische Ziele verfolgenden Geheimgesellschaften sicher zu unterscheiden. Neben dem Verbot des Freimaurertums wurde außerdem verfügt, daB alle ehemaligen . Mitglieder einer Loge oder Gesellschaft («cleny obక̌čestva») eine schriftliche Erklärung zu unterzeichnen haben, wonach sie an Eides statt versichern, unter keinen Umständen wieder einer Gesellschaft im In- oder Ausland beizutreten. ${ }^{219}$ Nach Niederschlagung des Dekabristenaufstandes (1825/26) wurde diese Verfügung bekräftigt, ${ }^{200}$ zumal viele Urheber und Förderer, wie sich später herausstellen sollte, ehemalige Mitglieder der Hochgrad-Freimaurerei - insbesondere Rosenkreuzer und Martinisten - waren. ${ }^{25}$

Von daher ist es nicht verwunderlich, daß ein Teil der späten zaristischen Forschung den Dekabristenaufstand als den Höhepunkt einer Entwicklung beurteilte, die von einer Freimaurerei als einer geschlossenen, mitunter aus dem katholischen Ausland inspirierten, ausschließlich politische Ambitionen verfolgenden Bewegung («tajnye obščestva», «masonskoe dejstvo») ausging. ${ }^{252}$ Außerdem gibt es Abhandlungen, die den freimaurerischen Wendegang der Dekabristen unabhängig von den späteren politischen Ereignissen

641-64. Als Exempel einer nichtpolitischen Geheimgesellschaft wird in einem Abschnitt auch der Dichtertureis «Arzamas* (1815-1818) im Zusammenhang mit der Freimaurerei abgehandelt. Angeblich hatten aufkommende politische Ambitionen einzelner Mitglieder dazu geführ, dab der Kreis ein "naturliches Ende" gefunden habe; so wie alle Gesellschaften, denen von seiten des Staates keine Richtung zugewiesen werde, zerfallen müssen (655/56).

248

PYPIN (1916), 522; KUSELEV (1877), 650.

249

KUŠELEV (1877), 650/51.

250

PYPIN (1916), 532.

281

Zu den Dekabristen, die bis Anfang der 1820 er Jahre aktiv, mitunter auch in mehreren Freimaurerlogen, tätig waren, gehörten: P. I. Pestel', M. F. Orlov, F. N. Glinka, N. I. Turgenev, M. A. DmitrievMamonov, A. N. Murav'ev (LOTMAN (1966), 168/69). Weitere weniger aktive ehemalige Freimaurer unter den Dekabristen kennt FRIEDRICHS (1904), 160: M. I. Murav'ev-Apostol, S. I. Murav'evApostol, N. M. Murav'ev, Fürst S. G. Volkonskij. A. A. Bestužev(-Marlinskij), N. A. Bestužev und au guter Letzt G. S. Batenkov, dessen Memoiren (1863) auch die .,alte Freimaurerei” behandeln und deshalb von Pypin und Friedrichs zitiert werden. (PYPIN (1916), 458-72; FRIEDRICHS (1904), 160)

${ }^{252}$ Zwar hatten die Kriegsereignisse an dem enormen Zulauf der Männerbinde in der dritten Phase der Geschichte der Freimaurerei in RuBland einen entscheidenden Anteil - vor alkem nach der Besetzung von Paris traten viele Offiziene zunächst im französischen und deutschen Ausland Freimaurerlogen bei -, doch darf nicht vergessen werden, daB die geduldeten, weil nichtpolitischen Geheimgesellschaften in RuBland zu dieser Zeit zum zweiten Mal in Ungnade gefallen und somit keinesfalls erst eine Erscheinung des 19. Jahrhunderts waren. (LEBEDEV, A. A.: K zakrytiju masonskich loz v Rossii, in: RS 149 (1912), 523-38, hier 524/26; TOL' (rozd. gr. Tolstaja), S. D.: Masonskoe dejstvo. Istoriceskjj oberk o zagovore dekabristov, S.-Peterburg 1914; IVANOV, V. F.: O Petra pervago do nasich dnej. Russkaja intelligencija i masonstvo, Charbin 1934; IVANOV, V. F.: Pravoslannyj mir i masonstvo, Charbin 1935) 
wiirdigen. $^{253}$

Unbestritten ist jedoch, daB die geduldete freimaurerische Organisation sich den Dekabristen laut eigener Aussagen für ihre politische Ziele als ein willkommenener Deckmantel («pokrov») $)^{2 s}$ geradezu anbot und sie bewuBt davon Gebrauch machten. Dennoch werden einige Dekabristen in der aufklärerisch-freimaurerischen Ideologie einen nicht $\mathrm{zu}$ unterschätzenden moralischen Rückhalt gefunden haben. ${ }^{25 s}$ Diese These bildet jedenfalls die Grundlage der Analyse der Schriften Puškins mit autobiographischem Charakter. (vor allem Widmungslyrik, Aufsätze, Tagebuicher).

253

Das betrifft vor allem die Arbeiten Pypins, Vemadskijs, Bakuninas und des russischen Exilfreimaurers B. Telepnev.

254

So Murav'ev (zitiert nach NEČKINA, M. V.: Dviženie dekabristov, tom II, Moskva 1955, 152). A. N. Murav'ev soll sogar mit Erfolg die Mitglieder des am 9.2.1816 konstituierten „Bundes der Rettung " («Sojuz spasenija») aufgefordert haben, , in die Freimaurerei einzutreten“. Somit gewannen die $\mathrm{Zu}-$ sammenkünfte einen freimarerischen Charakter. Nicht nur, daB die Zusammenkünfte an die der Freimaure erinnerten; auch die Grad- und Initiationssysteme seien nachweislich umfunktioniert worden. (ROGALLA VON BIEBERSTEIN (1980), 648) Für Vemadskij dienten die Logen als vorbereitende Schulen für die zukünftigen Mitglieder der revolutionären Bünde (VERNADSKU, G. V.: Pushkin and the Decembrists, in: CROSS, S. H./SIMMONS. E. J.: Centennial essays for Pushkin, Cambridge 1937, 47).

2ss

ROGALLA VON BIEBERSTEIN, J.: Die Bedeutung det Freimauretei für nationalemanzipatorische Gesellschaften in Polen und RuBland 1815-1825, in: Zeitschrift für Ostforschung 29 (1980), Nr. 4. 649. 


\section{KAPITEL IV}

\section{FREIMAURERISCHES IDEENGUT - EIN IDENTIFIKATIONSPROBLEM}

\section{Aspekte der Freimaurerdichtung}

Dem im zweiten Kapitel vorgestellten schematischen Konzept einer verkörperten und nichtverkörperten freimaurerischen Symbolik sowie der Personen- und Institutionengeschichte des Bundes schließt sich vor der eigentlichen Textanalyse die Frage nach den Merkmalen der Freimaurerliteratur an. Unterschieden wird zwischen einer in diesem Kapitel behandelten Freimaurerdichtung im primären Sinn des Wortes und einer Literatur, die durch ihre Geheimbund-Allusionen eine Verbindung zum Freimaurertum aufweist. (Kap. 14)

Die als "freimaurerisch gekennzeichneten Themen und Motive" gehen zum großen Teil auf alte Traditionen (AT, NT, Mystik, Kabbala) zurück und zählen „zum Gemeingut der europäischen Literatur des Mittelalters und der Neuzeit“. ${ }^{256}$ Nach LAUER (1979) ist daher eine Isolienung der „Freimaurerdichtung" für den Gesamtbereich der Literatur in den europäischen Kulturzonen und somit auch in Rußland kaum möglich. ${ }^{25}$ Äußere Kennzeichnungen der Freimaurerdichtung als „Weltbürgertum, Toleranz und aktive Menschenliebe, häufig mit mysteriösem Einschlag", nehmen sich zu allgemein aus, als daB sie allein für die Literatur der Freimaurerei stehen könnten. ${ }^{2 s t}$ Noch schwieriger ist es, wenn eine kultisch-logeninterne Funktion des Werkes als gesichert ausgeschlossen werden kann, historisch aber gesichert ist, daß der Dichter aktives Mitglied des Bundes war und der Text eine entsprechende Thematik enthält.

Unbezweifelbare Gebrauchstexte der Logen können somit allein zur Freimaurerliteratur gezählt werden. Das gilt vor allem für Lieder, Hymnen, Kettenlieder und -sprïche, Geleit- und Wandersprüche, Tafellieder, Trauergesänge, Leitsprüche (Prologe), ${ }^{299}$ die nach LAUER (1979) aufs engste mit der Geselligkeit und den Ritualen der Logen verbunden sind. $\mathrm{Zu}$ den genuin poetischen Gattungen des Prosabereichs einer Freimaurerdichtung gehört die Rede, das erbauliche Traktat und die allegorische Erzählung. ${ }^{200}$ Die Identifizierung von Liedern und Spruchtexten nach ihrer kultischen Funktion sind für Lauer nicht so problematisch ${ }^{201}$ wie ihre Einstufung nach ideologischen Gesichtspunkten.

26

LAUER, R.: Russische Freimaurerdichtung im 18. Jahrhundert, in: BÁLAZS, E. HJ(...): Beförderer der Aufflärung in Osteuropa (1979), 271-91.

287

LAUER (1979), 272.

26)

WILPERT (1979), 284; LAUER (1979), 272.

259

LENNHOFF/POSNER (1932), 365.

200

LAUER (1979), 272.

201 Mit der Verbreitung der freimaurerischen Liedsammlungen in Westeuropa erschienen bereits auch in RuBland freimaurerische Sammelbände. Siebzig nussische Freimaurentioder, datiert auf die 2. Häfte des 18. Jahmunderts, sind aus sieben Sammelbänden zusammengetragen bei: POZPDNEF 
Das gelte für andere europäische Kulturzonen wie auch für Rußland, da auch dort das ganze theologische Spektrum der Freimaurer (vom rationalistischen Deismus über die christliche Lehrart des Schwedischen Systems bis zur Theosophie der Rosenkreuzer) rezipiert worden sei. ${ }^{202}$

Mit LAUER (1979) wären die von POZDEEV (1962) nach thematischen Gesichtspunkten vorgestellten russischen Freimaurer-Liedtexte des 18 . Jahrhunderts den freimaurerischen Tugenden und Bildvorstellungen der verkörperten wie nichtverkörperten freimaurerischen Symbolik zuzuordnen. Es ist BAEHRS (1976) Ansicht, daB die Vorstellung von der Wiederherstellung des Goldenen Zeitalters in der Loge zu den Grundpositionen einer „Freimaurerideologie" gehört ${ }^{203}$ habe und nur ein Indiz für Freimaurerdichtung sein kann. Die Schwierigkeit bestehe nämlich darin, daB das lückenlos freimaurerisch interpretierte Textvokabular sich ebensogut auch auf andere Lebenssituationen beziehen lasse. Eine thematische Eingrenzung vor allem der russischen „Freimaurerdichtung" (Lyrik) sei nicht möglich. ${ }^{20 s}$

Auch eine für die deutsche Freimaurerlyrik des 18. Jahrhunderts unternommene Untersuchung kommt zu dem Ergebnis, daß der Wortschatz der Freimauret in keiner Weise originär sei. ${ }^{26}$ Zwar sei im Bereich des ,Mauems am Tempel der Menschheit“ - faBbar in den Termini des „rohen" und „rauhen“ Steines des Lehrlings, der zum „behauenen“ oder

Rannye masonskie pesni, in: Scando-Slavica 8 (1962), 32 ff.

$\mathbf{2 0 2}$

LAUER (1979), 273-75. Als die wichtigsten literarischen Konzentrationspunkte der Freimaurerdichtung in RuBland (des 18. Jahrhunderts) sieht Laver in dem Cheraskov-Kreis, die Journale Novikovs im Zeitraum 1777-1785, das Freimaurermagazin «Magazin svobodno-kamensxixeskij» (1784) und die von Pozdneev beschriebenen handschriftlichen Liedsammlungen.

263

BAEHR, S. L.: The Masonic Component in Eighteenth-Century Russian Literature. A Collection of Essays, in: CROSS, A. G.: Russian Literature in the Age of Catherine the Great, Oxford 1976, 121 39, hier 123. BAEHR, S. L.: Freemasonry in Russian Literature: Eighteenth Century, in: The Modern Encyclopedia of Russian and Soviet Literatures 8 (1987), 28-36. Bachr favorisiert fur die Literatur des 18. Jahrhunderts die freimaurerischen Komponenten: Die Wiederholung der Inschrift des Orakels von

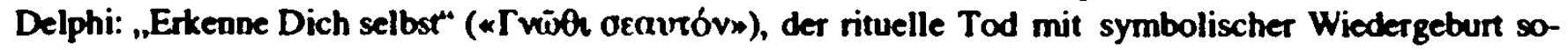
wie die symbolische Reise gen Osten. Als Reaktion auf den starken freimaurerischen EinfluB glaube Bachr eine antimaurerische und sogar eine anti-antimaurerische Bewegung im russischen 18. Jahrhundert ausmachen zu können. (29-35)

23

LAUER (1979), 276/9. Diese seien vor allem die Ehrlichkeit, Gerechtigkeit, Armenhilfe, Schutz der Ungliucklichen, Bescheidenheit und Verachtung der Eitelkeit, Bruderlichkeit und Gleichheit (POZDNEEV (1962), 40). Ebenso seien die ,spezifischen Bilder und Symbole“, die aus dem methodischen Teil bekannt sind, verzeichnet: Dreifaches Licht, dreimaliges Klopfen und SchieBen, die sieben Stufen, Dreiock und Richtblei, die Kette der geflochtenen Hände oder Herzen, Salomos Tempel, der Thron der Wahrbeit, das Auseinanderziehen des Vorhanges (als Entdeckung des Geheimnisses), Sonnenstrahl und Licht aus dem Osten, Erhellen und Verdunkeln, das Uberschreiten der Schwelle u.s.w. (siehe Kap. II, 3/4)

sos

LAUER (1979), $276 / 79$.

206

ANTONl, O.: Der Wortschaz der deutschen Freimauret-Lyrik des 18. Jahrhunderts in seiner geistesgeschichtlichen Bedeutung, München (Diss.) 1968, 459. 
„kubischen“ des Gesellen geformt werden soll - eine Eigenleistung der Freimaurer zu erkennen; dennoch sei gerade dieses Wortfeld in der allgemeinen Sprachgeschichte ohne Nachwirkung geblieben. Auch könne die Metaphorik des „Stirb-und-Werde-Gedankens" und der "Wortschatz des aufklärerischen Erziehungs- und Bildungsideals" eine Freimaurerlyrik im Rahmen des 18 . Jahrhunderts nicht zureichend charakterisieren. ${ }^{207}$ Dennoch gelten für LAUER (1979) bestimmte Antithesen, die sich aus dem dualistischen Denken . der Freimauret ableiten lassen, als ein „unmittelbar motiviertes Verfahren“ der untersuchten Freimaurerlyrik. Folgende stereotype Gegensatzpaare finden sich darin in signifikanter Häufigkeit: Licht-Finstemis, Freiheit-Gefangenschaft, Hollle-Paradies, Gift-Süße, Leben-Tod, Zar-Sklave, Bruder-Feind, Verstand-Seele, arm-reich, Geist-Körper, GeistFleisch, Vernunft-Natur, Stadt-Land, Freundschaft-Liebe, Glaube-Wissenschaft, gute Tat-Verbrechen u.a.

207 Ebenda, 459. Das gilt auch für die .Logengedichte" Goethes, die zu den wenigen Werken einer nicht nur unter Freimaurem bekannten Lyrik gehören. In den meisten Gedichtsammlungen und Ubersetzungen wurden sie unter dem Titel "Loge“ zusammengefabt. Vollständig verzeichnet sind seine Logengedichte bei: LENNHOFF/POSNER (1932), 365, 618/619. 


\section{Literatur mit Geheimbund-Allusionen}

Angesichts der Schwierigkeiten, die sich aus der stilistisch nur unzureichend typisierbaren Freimaurerliteratur ergeben, lassen sich freimaurerische Einflüsse in der nicht für den Logengebrauch bestimmten künstlerischen Literatur nur unter größten Vorbehalten aufzeigen. Leicht zu identifizieren sind zwar so herausgestellte Aufnahmerituale (wie bei Tolstoj), schwerer dagegen auf Männerbünde bezogene Andeutungen und Anspielungen zwischen ehemaligen Freimaurem in Widmungslyrik («poslanie») und Brief- oder Tagebuchliteratur zu einer Zeit, da Logenaktivităten wie auch ihre bloße Thematisierung in der Literatur tabuisiert wurden. Bei Puškin gilt das in erster Linie für die Mitglieder der Loge "Ovidij», aber auch für die Aktivisten, die sich in der russischen Freimaurer-Historie hervorgetan haben und/oder in den amtlichen Veröffentlichungen ${ }^{209}$ mit der Freimaurerei in Zusammenhang gebracht werden.

Allein die Gegensatzpaare, die als "freimaurerisch" charakterisiert werden können, vermögen das Identifikationsproblem von Geheimbund-Allusionen nicht zu lösen.

Daher wird hier auf die Erkenntnis der Kapiteln I und II des ersten Teils zurïckgegriffen, in denen sowohl Grundmuster einer freimaurerischen Symbolik und des logeninternrituellen Geschehens thematisiert werden als auch die Geschichte der Freimaurer in ihren personellen und institutionellen Aspekten zur Darstellung kam. Die Textanalyse wird darauf aufbauend methodisch und historisch ausgerichtet sein.

Kennzeichnend für den methodischen Ansatz der Analyse freimaurerischer Traditionen in literarischen Texten Puškins ist die Unterscheidung von verkörperter und nichtverkörperter Symbolik. Weder das verkörperte noch das nichtverkörperte Symbol können losgelöst voneinander verstanden werden. Ein „freimaurerisches Symbol“ kann im Text als Geheimbund-Allusion ${ }^{270}$ nur dann als solche begriffen werden, wenn sich zur verkörperten ein Stück nichtverkörperter Symbolik hinzugesellt. Die Erwähnung einer Rose bei Puškin etwa, kann erst dann freimaurerisch gedeutet wenden, wenn sie in einem Zusammenhang mit nichtverkörperten symbolischen Formen gestellt werden kann. Darüber hinaus verweist auch eine signifikante Häufung nichtverkörperter Symbolik auf einen freimaurerischen Hintergrund. Historisch wird die genrespezifische Untersuchung den drei Etappen der russischen Freimaurergeschichte angepaßt.

1. Poetisches Schaffen vor Puskkins angeblicher Aufnahme (4.5.1821);

2. Zeit nach dem ersten Verbot der Freimaurerei (1.8.1822) bis zum Dekabristenaufstand (25.12.1825);

3. Werke der Periode nach dem emeuerten Verbot der Freimaurerei (21.4.1826).

20

270

Siehe RA, RS, ZMNP.

Der in dieser Untersuchung eingefuihrte Begriff „Geheimbund-Allusion“ ist in der Lage, alle freimaurerischen Kategorien literarisch zu erfassen, dafü aber macht er es erforderlich, von der Verwendung der Bezeichnung "freimaurerische Motive" (wie bei ALTSHULLER (1982), 1) abzusehen, da er die Trennung von literarischen Texten und Realia, die ihnen zugrunde liegen, nicht zu leistens vermarg.3954790715 


\section{KAPITEL V ALLUSIONEN ZUR GESCHICHTE UND ZEICHENWELT NICHT- POLITISCHER GEHEIMBUUNDE IM WERK A. S. PUŠKINS}

\section{Geheimbund-Allusionen in Puskins Lyrik}

\section{Lyrisches Schaffen vor 1821 (4. Mai)}

Die Gedichte der "Lyzeumsperiode“ (1813-17) lassen sich mit den vorgestellten Aspekten des Freimaurertums kaum in Einklang bringen. Das gilt zum einen für die frühe Widmungslyrik, deren männliche Adressaten (mit Ausnahme von Del'vig und dem Onkel Pußkins) allesamt zu keiner Zeit dem Bund angehörten: ${ }^{2 m}$ «Knjazju A. G. Gorčakovu» (1814), «K Batjułkovu» (1814), «K N. G. Lomonosovu» (1814), «Batjuskovu» (1815), «K Pusčinu» (1815), «K Galiču» (1815), «Vospominanie (K Pušcinu)» (1815), «Poslanie k Galixu* (1815), «K Del'vigu» (1815), «Aleksandru» (1815), «Poslanie k Judinu» (1815), «K Zukovskomu» (1816), «Sił̌kovu» (1816), «Djade,

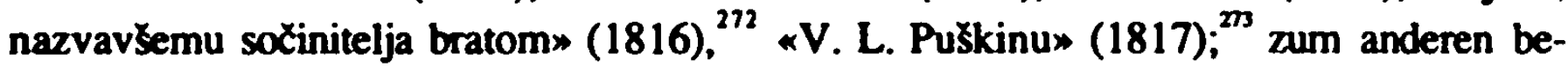
trifft das aber auch die Bezüge auf herausragende Freimaurerpersönlichkeiten (z.B. Wolfgang Amadeus Mozart, Aleksandr Vasil'evic Suvorov) in den Gedichten «K sestre" (1814) und "Vospominanija v carskom sele» (1815). Ferner kann auch die Rose in dem französisch verfaßten Frühwerk "Stances“ (1814) als „'image d'amour", in *Leda» («Kantata») (1814) als «deva krasoty», sowie in «Roza» (1815) ${ }^{214}$ als Symbol für die Liebe ebenfalls nicht mit rosenkreuzerisch-freimaurerischen Bedeutungstraditionen in Verbindung gebracht werden. ${ }^{2 m}$ In der Petersburger Periode (1817-20) häufen sich die Inhalte, die sich mit den Männerbünden in RuBland in Verbindung bringen lassen. A. I. Turgenev wird von Puskin in seinem Widmungsgedicht *Turgenevu» (1817) als wahrer Beschuitzer der Popen, Juden und Skopzen - aber auch als Jäger der Jesuiten und

21

Soweit das aus den Angaben von BAKOUNINE (1967) und PYPIN (1916) hervorgeht.

$\boldsymbol{m}$

In diesem finfzeiligen Briefauszug an seinen Onkel Vasilij L'vovix (22.12.1816) verwiff der 17jöhrige Puxkin das Bruderverhältnis, das der Dichter und Freimaurer Vasilij L'vovix (seit 1810 «Les Amis réuisw) seinem Dichterneffen angeboten hatte. Neben der dominanten Bedeutung des dichterischen Bruderverhälthisses könnte von seiten des Onkels auch die freimaurerische Gesimung seines Neffen gemeint sein, die in diesem Fall A. S. Puskin bewußt oder unbewußt verworfen hätte. Dennoch darf die Bezeichoung abrato fir dichtverwandischaftliche Beziehungen wie auch die des öfteren in der. Iyzeumslyrik" vorkommende Anrede der Freunde «tovariš ohne weitere Anhaltspunkte nicht als Quasi-Code fir die Bundzugehörigkeit verstanden werden.

m3

PSS I, 56-257.

274

PSS 1, 95/477 («Stances»); $92 / 477$ ( Kledax ( KKantatax)); 152/483 («Rozax).

zns

Die Rose steht in Pußkins , Lyzeurnslyrik“ woder für die Wiedergeburt oder das höhere Leben noch deutet sie auf die Nawur uod die Schöpfung in toto hin, wie es von den Rosenkrewzern bekannt ist (LAUER (1988), 612), siehe auch Anmerkungen 101 und 168. 
Durnmköpfe bezeichnet:

2 «Тургенев, верный похровитель

3 Попов, евреев и скотцов,

4 Но слишхом счастливый гонитель

ऽ И езунтов, и глупцов, ...

6 Забыв любви свосй печаль,

7 С улыбкоя дремлешь в Арзамасе ....
[.. Turgenev, ehricher Beschützer

der Popen, Juden und Skopzen, aber allzu glïcklicher Jäger auch der Jesuiteo und Durmmköpfe, ... Nachdem Du Deinen Liebeskummer vergessen, träumst Du lïchelnd vom Arzamas ..."]

Bekannt ist, daB Pułkin sich oft im Hause der Briider Turgenev aufgehalten hat und der hier gemeinte Aleksandr Ivanovið seit 1810 Direktor des Departements für geistliche Angelegenheiten war. ${ }^{2 m}$ Auf diese Tätigkeit spielt Puškin an. Es wäre daher sicher zu weit hergeholt, A. I. Turgenev in diesem Gedicht als ein von Puškin allusiv-figurierten Freimaurer anzusehen; trotzdem läßt sich aus dem von Puškin fingierten besonderen Verhältnis Turgenevs zu den genannten Konfessionen und Geheimgesellschaften ${ }^{2 n}$ immerhin eine ideologische Nähe zum Freimaurertum ableiten. ${ }^{2 m}$ In der Literatur wird die Mitgliedschaft Turgenevs im Bund bisweilen angezweifelt; dennoch ist bekannt, daB er in St. Petersburg dem Kreis um Fessler angehörte. ${ }^{200}$ Außerdem war Turgenev zusammen mit Puškin zur selben Zeit Mitglied in dem Dichterkreis «Arzamas» (1815-18/20), der bekanntlich freimaurerisches Brauchtum adaptierte.

276

PSS 1, 316 (Z. 2-4); 317 (Z. 4/5). In diesem Zusammenhang sei darauf hingewiesen, daß Puskins langjähriger Freund Vjazemskij den *Arzamas» als eine Ant ,literarischer Freimaurerei" bezeichnet hat. (VJAZEMSKU, P. A.: Polnoe sobranie soxinenij, toma I-XII, S.-Peterburg 1883, tom VIII, 416-26)

m

PSS I, 501; BAKOUNINE (1967), 570 (Turgenev, A. I.)

$2 m$

FRICK (1975) sieht in Chlysten und Skopzen Anhänger von gnostisch-theosophischen Geheimgesellschaften, deren Lehre und Ritual im Gegensatz zu den Freimaurem niche von Westen, sondern aus Vorderasien und dem suidosteuropäischen Raum her in RuBland eindrangen. (FRICK, K. R. H.: Licht und Finsternis: gnostisch-theosophische und freimaurerisch-okkulte Geheimgesellschaften bis an die Wende zum 20. Jahrhundert, Graz/Austria 1975, 450-60)

279

Das Konstitutionenbuch schreibe vor, daB jede Glaubensrichtung in den Logen Platz finden können soll. Daher wird Gott auch als der 'Allmächtige Baumeister aller Welten' (ABaW) verstanden. (LENNHOFF/POSNER (1932), 134/35) Da der Papst sich in seinen Bullen schon frihzeitig offensiv gegen die Freimaurerei gewandt hatte, standen die Jesuiten bei den Freimaurem in Westeuropa wie besonders in RuBland in dem Ruf, militante Gegner der Bewegung zu sein. (LENNHOFF/POSNER (1932), 775-79)

200

BAKOUNINE (1967), 570; LENNHOFF/POSNER (1932), 469-72.

21

Nach Leighton seien im «Arzamas» freimaurerische Riten parodien worden, Vorträge seien von freimaurerischer Rhetorik und Spitznamen voll gewesen, die den Logennamen bekannter Freimaurer blobstellten. (LEIGHTON, L. G.: Freemasonry in Russian Literature: Nineteenth Century, in: The Modern Encyclopedia of Russian and Soviet Literatures 8 (1987), 40) Wie bei den Freimaurerlogen hatten die Sitzungen im «Arzamas» rituellen Charakter, und es herrschte der "Kult der Freundschaft". Das bevorzugte Geore im «Arzamas» war das freundschafuliche Sendschreiben (udružeskoe poslaniex), wobei anzunnerken ist, daB die Mitglieder keine einheitliche künstlerische Richtung in der Literatur vertraten.

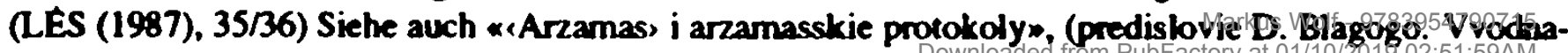


Vor Pułkins angeblicher Aufnahme in die Loge «Ovidij» ist zunächst nur ein weiteres Widmungsgedicht von Interesse: "Čaadaevu» (1821). ${ }^{22}$ Da P. Ja. Caadaev in der Petersburger Loge „Les Amis reunis “200 ${ }^{\text {“20 }}$ von 1816-19 Mitglied war und sogar den Meistergrad innehatte, ${ }^{2 n}$ sind Bezäge auf seine Mitgliedschaft in diesem Widmungsgedicht nur zu wahrscheinlich. Doch weder die aufklärerischen Gedanken («Вольнолюбивые надеждды охкиим»), weder die tiefen Freundschafts- und Liebesbekundungen ("Когда гордиться мог я дружббю твоею?»/«Когда соединим слова любви и руки?»/ «Твой жар воспламенял к высокому любовь») nоch Pułkins Bekenntnisse zum stoischen Ideal («И жизнь перенесу стоической душою») können im Rahmen einer freimaurerischen Allegorik gelesen werden. Abgesehen von bei Puškin nicht thematisierten historischen Hintergründen zu einzelnen Freimaurerpersönlichkeiten und der Anspielung auf den «Arzamas» in den Versen auf Turgenev, nimmt Puskin in der Lyrik vor dem besagten 4.5.1821 keinerlei Bezug auf die Freimaurerei.

\section{Verbannungslyrik (1821-26)}

Erste Anhaltspunkte auf das Freimaurertum bietet dagegen die Dedikation auf den Gründer und Stuhlmeister der Loge «Ovidij» in Kiß̌nev, General P. S. Pušcin," "Generalu Puscinu" (1821).

1 «ГЕНЕРАЛУ ПУЩИНУ

2 В дыму, в хрови, сквозь тучи стрел(а)

3 Теперь твоя дорога;

4 Но ты предвндишь свой удел,

(a)

\section{I.,FUR GENERAL PUŠČIN}

Durch Rauch, durch Blut, durch ein Pfeilenmeer bahnt sich jetzt Dein Weg;

ja stat'ja M. S. Borovkovoj-Majkovoj), Leningrad 1933; GILLEL'SON, M. I.: Molodoj Puškin i arzamasskoe bratstvo, Leningrad 1974).

$2 \mathbf{2}$

PSS II, 51-53. AbgefaBt am 6.4. des Jahres.

203

Zur Loge *Les Amis reunisw siehe 55 (Anmerkung 204), 57 (Anmerkung 57) und 68 (Anm. 272).

$2 \mathrm{n}$

Der Artikel von *N. D.» (Petr Jakovlevix Caadaev (Materialy dlja ego biografii), in: RS 104 (1900), 582-88) referiert wie Caadaev nachträglich zu seinem Verhältnis zur Freimaurerei befragt wurde. da er in Ausland vergessen hatte, die Erklärung zu unterschreiben, die jedem Bearnten nach dem Verbot aller Logen abgefordert wurde.

2as

Puscin war zeitgleich mit Caadaev Mitglied der Loge «Les Amis reunis» und wie er in den dritten Grad des Meisters eingeweiht worden. (BAKOUNINE (1967), 429/30) Die Behauptung, daß Puščn Grobrneister und somit Vorsteher einer Grobloge war, entbehrt jedoch jeglicher Grundlage; vermutlich verwechselie CJAVLOVSKAJA (1975) das Groblogenmeisteramt mit dem des Logenstuhlmeisters. (CJA VLOVSKAJA, T. G.: Otkliki na sud'by dekabristov v tvorěestve Puskina, in: BAZANOV, V. G./' VACURO, V. E.: Literaturnoe nasledie dekabristov, Leningrad 1975, 205)

226

Da das exakte Entstehungsdatum dieser Verse auf General P. S. Puscin nicht angegeben ist, wersen sie mit Blick auf den Tagebucheintrag von Puskins angeblicher Aufnahme in den Bund um den 4.5.1821 datiert. (PSS II, 404) 


\begin{tabular}{|c|}
\hline 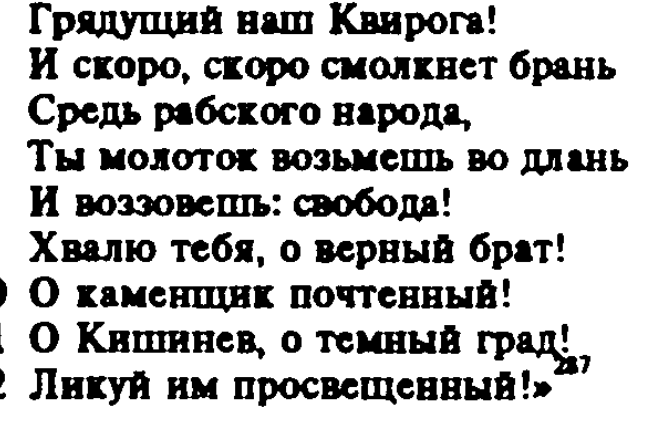 \\
\hline
\end{tabular}

5 Грядуший ват Kвирога!

6 И схоро, сторо смолхнет брань

6 Средь рабского варода,

7 ТЫ модоток возьмешь во ДЛ ань

8 И воззовешь: Свобода!

9 Хвалю тебя, о верный брат

11 O Kнтинев, о темнын трад!

12 Лнхуя им просвещеввыи! (b) (Du, unser kinftiger Quiroga!

(c) Und bald, bald wird der Streit verstummen

(d) mitten in geknechteten Volk.

(c) Du wirst dea Hammer in die Hand nehmen

(d) und herausrufen: Freihein!

(C) Ich preise Dich, ob whre Bruder!

(f) Ot Du Maurer, chrwirdiger!

(e) On Kisinev, oh ditstere Stadt!

(f) Feiere ihn-durch ihn aufgeklärt.]

Puscxin wird darin zunächst in seiner Eigenschaft als kriegführender Soldat beschrieben; doch findet sich diese Thematik ausschlieBlich in dem ersten Drittel des zwölfzeiligen Gedichts. " «V dymu, v krovi, skvoz' tuci strel» kann mit dem Freimaurertum nicht in Verbindung gebracht werden. Gleiches gilt für den Vergleich Pušxins mit den militärischen Erfolgen des spanischen Generals Antonio Quiroga ${ }^{300}$ ( $\ll$ Grjadušcij nas Kviro$g a ! »)$, weil von diesem keine freimaurerischen Aktivitäten bekannt sind. ${ }^{291}$ Mit der Konjunktion "r" setzt in Zeile 5 ein neues Sujet ein. ${ }^{22}$ Offensichtlich ist mit der Erscheinung

207

PSS II, 57.

me

In der deutschen Version von «Generalu Pusxinuw bei LOTMAN (1997) ist die Zeile 9 «Chvalju tebja, o vernyj bra!! seines freimaurerischen Inhalts beraubl. Aus ,ich preise Dich, oh wahrer Bruder" im Sinne einer freimaurerischen Lobanrede - wird "Wohl dem, der Dich zum Bruder har" eine nicht auf die freimaurerischen Zusammenhänge dieser Zeilen ausgericheete Lesart, denn das Wohl nur auf Freimaurerbrider zu reduzieren, ist nicht die Intention Puskins gewesen und schon gar nicht mit diesen Versen. (LOTMAN, Ju. M.: RuBlands Adel. Eine Kulturgeschichte voo Peter I. bis Nikolaus I., KölnWWeimar/Wien 1997, 411)

209

Der ,Zwölfzeiler' besteht aus drei zusammenhängenden Vierzeilern, die je einen Kreurreim (abeb, odod, efef) bilden.

200

Vor allem gegen Napoleon (1815). Siche tom 18, 878-79.

201

Weder ist A. Quiroga (1784-1841) je für die Freimaurer in RuBland von Interesse gewesen, noch verzeichnet ithn das Internationale Freimaurerlexikon: BAKOUNINE (1967), LENNHOFF/POSNER (1932). Der Vergleich Quirogas mit Pušxin hat vor allem die sowjetische Forschung veranlaße, auf die revolutionären Parallelen bei Puskin hinzuweisen. Dennoch dominieren vor allem seine militärischen Erfolge gegen Napoleon. (VERESAEV, V. V.: Sputniki Puskina, tom I-II, Moskva 1937, 265/66; CJAVLOVSKAJA (1975), 205)

202

Sollte der erste Teil (Verszeile 1-4) bei der Zusammenstellung nicht erst später dem Gedicht zugeordnet worden sein, ist die thematische Dominanz der beiden folgenden Vierzeiler daran zu ersehen, dab sie auch schon einmal alkein erschienen sind. In der Zeitschrift «Russkij archiv» ist «Generalu Puszinu» erst ab Verszeile 5 abgednuckt. In dem Vorwort weist GERBEL' darauf hin, daB die Zensur die bisherige Veröffentlichung so mancher Gedichte in det Annenkov-Gesamtausgabe verhindert habe. Uberschrieben ist das Gedicht mit «Ekspromtw. Damit gehören nach GERBEL' die Verse auf Puszin in das Fach „Improvisation" oder "Stegreifdichtung“. Zu Lebzeiten Puskins wurden diese Verse niche veröffentlicht; nach GERBELS Angaben scheinen sie 1874 in der Zeitschrift «Vestnik Evropy* zum ersten Mal publizien worden zu sein (GERBEL', N. V.: Dlja budušcego poinago sobranija soxinenij A. S. Puškina. Stichotvorenija A. S. Puskina, in: Russkij anchiv 10 (1876), 205-44, hier 215). Auch BAKUNINA

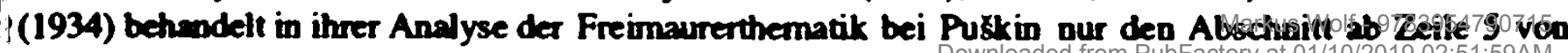


Pušcins das baldige Ende eines "Streits“ oder „Gezänks“ («skoro smolknet bran'») "mitten im geknechteten Volk“ («Sred' rabskogo naroda») verbunden. Wie oben bereits gezeigt, verbittet sich der Logenstuhlmeister in der vienten Stufe des freimaurerischen Rituals vor Eröffnung der Loge unter den Briidern in einer rituellen Sentenz Zank und Streit. ${ }^{203}$ Danach greift ex kraft Amtes zu seinem hölzernen Hammer, um die Eröffnung der Loge mit drei Hammerschlägen auf den Tisch zu signalisieren. ${ }^{204}$ Pušcin nimmt auch. bei Puskin den Hammer in die Hand («Ty molotok voz'mes' vo dlan'»), doch zum Klopfen kommt es nicht. Mit der Konjunktion $\alpha I »$ werden zwei aufeinander folgende Hand- lungen Pušxins miteinander verbunden. («Ty molotok voz'mes' vo dlan' I vozzoves': svoboda!») Der Wunsch nach Freiheit, dem Pušxin, anstatt die Loge of fiziell zu eröffnen, Ausdruck gibt, muB jedoch nicht notwendig politisch verstanden wenden. ${ }^{\text {sos }}$ Vielmehr gehört die Freiheit mit zu den Grundgedanken des orthodoxalen Freimaurertums, ${ }^{206}$ die noch vor der französischen Revolution (Freiheit, Gleichheit, Brüderlichkeit) ihren Anfang nahmen. ${ }^{207}$ Dazu kommt, daß die thematische Opposition des Gleichklangs («rabskogo naroda (...) svoboda») zu den stereotypen Gegensatzpaaren gehört, die LAUER (1979) in der russischen Freimaurerlyrik in signifikanter Häufigkeit angetroffen hat. ${ }^{20}$ Daher

aProrok». (BAKUNINA (1934), 88/89) So auch bei LERNER, N. O.: Trudi i dni Puskina, S.-Peterburg 1910, 72.

${ }^{203}$ Nach Eröffnung der .Arbeit" heißt es bei PYPIN (19116) im Hoch- und Hauptritus: «3attmъ мaстеръ снимаетъ шляпу и объявляетъ ложу отхрытоһ, сльдуюиими словами: жЭта лоха отхрыта во имя св. Іоаяна; я запрещаю всяхую брань, клятвы или шопоть, и всь профанные разговоры, кахого бы рода ни было, подъ неменьшимъ штрафомъ, чБмъ хахоһ положить большинство“. Мастеръ ударяетъ три раза о столъ деревяннымъ молотхомъ и надеваетъ шяяпу; остальные братья остаются безъ шлятъ. Онъ спрашиваеть потомъ, готовъ-ли къ

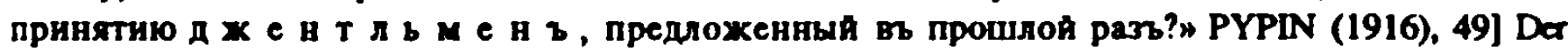
Logenstuhlmeister macht darauf aufmerksam, daB er die Loge nunmehr eröffnen möchte und freimaurerische Regeln zu beachten sind.

29

Neben dem Stuhlmeister sind auch noch die genannten Aufseher [«pervyj i vtoroj natziratel' $x$ ] berechtigt, innerhalb der Loge das freimaurerische Symbol des Hammers [*molotok»] zu führen; doch kommen diese hier nicht vor, da nur Puscin als Stuhlmeister stilisiert wird. Mit dem Hammer in der Hand wird Puscin sicher nicht ,gleich" gradspezifische Klopfzeichen vornehmen "wollen“, zu denen er auch berechtigt wäre, wohl aber ist anzunehmen, daB der General gleich mit drei Hammerschlägen die .Logenarbeir" cröffnen wird.

2os

PSS II, 404 (primexanija), CJA VLOVSKAJA (1975), 205.

206

Die Freimaurerei verlangt von ihren Angehörigen, dab sie freie Männer von gutem Rufe seien, vertritt also die sittliche Freimourerei. Voraussetzung für den Logenbetrieb ist die Unabhängigkeit ihrer Mitglieder. Daher könnte die Fordenung nach Freiheit auch als programmatische Leitlinie des Logenstuhimeisters fir den Logenbetrieb verstanden werden. (LENNHOFF/POSNER (1932), 525 ("Freiheir"))

207

Das ,Internationale Freimaurerlexikon" vermerkt hierzu: „Die Devise des französischen Volkes wurde zuerst in französischen Freimaurerlogen des 18. Jahhunderts ausgesprochen und hat auch heute in dem Ritual und Dokumenten der französischen Freimaurerei ihren Platz". (LENNHOFF/POSNER (1932), S26) 
könnte der Pušx̌in symbolisch zugeschriebene Ausruf "Freiheir" auch aus dessen freimaurerischer Gesinnung heraus motiviert sein und nicht nur politische Hintergrinde vermuten lassen, die hinter den logeninternen Gebräuchen "versteckt" wurden."

Im letzten Abschnitt sind weitere Oppositionen auffallig: «Vernyj brato/kkamensxik poctennyj» - «temnyj grad»/«Likuj im prosvešennyj». Pułkin gebraucht hier die Anredeformen, die die orthodoxalen Freimaurer untereinander verwenden und stellt damit die Person Pušcin der "düsteren", nichtaufgeklärten Stadt Kišinev gegenüber. In der letzten Verszeile drückt der Verfasser seinen Wunsch aus, durch den Logenstifter Pušx in möge dieses Dunkel der Nichtaufgeklärtheit und Ungebildetheit der Stadt Kißinev überwunden werden ( $\alpha$ Likuj im prosvešcennyj»). Seinen spielerischen Charakter erfährt das Gedicht aber nicht durch den pathetischen Ausruf («svoboda!»), sondem dadurch, daB der Autor zuerst den "wahren Bruder" anredet und dann auch die Stadt Kišnev aufruft ( $₫$ Kiłinevn). Damit wird das ungleiche Verhältnis des stilisierten Stuhlmeisters Pušcin zu der unaufgeklärten Stadt Kiß̌inev deutlich. Es drängt sich die Frage auf: Kann Pušcin wirklich alkein die Stadt Kiß̌nev aufklären? Zwar liegt Ironie in der Unmöglichkeit dieses Unterfangens; dennoch gewinnt damit die Person Puscins nicht nur als Gründer und Vorsitzender der Loge «Ovidij», sondem auch als Wegbereiter der Aufklänng in Kißinev für den Autor große Bedeutung, zumal in den anderen Gedichten die Stadt Kiß̌inev ebenfalls nicht im positiven Licht erscheint. ${ }^{300}$ Deutlich ist, daB Pułkin die freimaurerische Ideenlehre des Generals mit der Aufklärung/Bildung und mit der Vorstellung von einem

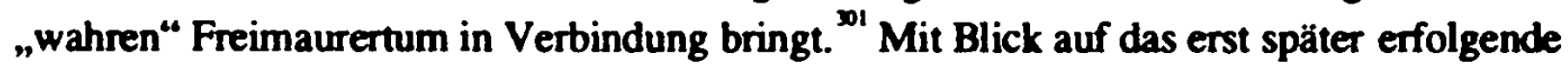
Verbot der Freimaurerei (1.8.1822) ist es daher auch verfehlt, die Analyse des Gedichts mit Angaben zu vermengen, die Pułkin in einem späteren Brief an Žukovskij (20.1.1826) zur I Loge «Ovidij» gemacht hat. Denn diese Verse zeigen eben nicht, daß Pußkin in der Freimaurerloge eine ,politische Organisation“ sieht, was auch immer für spätere Geheimbund-Allusionen gelten mag.

Finsternis, Hölle-Paradies, Gift-SuBe, Leben-Tod, Zar-Sklave, Bruder-Feind, Verstand-Seek, amn-reich, Geist-Körper, Geist-Fleisch, Vernunft-Natur, Stadt-Land, Freundschaft-Liebe, Glaube-Wissenschaft, gute Tat-Verbrechen) fir ein "unmittelbar motiviertes Vefahren" der untersuchten russischen Freimsuretyrik des 18. Jahrhunderts (LAUER (1979), 288/291)

290

CJAVLOVSKANA (1979), 205.

300

In der Gesamcausgabe finden sich die Verszeilen: «Пролляты город Кншиневм (C2.195.1), «Я Кншинев равнять не смего (C2.195.13) und жНо в Кншиневе знаешь самн ( C2.195.28), nach SHAW, J. T.: Pushkin. A concordance to the Poetry, Vols. 1-2, Columbus/Ohio 1985, hier vol. 1, 421. 301

Die Verbindung zwischen Puskin und Puscin muB wohl niche besonders eng gewesen sein, obwohl der junge Dichter sich des öfteren beim General aufgehalten hatte. DaB er aber, wie Veresaev be hauptet, Puxtin verspottete, geht weder aus dem Gedicht noch aus anderen Schriften bervor. (VERESAEV, V. V.: Sputniki Puskina, toma 1-2, Moskva 1937, 265-67 (Pavel Sergeevix Pusxin). 
Weitere Anspielungen auf das Freimaurertum und besonders die Loge in Kišinev sind darüber hinaus in den Gedichten zu vermuten, die Puškin dem römischen Dichter Publius Ovidius Naso (43 v. Chr. - $18 \mathrm{n}$. Chr.) gewidmet hat oder die dessen Namen erwähnen, weil die Loge unter Puscin nach Ovid benannt ist. Das vor allem deshalb, weil Pußkin sein Schicksal während seiner Verbannung und insbesondere zum Zeitpunkt der Gründung der Freimaurerloge mit dem des antiken Dichters hăufig in Verbindung bringt. In, der Widmung an Caadaev « «aadaevu» (1821) - es ist abgefaßt vor Pußkins angeblicher Aufnahme in die Loge (20.4.) - tut er dies nicht zum ersten Mal: «Gde prach Ovidiev pustinnyj moj sosed». ${ }^{303}$ Doch weder an diesen Stellen, weder in der Widmung «K Ovidiju» $(26.12 .1821)^{304}$ noch zu einem späteren Zeitpunkt ${ }^{\text {sos }}$ lassen sich Geheimbund-Allusionen als Anspielungen auf die Loge «Ovidij» ausfindig machen. Dagegen fallt die Namengebung ovvidij» für den Bund in Kišnev aus dem Muster des üblichen freimaurerischen Benennungsverfahrens heraus. Das gilt zum einen für die Angaben des "Internationalen Freimaurerlexikons ${ }^{\text {(306 }}$ wie für die Namen der anderen 24 Logen in der GroBloge *Astraeax, ${ }^{\text {on }}$ zu der bekanntlich die Loge «Ovidij» gehörte. LOTMAN (1997: 407-13) kommt in bezug auf die Bedeutung des Logennamens «Ovidij» zu dem gleichen Ergebnis. Der Logenname entfiel nicht aus freimaurerischen Erwägungen auf den Namen «Ovidij», sondern hängt mit der Dichtung Puškins wie mit seinem persönlichen Verbannungsschicksal zusammen. Möglicherweise haben die befreundeten Freimaurer-„Brüder"

203

Davor finden sich zwei weitere Stellen in der Gesamtausgabe: «Пускаи любовь Овидии поют» (C1.60.9) und «Овндия мрачны дни влачил» (C2.128.2), nach SHAW (1985), Vol. 2, 680.

304

«ОвнднА, я живу близ тихих береговн (С2.148.1); «Я сердцем следовал, Овидий за тобоюн (С2.148.12); «Я повторнл твон, Овиди и песнопеньян (C2.148. 60). Obige Angaben beziehen sich auf die Gesamtausgabe, nach SHAW (1985), Vol. 2, 680, hier: PSS II, 67-70.

sos

«B тебе Овндия жнвого" (C2.157.12) und «Клянусь Овндиевой теньюн (C2.218.7) nach SHAW (1985), Vol. 2, 680.

306

Zunächst haben sich in ihrer Entwicklung die Bennungen der Logennamen nach den Tavernen unterschieden, in denen sich die "Brider" zu versammeln pflegten (,Zur Gans und zum Bratrost", "Zum Römer und zur Traube", ,Zur Krone", „Zum Apfelbaum"). Später haben die Logen angefangen, sich Namen zu geben, die mit dem Inhalt der Freimaurerei zusammenhingen. Bisweilen aus der freimaurerischen Symbolik entlehnt, taucht des öfteren die Verbindung mit den Zahlen der Freimaurer auf (,Zu den drei Degen (Härmmern, Zirkeln, Schwertern)"). Später erst wurden Losungen, Eigennamen oder Namen von Herschen oder verdienten Freimaurem gewählt. (LENNHOFF/POSNER, 1089/90 (.Namen der $\left.\left.\log _{(0+0)}{ }^{4}\right)\right)$

307 1. «Петра хъ истинь», 2. «Палестинын, 3. «Изндан, 4. «Нептунъ къ Надехдын, 5. «Избраннаго Миханла», 6. «Алехсандра Коронованнаго къ Пелихануж, 7. жЈорданан, 8. „Соеднненных Друзеиж, 9. «Пламеньющей звђздей, 10. «Военная, Георгія Побьдоносцаж, 11. «Резстяннаго Мраха», 12. «Трехъ Съкиръ», 13. «Александра къ Тройтвенному Благу», 14. «Трехъ Коронованныхъ Мечей, 15. «Ключъ хъ Добродьтелеиж, 16. «Орла Россійсаго», 17. «Соеднненныхъ Славякъ,, 18. кЛюбовъ къ нстинь», 19. “Сьверныхъ Друзей, 20. «Белаго Орлан, 21. «Золотаго Кольцан, 22. «Алехсандрь къ Пчель», 23. «Восточнаго Свътилан, 24. «Ознриса къ Пламеньющей 3вtздьн. (KUSELEV (1877), 661-64; LEKGHTON (1982), 259-61) 
(Pušcin, Inzov, oder andere) dem jungen hoffnungsvollen Dichter Puskin zu Ehren den Namen des großen römischen Dichters gewählt oder ihn damit in seiner Verbannung trösten wollen.

In einem späteren Widmungsgedicht - es ist abermals an den Freund und Freimaurer, P. Ja. Caadaev gerichtet - « Caadaevuw (1824) kommt zwar die signifikante Anredeform («brats) vor, dennoch läBt sich diese, wie auch die Vertherrlichung der ,heiligen Freundschaft" durch eine lithographische Inschrift («kamen'») nicht d la maçonnerie deuten.

\section{Lyrik der Nachverbannungszeit (1826-36)}

In «Prorok» (1826) verarbeitete Puškin ein biblisches Motiv aus dem sechsten Kapitel Jesajas.

\section{1 «ПIPOPOK}

2 Духовной жахкдою томнм,

3 В пустыне мрачной я влачился

4 И тестнхрылын серафнм

5 На перепутье мне явнлся;

6 Перстамн легони хах сон

7 Монх зеннц госнулся он:

8 Отверзлись вещне зеннцы;

9 Ках у нспутанной орлицы.

10 Монх ушей хоснулся ов.

11 И их наполвнл шум и звон:

12 И внял я неба содроганье,

13 И горния антелов полет,

14 И гад морских подводный ход.
[Der Prophet

Getrieben voo des Geistes Gier, Dartit ich in Wisten, als sich neigte

Ein sechsflugliger Seraph mir. Wo sich der Weg zurn Kreuz verzweigte. Und seines Fingers Traungebild Berihrte meine Augen mild: Und Seheraugen, furchtios-wahre, Erwachten wie erschreckte Aare, Und in mein Ohr sein Finger drang. Und es erfüllic Schall und Klang: Und ich vernahm des Himmels Beben. Der Engel sternumwehten Flug. des Meergetiers vertorgnen Zug

300

Das könote auch ein Grund dafir sein, daB Puskin in seinen Werken, wie vor allem in den autobiographischen Schriften, den Logennamen «Ovidij» geradezu meidet.

In Jesajas Berufung heißt es (Jes. 6, 2-10): «2 Вохруг Него стояли Серафнмы; у кахдого из нвх по шести хрыл: двумя захрывал кахдын лице свос, и двумя захрывал ноги свон, и двумя летал. 3 И взывали они друг хо друту, и говорили: Свят, Салт, Свят Господъ Саваоф! вся земля полна славы Его! 4 И похолебались верхи врат от гласа восклицаюиих, и дом наполнился хуреннямн. 5 И скәзал я: горе мне! погиб я! ибо я человек с нечистымн устамн, и хиву среди народа таххке с нечистыми устами, - и глаза мои видели Царя, Господа Саваофа. 6 Тогда прнлетел хо мне один из Серафнмов, и в рухе у него горяший уголь, хоторый он взял глепими с ххертвенника, 7 и коснулся уст монх, и схезал: вот, это хоснулось уст твонх и беззаконие твос удалено от тебя, и грех твон очищен. 18 И услышал я голос Господа, говордщего: хого Мне послать? и кто пойдет для Нас? И я сказал: вот я, пошли меня. 9 И сказал Он: поһдн и скахи этому народу: слухом услышите, и не уразумеете; и очами смотреп будете - и не увидете. 10 Ибо огрубело сердце народа сего, и ушами с трудом сльшат, и очи свон сомхнули, да не узрят очамн, и не усльшат ушами, и не уразумеют сердием, и не обратятся, чтобы я исцелял их. («Biblija, knigi svjascennogo pisanija Vetchogo i Novogo Zaveta kanoniceskie, biblejskie obscestvan 0.O., o.J.) 
15 И дольней лозы прозябанье.

16 И ов $x$ устам монм прннвх,

17 И вырвал грешный мой язык,

18 И празднословный в лукавы,

19 И хало мудрыя змен

20 В уста замершне мон

21 Влохол десннцею хровавой.

22 И он мне грудь рассек мечом,

23 И сердие трепетвое вынуд,

24 И угль, пылающни огнем,

25 Во грудь отверстую водвинул.

26 Ках труп в пустыне я лежая,

27 И бога глас хо мне воззвая:

28 зВосстань, пророх, и вижљ, и внемли,

29 Исполнись волею моей,

30 И, обходя моря и земли,

31 Глаголом жти сердца людея $>.{ }^{330}$
Das Tasten erdennaher Reben.

Und er griff tief in meinen Schlund

Und riB die Zunge aus dem Mund,

Die eitle, simdhafte und bange,

Und durch erstarrer Lippen Rand

Stieb seine blutbespritzte Hand

Dea weiseo Stachel ein der Schlange.

Und meine Brust sein Schwert durchstob,

Und ihr mein bebend Herz entrang $a$,

Und in die offeac Wunde schob

Er eine Kohke, fimmenschwanger.

Ich lag in Wistensand wie toh.

Und Gottes Stimme mir gebot:

Steh auf, Prophet, und sich und höre.

Verkünde mich von Ort zu Ort.

Und wandernd uber Land und Meere,

Die Herzen brenn mit deinem Wort"...]"

Die These, in «Prorok» eine "reine Verkörpenung der freimaurerischen Idee" zu sehen, $^{312}$ ist zweifellos übertrieben. Dennoch finden sich in Puskkins Bearbeitung der Berufungsvision des Propheten Jesaja semantische Indizes, die an den Eidschwur des in den Freimaurerbund aufzunehmenden Kandidaten wie auch an das Ritual der Meistererhebung erinnern: Die Verwandlung des Ich-Erzählers in den Propheten wird zunächst mit dem Herausreißen der „sündhaften Zunge“ ( $\star$ I vyrval grešnyj moj jazyk») begonnen. Da gerade dieser Passus von der biblischen Vorlage nicht abweicht, sich aber eng an die freimaurerische Eidesformel anlehnt, ist anzunehmen, daß sich Pußkin ihrer entsonnen hatte und diesem Gedicht den metaphysischen Charakter zu verleihen, für den es bekannt ist."

Auch das DurchstoBen der Brust mit dem „Schwert" ( $\alpha$ I on mne grud” rassek mexom») im Akt eines Wandlungsprozesses findet sich nicht in der biblischen Vorlage und erinnert an die Aufnahme des Freimaurers in den Meistergrad, wo der in der Mitte liegende Kandidat von den „Brïdern" mit gezückten und auf seine Brust gerichteten

310

PSS II, 338/39, nach Kommentar 437 abgefaßt am 8.10.1826.

$31 !$

Diese stilisierte Ubersetzung ist von Wolfgang E. Groeger (1923) in: A. S. Puschkin: Gedichte, Berlin/Weimar 1985, 254.

312

BAKUNINA (1934), 87/88. Vom freimaurerischen Mystizismus vermutlich in Ankehnung an BAKUNINA (1934) spricht IVANOV, V. F.: A. S. Puskin i masonstvo, Charbin 1940, 67/68.

313

Darin schwört der aufzunehmende Freimaurerkandidat: «ни писать, ни печатать, ни вырызывать, ни рнсовать, ни храснть или гравировать, ни подавать повода хъ тому, чтобы это случвлосъ, ни на кахов вещи подъ небесами, подвихкой или неподвнхноЯ, на хоторый бы она могда быть прочитана или понятнаң, - дия того, чтобы тайа не могда быть пріобрьтена хьмъ-нибудь незахонно. Все это обьщается безъ всякаго холебанія, внутреннято умолчанія и хахоһ бы на было увертхи, и подъ страхомъ тахого нахазанія: (...) пусть мнь будеть перерьзана пея, языхз вырванъ съ корнемъя (siehe oben 31 ). 
Schwertern umringt wird." Mit der wieder biblisch belegten ,glühendheißen Kohle" («gorjass $x_{i j}$ ugol' ), ," die an die Stelle des herausgenommenen Herzens implantiert wird, kulminiert die physische Transformation des Ich-Erzählers zum Propheten.

23 И сердие трепетное вануд

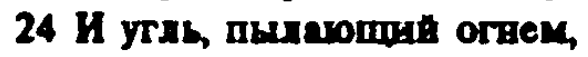

25 Во грудь отверстуро водвануд.

Nun ist zwar der Akt der spirituellen Umwandlung beendet, die psychische Transformation allerdings noch nicht abgeschlossen, da der Ich-Erzahler noch "wie ein Leichnam in der Wïste" liegt («Kak trup v pustyne ja lezalv). Mit der Aufforderung Gottes, sich nunmehr zu erheben, weicht das Gedicht abermals von der biblischen Vorlage ab. ${ }^{316}$ Das «pojdi» wird bei Puß̌kin zum «vosstan'», das ebenfalls im Ritual der Meistererhebung des "Stirb-und-Wende" seine Entsprechung hat."

In «Prorok» (1826) wird die metaphysisch-verordnete Tötung des irdischen Menschen symbolisch vollzogen, wobei erst in ihrer Folge der Eintritt in ein reines und vollkommenes Propheten-Leben möglich wird. Die 'initielle Aufnahme' in den Stand der (Dichter-)Propheten als einer neuen physischen wie spirituellen Geburt, ohne menschliche Gebrechen, hat bei Puskin in der Abweichung vom biblischen Paradigma des „Stirbund-Wende" seine Parallele in der freimaurerischen Meisteraufnahme. Der Ich-Erzähler vergleicht den biblischen Propheten mit dem Dichter. Mit det nächsten Identifizienung des Dichterpropheten mit dem zukünftigen Freimaurermeister wird das religiöse Sujet des Gedichts unterstreicht die spirituelle Bedeutung des Dichterpropheten.

Bei Abfassung von «Prorok» (28.09.1826) lag die regierungsamtliche Bestätigung des Verbots aller Geheimgesellschaften einschlieBlich der Freimaurerei von 1822 (in Folge des Dekabristenaufstandes) seit mehreren Monaten vor (21.04.1826). DaB sich viele Freimauret nach 1822 und auch nach 1826 noch Hoffnungen machten, daB die Logen wie schon mehrmals zuvor - ihren Betrieb wieder aufnehmen würden, zeigt eine Erklä-

${ }^{314}$ Davon existieren mehrere Gravuren und Stiche. Er liegt zuweilen in einem Sarg mit einem blutbedeckten Handtuch über dem Kopf oder ersatzweise auf einem Bodenteppich. (SOKOLOVSKAJA (1915), 112)

315

An dieser Stelle sei darauf hingewiesen, daB die Symbolisten (vor allem Sologub, Bal'moot) sich an diese Themarik des vom Feuer (der Begeisterung, der Ekstase) effabteo Dichters, der dem ,ewigen Fever des Todes" zustrebt (Feuermotiv), angelehnt haben. (HANSEN-LÖVE, A. A.: Der russische Symbolismus: Diabolische und mythopoetische Paradigmatik, Wien 1984, darin das Kapicel 16: „Thanatos und Eros: Liebestod und Todesliebe")

316

Im biblischen Text fordert Gott den werdenden Propheten nicht dazu auf, sich zu etheben: 49 И схазал Он: поһди, и скаххн этому народу: слухом услышите, и не уразумеете; и очами смотреть будете, в не видете».

317

Die Enhebung ist das wichtigste Ereignis der Meisteraufnahme. Sie wird initiient durch das Meisterwort Dean erst nachdem der Meister vom Stuhl dem Ethobenen das Meisterwort ims Ohr geflistert hat, erwacht der neve Meister zu einem neven Leben. 
rung der ehemaligen Mitglieder aus dem Jahr $1827 .^{318}$ In seiner damaligen Situation hat Pusklin in jedem Fall Grund gehabt, nach der Hinrichtung führender Aufständler sich mit literarischen Bezügen zum freimaurerischen Ritual nicht zurückzuhalten und nicht weiteren Verdacht auf sich zu lenken. Das erklärt, wanum vor allem nach dem Ukas von 1826 die Thematisierung des Freimaurertums nicht nur in seinen Gedichten zu einem nur für aufgenommene Meister entschlüsselbarem "Code“ innerhalb eines poetischen Gesche-. hens transformiert wird. Dennoch bleibt «Prorok» (1826) für die "Nachverbannungszeit" bei Puskan das dominierende lyrische Exempel für die poetische Verarbeitung freimaurerischer Symbole und Rituale. Wenngleich noch vereinzelt prominente Mitglieder verschiedener Logen in den Gedichten *Literaturnoe izvestie* (1829) ${ }^{319}$ und *Moja rodoslovnajaw (1830) ${ }^{300}$ erwähnt werden, sich nicht als Allusionen auf ihre Aktivitäten als Freimaurer. Für Puškins Lyrik bleibt daher festzuhalten, daß vornehmlich in den Werken «(Seneralu Pusxinu* $(1821)^{51}$ und «Prorok» $(1826)^{32}$ das orthodoxale Freimaurertum thematisiert wird.

318 Mit dem Dokument «Постановление, принятое масонами в сентябре 1827, по случан з8прещения лохк schliebt Pypin seine akribische Studie zur Geschichte des russischen Freimaurerturns. (PYPIN (1916), 472-80)

319

PSS III, 109. (Z.B. V. K. Tred'jakovskij oder auch I. P. Elagin, welcher nicht nur wegen seines archaischen Stils in seinen Obersetzungen Puskin bekand gewesen sein dirfie. (PSS III, 497 primexnija)

3200 « Пушкин просто, не Мусин" (PSS III, 210). Aus der Familie Musin-Pußkin-Brjus' kamen vier Freimaurer. (BAKOUNINE (1967), 353-55)

321

Rituelle Sentenz des Logenstuhlmeisters bei Logeneröffurng, Signalisierung der Logeneröffuung mit dem freimnurerischem Symbol des Hammers und Stilisierung des wahren Freimaurers Puscin als Befönderer der freimaurerischen Aufklïnng in Kisinev.

30

Elemente des Meisteraufahme-Rituals. 


\section{Geheimbund-Allusionen in Puskins prosaischen Gattungen}

\section{Verbannungsprosa (1821-26)}

In der frühen Lyrik (vor 1821), in der spärlichen Prosa des gleichen Zeitraums wie insbesondere in den Poemen und Märchen lassen sich keine Allusionen oder semantische Indizes entdocken, die als poetische Strukturen auf Freimaurertraditionen zurïckgeführt werden können. Anders in Puskins Versroman «Evgenij Onegin» (1823-30). Im ersten Kapitel, das er übrigens noch am 9. Mai 1823 in KiXinev begonnen hat, vergleicht er seinen Romanhelden «Evgenij» zunächst mit Freund Caadaev.

5 «Второй Чадаев, моһ Евгеняй,

6 Боясь ревнявых осухденй,

7 В своен одехде был педант

8 И то, что мы назвали фракт.

9 Он три часа по храйней мере

10 Пред зерхалами проводнл

$11 \mathrm{H}$ н3 уборной выходил

12 Подобный ветреной Венере,

13 Когда, надев мухскои наряд,

14 Богиня едет в маскарад." [oo Mein Onegin war ein zweiter Casdaev, in Furcht vor eifersichtiger Kritik. in seiner Kleidung ein Pedant und das, was wir einen Stutzer nenoen. Drei Stunden mindestens brachte er vor dem Spiegel zu, und aus dem Anldeidezimmer trat er heraus ahnlich wie die keichtertige Venus, wenn, in Männertracht gekleidet, die Gö̈tin auf einen Maskenball fährt. "]

Wie in den obigen Widmungsgedichten, erlauben auch die letzten Stilisierungen Caadaevs im prosaischen Text keine Rückschlüsse auf das Freimaurertum, auch wenn die Dreizahl der „Stunden“, die Caadaev bei Puškin für gewöhnlich "vor dem Spiegel“ zu verbringen pflegt, manchen Freimaurer interessieren mag. ${ }^{\text {"s }}$ Geläufig ist aber dem russischen 'vol'nyj kamenscik' oder 'frank(-)mason' auch die nunmehr veraltete russische Bezeichnung ( farmazonx), die Puškin im II. Kapitel benutzt, um den öffentlichkeitsscheuen Onegin aus der Sicht der Nachbarn («obsxij glas», „vox populi“) zu schildern.

9 к Сосед наш неуч; сумасброднт;

10 Он фармазон; он пьет одно

11 Стаханом храсное внно;

12 Он дамам х ручхе не подходит;

13 Все da да нет; не скаххет да-c

14 Иль нет-о. Тахов был общия глас." ${ }^{325}$
.Unser Nachber ist ein Flegel; bei ihm stimmt's nicht ganz; er ist ein Freimaurer; a trinkt Rotwein pur aus dem Trinkglas; den Damen kübt a nicht die Hand; immer sagt er nur ja' oder ,nein' - niemals jawohl, gnädige Frau' oder , nein, gnädige Frau'. So lautete die vox populi. ${ }^{327}$

323

PSS V, 20 (Kap. I, XXV, 5-8)

324

Die Obersetzung ist von Kay Borowsky und entnommen aus: A. S. Puschkin: Eugen Onegin. Ein Roman in Versen, Stuttgart 1977, 16.

325

Die "Drei" spielt in der freimaurerischen Zahlensymbolik, von der die gesamte verkörperte wie die nichtwertörperte freimmurerische Symbolik geprägt ist, die wichtigste Rolle. Doch diese kann nur im Zusammenspiel mit anderen Hinweisen Anzeichen fir Freimsurerei sein. (LURKER (1988), 148)

320

PSS V, 38 (Kap. II, V, 9-14).

327

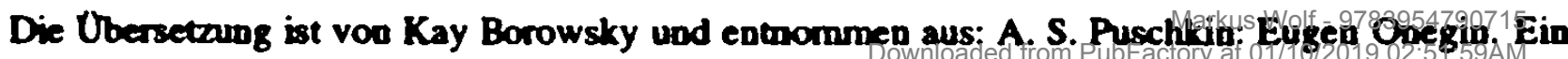


Wie beim Vergleich mit Caadaev bestimmt auch an dieser Stelle das Autoren-Ich die Erzählstruktur; ${ }^{\text {sad }}$ nur hier mit dem Unterschied, daß es die Meinung der "vox populi““ über den neuen Nachbarn in wörtlicher Rede wiedergibt. Die Schmähungen verunglimpfen den fremden Onegin zunächst aus der Sicht der Alteingesessenen (« «osed naš neǔx; sumasbrodit; I On farmazon»), bevor dann schlaglichtartig die Erfahrungen mit dem neuen Anrainer geschildert werden ( $~ \mid$ (...) on p'et odno I Stakanom krasnoe vino; I On damam $k$ rucke ne podchodit; I Vse da da net ; ne skažet da-s I I' net-s>. (...)»), die zu diesen Beleidigungen erst AnlaB gegeben haben. Puskin bettet («farmazon») nicht in einen Reimzwang, ${ }^{30}$ aber in einen anstöBigen Kontext.

Doch ist unter «farmazon» nicht nur die veraltete, umgangssprachliche Bezeichnung ${ }^{30}$ für einen Anhänget des orthodoxalen Freimaurertums («frank-masonstvo», «vol'nokamenscxizestvo») zu verstehen. Puškin verwendet diesen Ausdruck zur Bezeichnung eines plumpen Menschen («neskladnyj Celovek»), der auch als Freidenker («vol'nodumec») oder Nihilist («nigilist») auftreten könnte. ${ }^{331}$ Mit der umgangssprachlichen Bezeichnung $^{32}$ werden aber noch weitere Assoziationen geweckt. Abergläubische Vorstellungen, die mit den Freimaurem oder dem 'Freimaurer par excellence' als Anhänger ei-

Roman in Versen, Stuttgart 1977, 35.

som

Karia Hiclscher beurreilt das Autoreo-Ich im *Evgenij Onegin» als das ,gnundlegende Struknurelement des Romans". Seine Einzigartigkeit liege in der Frage, wie Autorengestalt und lyrische Abschweifungen miteinander verknüpft seien, weil dadurch verschiodene Formen der Einbezichung der Lo ser entstehen. (HIELSCHER, K.: A. S. Puskins Versepik. Autoren-Ich und Erzähistruktur, München 1966, in: Slavistische Beiträge 22 (1966), 112ff.)

320

GERO VON WILPERT: Sachwörterbuch der Literatur, Stuttgart 1979, 668.

300

SSRLJa (1957) VI, 1262. ( «farmazon»)

31

Ebenda, 1262. In den Ubersetzungen kann diese Breite der Assoziationen auch nur dadurch pröseat gehalten werden, indem suf die Ubertragung von ,farmazon" verzichtet wird. So geschehen bei KEIL, R. D.: Alexander Puschkin. Jewgeni Onegin. Roman in Versen, MünchenZUtrich 1987, 44 (,Ein Farmason"). Nicht dagegen bei: BOROWSKY, K.: Alexander S. Puschkin: Eugen Onegin. Ein Roman in Versen, Stuttgart 1972, 35 („Er ist ein Freimaurer"), sowie von T. Commichaw, in: RAAB, H. (Hrsg.): Alexsoder Sergejewitsch Puschkin. Gesammelte Werke in sechs Bänden, Frankfurt am Main 1982, Bd. 3. 38 und (engl.). NABOKOV, V. N.: Eugene Onegin, Vols. I - IV. Bollinger series LXXII, New York 1964. Vol. I, 131. ("He's a freemason", V, 10-11)

32

LOTMAN (1983b) nennt afarmazonn eine verdarbene Bezeichnung fir das Mitglied einer Freimaurerloge. Später sei es zu einem Schimpfwort degenerier, das einen avol'nodumeco bezeichoe. (LOTMAN, Ju. M.: Roman A. S. Puskina «Evgenij Onegin». Kommentarij. Posobie dlja Ctenija, Lo ningrad 1983, 180), NABOKOV (1964) bezeichnet afarmazons als einen Vulgarismus fit den Freimaurer, det von dem französisch ausgesprochenen, "franc-mapon" abgekeitet sei und in Sinpe des, arrogant freethinker" Verwendung finde. (Vol. II, 226) 
nes sektiererisch-mystischen oder satanischen Männerbundes verbunden sind, ${ }^{30}$ waren nicht nur bis kurz nach dem Verbot der 'Bündelei' und nicht nur in RuBland vertreitet. Puskin stilisiert damit Onegin nicht nur als Junggesellen ohne Manieren dar, sondem entwirft im sektiererischen Fremdling auch den vereinzelten Antipol zum „vox populi““. Notwendige klärende Erläuterungen für Nichteingeweihtec $\mathrm{zu}$ den ursprünglichen Zwecken des orthodoxalen Freimaurertums werden in der Charakterisienung Onegins durch Puskin unterschlagen. DaB mit dieser Verballhomung der Freimaurerbezeichnung zuvorderst mündlich tradierte Vorstellungen des Volksglaubens über die Freimaurer spiegelt sich auch bei anderen Literarisienungen von «farmazon*."

Onegin kommen in den metonymischen Gegenüberstellungen mit det „Göttingianischen Seele“ des romantischen Dichters Lenskij («Volna», «stichi», «plamen'») ${ }^{335}$ zwar die Attribute («proza», «led» und auch *kamen'») zu, doch kann der "Stein" alleine nicht als freimaurerisches Symbol gedeutet werden. Das gilt auch in Anbetracht der thythmischen wie euphonischen Äquivalenz bei («kamen' * - «plamen' $*)$.

Ebenfalls ,allusionsverdächtig“ sind im *Evgenij Onegin» Bezïge auf Dichter, die zeitweise orthodoxalen oder pseudomaurerischen Männerbünden angehört haben. Doch spielen weder die Hinweise auf Goethe und Schiller, ${ }^{37}$ oder Walter Scott, ${ }^{33}$ oder die als Motti eingearbeiteten Sentenzen ${ }^{39}$ von I. I. Dmitriev ${ }^{300}$ und A. S. Griboedov ${ }^{311}$ auf ihre Mitgliedschaft in Männerbünden an. Zu guter Letzt verdient noch das zehnte Kapitel des

333

Es war die Betooung des Geheimnisses, das als Merkmal des maurerischen Selbstverständnisses auf seiten det ,profanen" Welt zu allerhand Spekulationen und neben politischen Verieumdungen sogar zu einer Reihe abergläubischer Vorstellungen gefithrt hatte, die bis heute präsent sind. Des "Handwärertuch 2 um Deutschen Aberglauben" (1931) vermerkt eine Reihe abwegiger Vorstellungen des Volksglaubens iber die angeblichen Besonderteiten der Freimaurer.

33

Alekendr Gercen setat den afarmazon mit den Jesuiten gleich, der wie sie einen Glavben hebe und ein Möochsleben fihre. ( Zapiski odnogo molodogo celovekas (1840/41), Kap. III) Bei Dostoevskij («Selo Stepancikogo» (1859) (1, 2)) verbreiten die «fammazony den „Unglauben“ («neverie»), und bei Gor'kj betritt der «farmazon* stets das Haus, ohne sich zu bekreuzigen. ( $* V$ ljudjach» (1918), 7 ) (SSRLJa 6 (1957), 1262 («farmazon*))

335

PSS V, 41/42. (Vers XIII)

336

LOTMAN, Ju. M.: Die Struktur des künstlerischen Textes, Frankfurt am Main 1973, 187.

337

PSS V, 40. («Pod nebom Sillera i Gëte», Vers IX, 6) Sowohl bei Goethe als auch in Schillers Wetcen finden sich Bezige auf die Freimaurerei. (LENNHOFF/POSNER (1932), 616-20 (Goethe), $1391 / 92$ (Schiller)

33

PSS V, 9495 (Vers XLIII, XLIV) und LENNHOFF/POSNER (1932), 1447.

339

PSS V, 140 (Anfang Kap.VII).

30

Der Dichter Ivan I. Dmitriev (1760-1837) gehörte verschiedenen Freimaurergesellschaften an. (BAKOUNINE (1967), 121/22) $\mathbf{3 1}$

Griboedov war $1816 / 17$ Mitglied der Loge ales Amis reunis» und gehörte $1817 \mathrm{mit} 2 \mathrm{des}$ Gribdern de Loge "Du Bien". (BAKOUNINE (1967), 189) 
«Evgenij Onegin» mit seinen verschlüsselten Strophen ${ }^{3 / 2}$ besondere Aufmerksamkeit. Da die Kapitel des «Evgenij Onegin* zusammenhängend abgehandelt werden sollen, wird das zehnte noch in diesem Abschnitt (Verbannungsprosa 1821-36) berücksichtigt, auch wenn Puskin diese Strophen erst 1830 - also Jahre nach dem Dekabristenaufstand und dem endgültigen Verbot der Geheimbünde - verfaBte. Darin finden sich zwar viele Anspielungen auf die Geheimgesellschaften der Dekabristen, nicht aber auf die signifikanten . Aspekte der verkörperten wie der nichtverkörperten Symbolik des orthodoxalen Freimaurertums.

«Безрухии хнязь друзьям Морен

Из Кишвневя уж мигал.

Кннжал Л, тень Б

...................................13
Dex cinsmige First blinzelte schon aus Kisinev den Freunden der Moreja zu

Der Dolch L, der Schatten von B .$^{34}$

Sowohl der „Dolch" als auch der „Schatten“ muten zwar freimaurerisch an, dennoch fehlt jeder weitere entsprechende Anhaltspunkt. Auch kodifiziert die Stadt Kiß̌inev - wie durchaus angenommen werden könnte -, nicht die Loge «Ovidij». Ungeklärt ist auch die Bedeutung der Buchstaben „L“ und „B“; zu vermuten ist, daB es sich um verabredete Zeichen oder um Abbreviaturen handelt, die für zuvor festgelegte Namen stehen. ${ }^{\text {us }}$ Zwar gehört der Gebrauch von Abkürzungen zu den Traditionen der orthodoxalen Freimaurer, dennoch fehlen die bekannten "drei Punkte" $(\therefore)$, die den einzelnen Buchstaben nachstehen müssen, damit die Abbreviaturen als eindeutig freimaurerische Siglen identifiziert werden können. ${ }^{36}$ Gegenstand der anderen Anspielungen ist in den weiteren Strophen des zehnten Kapitels keineswegs die traditionelle Bewegung der Freimaurer, sondern allein die Dekabristen und ihre politischen Verbände.

19. Prosa nach erneutem Verbot der Geheimbünde (1826-36)

Die ersten Pläne für die Niederschrift des kurzen Dramas «Mocart i Sal'eri» $(1830 / 31)^{37}$ kamen Puskin 1826 in Michajlovskoe kurz nach Salieris Tod am 7.5.1825. Von M. P. Pogodin (1800-75) liegt für diese Zeit eine Tagebuchnotiz vor, wonach dieser glaubte,

${ }^{312}$ KOŽEVNIKOV, V.: Šivrovannye Strofy «Evgenija Onegina», in: Novyj mir 6 (1988), $259 f$.

343

SS, tom V, 211. (Kap. 10, Vers IX)

m

Die Ubersetzung ist von Kay Borowsky, entnommen aus: A. S. Puschkin: Eugen Onegin. Ein Romon in Versen, Stuttgart 1977, 234.

PSS V, 211. (Vers IX, Anm. 1)

${ }^{346}$ LENNHOFF/POSNER (1932), 5-7, siehe auch KOZZEVNIKOV (1988), 259-61, 264-65.

37

PSS V, 357-68. 
daß das Stück von Puskin bereits abgefaßt worden war. ${ }^{34}$ Puskin konnte es aber erst 1830/31 auf dem väterlichen Gut Boldino fertigstellen und zwar dort, wo auch das zehnte Kapitel des «Evgenij Onegin» entstand. ${ }^{319}$

Der Zweiakter ${ }^{350}$ baut auf eine zeitgenössische, womöglich auf die Zeit Mozarts zurückgehende Mär ${ }^{351}$ auf, derzufolge der Komponist Salieri den begnadeten Mozart aus Neid vergiftet haben soll. Keinesfalls kann an dieser Stelle der über zweihundert Jahre währende Streit über die wirklichen Gründe für den Tod Mozarts (1791) aufgegriffen werden. Fest steht aber, daB nicht erst in Folge Salieris Selbstanklage in Angesicht des Todes $^{352}$ das Mozart-Mordgeriicht in Europa in aller Munde war und Puškin ,zumindest in der Zeit der Abfassung des Dramas von der Schuld Salieris fest überzeugt war". Andernfalls wäre es undenkbar gewesen, daß er diesen Stoff derart gestaltet hätte. Hierfür spricht auch, daß Puškin in einet späteren Notiz «O Sal'eri» (1832/33) den Versuch unternommen hat, sich für das inzwischen überkommene Sujet des Giftmordes durch Salieri im Drama zu rechtfertigen. ${ }^{354}$ Einzelheiten über Mozarts Tod und die Person Salieris waren Puškin offenbar nicht nur aus schriftlichen Quellen, ${ }^{\text {sss }}$ sondern auch aus mündlichen Uberlieferungen bekannt. ${ }^{366}$ Die Zugehörigkeit Mozarts zum Bund wie der EinfluB,

34

PSS V, 614 (primexanija). Pogodins Eintrag ist vom 11.10.1826.

309

Siehe oben $79 f$.

350

In der ersten Redaktion ist dieses Drama mit Neid (Kavist' ') betitelt. Die Handschrift ist nicht erhalien, wohl aber die Úberschrift auf dem dazugehörenden Umschlag. (PSS V, 615 (primexanija))

351

DaB Mozart vergiftet worden sei, was schon in den ersten Nachrichten úber seinen Tod verbreitet worden, und zwar zuerst in Prag. Braunbehrens zitient in einer neuen Salieri-Biographie einen Korrespondentenbericht, det erstmalig im seriösen Berliner "Musikalischen Wochenblat" veröffentlicht wurde. (BRAUNBEHRENS, V.: Salieri. Ein Musiker im Schatten Mozarts, München 1989, 13)

332

BRAUNBEHRENS (1989), 273.

353

STÖCKL, E.: Pußkin und die Musik. (Die Bedeutung der Werke A. S. Puskkins für die Tonkunst), Mit einer annotierenden Bibliographie der Puskinvertonungen (1815-1960), Bd. 1-2, Jena 1962. 1: 62.

354

STÖCKL (1962), Bd. 1, 62. «Сальери умер лет 8 тому насал. Нехоторые немецкие журналы говорили, что на одре смерти прнзнался он будто бы в ужасном преступлении - в отправлении великого Моцарта». (PSS VII, 263 («Статъи и заметкни)) жЗавнстник, хоторыи мог освистать «Дон Жуана), мог отравить его творца».

3ss

Fir STÖCKL (1962) ist es erwiesen, dab Puskin den Nekrolog auf Salieri von J. F. Rochlitz (,Allgermeine Musikalische Zeitung“ 24 1825, 413) gekannt habe. (62) Siehe auch BRAUDO, E. M.: Mocart i Sal'eri, in: Orfej. Sbornik stat'ej o muzyke raznych avtorov, Petrograd 1922, 107 und NAJDIS, E.: Pułkin i chudožnik G. G. Gagarin, in: Literaturnoe nasledstvo 58 (1952), 272.

336

Für STÖCKL (1962) könnten zuvorderst N. B. Jusupov (36), N. B. Golicyn (29) und M. Ju. Viel'garskij (40-42) Nachrichten aus der Wiener Musikwelt ibermittelt haben, da sie die österreichische Residenzstadt gut kannten und auch einen ,engen Kontakt zu Westeuropa und seiner Kultur insbesondere

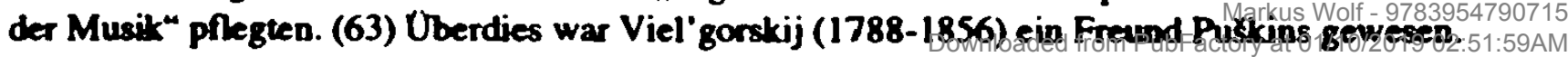


den das Freimaurertum und ihre Symbolik auf das musikalische Schaffen Mozarts ${ }^{357}$ einnimmt, wird Pußkkin daher kaum verborgen geblieben sein. ${ }^{39}$ Soweit zunächst de historischen Aspekte der Entstehung von «Mocart i Sal'eri».

Beide im Titel benannten Protagonisten repräsentieren unvereinbare Standpunkte zum Wesen der Kunst und der Berufung des Künstlers. ${ }^{39}$ Puskin ging es um das Gegenüber zweier unterschiedlicher Künstlerfiguren, für die die Namen 'Mozart' und 'Salieri' histo- ' rische Folien bilden. ${ }^{300}$ Salieri steht dabei für die entsagungsreiche "nichtbrennende“ Liebe zur Kunst, die sich unter Selbstaufopferung und mit dem FleiB eines Handwerkers den Weg sucht, während der müBiggängerische aber spielerisch-heitere Genius eines Mozart sich seiner göttlichen Begabung nicht gewahr wird.

Das Stück beginnt mit einem Monolog Salieris, worin er zunächst seiner Liebe zur Kunst («Rodilsja ja s ljuboviju $k$ iskusstvu») ${ }^{31}$ Ausdruck gibt. Erste Analogien zum Freimaurertum klingen in dem Vergleich seiner Kunst mit der Tätigkeit eines Handwerkers an («Remeslo postavil ja podnožiem iskusstvu; ja sdelalsja remeslennik»). ${ }^{\$ 2}$ Künstlerisches Handwerk im Vergleich mit det Tätigkeit eines sezierenden Mediziners, der einen abstrakten "Leichnam" bearbeitet («Muzyku ja raz"jal kak trup») ${ }^{363}$ und in gottverbundener "Stille" und „insgeheim" ( $«$ Ja stal tvorit", no $v$ tišine, no $v$ tajnem) ${ }^{304}$ sein "Werk vollbringt", entspricht der Gesinnung und Teilen der symbolischen „Arbeit" der Freimaurer im Meisterritual. ${ }^{\text {.65 }}$ Mozart spielt Salieri ein neues Stück vor, und bevor er ihn um sei-

357

LENNHDFF/POSNER (1932), $1068-70$ (Mozart); NETTL, P.: Musik und die Freimaurerei. Mozart und die königliche Kunst, EBlingen 1956; NETTL, P.: W. A. Mozart. Als Freimaurer und Mensch (Ziegeldecker-Reihe), Hamburg 1956. Auch der Verfasser der neven Salieri-Biographie würdigt den EinfluB der Freimaverei auf das Leben wie auf die Werke Mozarts in einer Lebensbeschreibung. BRAUNBEHRENS, V.: Mozart in Wien, München 1986 (Kapitel 6 Mozart und die Freimaurerei), 243-85.

334

Viel'gorskij war von 1810-14 Stuhlmeister der Petersburger Loge «Palestinan und hatre bis 1822 - dem Ende der Freimaurerei in RuBland - in vielen Logen hohe Ämter inne gehabe. Die Zugehörigkeit Viel'gorskjis zum Bund wie die genauen Kenntnisse von der Biographie Mozarts (Jusupov, A. D. Ulubyšev, der als Bekannter von Puskin 1843 eine Mozartbiographie veröffentlichte) deuten darauf hin, daB Puskin der Zusammenhang zwischen der Musik, dem Leben Mozarts und dem Freimaurertum bekannt wer.

359

Siche auch KOCH, C.: *Mocart i Sal'erix, in: Kindlers Literatur Lexikon 8 (1986), 6379/80. HEISELER, H. v.: Kleine Tragödien, in: RAAB, H. (Hrsg.): Alexander Sergejewitsch Puschkin. Gesammelte Werke in sechs Bänden, Frankfurt am Main 1982, Bd. 3, 459.

300

BRAUNBEHRENS, V.: Salieri. Ein Musiker im Schatten Mozarts, München 1989, 11.

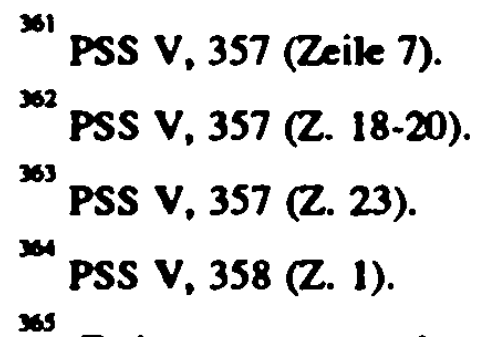

Freimaurer verwenden die Bezeichnung ,königliche Kunst" (kkorolevskoe remeslow) fitr ihr Brauchkum im Tempel («vnutrennyj chram*) oder während der Logenapbeit (arkis 
ne Meinung bittet, entwickelt Mozart selber ein Sujet für sein Stück am Piano:

nMouapt

(30 фортепиано)

Представь себе... гото бы ?

Ну, хоть мевя - вемного помолохе;

Bлюблеявого - ве сляшиом, а слегха -

C храсотхон, или с другом - хоть с то-

бон. Я весел... Варут вдденье гробовое,

Незатвый мрах вдь тто-нибудь тахое...

Hy, crymat xe.n

\section{Noeent \\ (hinter dem Piano)}

Stell Dir vor... wen könnte? Nun, ctwa mich - ein wenig jutnger, Einen Verieben nicht allzu, aber ein wenig -- Mit einer Schöoheit, oder mit einem Anderen - nun mit Dir. Ich bin glücklich... Plötzlich eine Graberscheinung, eime unerwartete Finsternis oder ingeodwas derartiges... Aber hör' doch."

Die Assoziationen, die Salieri zur Erläuterung des neuen Stïckes beim Spiel erzählt werden, erfahren einen Bruch, der den Wechsel einer Tonart oder der Lautstärke markieren könnte. Zuerst ist Mozart, wie et sagt, „glïcklich“, plötzlich aber kommt ihm „Gestalt aus dem Grabe ${ }^{437}$ oder ein ,jähes Dunkel“" in den Sinn ( $\mathrm{JJa}$ vesel ... Vdrug: viden'e grobovoe, I Nezapnyj mrak»). Diese von Puškin scheinbar unmotivierten, psychologischen Facetten des stilisierten Mozart sind frei von maurerischen Ideen. Gleichwohl verdichten sich in diesem Passus die auch für die Freimaurerei typischen Dualismen wie "Licht Finstemis", „Leben - Tod", „Paradies - Hölle“"."

Als Mozart Hunger verspürt, beschlieBt er mit Salieri, beim Wirt ,Zum Goldenen Löwen" ( V traktire Zolotovo L'va») ${ }^{369}$ Mittag zu essen. Die erste Szene schlieBt, wie sie begann: mit dem Monolog des künftigen Giftmörders. Salieri stellt darin das Gift als "heiliges Geschenk der Liebe“" («zavetnyj dar ljubvi») ${ }^{350}$ vor, das für den Kelch der Freundschaft ( $₫$ čš̌a družby») ${ }^{3 \prime \prime}$ bestimmt ist. In der zweiten Szene berichtet Mozart, wie ein schwarzer Mann («čelovek otdetyj v cernom»), ${ }^{3 n}$ der ihn höflich begrüßt («UČtivo pokloniv $X_{i s}$ 's), ${ }^{33}$ bei ihm ein Requiem bestellt habe, ihn seitdem im Schlaf verfolge. Auch am Tag jage der schwarze Mann immer hinter ihm her, und jetzt sei es ihm, als säBe er als dritter mit am Tisch («Mne kažetsja, on s nami sam-tretej I Sidit»). ${ }^{\text {"4 }}$ Später fallt

306

PSS V, 361 (2. 5-12).

367

Das oxymorale Paradigma der Graberscheinung («viden'e grobovoex) ist im „lebendigen Leichnam" auch im altslavischen Tolenbrauchtum geläufig. (LURKER (1988), 738)

362

LAUER (1979), 288/291.

360

Ein Tavernenname, der, wie nur wenige andere, immerhin geeignet ist, als Bezeichnung einer Freimsurerloge zu fungieren. (LENNHOFF/POSNER (1932), 1089/1090)

300

PSS V, 363 (Z. 22).

371

PSS V, 363 (Z. 23).

${ }^{3 n}$ PSS V, 365 (Z. 11).

373

PSS V, 365 (Z. 12).

M4

PSS V, 365 (Z. 29/30). 
die Rede auf den Dramatiker P.-A. Beaumarchais, ${ }^{375}$ der erstmals von Salieri (wörtlich) zitient wird. Beaumarchais bekundet in diesem Zitat das enge Verhältnis zu Salieri mit der Anrede "Bruder" («Slusaj brat Sal'eri»)," die für Freimaurer typisch ist, dem Nachnamen vorangestellt. Mozart überrascht den seinen Mord planenden Salieri mit der Frage, ob es wahr sei, daß Beaumarchais einst jemanden vergiftet habe. Salieri entgegnet ihm:

кНе думаю: Он слиштом был смешон Дия ремесла такого.»
"Ich denke nicht: er war zu komisch fuir ein solches Handwerk."

Auch hier wird der Vergleich mit dem „Handwerk" emeut zum Topos; nur hier ist mit „Handwerk" nicht die schöpferische Tätigkeit als Komponist gemeint, sondern wird mit der „Kunst des Giftmondes“ verglichen. Die Tötung Mozarts begreift der den Schierlingsbecher reichende Salieri als berufsmäBig-ausgeübte Tätigkeit. Mozart hält Beaumarchais nicht für einen Mörder und ahnt nichts von Salieris bösen Absichten. Sind doch für ihn „Genie ${ }^{\text {(637 }}$ und „Verbrechen/Untat ${ }^{\text {(379 }}$ unvereinbar. Nachdem dann Salieri das Gift in den Becher geschüttet hat, stößt Mozart mit seinem „Freund" auf den herzlich-innigen Bund («za iskrennyj sojuz») an, ${ }^{300}$ der ihn mit Salieri als den „zwei Söhnen der Harmonie" verbindet.

«Здоровье, друт, за искренный союз, Связуюший Моцарта и Сальери, Двух сыновей гармонии (...)"
"Auf die Gesundheit, Freund, auf eine aufrichtige Freundschaft, die Mocart und Sal'eri verbindet, die Söhne der Harmonie".

Mozart trinkt den Schierlingsbecher aus, und Salieri weint „leidvolle und liebliche Tränen“, als hätte er eine „schwere Pflicht erfült" («Kak budto tjažkij soveršil ja dolg»). ${ }^{302}$ Auch der sich anschließende Vergleich mit dem Mediziner, der mit einem Messer das

375

P.-A. Caron de Beaumarchais (1732-99) war Buihnenautor und hatte noch andere Benufe (Börsenspekulant, geheimer Polizeiagent, Reeder, Kaufmann). Er ist der Verfasser vom „Barbier von Sevilla" und von der "Hochzeit des Figaro" und hatte mit diesen Stücken groben Erfolg. Mozart vertonte später die "Hochzeit des Figaro". Salieri bringt zuerst das Gesprïch auf Beaumarchais, der im Gegensazz zu Salieri dem Freimaurerbund angehörte. Gleiches gilt auch für Haydn, der noch am Ende des ersten Kapitels genannt wird. (PSS V, 363 (Z. 20)

376

PSS V, 366 (Z. 4).

m

PSS V, 366 (Z. 16/17).

m

«Geaij» (PSS V, 366 (Z. 19-20).

379

×Zlodejstvo» (PSS V, 366 (Z. 19-20).

300

PSS V, 366 (Z. 28).

31

PSS V, 367 (Z. 1-2).

32

PSS V, 367 (Z. 17). 
"kranke Glied" abtrennt, ist längst nicht mehr auf die Kunst des Komponisten bezogen. Salieri beschreibt den künstlerischen Akt der Vergiftung: "Als hă̈t' ein heilsam Messer fortgeschnitten ein wehes Glied!" ${ }^{33}$ und fordert "Freund Mozart ${ }^{334}$ zum Weiterspielen auf, der, als einer der wenigen Glücklichen und Auserwählten, die „Kraft der Harmonie“ ( $*$ sila Garmonii») ${ }^{305}$ für sich und andere erlebbar zu machen versteht.

Auf den ersten Blick ergeben sich mit dem in Wort und Bewegung symbolischen Brauchtum der Freimaurerlogen zunächst keine direkten Parallelen in *Mocart i Sal'eri» (1830). Auffällig aber ist die von Puškin verwendete Allegorik: die „Liebe zur (königlichen) Kunst", der Vergleich mit der Profession des „Handwerks" und die Mit- „Handwerker" - die wie Haydn und Beaumarchais" dem Bund angehört haben -, der in schwarz gekleidete Mann," der sich als "dritter" mit an einen Tisch setzt, wie die Sohnschaft der "Harmonie ${ }^{\text {" }}{ }^{\text {wat }}$ der beiden Komponisten - all diese Assoziationen sind in einer Dichte in diesem kurzen Stuick gewählt, daB im mindesten von einer unbewuBten freimaurerischen Allegorik *Mocart i Salieri» (1830) ausgegangen werden muB.

Die „Handwerkskunst" Salieris, die für sein Schöpfertum als Komponist steht, wird am Ende der zweiten Szene zum Motiv der handwerklichen Vergiftungskunst. In Erfüllung einer angeblich ,heiligen Pflicht" wird Salieris Handwerkskunst zur Mordkunst am einzelgängerischen Genius. Hierzu verhält sich das ausschließlich mündlich tradierten, abergläubischen Wahnvorstellungen entsprungene Geriucht vom rituellen „freimaurerischen Logenmond ${ }^{4300}$ analog. Die zeremoniellen Abläufe hinter verschlossenen Türen im

${ }^{303}$ Ubersetza von HEISELER, H. v.: Mozart und Salieri, in: RAAB, H. (Hrsg.): Alexander Sergejewitsch Puschkin. Gesammelte Werke in sechs Bänden. Bd. 3, 309. "Ках будто нож селебнын мне отсех Страдавиия член!». (PSS V, 367 (Z. 18/19)

31

PSS V, 367 (Z. 19).

3 as

PSS V, 367 (Z. 23/24).

30

LENNHOFF/POSNER (1932), 678 (Haydn); 140/141 (Beaumarchais)

307

Das kurz vor Mozarts Tod ein in schwarz gekleideter Mann ein Requiem bestellte, ist - wie heute feststeh, arthentisch. Graf Walsegg bestellte damals das Requiem, um es als sein eigenes auszugeben. (PSS V, 615 primezanija)

30

"Die Freimaurerei erstrebe die Harmonie der geistigen Kräfte: Weisheit, Schöaheit und Stărke, die in ihrem Riwal derngemäß eine wichtige Rolke spielen." (LENNHOFF/POSNER (1932), 672/73)

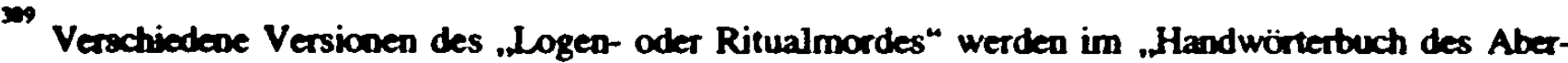
glaubens in Deutschland" erzählt. Von den Freimaurern werde erzählt, da8 von jedem Mitglied ein Bild in der Loge binge, und wean es wackelt, sei dies ein Zeichen, daB das betreffende Mitglied den Bund „verraten" habe. Das Bild werde dann durchbohrt, woraufhin der Schuldige sterbe. (..Bildertod", I, 1294) Eine andere Verleurndung besagt, die Freimaurer losen jedes Jahr einen unter sich aus, der noch im selbea Jahr sterben mikse. (,Jahresopfer", IV 597) Uberdies geht die Sage, daB die Freirnaurer einen Veräter oder des fillige Todesopfer ihres Bundes dadurch bestimmen, indem sie schaven wessen an die Kene gehallener Zetiel nicht oder zuletzt anbrenne. (Jahresopfer", IV 1250) Auch sollen die Freimsurer, falls sie aum Sterben durch das Los bestimmt seien, sich einen Stellvertreter kaufen dürfen. Das duirfe aber

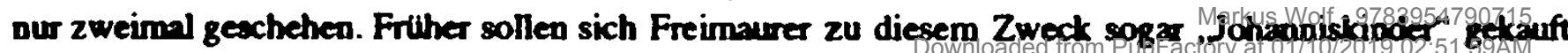


Einklang mit der verordneten Verschwiegenheit der Arkanpraxis über jegliche Logeninterna leisteten hartnäckigen Verdächtigungen Vorschub, Freimaurer vollziehen rituellmotivierte periodisch-wiederkehrende Tötungsakte, und zwar vorzugsweise an Abtrünnigen.

Neben der Gegenüberstellung der ungleichen Komponisten bilden in «Mocart i Sal'eri» (1830) freimaurerische Themen in ungeordneten Facetten eine weitere Schicht des künstlerischen Textes. Das wird auch in einem Aufsatz einer offiziellen Freimaurerzeitschrift deutlich, die den „dramatischen Beitrag" Puskins und den Giftmord Mozarts durch Salieri als "mysteriös" beurteilt. In der sich anschließenden Besprechung des Stücks wird die potentielle freimaurerische Allegorik in Puškins «Mocart i Sal'eri» unkommentiert zusammengefaBt, wobei auf das Paradigma des freimaurerischen Ritualmordes als einer Vorstellung des Aberglaubens nicht eingegangen wird.

Für das Drama «Mocart i Sal'eri» bleibt festzuhalten, daß die Mär der Ermordung Mozarts durch einen beauftragten 'freimaurerischen Bruder' immerhin lexikalische Nahrung erhält, obgleich der Verdacht unausgesprochen bleibt. Die Verdachtsgründe für den Logenmond Mozarts stützen sich auf die Tatsache, daß der große Komponist im Anschluß an zwei wichtige freimaurerische Ereignisse den Tod fand. ${ }^{301}$ KERNER (1971) weist auf die Premiere der ,Zauberflöte ${ }^{\text {“32 }}$ am 30. September 1791 und die Tempelweihe - gemeint ist die Einweihung einer Freimaurerloge - am 18. November hin, für welche Mozart auf 18 Blättem eine Kantate komponiert habe. Nicht zu vergessen ist auch, daß Puškins Salieri das „letzte Geschenk der Todesgöttin Isora“ («jad») genau achtzehn Jahre

haben. (.Loskaufen v. Tod", IV 1177) Nach BÄCHTOLD-STÄUBLI (1927-41) ist der Grund für derart Abstrusität darin zu sehen, daB man die freimaurerischen Rituale nicht kenne, wohl aber sich Vorstellungen davon machen versuche. AuBerdem leiste das Moment der Absonderung des Freimaurerbundes als einer "selbstgewollien Geheimgesellschaft" diesen abwegigen Vorstellungen Vorschub (BÄCHTOLD. STÄUBLI (1927-1941), Bd. 3, 23ff. (siehe unter .Freimaurer"). Im Rahmen der umfangreichen medizinischen Literatur zur Untersuchung der Todesursachen Mozarts ist immerhin eine diagnostizierbare Quecksilbervergiftung bis in heutige Tage AnlaB gewesen, den freimaurerischen Logenmord zu unterstellen. (STÖCKL, E.: Puškin und die Musik. Die Bedeutung der Werke A. S. Puskins für die Tonkunst) Mit einer annotierenden Bibliographie der Puskinvertonungen (1815-1960), Bde. 1-2, Jena 1962, 1: 61; DUDA, G.: „GewiB - man hat mir Gift gegeben!” Eine Untersuchung der Krankheiten Mozarts nach den Briefen der Familie und den Berichten der Zeitgenossen, PählObb. 1958, 123/143/44; DALCHOW, J JDUDA, G./KERNER, D.: W. A. Mozart. Die Dokumentation seines Todes. Zum 175. Wiederkehr seines gewaltsamen Todes am S. Dez. 1966, PählObb. 1966.

30

DIE VEREINIGTE GROSSLOGE (hrsgg. von der Vereinigten Grobloge der alten freien und angenornmeneo Maurer von Deutschland), Frankfurt an Main, Heft 12 (1955/56), 275.

391

Mozart starb am S.12.1791.

392

Entgegen anderslautenden Auskünften, beinhaltet die ,Zauberflöte“ nach KERNER (1971) tatsächlich ein ,freimaurerisches Geheimnis", das sich nur dem Eingeweihten offenbart und auf das bereits Goethe in seinen Gesprächen mit Eckermann hingewiesen hat. Demnach sei die Gestaltung des 18 . Hochgrades, des sogenannien Rosenloreuzergrades, der Mittelpunkt der Oper und zwar im Rahmen der Fever- und Wasserprobe. (II, 28) (KERNER, D.: Mozarts Tod 1791/1971. 180 Jahre MiBbrauch einer Dokumentatico, Mainz 1971, 12) 
lang bei sich getragen hatte.

Die «Povesti pokojnogo Ivana Petroviča Belkinas schrieb Puskkin auf dem väterlichen Landgut Boldino im September/Oktober 1830." Sie sind die ersten von Puškin vollendeten, rein prosaischen Erzählungen. Der ganze Zyklus plant er schon vor 1830 (vermutlich im Herbst 1829) in Pavlovskoe/Tver'. Chronologisch steht der «Grobovకzcik» (9.9.) neben «Stacionnyj smotritel’» (14.9.), «Baryšnja-krestjanka» (20.9.), *Vystrel» (14.10.) und *Metel'» (20.10.) an erster Stelle und ist im Hinblick auf die Literarisierung von Freimaurerei unter den $*$ Povesti (...) Belkina» allein von Interesse." Es ist das Verdienst von ELKE NERRE (1986), auf Elemente der Freimaurertums im «Grobovšcik» $(1830)^{\text {m? }}$ aufmerksam gemacht zu haben, wobei sie von WOLF SCHMID zu ihrem Aufsatz inspiriert wurde. Die nachfolgende Analyse soll NERRES (1986) zahlreiche Erkenntnisse ergänzen.

Adrijan Semenovič Prochorov ist ein emsiger Sargmacher und soeben in ein neues Haus eingezogen. Alsbald wird er von seinem neuen deutschen Nachbarn Gotlib Sul'c besucht, der ihn zu seiner Silberhochzeit einlädt. Dort erscheint Adrijan mit seinen Töchtem um Punkt zwölf und trinkt eifrig zusammen mit den ebenfalls geladenen, zumeist deutschen Handwerkem. Dabei werden auch verschiedene Toasts ausgebracht, wobei die Einzigartigkeit des Totengräberhandwerks zum Ausdruck kommt. Das gemeinsame Trinken auf das Wohl der Kunden wird beim russischen Sargmacher wie folgt auf den Punkt gebracht: "Auf das Wohl deiner Leichen“, was den fleißigen und profitbedachten Sargmacher beleidigt. Der sich anschlieBende Erzählteil setzt mit der Nachricht des Ablebens det "Trjuchina" ein, was Adrijans kaufmännische Ambitionen weckt. Nach Abschluß des Geschäfts wieder zu Hause, erwarten ihn (im Traum) jene Toten - und zwar wieder lebendig -, denen gegenüber er ein schlechtes Gewissen hat. Ein sich bewegendes Skelett erinnert ihn, daB er seinen ersten Kiefernsarg im Jahre 1799 (das Geburtsjahr Puskkins) für Eiche, also überteuert, verkauft hat. Er stößt das Gerippe um, woraufhin die umherstehende Menge sich zusammentut und Adrijan drohend nähert. In diesem Moment der Todesgefahr erwacht Adrijan innerlich verändert aus seinem Traum.

Wie Puskkin in einer seiner typischen Digressionen nach dem ersten Absatz den Leser erinnert, hat die Verarbeitung des Totengräbermotivs im *Grobovšcik» (1830) schon Vorläufer in den Werken von W. Shakespeare ${ }^{300}$ und W. Scott. ${ }^{390}$ Im Unterschied zu die-

393

PSS V, 362 (Z. 27/28).

39 PSS VI, 758 (primexanija).

395 PSS VI, 758 (primexanija).

396

NERRE, E.: Puskins aGrobovscik» als Parodie auf das Freimaurertum, in: Wiener Slavistischer Almanach 17 (1986), 5-32.

397

PSS VI, 119-128 ( (Grobovscikx).

ma

Hanjer (5. Akt, 1. Szene) 
sen „fröhlichen" Sargmachern entspreche das Gemüt seines «Grobovšxik» jedoch mehr dem "düsteren Handwerk". ${ }^{\infty}$ NERRE (1986) sieht indessen in dem traurigen Handwerk nicht den eigentlichen Grund für Adrijan Prochorovs "düsteren Gemütszustand“, sondem in seinem Sinn für das Geschäftliche. Und um das steht es bei Adrijan gerade nicht zum besten. ${ }^{102}$ Vieles ist absurd an Adrijan. AusschlieBlich der Tod anderer kann ihm Gewinn bringen. Der Tod ist für ihn daher ein „Lebensmittel". jans Sinneswandel verursacht. Obwohl er nach der Logik seines geschäftlichen Denkens betrübt sein müsse und audem keine Einnahmen ins Haus stünden, sei er dennoch von frohem Gemüt und „erfreut" (cobradovannyj»). Adrijans Sinneswandel hängt für NERRE (1986) mit der Freimaurerei zusammen. Zum einen seien „Elemente des freimaurerischen Rituals" in "Grobovšcik» (1830) verarbeitet: Zum anderen weise die Erzählung in ihrer Gesamtkonstruktion „Züge der freimaurerischen Literatur" auf."

Angefangen mit einem dreimaligen Klopfen nach Art der Freimaurer, wodurch der Gedankengang Adrijans unterbrochen wird ( Sii razmyšlenija byli prervany nexajanno tremja franmasonskimi udarami $v$ dver' $n$ ). ${ }^{.06}$ Gotlib Sul'c, der deutsche Schuhmacher, sucht bei Adrijan Einlaß, um sich als neuer Nachbar vorzustellen. ${ }^{07}$ Indem der Sargmacher wörtlich mit einem „Wer dort" («Kto tam?») antwortet, liegt eine Anspielung auf

399

Walter Scott war Freimaurer, gleichwohl steht sein "frühlicher" Totengräber in der "Braut von Lammermoan" (The Bride of Lammermoor (Kap. 16)) aicht mit dem Freimaurerbrauchtum in Verbindung.

PSS VI, 120. «нрав нашето гробовицка совершенно соответствовал мрачному сго ремеслун. (Z. 15/16)

$\infty 1$

In einem französisch abgefaßten Brief an seine spätere Frau N. N. Gontarova macht Puskin ihr Vorwirfe, trotz Pest in der Nikitskaja-StraBe zu bleiben. Ironisch fügt er hinzu, daB das für ihren .Nachbern Adriag" sicher gut sei, zumal der dabei gute Geschüfte mache (PSS X, 313 (363. N. N. Gonzarovoj, 4.11.1830)). Daher kann nicht ausgeschlossen werden, daB Puškin für seine Erzählung einen realen Sargmacher auswählte. (PSS 6, 761 (primexanija)) Auch die Namengebung für den Sargmacher durch Puskin ist interessant. keineswegs ist die Ubereinstimmung der Initialen des Protagonisten Adrijan mit denen Puskins zufällig. (NERRE (1986), 26) Adrijan klopft nach Art der Freimaurer, Puskin war

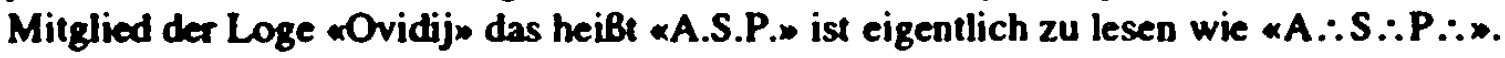

102

NERRE (1986), 6.

$\cos$

NERRE (1986), 6.

son

NERRE (1986), 7. (PSS VI, 128 (2. 30)

$\cos$

NERRE (1986), 7.

$\infty$

PSS VI, 121 (Z. 8/9).

07 Wie im «Evgenij Onegin» wird auch in dieser Erzählung ein never Nachbar («sosed», PSS VI, 121, Z. 8-14) mit dem freimaurerischen Männerbund in Zusammenhang gebracht. Onegin und Sul'c werden als neve Anlieger von ihrem jeweiligen Gegeniber gleichermaben als Angehörige des Bundes identifizient (PSS V, 38 (Z. 15/16).

-

PSS VI, 121 (Z. 9/10). 
den beginnenden "Teil des freimaurerischen Initiationsrituals" vor. ${ }^{100}$ Dies ergibt sich aus der engen Verbindung des ,dreimaligen freimaurerischen Klopfens" mit der stereotypen Antwort «Kto tam?», die alleinstehend als Phrase des alltäglichen Gebrauchs verstanden werden müßte. Hier wird ein weiteres $\mathrm{Mal}$ deutlich, wie wichtig eine Unterscheidung zwischen verkörperten und nichtverkörperten freimaurerischen Symbolen für diese Analyse ist. Obwohl beide Handwerker kein „offenes Wor" uber den Bund wechseln," muB ihr Verhalten von "Eingeweihten" unweigerlich als Zeichen ihrer freimaurerischen Bundzugehơrigkeit verstanden werden. Auch wenn dabei wichtige Teile des Rituals fehlen, tut das diesem Verständnis keinen Abbruch. Charakteristisch für den «Grobovšcik» ist für NERRE (1986) überdies die Lexik in Adrijans Traum. Sie wechselt vom Bereich 'Leben' in den des 'Todes' und umgekehrt." Eine Anbindung zum Freimaurertum entstehe durch die poetische Verarbeitungsart verschiedener Phänomene und Einzelheiten im Traum.

Adrijan verkauft nicht nur "Särge“, sondern bietet auf seinem Aushängeschild absurderweise an, Katafalke auch zu „verleihen“ oder „auszubessem“."12 Die Freimaurer verwenden bei ihrer Meisteraufnahme bekanntlich einen Sarg, worin der sich totstellende Kandidat zum Zweck seiner Erhebung Liegestatt nimmt. Das ebenfalls freimaurerisch lesbare Motiv des „lebendigen Leichnams“, das bereits in «Prorok» vorkam, hat in der Erzählung *Grobovšcik» seine Entsprechung in der Begegnung Adrijans mit dem sich bewegenden und sprechenden Skelett in des Sargmachers Traum. ${ }^{13}$ Bemerkenswert ist, daB sich das Fleisch von den Knochen des Skeletts, das Adrijan des einstmaligen Betruges beschuldigt, gelöst hat." Darin sieht NERRE (1986) ${ }^{415}$ zu Recht eine Ubereinstim-

$\infty$

Mit PYPIN (1916) lautet der rituelle Passus wie folgt: «Когда всь приготовленія хончены, предлагающін стучитъ три раза въ дверь лохи; мастеръ отвьчаетъ тремя ударами молотка, и млапшій надзиратель спрашивастъ: Кто тамъ? Кандидатъ (научаемый провожатимъ) отвђчдетъ: ‘Человькъ, которыи желаетъ имђть и просить участія въ благах этой достопочтенно пожи, посвященной Св. Іоанну, хахъ это сделали до меня многіе братья и товаpruuи (...)>»] siehe oben 30.

${ }^{110}$ PSS VI, 121 (Z. 9/10); NERRE (1986), 7.

"NE NERRE (1986), 11.

412 PSS VI, 120 (Z. 4-6). Die Aufschrift («подинсь») lautet: «Здесь продаются и обиваются гробы простые и храшеные, тахже отдаются напрохат и починяются старыен.

413

Nachdem Adrijan sein Zimmer betreten hat, erkennt er jene Leute wieder, die er begraben hat. Deshalb vermutet ex einen "Teufelsspuk". («дьявольшина», PSS VI, 126 (Z. 27)) Fast alle erkennt a wieder, nicht aber das ,kleine Skelett", das mit ihm spricht: «B эту мннуту маленьхнй скелет продалсх схвозь толпу и прнближился х Адрияну. Череп его ласково улыбался гробовшиху. Ключхи светло-зеленого и храсного сухна и ветхой холстины хой-где висели на нем, хах на шесте, а хости ног биинсь в больших ботфорах, хах пестики в ступах. Ты не узнал мевя, Прохоров, - скмзал скелетн. (PSS VI, 127 (Z.16-24) Es stelle sich als «Pet Petrovic Kurilkin» vor.

414

Die Aufrichtung des im Sarge (oder auf einem Teppich) liegeoden Kandidaten erfolgt mach SCHWARTZBOSTUNITSCH (1928) mit den Worten: "Die Haut verläBt das Fleisch" - "Das Fleisch

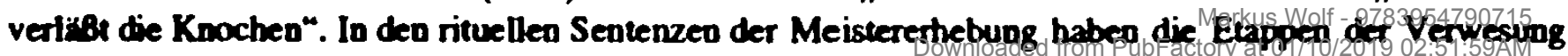


mung mit der Hiram-Legende, ${ }^{16}$ die neben dem Andersonschen Konstitutionenbuch das "Kemstiuck" der Freimaurerbundtradition wie zuvorderst der Beförderung des Freimaurergesellen zum Meister darstellt. Weitere rituelle Parallelen finden sich in Adrijans "Heraufschreiten der Treppe" nem Umzug in das neue Haus zu Beginn der Erzählung " und in der nur spärlichen Beleuchtung im Haus durch das geheimnisvolle „Mondlicht“." Außerdem will in Adrijans. Traum das Skelett „Kurilkin" den Sargmacher umarmen, wobei dieser es überrascht umstöBt. " Empört treten die anderen "Toten" für die Ehre ihres derart miBhandelten Bundesgenossen («tovarišc») ein. ${ }^{21}$ Ferner prosten sich auf dem Fest von Gotlib Sul'c alle Handwerker auf die Gesundheit der Meister und Gesellen («zdorov'e masterov i podmaster'ev») an," was unweigerlich an die postrituellen "Toasts" in den Handwerkerzuinften und Freimaurerlogen erinnert. ${ }^{42}$ Die 'lebendigen Toten' in Adrijans Traum sind mit "Schmuck“ oder „Uniformen“ ausstaffiert, wie auch die Freimaurer in der „gedeckten Loge" stets Abzeichen und Embleme anzulegen pflegen. DaB das „Trinkgelage“ im Traum - als Adrijans stilisierter Aufnahme zum Freimaurermeister ausbleibt -, stellt zwar nach NERRE (1986) eine „Inkongruenz“ dar, ändert aber nichts an dem vollständigen Vollzug der Meisterweihe an Adrijan. ${ }^{24}$ Sein „Wegsterben“ im Moment des im Ritual des Traums bedrohlichen Herannahens einer feindlichen Menge führt zum Erwachen ('Stirb-und-Werde') in einer neuen Welt. Adrijan kehrt nach seiner "Meisterweihe“ in die vorherige, alte Welt nicht mehr zurück.

Keinesfalls sind die freimaurerisch-inspirienten Passagen in «Grobovšcik» (1830) nur auf Adrijans Traum beschränkt. In der ersten Begrüßung der beiden Handwerker wird offen das freimaurerische Symbol des "dreimaligen Klopfens“ ins Spiel gebracht. Für NERRE (1986) ist die Assoziation mit dem Freimaurertum sogar aus Adrijans Perspek-

des gestellten „Toten“ einen wichtigen Plat.

"1s NERRE (1986), 13-15.

416

Siche auch 32-35.

417

«Калитха была отперта, он пошел по лестницун. (PSS VI, 126 (Z. 24/25)) Auch LURKER

(1988) sicht in der Leiter/Treppe ein freimaurerisches Symbol. (419)

418

«Переступив 32 незнахомый порог». (PSS VI, 119 (Z. 17)

419

PSS VI, 126 (Z. 29); NERRE (1986), 15.

${ }^{200}$ Der gestellte Leichnam und Meisterkandidat wird von dem zweiten Aufseher aufgerichtet, wobei mehrere Körperberi'hrungspunkte zum Erhebungsritual gehören. Siche oben 26, 31, 33.

21 PSS VI, 127 (Z. 27-34) In der ursprünglichen Fassung war die Anrede atovarisč, die auch deo Grad eines Freimaurergesellen bezeichnet, nicht enthalten. (NERRE (1986), 16)

12

PSS VI, 124 (Z. 6).

100

Unter *Tosty», siche auch 31 (Anmerkung 90).

a

NERRE (1986), 18. 
tive heraus erzählt. ${ }^{\text {2s }}$ Darüber hinaus spielen noch Teile ritueller Sentenzen, der logenverwandte Charakter des Inventars der beschriebenen Gebäude sowie die stereotyp-freimaurerischen Gegensatzpaare in der Thematik ${ }^{4 x}$ auf die Bräuche der Freimaurer an.

Der These NERRES (1986), daB sich der Sargmacher Adrijan von dem Freimaurertum und dessen charakteristischer "Liebe zum Tod" infolge seines Traums abgewandt habe," ist jedoch nicht beizustimmen. Im Gegenteil: Die stilisierte Meisterweihe im Traum bewirkt die Läuterung Adrijans, die mit dem revidierten Leben-Tod-Verhältnis einhergeht. Damit vollzieht sich aber genau das, was dem Freimaurer erst mit dem Meisterweihe-Zeremoniell als Kandidaten bewuBt gemacht werden soll und eben mit der "Liebe zum Tod" allein nicht hinreichend beschrieben ist." Adrijans zunächst ungeläuterte Beziehung zum Tod, die aus seiner paradoxen Situation als emsiger Totengräber heraus verständlich ist, ${ }^{29}$ kehrt sich nach seinem Erwachen um: Die Trjuchina ist noch nicht verstorben, und er freut sich darüber. Seine Töchter, die schon zur Silberhochzeit bei Gotlib Sul'c mit leuchtenden Farben ${ }^{400}$ (Leben) erschienen waren und zum Kaftanträger Adrijan (Tod) einen Kontrast bildeten, dürfen sich nach seinem Erwachen erstmals seiner Aufmerksamkeit erfreuen. Diese durch den Traum initiierte Läuterung (als einer neuen Hinwendung zum Leben in der gedanklichen Überwindung des Todes) kann aber auch ebensogut allein in dem geträumten Meisteraufnahme-Ritual und somit im Freimaurertum begründet sein.

Daher muß auch die Frage nach dem Charakter des «Grobovšcik» als einer „Parodie auf das Freimaurertum" (NERRE) offen bleiben. In der Tat entbehrt Puskins kommentarlose Reduzierung des „Freimaurer-Symbolischen“ auf das „Konkret-Dingliche, das

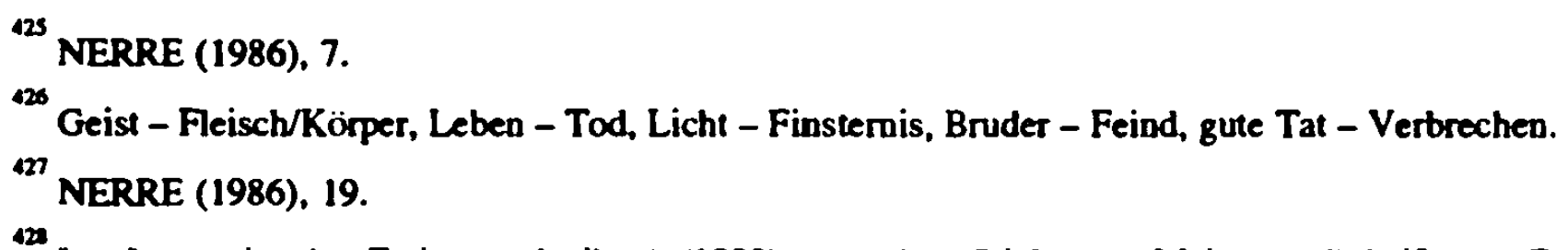

Im .Internationalen Freimauretexikon" (1932) unter dem Stichwort "Meistergrad" heißt es: „Der Meistergrad heibt den Freimaurer, Stellung zum Problem des Todes nehmen, der im freimaurerischgeistigen Sinne nicht Vernichtung bedeutet, läßt den zu erthebenden Gesellen die Zusammenhänge von Leben, Tod und Auferstehung im Sinne des Goetheschen „Stirb und Werde!” erleben (...). In allen Riten aber enthäh der Grad die Lehre von der Erhebung des Guten im Menschen durch die Kraft der fünf Meistertugenden: Weisheit des Herzens, Wahrheit in Worten, Vorsicht im Handeln, Unerschrockenheit bei unvermeidlichen Ubeln, unermuidlicher Eifer in Bewirkung des Guten. Die Ubersetzung aus dem Mystischeo in das Ethisch-Humanitäre zeigt sich also darin, $\mathrm{daB}$ an die "Stelle der mystischen Vergewisserung der Unsterblichkeit die Pflichterfüllung bis zum Tode als Voraussetzung fut die Gewinnung der Lebenskrone gesetzt und die Erlösung nicht im Mystischen gesucht wird, sondern in der tapferen Bejahung des Schicksals (...)." (LENNHOFF/POSNER (1932), 1018/19)

129

Pưłkin kündigt nämlich an, sein «Grobovsčik» sei kein fröhlicher Mensch, was eigentlich gane der Tä́igkeit seines Handwerks entspreche. (PSS VI, 120 (Z. 9-16)) Auch die Auswahl des Titels Krobovzzik - Puskin hatte, soweit bekannt ist, zu keiner Zeit mit einem anderen geliebäugeh - verstäht die traditionelke Assoziation des Helden mit seinem „düsteren Handwerk“. 
Vordergruindig-Realistische “" nicht einer gewissen Komik. DaB Adrijan (im Sinne einer Selbststilisierung Pußkins wegen der identischen Initialen zwischen Autor und Held A.S.P.) sich jedoch vom Bund innerlich gelöst haben soll, woraus eigentlich erst eine poetische Distanz zum Freimaurertum als einer aufklärerisch-sittlichen Bewegung entstünde, ist indes nicht zu halten. ${ }^{432} \mathrm{Da}$ diese Bedeutungsebene aufgrund der Personenkreisbezogenheit dieser Männerbundtradition nur von aktiven Eingeweihten dechiffriert werden kann, ergeben sich allerdings zumindest verschiedene Lesarten des Traums:

1. Für den Nichteingeweihten liegt der Grund für die Läuterung Adrijans in der mythisch-traumatische Vorstellung des lebendigen Leichnams als mahnenden "Wiedergänger". 133 (Läuterung durch Angst)

2. Für den Kenner oder eingeweihten Meister (mindestens 3. Grad) wind dieser Wiedergänger als läutemde rituelle Mahnung des Freimaurertums verstanden. (Lăutenung durch das Ritual des Männerbundes)

Somit kann der Traum im «Grobovšxik» nicht als „Parodie auf das Freimaurertum" (als Objekt der Komik), sondem muß zuvorderst als versteckte Verarbeitung des freimaurerischen Meisterrituals (wie auch seiner sittlichen Ziele) durch GeheimbundAllusionen im Traum Adrijans begriffen werden. Dieses Verständnis wird durch vorherige Anspielungen auf das Freimaurertum vorbereitet.

Freimaurerische Substrukturen lassen sich noch in einem weiteren prosaischen Werk Puskins entdecken. Es ist die amerikanische Forschung, ${ }^{4 x}$ die sich dieser Frage in «Pikovaja dama» (1833/34) gezielt annimmt. Puškin verfaßte seine «povest'» - wie auch den «Grobovšcik* (1830) - nach dem endgültigen Verbot der Männerbünde in RuBland

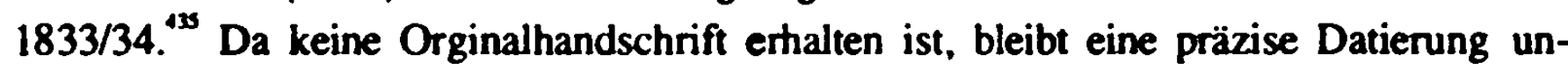
möglich. Das Sujet geht mutmaßlich auf Angaben zurück, die der Enkel der Gräfin N. P. Golicyna, die ihrerseits die Mutter des Moskauer Generalgouverneurs war, Puškin ge-

431

NERRE (1986), 19.

432

NERRE (1986), 19.

433

LURKER (1988), 738. (,Totenbrauchtum)

${ }^{434}$ Mit der Freimaurerei in Pußkins «Pikovaja dama* (1833) beschäftigten sich: WEBER, H. B.: Pikovaja dama: A Case of Freemasonry in Russian Literature, in: SEEJ 12, 435-47; LEIGHTON, L. G.: Gemwia in "The Queene of Spades": A Decembrist Puzzle, in: SEEJ 21 (1977), 455-69; LEKGHTON, L. G.: Puskin and Freemasonry: "The Queen of Spades", in: GUTSCHE, G. J. REIGHTON, L. G.: New Perpectives on Nineleenth-Century Russian Prose, Columbus/Ohio 1982, 15-25; LEIGHTON, L. G.: Puxkin and Marlinskij. Decembrist Allusions, in: Russian Literature 14/15 (1983), 351-82; LEIGHTON, L. G.: Freemasonry in Russian Literature: Nineteenth Century, in: The Modern Encyclopedia of Russian and Soviet Literatures 8 (1987), 36-42; W. SCHMID: „Pique Dame” als poetologische Novelle, in: Die Welt der Slawen 42 (1997), 1-33. 
genüber gemacht hatte. ${ }^{430}$ Dieser gab an, einmal im Spiel verloren zu haben, woraufhin der seine GroBmutter um Geld gebeten habe. Die Gräfin Golicyna habe ihm damals zwar kein Geld gegeben, ihm abet dafür immerhin drei Karten genannt, die ihr einst Graf Saint-Germain in Paris zugefluistert hatte. ${ }^{37}$

Neben der Verarbeitung dieses Sujets finden sich in «Pikovaja dama» (1833/34) sowohl Beziige auf bekannte Freimaurer, Einstreuungen freimaurerischer Symbole, Parallelen zu einer auf die kabbalistischen Traditionen zurückgehende freimaurerische Zahlensymbolik wie auch - sicher nicht ohne Verbindung zu dem drei Jahre zuvor entstandenen «Grobovšik» (1830) - Strukturen der freimaurerischen Meistererhebung im Rahmen der Hiram-Legende. Zunächst seien die Hauptstränge der Handlung zusammengefaBt.

Von der „alten Gräfin“ wird im ersten Kapitel erzählt, daß ihr in Paris von dem als Mystiker bekannten Grafen Saint-Germain drei unfehlbare Karten genannt wurden, als sie wegen einer hohen Kartenspielschuld in Verlegenheit war. Ihr Kartengeheimnis, das die Gräfin nicht einmal nächsten Verwandten preisgegeben hatte, will der deutschstämmige Hermann um jeden Preis ertrotzen. Dazu erschleicht er sich das Vertrauen der armen Gesellschafterin der Gräfin, Liza, und dringt in Abwesenheit der Alten in ihr Haus ein, um der Aufgelauerten nach ihrer Ankunft das Geheimnis abzuringen. Nach mehrmaligem, vergeblichem Bitten zieht er zur verschärften Bedrohung die Pistole, woraufhin die verstummte 87jährige vor Schreck stirbt. Hermann nimmt am Begräbnis teil, wo die Tote ihm in einer ersten Vision zuzublinzeln scheint. In der folgenden Nacht kommt ihm abermals eine Erscheinung. Hier weiht die verstorbene Gräfin Hermann in das Geheimnis der drei Karten (Drei, Sieben, As) ein. An drei aufeinanderfolgenden Tagen setzt Hermann in dem berühmten Salon Cekalinskijs jeweils auf eine von den drei Gewinnkarten ( $\ltimes$ Sonika») und gewinnt die ersten zwei Male. Am dritten Tag, er verliert das entscheidende dritte Spiel, blinzelt ihm in einer dritten Vision statt der gesetzten Gewinnkarte "As" die „Pique Dame“" $\mathrm{zu}$, in der er die alte Gräfin zu erkennen glaubt, woraufhin er im letzten Kapitel wahnsinnig wird und stirbt.

Mit den bekannten Mystikem Graf von Saint-Germain, ${ }^{48}$ Giacomo Casanova, ${ }^{49}$ Ema-

436

Die Angaben úber diesen unbenannten, realen Enkel überlieferte P. I. Bartenev (1829-1912), der Begribder der schon zitierten historischen Zeitschrift «Russkij archiv». Er konnte sich auf mündliche Äuberungen Pułkins berufen, die dieser P. V. Našokin gegenüber gemacht hatte. (PSS VI, 773 (primetanija); RAAB (1982), IV, 486)

437

PSS VI, 773 (primexanija).

434

Saint-Germain behauptete, in die höheren Grade der Freimaurerei eingeweiht zu sein und grindete in Frankreich Logen, die - entgegen der Programmatik einer orthodoxalen Freimaurerei - auch Fraven zulieben (LENNHOFF/POSNER (1932), 1372/1373). Saint-Germain, der sich als "Ewiger Jude“, als Erfioder des Lebenselixiers und als Hưter des Steins der Weisen ausgab, eröffnet in «Pikovaja dama* der alten Grifín das Kartengeheimnis, das dem Leser verschlossen bleibt. (PSS VI, Kap. I, 321/22)

439

Giscomo Casanova (1725-1798) gehörte nachweislich dem Bund der Freimaurer an. In seioen Memoireo schildert er seine Aufnahme in einer Loge in Lyon. In Venedig lieb ihn der Rat der Zehn im

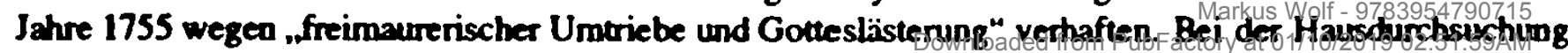


nuel Swedenborg ${ }^{40}$ sowie dem französischen Großlogenmeister Louis Joseph Philippe Herzog von Orlkans ${ }^{\text {"I }}$ evoziert Puskin zunächst Verbindungen zu gesamteuropäischmystischen Entwicklungen der Freimaurerei des 18. Jahrhunderts. Selbst orthodoxale Richtungen kommen in ihrer Geschichtsschreibung bis heute nicht umhin, diese Abenteurer abzuhandeln. ${ }^{42}$ Scheinbare Anspielungen auf zeitgenössische russische Freimaurer sieht WEBER (1968) auch in den stilisierten Gestalten in *Pikovaja dama*. ${ }^{\text {43 }}$ Unter den' Gründern der Loge «Les Amis rénis» vermerkt PYPIN (1916) auch die Namen von E. I. Caplix und P. P. Cekalevskij, "14 die nach WEBER (1968) Puskin in Caplickij und Cekalinskij $^{\text {ts }}$ umgeändert habe. Utberdies sehe er eine weitere Analogie in der Bezeichnung des Krankenhauses «buchovskaja bol'nica», in welchem Puskkins deutschstämmiger Held Hermann (nGermann») am Ende der Erzählung umkomme. Direktor dieses authentischen Krankenhauses war nämlich Dr. G. H. Ellisen, einer der Hauptakteure des Schismas in der russischen Freimaurerei von $1814^{400}$

Letzte Zweifel an der Intention Puskins, in «Pikovaja dama» vorkommende Gestalten mit der Freimaurerei in Verbindung zu bringen, lassen sich nicht ausräumen. Immerhin werden bei den zahlreichen Petersburger Maurem zehn Jahre nach dem Verbot des Bun-

lieB man gezielt nach freimaurerischen Beweisstiicken suchen. (LENNHOFF/POSNER (1932), 259) In «Pikovaja damaw werden diese Memoiren Casanovas zitiert. Demnach sei bekannt, daB Saint-Germain ein «కariatan» und $\alpha$ spion sei. (PSS VI, Kap. I, 321)

40

Emanuel Swedenborg (1688-1772) entwickelte nach Traumerlebnissen ein esolerischtheosophisches „System", das sich an kabbalistische Methoden anlehnte. Da er wie kein anderer EinfluB auf die mystischen Richtungen in der Freimaurerei ausübte, wurde er unweigerlich mit der Bewegung in Verbindung gebracht, obwohl er weder Freimauret war noch Logen gründete. Das taten aber seine Schdler. (LENNHOFF/POSNER (1932), 1538-1539)

MI

Der Cousin des Königs Ludwig XV., Louis Joseph Philippe Herzog von Orltans (1747-93), wurde Grobmeister der französischen Großloge. Ludwig XVI. protestierte 1774 gegen dessen Annahme dieses exponierten aber als kirchen- und staatsfeindlich betrachteten Amtes. Dies störte indessen den Herzog jedoch nicht. In der französischen Revolution wurde er Jakobiner und sagte sich 1793 als „Philippe Egalite" in öffentlicher Zeitungserklärung (Journal de Paris", 22.2.) von der Freimaurerei los, deren Freiheitsbegriff ihm zu wenig Realität harte: "J'ai depuis quitté la fantôme pour la rélite”. Im gleichen Jahr noch wunde er geköpft und danach fur die Dauer der Revolution die Arbeit der Logen in Fran'oreich verboten. (LENNHOFF/POSNER (1932), 1165)

42

LENNHOFF/POSNER (1932), 595-597. (,Geschichtsschreibung der Freimaurerei“)

43

WEBER (1968), 436.

4

PYPIN (1916), 387.

us Caplickij kommt in «Pikovaja dama* nur im Bericht Tornskijs als unglücklicher Spieler vor, und zwar als der, der durch die noch junge Gräfin verlorene Unsummen zuruckgewinnt, da sie ihm drei Gowinnkarten aennen kann. Dies tut sie nur unter der Bedingung, daB er nie wieder spielt. (PSS VI, Kap. I, 323) Cekalinskij dagegen erscheint in letzten Kapitel, wo es heiBt, er habe einer Moskaver „Gesellschaft reicher Spielen" vorgesessen und sein ganzes Leben beim Kartenspiel zugebrach. Zu ihm wird Hermann gefithrt und macht dort das entscheidende Spiel. 
des noch genügend Kenntnisse über die freimaurerischen Traditionen bestanden haben, die literarische Intentionen, mit der maurerischen Kultur zu spielen, rechtfertigen würden. Die Uberlegungen von WEBER (1968) haben aber auch insofern einiges für sich, da sich in «Pikovaja dama» weitere Strukturen entschlüsseln lassen, die mit den Bräuchen der freimaurerischen Männerbünde zusammenstimmen. ÄuBerlich besticht in «Pikovaja dama» zunächst die Dominanz bestimmter Zahlen. Die arme Liza, über die der Junggeselle an die alte Gräfin kommen möchte, zerreiBt am "dritten“ Tage den „dritten“ Brief." Die Lüftung des durch die Gräfin gehüteten Geheimnisses der "drei wahren Karten" ist Hermann zunächst nur eine Versuchung. „Berechnung, Sparsamkeit und Fleib“: das seien zunächst seine "drei sicheren Karten“, die zur „Verdreifachung" oder "Versiebenfachung " des ererbten Vermögens beitragen." Nach seinem Eindringen in die Gemächer der Gräfin bittet der nunmehr von der fixen Idee besessene Hermann sie drei Mal darum, ihn in das Geheimnis der "drei wahren Karten" einzuweihen." Beim letzten Mal kniet er sogar in ritualistischer Manier vor ihr nieder und beschwört sie bei ihren „Gefühlen als Gattin, als Geliebte, als Mutter ${ }^{400}$ nicht nur für ihn, sondern auch für seine „Kinder, Enkel und Urenkel"," ihm das Geheimnis der "drei wahren Karten“" preiszugeben. Diese werden ihm erst später als Drei-Sieben-As (3-7-1) bekannt. Auf anderen Ebenen sind diese Zahlen ebenfalls verarbeitet. Puškin unterteilt die Geschichte in sieben Teile ${ }^{452}$ und stellt in «Pikovaja dama» drei Hauptfiguren vor. Numerologische Gründe sieht WEBER (1968) daher in der „antiklimaktischen" Wiederkehr des dritten Helden Tomskij anstelle der vakanten Gräfin im letzten Abschnitt der Erzählung. ${ }^{\text {4s }}$ LEIGHTON (1987) weist darauf hin, daB diese Zahlenmystik (Dominanz der Drei und der Sieben) sich eng an die vor allem im Ritual verarbeitete Zahlensymbolik der Freimaurer anlehne, die - wie auch das Taro(t/ck)-Kartenspiel ${ }^{\text {ss }}$ - von der Kabbalah abstamme. ${ }^{45 s}$ Von dem orthodoxalen Frei-

47

PSS VI, Kap. III, $334 / 35$.

4s

«Нет! расчет, умереноость и трудолюбне: Вот мон три верные харты, вот что утронт, усемерит моһ̆ хапитал и доставит мне похой и незавнсимостъ!» (PSS VI, Kap. III, 331)

us

PSS VI, Kap. III, 340/41.

450

кТо умоляю вас чувствами супруги, любовницы, матерн, всем, что ни есть святого в хизни" (PSS VI, Kap. III, 340 (Z. 32-34)).

41

«Не тольхо я, но дети мон, внуки и правнукнж. (PSS 6, 341 (2. 9)

452 WEBER (1968) weist darauf hin, daB zuerst SHAW (1962) betoat habe, daB der siebte Teil («zaključeniex) für die Erzählung nicht streng notweadig sei, und dies köane bedeuten, daß Puskin diesen Teil alkin aus numerologischen Symmetricerwägungen heraus hinzugefugt habe (443), siche auch SHAW, J. T.: The 'Conclusion' of Puskin's "Qucen of Spades", in: Studies in Russian and Polish Literature (1962), 1196.

453 WEBER (1968), 443.

444 Nach LURKER (1988) sei das vierfarbige Spielkartensystem des Tarock (ital. tarocoo, frz. tarot) seit dem 14. Jahmundert nachweisbar und habe 78 Blärter. Den Tarock-Karen werde eine in Astrologie,

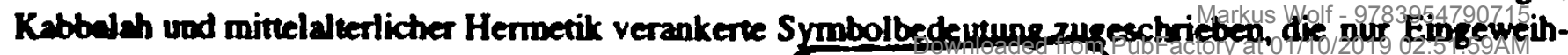


maurertum ist überdies bekannt, daB aus den esoterischen Bedeutungen der Kartenbilder des Taro(t/ck) Beziehungen zu den Initiationen der Freimaurer gesucht worden sind. ${ }^{46}$

An diese Verbindung von Glücksspiel und Wahrsagekunst im Kartenspiel ist in «Pikovaja dama» auch die für die Freimaurerei typische Hiram-Legende ${ }^{\text {(s7 }}$ gekoppelt: Hermann widerfährt mit der alten Gräfin in ihren Gemächern das gleiche Schicksal wie den Mördern von Hiram-Abif (dem freimaurerischen Märtyrer und Erbauer des Salomo- nischen Tempels), der lieber stirbt, als das Geheimnis der Handwerkszunft einer nichtorthodoxen Uberlieferung preiszugeben. Ohne ihm die geheimnisvollen Karten zu nennen, stirbt die Gräfin vor Schreck in dem Moment, als Hermann - um das Geheimnis ihret „Kartenkunst“ zu erpressen - die nichtgeladene Pistole zieht. WEBER (1968) weist erstmals auf die enge Beziehung der freimaurerisch-tradierten Hiram-Legende mit dem 'Geheimnis-Verweigerungs-Tod' der Gräfin hin. ${ }^{\text {'st }}$ Einmal in ihrem Haus, warte Hermann wie ein freimaurerischer Kandidat in einem kleinen "verdunkeltem Vorraum" auf sein Opfer. ${ }^{490}$ Dort fand er das Schlafzimmermobiliar in "trauriger Symmetrie" ${ }^{460}$ die nach WEBER (1968) die Stellung der diensthabenden Freimaurer in der Loge symbolisiere. ${ }^{401}$ Der rituelle Charakter der Szenerie wird zudem durch die periodisch wiederkehrende Angabe der Uhrzeiten verstärkt. ${ }^{402}$ Nachdem die Gräfin in ihrem Sessel Platz genommen hat, die Kerzen herausgetragen worden sind, hätte Hermann beobachtet, wie sie vor dem "Spiegel“ hin- und hergeschwankt sei. Diesen „verborgenen Galvanismus“ sieht WEBER (1968) im Kontext mit den beweglichen Skeletts in dem Vorraum der Loge, die den Kandidaten im Meisterritual mahnen sollen. Auch sonst sei die Ähnlichkeit zu einem rituellen Totenkopf deutlich: der Schädel des Kandidaten werde für den stillen Betrachter zu einem „grauhaarig-kurzgeschorenen Kopf ${ }^{c^{403}}$ und „toten Gesichr" ${ }^{404}$ der Gräfin. Au-

ten verständlich sein solle. Der zweifache Gebrauch der Karten - Spiel und Wahrsagung - sei immer untrennbar gewesen, wobei sich eine esoterische Ausdeutung anbietet.

455

LEIGHTON (1987), 39.

4s6

LENNHOFF/POSNER (1932), 1554/55. (.Taro**)

457 Zur Bedeutung der Hiram-Legende für das Freimaurertum, siehe oben 32-35, 39, 92.

158 WEBER (1968), 439/40 und in Anlehnung an ihn: LEIGHTON (1982), 18-20 und (1987), 39.

459

«Но он воротился и вошел в темный кабинет». (PSS VI, 338 (Z. 10/11))

$\infty 0$

кПолинялые штофные кресла и диваны с пуховыми подушками, с сошедшен позолотою, стояли в печальной симметрии около стен, обитых китайскими обоями". (PSS VI, 337 (Z. 24-26))

$\$ 61$

WEBER (1968), 440.

162

«Время шло медленно. Все было тихо. В гостиной пробило двенадцать; по всем комнатам часы однн 39 друтими пронзвонили двенадцать и все умолкло опять» (...) кЧасы пробили первы и и второй час утра». (PSS VI, 338 (Z. 12-19)

(6)

"Седоя и плотно остриженной головы". (PSS VI, 338 (Z. 34$) / 339$ (Z. 1))

164

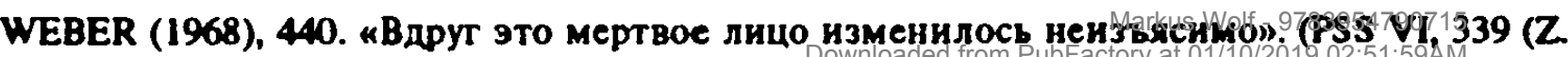


Berdem wird, nach WEBER (1968), ihr gespenstisch-unmenschliches Schweigen während der ganzen Szene nur durch eine einzige Äußerung unterbrochen.

Wenngleich sich auch nicht - wie in «Prorok* - direkte Sentenzüberschneidungen mit freimaurerischen Ritualen, aufzeigen lassen, so schwört doch Hermann der Gräfin - wie ein Meisterkandidat vor einem Grobmeister -, das Geheimnis "wie ein Heiligtum" zu ehren. ${ }^{406}$ Am Ende dieser Szene vollfühn Hermann einen weiteren rituellen Akt. Von Lizas Zimmer aus kann er nur über die "Wendeltreppe"," die ihn abermals in das Schlafzimmer der Gräfin führt, über eine Geheimtreppe ins Freie gelangen. Der "Schlüssel“, den Hermann von der verliebten Liza für die Geheimtreppe empfängt, findet sich in verschiedenen Traditionen wie auch in der freimaurerischen Symbolwelt wieder. ${ }^{406}$ Das gilt ferner für die „Rose“, die eine junge Schönheit in ihrem Haar auf einem Portrait trägt. ${ }^{400}$ Die Frauenhaube, die die ehemalige „Venus moscovite“ vor ihrem Spiegel abnimmt, ist gleichermaBen ,mit Rosen beschmückt". ${ }^{40}$ Die späteren Ereignisse vorwegnehmend sind diese "Rosen" als Sinnbild der Schönheit an dieser Stelle auch geeignet, in freimaurerisch(-rosenkreuzerischer) Lesart die baldige Wiederkehr der sterbenden Gräfin anzukündigen. ${ }^{4 n}$ Beim Totenamt in der Kirche ist die verstorbene Gräfin in einem "Sarg" auf einem „reichen Katafalk“ aufgebahrt; darüber befindet sich ein "samtener Baldachin“."

20))

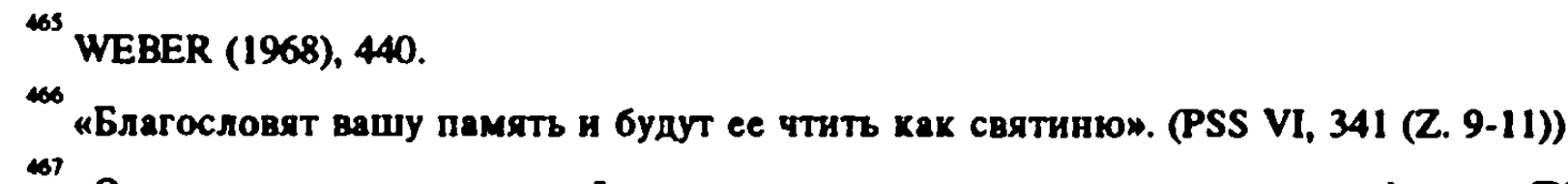

"Он спустился вннз по внтой лестнице и вошел опять в спальную графнни». (PSS VI, 346 (Z. 6)) Die "mystische Wendeltreppe" spielt im englischen System im II. Grad eine starke symbolische Rolle. Sie fand sich im "Salomonischen Tempel", der für die symbolischen Handlungen da "Johannismaurerei" wichtig ist, bestand aus drei, füf und sieben Stufen und fuhrte zurm Eingang in die mittlere Kammer, d.h. zum Alkertheiligsten. Dort wurden nämlich die Gesetze und der Name Gottes arbewahn. (nach I Kö 6,8) (LENNHOFF/POSNER (1932), 1696)

set.

In manchen Systemen symbolisiert der Schlüssel in Analogie zur formähnlichen Zunge die Verschwiegenheit. Im schwedischen System ist er auch ein Abzeichen der Meisterwitirde. Als elfenbeinerner Johannismeisterschlussel dient er symbolisch zum ErschlieBen des Herzens als der wohlverwahrten Schatzkammer des maurerischen Geheimnisses. Er öffnet aber auch den Eingang zU alkn Johannis-, Lehrtings-, Gesellen- und Meisterlogen. Im IV. und XIII. Grad des Schottischen Ritus spieh der Schlítssel eine wesentliche Rolk. (LENNHOFF/POSNER (1932), 784; 1396/97)

$\infty$

«Друтои - молодою храсавнцу с орлиным носом, с зачесанными висками и с розоюо в пудреных волосахн. (PSS VI, 337 (Z. 32/33))

40

«Графння стала раздеваться перед зерхалом. Отхолнли с нее чепец, ухрашеннын розамнж. (PSS VI, 338 (Z. 32/33))

411

Bei den Rosenkreuzern wie bei den Johannismaurern steht die Rose futr die Schönheit wie auch fitr die Sehnsucht des Menschen nach einem höheren Leben. (LENNHOFF/POSNER (1932), 1329/30. "Wiodergecturtssymbor")

4n 17/18))

«Гроб стоял на богатом хатафалхе под бархатным балдахнномМ. (PSS VI 347 (Z. 
Neben dem im Meisterritual üblichen Sarg, der schon in «Grobovšcik» eine 'freimaurerische Nebenrolle' gespielt hat, gehört der „Baldachin“ in manchen Systemen ebenfalls zum Inventar einer Freimaurerloge. ${ }^{43}$ Nachdem die Gräfin Hermann in der dritten Vision erschienen ist und ihm drei Karten genannt hat, begegnen die Ziffern der geheimnisvollen Karten ihm noch in anderen Formen: Auf die Frage, wie spät es sei, antwortet er. „Fünf Minuten vor Sieben“." In seinem Traum blüht die "Drei" üppig wie eine "große Blume", die "Sieben" erscheint ihm wie ein "gotisches Tor" und das "As" als eine "Riesenspinne"." Neben der Verwendung der den Freimaurern heiligen Schlüsselzahlen $(3,5,7)$, die mitunter für den Lehrling/Gesellen/Meister stehen, könnte für die Frage nach der Uhrzeit auch die rituelle Feststellung der Zeit des Meisters bei Ritus(-Eintritt/Austritt) gedient haben..$^{77}$ Die üppige Blume («pyšnyj grandiflor»), die Hermann im Traum mit der "Drei“" verbindet, wird zwar nicht näher bezeichnet. Dennoch hält WEBER (1968) es für sehr wahrscheinlich, daB auch sie eine verborgene, freimaurersignifikante Rose sei." Im Vergleich mit dem „gotischen Tor" sieht WEBER (1968) nicht nur eine intendierte Assoziation mit einer Kathedrale, sondern vor allem mit dem „Salomonischen Tempel“, der als Lehrbild für die symbolische Tradition der Freimaurer sehr wichtig ist."

In Anlehnung an die Ergebnisse WEBERS (1968) hat auch LEIGHTON (1982) in «Pikovaja dama» allusive Kryptonyme des Namens 'Kondratij F. Ryleevs', ${ }^{479}$ dem Freimaurer und 1826 hingerichteten Dekabristen, aufgespürt. ${ }^{20}$ Diese versteckten Anagramme gehen nach Leighton auf die kabbalistische Kunst des Gematria zurück, wonach mit Hilfe der Zahlenwerte der Buchstaben eine geheime Botschaft in den Texten entziffert

473

Der Baldachin als der von den Säulen getragene Himmel über dem Meistersitz oder der ganzen Loge als Zeichen des Himmels oder zum Zeichen der Universalitït der Freimaurerei. (LENNHOFF/POSNER (1932), 119) Von PYPIN (1916) ist bekannt, daB der Baldachin die von Jakob im Traum erblickte Himmelskeiter (1 Mose 28, 121) symbolisien und eine Verbindung zwischen Erde und dem Himmel herstellt. (65) Siehe oben $34 / 36$.

${ }^{74}$ «У него спрашивали: (Который час?), он отвечал: ббез пяти мииут семерка)н. (PSS VI, Kap. VI, 351 (Z. 14/15))

a7s

«Троиха цвела перед инм в образе пышного грандфлора, семерка представлялась потичесхнми воротами, туз - огромным паухом". (PSS VI, Kap. VI, 351 (Z. 18-21))

476

Im aufsteigenden Ritus (siehe oben Stufe Ib); im absteigenden Ritus (siehe oben Stufe VI).

an

WEBER (1968), 442/43.

47

WEBER (1968), 442; LENNHOFF/POSNER (1932), 1565-68, bes. 1567. ROSEN (1975) sieht dagegen in dem traumatischen Vergleich keine Assoziation mit freimaurerischen Implikationen, sondem eine Analogie zur Farbe 'Pique' im nussischen Kartenspiel von 1830, das sich auch bei ihm abgebildet findet. Seine 'Pique Dame' häl auch eine Rose in der Hand. (ROSEN; N.: The Magic Cards in the Queen of Spades, in: SEEJ 19 (1975), 255-75, hier 261/264/266)

479

Det Dichterfreund Puskins war dem Freimaurerbund sehr ergeben, nachdem man ihn 1820 in der Loge "Etoile flamboyante" aufgenommen hatte. (BAKUNINA (1967), 465/66)

$\infty$

LEIGHTON (1977), 455-65, hier 460/61; LEIGHTON (1982), 21) Markus Wolf - 9783954790715 
werden kann." Die Anagramme finden sich im dritten Kapitel in der Passage, wo Hermann vor dem Haus der Gräfin wartet. Unter Berücksichtigung der Zahlenwerte 3 und 7 lassen sie sich wie folgt entschlüsseln: Mit dem 21. Wort (drei Mal Sieben) beginnend, dient eine Kette von sieben aufeinanderfolgenden Worten als Grundlage für das Anagramm Kondratij F. Ryleevs:

кветер выл, мокршй снег падал хлопьяма; фонарнж."

[,Der Wind wehte, nasser Schnec fiel in Flocken; Laternen."]

Die ersten drei und das siebte Wort bilden die Silben:

«ветер выл, мохрый фонарнн.

Durch Umstellung läßt sich dann nach LEIGHTON (1982) der Name (ko nra ti fy le ev) bei numerierter Reihenfolge wie folgt rekonstruieren:

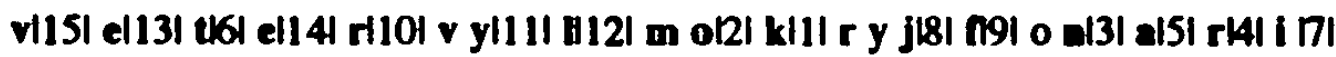

vmryo

Von den darin enthaltenen zwanzig Buchstaben werden nur fünf nicht verwendet. Von diesen wiederum kommt nur der zweite (m) überhaupt nicht vor. Leighton gibt für «Pikovaja dama» weitere kryptogrammatische Beispiele für den Namen des mit Puskkin befreundeten Dekabristen:

«Фонарн светились тусхло; улицы были пусты.» ${ }^{483}$ । «Ваньха на тощей хляче своећ, высматривая запоздалого седоха." графнинну харету подали Германн вндел ках лақен вынесли под рухин. " І жрыхлому снегу. Швейар запер дверн.» ${ }^{4}$ жработы слав ного Лероы, хоробочкн, Аулетки, веера и разные дамские игрушки, изобретенные в концен.

Die gematrische Praxis war unter Gold- und Rosenkreuzern wie auch bei den russischen Freimaurem des 18. Jahrhunderts üblich." ${ }^{42}$ Die These, daB Puskin gerade den Namen des Dichters, aktiven Freimaurers und hingerichteten Dekabristen Kondratij F. Ryleev in «Pikovaja dama” "krypt(onym)isch" verarbeitet haben könnte, ist nicht abwegig. In seinem Briefwechsel ist der Name 'Ryleev' vor dem Dezember 1825 hăufig, dann

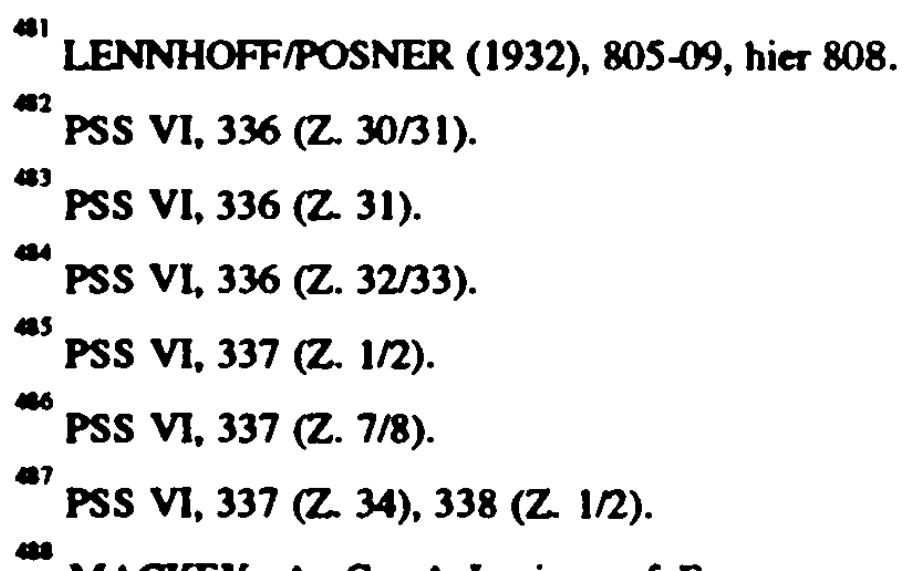
(1982), 21. 
zuletzt bis Ende November 1825 selten und danach nicht mehr vermerkt. ${ }^{45}$ Diesen in seinem Euvre nach dem gescheiterten Putsch 'buchstäblich' zu verstecken, könnte ein legitimes Verfahren sein, seinem Freund wenigstens über dessen Tod hinaus ein literarisches Andenken zu bewahren.

Selbst wenn Kryptogrammtiken nicht jeden überzeugen und immer eine Spur der Ungewißheit anhaftet, bleibt die Tatsache, daß Puškin in «Grobovšcik» (1830) und der Er- . zählung «Pikovaja damas rituelle Elemente des Freimaurertums zur Gestaltung von Schlüsselszenen verwendet hat. Der Werdegang der alten Gräfin deckt sich mit dem Schicksal Hiram-Abifs, der allein durch Freimaurer tradierten Märtyrer-Legendengestalt. Anstatt das Geheimnis seines/ihres Handwerks dem verbrecherischen Erpresser zu offenbaren, stirbt et/sie mehr oder minder direkt durch die Hand des von dem Geheimnis Besessenen. Hermanns Insistieren, das Geheimnis zu ertrotzen, kulminiert in dem rituellanmutenden Kniefall mit den an die Gräfin gerichteten Sentenzen, die an die Eidesformel des Freimaurer-Neophyten erinnern. Potentielles Logeninventar (Dunkle Kammer, Wendeltreppe, Sarg) und freimaurerische Symbole (Schlüssel, Rose als Wiedergeburtssymbol) haben in «Pikovaja dama» einen für den Gang der Geschichte wichtigen Stellenwert. Daran schließen sich die reichlich verarbeiteten, magischen Zahlen (Drei, Fünf, Sieben) und Kartenfarben (As, Pique Dame) an, denen prädestinativer Charakter zukommt. Eine allusive Botschaft, die nur für Eingeweihte der gematrischen Praxis zu entschlüsseln ist, bildet in Form einer kryptischen Inskription des Namens 'Kondratij F. Ryleev' den SchluBpunkt.

Am Ende sei noch auf eine thematische Parallele zu "Grobovšcik» hingewiesen. Die Verarbeitung des freimaurerischen Rituals dient in beiden Werken dem Kulminationspunkt einer Konfrontation der Hauptfigur mit seinem visionären Gegenüber, das ihm einmal lebendig, einmal tot erscheint. 'Lebendiger Tod' (Leichnam) wie auch 'totes Leben' treten in ein rituelles Verhältnis zu dem Helden, dem es um die Kunst eines Handwerks (Bestattungs- bzw. Kartenspiel-Handwerk) zu tun ist.

Es bleibt zu fragen, was die Intention für so viel Freimaurerei in «Pikovaja dama» sein könnte. Sicher ist, daB unter den Zeitgenossen Puškins nur praktizierende Freimaurer und nur Kenner von Verräterschriften diese Bezüge auf das Freimaurertum erkennen konnten. WEBER (1968) hat zu zeigen versucht, daB diese Erzählung in mancher Hinsicht als 'Parodie auf das Freimaurertum' zu lesen sei, zumal emste Passagen - unter der freimaurerischen Folie besehen - sich als komisch, ja grotesk erweisen. Schließlich werden Teile freimaurerischer Ritualistik übertrieben und durch ihre Übertragung in Puskins literarische Welten verzerrt: Die Martyriums-Legende, die in der Männerbundtradition symbolisch an dem Gesellen vollzogen wird, bekommt im künstlerischen Text eine alte Frau zum Hauptakteur, während ein Dilettant, ohne eine festgelegte Ordnung oder einschlägige Tugenden zu beachten, das Geheimnis regelwidrig erschleichen will. 
Wenn die Parodie mehr ist als eine Überführung eines bestimmten Details - unter Beibehaltung seiner äußeren Form - in einem artfremden Bereich zum Zwecke der Verspottung oder nur bloßer Distanzierung kann sich der Verfasser dieser Arbeit der Lesart einer Parodierung freimaurerischer Inhalte (als Objekt der Komik) in «Pikovaja dama» (WEBER 1968) wie zuvor auch in «Grobovšcik» (NERRE 1986) nicht anschließen. Freimaurerische Elemente sind nicht nur eng mit dem Gang der Geschehnisse verbunden, sondern in diesen Werken sogar verstecktes Leitmotiv des Geschehens. Sie lassen sich nicht ohne Verlust des Ganzen wegdenken. Die Parodie will das Parodierte auf eine bestimmte Weise entlarven, bloßlegen und auflösen; von einer Entstellung freimaurerischer Inhalte kann aber bei Puškin nicht die Rede sein. Die grundsätzliche Anwendung des 'Parodie'-Begriffs hält auch SCHMID (1997: 11) für verfehlt, weil „Ironie bei Puskkin nicht mit Dekonstruktion verbunden" sei.

Neben der Parodienung einer Männerbundtradition käme für Pußkkin noch ein anderes Motiv in Betracht. Sollte die Kryptonymisierung des Namens des hingerichteten Dekabristen Kondratij $F$. Ryleev ein vom Autor intendiertes und kein posthum hineingelesenes und damit konstruiertes Faktum sein, wären Puškins Verarbeitungen freimaurerischer Inhalte insgesamt als kryptogrammtische Verfahren zu lesen, mit der erreicht wird, daß freimaurerische Inhalte nur für Eingeweihte dechiffrierbar dort weitergetragen werden, wo dies zu einem Tabu erklärt worden ist. Von daher wären Puškins GeheimbundAllusionen der literarische Versuch dem Freimaurentum eine decodierte Würdigung zuteil werden zu lassen. Der Name Ryleev stünde bei dieser Lesart Puškinscher Bezüge auf den Männerbund ganz obenan. Bis zum Aufstand der Dekabristen im Dezember 1825 bewahrte Ryleev auch nach dem Verbot der Männerbünde freimaurerische Dokumente bei sich auf und war davor, wie bekannt ist, der Bewegung nahezu ergeben." 


\section{Geheimbund-Allusionen in Pưkkins Aufsätzen, Tagebüchern und Briefen}

\section{Puškins kritische Schriften und Aufsätze}

In einem nicht beendeten Brief an den Herausgeber des «Moskovskij vestnik» gibt Pułkin 1828 zu, daB er beim Abdruck des 1824/25 verfaßten Dramas «Boris Godunov» darauf hingewirkt habe, jene Textstellen auszusparen, die AnlaB zu Auslegungen, An- spielungen und „allusions" (hier französisch zu lesen, Anm. d. Verf.) geben könnten." Verborgene Hinweise im künstlerischen Text gehörten nicht nur im *Boris Godunov» zu Puskins poetischem Repertoire."

Daß das Freimaurertum Puškin auch nach dem Dezember 1825 noch beschäftigt hat, ist auch durch Allusionen in seinen kritischen Schriften und Aufsätzen belegt. In einem beklagt er das Nichtvorhandensein der russischen Literaturkritik:

«Лттература у нас существует, но хритихи еще нет. У нас хурналисты браняться имением романтик, хак старушки бранят повес франмасонамн и волтернанцами не имея понятия ни о Вольтере, ни о Франмасонстве."
[.,Die Literatur gibe es bei uns, aber keine (Literatur-)Kritik. Bei uns streiten sich Journalisten über den Namen des Romantikers, wie alte Mütterchen Windbeutel als Freimauret und Voltairianer beschimpfen - ohne einen Begriff von Voltaire oder einem Freimaurer zu haben."]

Die Gegenüberstellung, zu der Puškin greift, um das Niveau der zeitgenössischen Joumaille und der Literaturkritik in RuBland zu beurteilen, ist für die Untersuchung von höchstem Interesse. „Wie die alten Mütterchen über Windbeutel, die Freimauret und Voltairianer streiten, ohne freilich einen Begriff von Voltaire oder den Freimaurem zu haben“, genauso kämpfen, nach Puškin, die Literaturtheoretiker „um die Romantik". Offenbar reklamien Puskin für sich eine exakte Vorstellung von dem, was ein Freimaurer ist und grenzt sie an dieser Stelle von den Vertretern progressiv-aufklärerischer Bewegungen und dem religiösen Freidenkertum à la Voltaire ${ }^{\text {tos }}$ deutlich ab. Außerdem setzt er hiermit ein bestimmtes Verständnis für diese aphoristische Differenzierung bei seinen Lesem voraus, ${ }^{4 \%}$ da diese Unterscheidung sonst unklar bliebe. Das Vorwissen, das

42

"Хотите ли знать, что еще удерживает меня от напсчатания моей трагедин? Те места, хои в нен могут податъ повод применениям, намехам, allusions». (PSS VII, 75 (Pis'mo k izdatelju «Moskovskogo vestnika*, 1828))

43

In «Boris Godunov» waren allerdings keine Hinweise auf freimaurerisches Ideengut entdecken. 44

PSS VII, 513. («Zametki $\mathrm{i}$ aforizmy raznych godov» 1829)

495

Der Begriff des "Freidenkertums" bïgerte sich in Frankreich um 1714 mit dem Termimus "librepenseu cin. Voltaire fithre - offenbar in Anlehnung an "franc-macon" - den Begriff ,franc-penseur" ein. RITIER, J. (Hrsg.): Historisches Wörterbuch der Philosophie, Bde. 1-12 [bish. ersch. 1-9 1970-1997], 2, 1062. ("Freidenker")

Die Unterscheidung dieser beiden aufklärerischen Bewegungen war 20 Zeit Puskkins, wie VER-

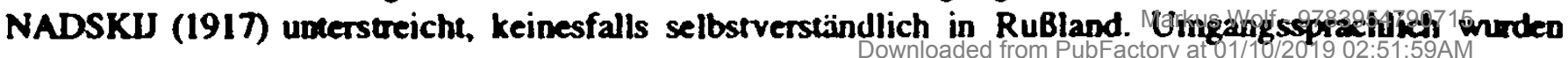


Puškin impliziert, könnte daher überspitzt lauten: Die meisten wissen, daB Freimaurer nicht - wie die Voltairianer - Feinde der orthodoxen Kirche und der feudalen Ordnung in RuBland sind.

Im Jahr 1830 zitiert Puß̌kin Teile des soeben erschienen Almanachs «Dennica», worin er eine Abhandlung des jungen Schriftstellers und Philosophen I. V. Kireevskij lobend erwähnt. Eine Passage ist dem Aufklärer und Karamzin-Lehrer, N. I. Novikov, gewidmet. Ohne diesen als Hauptvertreter des Rosenkreuzerbundes ${ }^{m}$ zu erwähnen, greift Puskin Kireevskijs Worte auf: Novikov habe in RuBland erstmals das Bedürfnis zu lesen geweckt. Nach Karamzin habe es nämlich zu Anfang in Moskau nur zwei Buchhandlungen gegeben. Dank Novikov seien es wenige Jahre danach zwanzig gewesen. Auch auBerhalb Moskaus gab es sie plötzlich. Bücher, die er für wichtig gehalten hatte, seien zu einem Spottpreis vertrieben worden, und das Vaterland Zeuge eines aufklärerischen Ereignisses gewesen: „Die Geburt der öffentlichen Meinung“.." Puškin zitiert diesen Passus ohne weiteren Kommentar. Noch Monate vor seinem Tod plante er einen Aufsatz über die Bibliothek Novikovs, der im «Sovremennik» erscheinen sollte. Doch kann Puskin dieses Projekt nicht mehr beginnen.

Die Freimaurer interessieren Puškin in seinen letzten Lebensmonaten auch noch an anderer Stelle. Ende 1836 verfaßte er über Radiščev einen Artikel, ${ }^{300}$ der ebenfalls für den «Sovremennik» bestimmt war. ${ }^{501}$ Darin verfocht er die These, Radišcevs skandalumwittertes Werk «Putešestvie iz Peterburga v Moskvu» (1790), ihn bei Ekaterina II. zum Aussätzigen werden ließ und dafür schwer bestraft worden war, ginge auf den EinfluB der Martinisten zurück. In Folge seines Auslandsaufenthaltes sei der junge Radiščv nämlich in diese Gesellschaft geraten. Von diesen Martinisten habe es in RuBland nur noch wenige Veteranen gegeben. Puškin zufolge charakterisierte diese "halbpolitische, halbreligiöse Gesellschaft jedenfalls „eine seltsame Mischung aus mystischer Frömmigkeit, philosophischen Freidenkertums, selbstloser Liebe zur Aufklärung und praktische

die Bezeichnungen «volter'janec» und «famazon» vielmehr synonym gebraucht. (99) Pußkin verzichtet an dieser Stelle auf die pejorative Verballhomung afarmazon». Bekanntlich verwendet ex sie nur im «Evgenij Onegin* zur Charakterisienung seines Helden aus der Perspektive der miBtrauischen Landhevölkenung. Indem er aber hier die freimaurerische Eigenbezeichnung \&franmason» wählt - ein russischer Gallizimus - wird ersichtlich, daB er sehr wohl zwischen der Bewegung, der er einst angehörte, und den Gerichien tber die Freimaurer zu unterscheiden weib.

497

Uber die Rolk Novikovs in der Geschichte det nichtpolitischen Geheimblinde siehe LENNHOFF/POSNER 1932: 1134/35).

$\infty$

«Рохдення общего мнения». (PSS VII, 109/10)

${ }^{499}$ PSS VII, 536.

100

aleksandr Radiscev». (PSS VII, 349-60; Ubertagen in Anlehnung an die Ubersetzung von MIERAU, FJ PFEIFFER, M.: A. S. Puschkin: Aufsätze und Tagebucher, Berlin 1984, 205f.) 
Menschenliebe ${ }^{402} .^{502}$ Menschen, die aus heimtückischer Verleumdung ihren Nutzen ziehen, hätten versucht, diese Martinisten als verbrecherisch-politische Verschwörer hinzustellen. Nach der französischen Revolution habe Ekaterina II. die Martinisten argwöhnisch beobachtet. Diese habe sie für „Prediger der Anarchie“ und „Adepten der Enzyklopädisten“ gehalten. ${ }^{303}$ Viele von ihnen zählten zwar zu den Unzufriedenen, doch ihr Unbehagen habe sich lediglich in "verdrießlicher MiBbilligung der Gegenwart", "unschuldigen Hoff- . nungen auf die Zukunft" und „doppeldeutigen Trinksprixchen auf den freimaurerischen Abendgesellschaften" geäußert. "Das Geheimnisvolle ihrer Unterhaltungen habe Radišcevs Phantasie entzindet. Nach der Lektüre des unter diesem EinfluB entstandenen Buches habe Ekaterina II. zu Chrapovickij über Radiš̌̌ev fälschlicherweise behauptet: „Er ist Martinist, er ist schlimmer als Pugačev (...)" Puß̌kin hatte für diesen letzten Artikel zum Thema „Martinisten“ bzw. Freimaurertum" von seinem Zensor keine Druckgenehmigung ethalten. Und das, obwohl er sich zu großen Zugeständnissen bei der Darstellung der Person Radišcevs bereit gefunden hatte.

Resümierend läßt sich über den Aspekt der Freimaurerei in Pułkins Aufsätzen folgendes festhalten: Anspielungen auf politische wie nichtpolitische Männerbünde stellen für ihn eine nicht nur literarische sondern auch publizistische Versuchung aber auch eine politische Gefahr dar. Einer strengen persönlichen Zensur ${ }^{\text {sos }}$ unterworfen, schreibt er einen Artikel ab, der den namhaften Novikov in verherrlichender Weise als Volksaufklärer schildert. Dieses wird zwei Jahre später mit einem Artikel, der Radiščev mit harmlosen nichtpolitischen Männerbünden in Verbindung setzt, veröffentlicht. In einem Aphorismus stellt er Freimaurer dem umstürzlerischen Voltairianismus gegenüber. Da diese Stellungnahmen zur Freimaurerei wie zum orthodoxalen Freimaurertum alle nach 1826 entstanden sind, ist deutlich, daß Pußkin auch nach dem Dekabristenaufstand noch sehr gut zwischen politischer Verschwörung, schwärmerisch-religiösem Freidenkertum und orthodoxalem Freimaurertum zu unterscheiden verstand und diese Differenzierung auch bei seiner Leserschaft wie selbstverständlich voraussetzte.

502

«В то время сушествовали в России люди, известные под имением мартинистов. Мы еще застали несхолько старихов, принадлежавших этому полуполитическому, полурелигиозному обществу. Странная смесь мнстической набохности и фнлософнческого вольнодумства, бесхорыстная лкоов х просвещеиию, практическая филантропия ярко отлғчали их от похоления, хоторому они принадлежали". (PSS VII, 352 (Z. 15-23))

503

PSS VII. 352 (Z. 23-31); 353 (Z. 1-3).

504

PSS VII, 353 (Z. 4-8).

$\operatorname{sos}$

In wekhem Mabe Pußkin der persönlichen Zensur unterworfen gewesen ist, geht aus einer Tagebuchnotiz woch aus dem Jahr 1834 hervor, worin er sich beklagt, daB der $\mathrm{Zm}$ sich nicht schäme, Puskkins Briefe a seine Frau zu lesen: «Однахо хахая гл убокая безнравственность в прнвычхах нашего правительства? Полиция распечативает письма мужа х жене и прнносит их читать царью (человеку благовоспитанному и честному), и царь не стыдиться в том прнзнаться (...)». (PSS VIII, 50 (Z, 23-28) 


\section{Puskins Tagebücher und autobiographische Schriften}

Eine Notiz in Puß̌kins Kißinever Tagebuch ist bereits in der Gliederung dieser Untersuchung in Erscheinung getreten: «4 мая был я принят в масоны». ${ }^{306}$ Dabei ist auf die exakte Formulierung zu achten. Puskkin spricht nicht davon, in einer bestimmten Loge aufgenommen, sondern lediglich "von den Maurern angenommen" worden zu sein. Den exakten Namen der Loge «Ovidij» erwähnt er an keiner Stelle seines Gesamitwerkes. Zeugnisse über sein Zusammentreffen mit den zu der damaligen Zeit legal-aktiven Freimaurem finden sich auch in anderen Einträgen seines Kißinever Tagebuches.

Am 9. April trifft er den Führer der Dekabristen, Pavel I. Pestel', den er als „einen der originellsten Köpfe", mit denen er zusammengetroffen sei, erlebt. Mit ihm unterhält er sich über Metaphysik, Politik und die Moral. Ende Mai trifft er im Hause Inzovs Pušcin ${ }^{\text {soe }}$ und seinen Freund Alekseev, einen der wenigen engen Vertrauten, die der Loge «Ovidij» angehört haben. Spätere autobiographische Aufzeichnungen nehmen nicht mehr Bezug auf die Freimaurerei.

Der Grund für die spärliche Berücksichtigung des aufklärerischen Männerbundes in den biographischen Werken muß aber im Kontext eines Fragments gesehen werden, das Puškin im Herbst 1834 in Boldino angefertigt hat. ${ }^{509}$ Darin berichtet er, daß er sich seit 1821 mehrere Jahre mit seiner „Autobiographie“ beschäftigt habe, infolge des Dekabristenaufstandes Ende 1825 aber diese Aufzeichnungen habe verbrennen müssen. Zwar bedauere er diesen Verlust zutiefst, da er historische Persönlichkeiten beschrieben habe. Doch sah er sich zu diesem Schritt gezwungen, wären diese Dokumente doch geeignet gewesen, die Zahl der Opfer noch zu vergrößern. ${ }^{510}$ In diesem Zusammenhang ist daher der nur geringe Stellenwert des Freimaurertums in Puškins autobiographischen Schriften zu sehen. Puškin hatte also guten Grund bei der Vernichtung des Materials nicht zwischen politischen und nichtpolitischen Geheimbünden zu unterscheiden, wie wir dies in dieser Analyse getan haben, da die offiziellen zaristischen Stellen dies nach 1822 auch nicht mehr taten.

${ }^{507}$ PSS VIII, 18 (Z. 14).

Und das, trotzdern nach Einstellung ihrer "Arbeir einige Biicher der Loge «Ovidij» in Puskins Besitz ubergegangen sind. Die Zeichnungen, die Puskin von den gehängten Dekabristen angefertigt hatte, befinden sich in diesen, als Logenbiucher bestimmten Kladden. (NEVELEV, G. A.: Istina sil'nee Carja (...) (A. S. Puskin v rabote nad istoriej dekabristov), Moskva 1985, Abb. 96/97)

P. I. Puxxin, offiziell der Begründer der Loge wOvidij».

PSS VIII, 76-82 (Nacalo avtobiografii). 
22. Briefe vor und nach dem Verbot aller Logen (1.8.1822)

Bis zu seiner wahrscheinlichen "Einweihung" in das Brauchtum des Freimaurertums (4.5.1821) verfaBt Puskin nur 18 Briefe; und in denen findet sich keinerlei Bezug zur freimaurerischen Männerbundtradition. Wenn Onkel Vasilij" seinen Neffen Aleksandr in einem Brief als seinen „Bruder" bezeichnet, und der siebzehnjährige Puß̌kin diese Anrede in einem Antwortschreiben verwirft, ${ }^{\text {s/2 }}$ könnte daraus abgelesen werden, daB Puškins Onkel auf eine künftige Mitgliedschaft von A.S.P. schon früh hinzuwirken versucht hat. Doch abgesehen davon und den Anspielungen auf den 'Arzamas', die schon in Verbindung mit Pußkkins früher Lyrik zum Teil behandelt worden sind, ${ }^{\text {s!3 }}$ finden sich auch in den weiteren 14 erhaltenen Briefen, die Puškin vor dem endgültigen Verbot aller Logen (1.8.1822) verfaßt hatte, keine Anhaltspunkte auf den russischen Freimaurerbund. $^{\text {s1d }}$

\section{Briefe nach Puß̌kins Kenntnis vom Dekabristenaufstand (Anfang 1826)}

Wie aus seinen Briefen hervorgeht, bekommt Puškin erstmals Mitte Januar 1826 Kenntnis von den Ereignissen des Dekabristenaufstandes. Mit einem Schreiben an seinen Freund und Literaturkritiker P. A. Pletnev ${ }^{\text {sis }}$ bittet er diesen, Žukovskij zu fragen, ob er (Pułkin) auf die ,allerhöchste Gunst des Zaren“ rechnen dürfe. Seit sechs Jahren befinde er sich schon in Ungnade. Nur wegen ,Zweier atheistischer Zeilen" habe ihn der verstorbene Zar auf das Land verbannt, und ,anderer Streiche“ sei er sich schlieBlich nicht bewuBt. ${ }^{\text {S16 }}$

Wenige Tage später richtet er eine Botschaft an seinen Freund und Dichterkollegen V. A. Zukovskij. ${ }^{\text {st7 }}$ Darin entschuldigt er sich zunächst vorab, ihm nicht vorher geschrieben zu haben, weil sich "keine passende Gelegenheit“" geboten habe." Darin bittet er Žukovskij, sich beim Zaren nunmehr persönlich für ihn zu verwenden, und zwar daB er der

S11 Ober den freimaurerischen Werdegang von Vasilij L'vovic Puskin und iber das nichtverwandtschaftliche Bruderverhältnis zu V. L. Puskin in einem frühen Gedicht A. S. Puskkins siehe oben 16, 55. 68.

«В письме Вагшем Вы назвали меня братом; но я ие осмелился назвать Вас этим имением, слишком для меня лестным». (PSS X, 10 (3. V. L. Pußkkinu, 28.12.1816))

313 Siehe oben $5 / 61$.

${ }^{514}$ PSS X, 39. Der ketate Brief vor dem Dekabristenaufstand geht an seinen Bruder und seine Schwester. (32. L. S. Puskinu i O. S. Pußkinoj, 21.7.1822)

PSS X, 197. (181. P. A. Pletnevu, nicht später als 25.1.1826)

516

PSS X, 197. (Z. 14-19)

${ }^{517}$ PSS X, 198/199. (183. V. A. Zukovskomu, 20.1.1826)

S18

PSS X, 198. (Z. 8/9) 
„Verschwörung" nicht angehöre und zu den "Aufrührern vom 14. Dezember keine politischen Beziehungen" unterhalten habe. Um nicht doch noch politischer Gespräche mit einem der Angeklagten überfüht zu werden, gibt er Žukovskij "Beweise" an die Hand, die seine reumütige Haltung unterstreichen und seine Unschuld dokumentieren sollen:

«В Кяшаневе я был друхен с майором Расвским, с генералом Пушиным и Орловым. І я был масон в Кишиневсхов̆ лохе, т.е. в тон, за хоторую уничтохевы в Россин все лохн. I Я наховец был с связн с большею частью нынешних заговорииков. I Похоһный император, сослав меня, мог тольхо упрекнуть меня в безверни.»"
„In Kisinev war ich befreundet mit dem Major Raevskij, mit dem General Puscin und Orlov. I Ich war Maurer in der Kisinever Loge, das heiBt in jeber, wegen der alle anderen Logen in RuBland abgeschaff wurden. I SchlieBlich war ich in Verbindung mit dem Grobteil der derzeitigen Verschwörer. I Der gnädige Zar konnte, nachuem er mich verbannt hatte, mir nur meinen Unglauben vonwerfen."]

Mit diesen freiwilligen Bekenntnissen steckt Puškin den politischen Problembereich ab, der ihn in den Augen der Regierung kompromittieren könnte. In Kiß̌nev sei et mit "Major Raevskij sowie den Generälen Puščin und Orlov" befreundet gewesen, außerdem habe er als „Freimaurer der Loge in Kißinev" angehört, wegen der „alle anderen Logen in Rußland" geschlossen worden seien. Letztlich habe er mit dem „gröBten Teil der jetzigen Verschwörer in Verbindung" gestanden. Die Verbannung, die der verstorbene Zar angeordnet habe, sei nur durch den Vorwurf der „Gottlosigkeit" begründet worden.

Der ursächliche Zusammenhang zwischen der Schließung der Loge «Ovidij» und der 1822 erfolgten Schließung aller Logen in Rußland, den Puškin an dieser Stelle herstellt, ist nicht belegt. Unter Berücksichtigung seiner zu diesem Zeitpunkt höchst gefährdeten Lage scheint aber diese politische Charakterisierung der nichtinkorporierten Kißinever Freimaurerinstitution durchaus verständlich: Auch wenn Puškin Žukovskij am Schluß seines Briefes auffordert, sein Schreiben zu verbrennen, so muß er doch auch bedacht haben, die Zensur könne seinen Brief zu Gesicht bekommen. Da staatlicherseits Freimaurerlogen nicht nur in Rußland und nicht erst seit 1822 zumindest als verdächtig gegolten haben, wäre es zu diesem Zeitpunkt von Puškin unangebracht, nicht in diese politische Diskreditierung einzustimmen. Die Freimaurer der Loge «Ovidij» scheinen bis heute eher nur unscheinbare Gestalten und eben keine Verschwörer gewesen zu sein. Sollte der Grund für das Ende aller Freimaurerlogen im zaristischen Rußland aber dennoch in Kišinev zu suchen sein? Puškins obiger Nachsatz läßt die Annahme zu, daß die politischen Ambitionen der Logenmitglieder nicht die Ursache dafür gewesen sein muBten. ${ }^{520}$

Fünf Monate nach dem Brief an Žukovskij wird Puškins demütig-offenherzige Hal-

siv PSS X. 198. (Z. 34/35); 199 (Z. 1-6)

520

Aus dem Brief Volkonskijs an Inzov geht hervor, diß die Regienung seinerzeit befirchtete, daB neben Puscin noch ein wichtiger General namens Tuxkov den Logen des kampfgefährdeten Südens beigetreten was, woraus sich aus der Ferne nahezu zwangsläufig die strategischen Bedenken der Regierung einstellen mubien. (siehe oben 61/62,75) 
tung in Sachen Geheimgesellschaften der Regierung gegenüber ein weiteres Mal deutlich. Diesmal sogar persönlich gegenüber Zar Nikolaj I. ${ }^{\text {S21 }}$ In seinem Schreiben bittet er diesen, sowohl aus Gründen seines nunmehrigen Besserungswillens wie auch aus Krankheitsgründen nach Petersburg oder Moskau zurïckkehren zu dürfen. Auf einem gesonderten Blatt verpflichtet er sich, fürderhin keiner Bündelei («tajnoe obšcestvo») anzugehören und erklärt, keinen Geheimgesellschaften dieser Art angehört und nichts von ihnen gewußt haben.

Das erhaltene Briefkorpus ließe den Schluß zu, daß sich Pußkin weder vor noch nach dem Verbot der freimaurerischen Männerbünde zu den "Mitbridern“ der Loge «Ovidij» wie $\mathrm{zu}$ anderen Mitgliedem des Bundes einer typischen Briefform ${ }^{32}$ bedient hat. Sieht man einmal von Alekseev ab, hat Puškin mit keinem „Logenbruder" auch nur korrespondiert. Kommentare über Geschichte, Sinn und Zweck der Bewegung - in Schriften aktiver Maurer weit verbreitet - fehlen ebenfalls. Direkte Angaben über seine Mitgliedschaft in der Loge in Kiß̌nev lassen sich nur nach dem Dezember 1825 ausfindig machen. Diese Angaben sind aber allein dadurch motiviert, sich in verdächtiger Lage gegenüber einer Regienung gütlich zu zeigen, die infolge der politischen Ereignisse zwischen wohlwollend-sittlichen Männerbünden und umstürzlerischen Verbänden nicht mehr unterscheiden kann. Mit dem abschließenden Blick auf diese Verhältnisse sei die These erlaubt, daB Puskin alles Geschriebene über die Freimaurerei vemichtet hat und zwar mit Ausnahme jener Teile, die ein in bezug auf die Behörden und den Zaren entlastendes Bild von ihm in Sachen unrechtmäBiger Freimaureraktivitäten entwerfen. 


\section{KAPITEL VI ZUSAMMENFASSUNG}

Am Schluß dieser Arbeit, die sich die Untersuchung der literarischen Bezige auf freimaurerische Geheimbünde in Puskins Euvre zum Ziel gesetzt hat, seien die wichtigsten Ergebnisse nochmals rekapituliert. Ein methodischer und historischer Teil, die zusammen den begrifflichen und inhaltlichen Bezugsrahmen absteckten, bildeten die unabdingbare Voraussetzung für die Analyse des lyrischen, prosaischen, literaturkritischen und autobiographischen Werkes, ergänzt durch Puxkins Briefe.

Die Unterscheidung zwischen einer verkörperten und nichtverkörperten Symbolik der Freimaurer sowie der Terminus 'Geheimbund-Allusion' wurde vor dem Hintergrund eingeführt, das logenintern-rituelle Geschehen, stereotyp-rituelle Dialogwendungen und Logenutensilien als spezifisch freimaurerische Symbole identifizieren und analysieren $\mathrm{zu}$ können.

Eine breite Berücksichtigung der freimaurerischen institutionellen und personellen Geschichte beinhaltete die Beschreibung des historischen Kontextes, in dem Puskins Werk zu sehen ist. Besondere Sorgfalt wurde dem historischen Abschnitt deshalb zuteil, weil die wissenschaftliche Beschäftigung mit dem Freimaurertum als einem aufklärerischnichtpolitischen Männerbund in Rußland wie auch in anderen Ländern noch am Anfang steht.

Die Analyse der Werke bemühte sich um eine Anbindung an die Biographie Puškins und auch an die allgemeine Geschichte des russischen Freimaurertums im frühen 19. Jahrhundert. Die Ergebnisse seien hier zusammengefaßt:

In Puskins früher Lyrik, bis zum Zeitpunkt seiner in dem Kiß̌inever Tagebuch vermerkten Aufnahme als Freimaurer (4.5.1821), sind, abgesehen von Anspielungen auf den Arzamas, keinerlei Bezüge auf die „königliche Kunst" nachweisbar. Auch in der Zeit bis 1836 sind nur zwei Gedichte auf den „Bund“ ausgerichtet: es sind dies “Generalu Pušcinu» (1821) und «Prorok» (1826).

Die ersten Verse, in denen Facetten logenintemen Brauchtums und auch der aufklärerischen Ziele der Freimaurer verarbeitet sind, finden sich in «Generalu Puščinu» (1821); ein Widmungsgedicht, in dem der Begründer der Loge «Ovidij» und Stuhlmeister General Pavel I. Puščin verewigt worden ist. Der Logenmeister, der den „Hammer" als Logenutensil in der Hand hält, steht in thematischer und syntaktischer Opposition zu der „dunklen Stadt" Kišinev, auf die sein (durch Puškin unterstelltes) Streben nach freimaurerischer Aufklärung abzielt. In ironischer Absicht stellt Puskin den General auf die gleiche Stufe mit KiSinev, in dem er die Stadt als Person anspricht und sie auffordert, sich den Zielen des überzeugten Maurers anzuschließen. DaB det Pušcin (in den Mund gelegte) Ausruf „Freiheir" ( SSvoboda! ) nicht nur politisch, sondem auch als freimaurerische Lehrformel verstanden werden kann, ergibt sich aus der freimaurerischen Allegorik des logeninternen Geschehens.

In «Prorok» (1826) kommen dagegen neben semantischen Indizes, die von der behandelten Bibelstelle in Jesaja abweichen und für die freimaurerische Eidesformel typisch 
sind, auch Motive des Meister-Erhebungsrituals vor, die eine Bewußtseinswandlung der Hauptfigur in dieser Erzählung Puskins umrahmen. In poetischer Anlehnung an die freimaurerische Meistererhebung durchläuft Puškins werdender (Dichter-)Prophet das bewuBtseinserneuernde "Stirb-und-Wende" zur Erlangung einer höheren Natur, indern er, in Abweichung vom Bibeltext, aufgefordert wird, sich - wie ein Meisterkandidat am Ende des freimaurerisch-rituellen Geschehens - zu erheben, jetzt allendings innerhalb des poetischen Geschehens der Erzählung. Hierfür wurde das poetologische Verfahren verwendet, freimaurerische Rituale in ein poetisches Geschehen zu überführen.

Im «Evgenij Onegin» (1823-30) wird Puskins Hauptfigur Evgenij als neuer Nachbar aus der Perspektive der miBtrauischen Landbevölkerung als «farmazon» charakterisiert. Mit dieser Verballhornung der Bezeichnung des Freimaurers assoziierten zeitgenössische Leser unweigerlich die reichlich vorhandenen, mündlich tradierten abergläubischen Vorstellungen über die freimaurerische Bewegung. Der einzelgängerische Onegin wird als Anhänger eines sektiererisch-mystischen Männerbundes dargestellt; auf logeninterne wie historisch-externe Aspekte des Freimaurertums wird im Spiegel abergläubischer Vorstellungen Bezug genommen.

Puskkins Vergiftungsdrama «Mocart i Sal'eri» (1830/31) hat die Gerïchte der damaligen Zeit auf eine literarische Ebene und damit zu einer Quelle von beinahe historischem

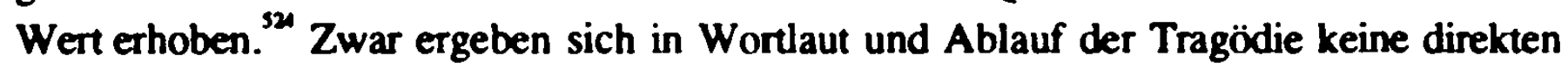
Parallelen zum freimaurerisch-rituellen Brauchtum. Puskin bedient sich darin aber einer Allegorik, die als freimaurerisch gewertet werden kann. Sie kulminiert in der Äußenung Salieris gegenüber dem aktiven Freimaurer Mozart, daB Beaumarchais nicht zu dem „Handwerk der Vergiftung" fähig sei. Die „Handwerkskunst", die bei Salieri zuvor für sein Schöpfertum als Komponist stand, wird somit am Ende der zweiten Szene zum allegorischen Motiv der ,handwerklichen Vergiftung“. In Erfüllung einer angeblich ,heiligen Pflicht" wird die „Handwerkskunst" Salieris zur "Mordkunst" am einzelgängerischen Genius Mozart, wozu sich die (angedeutete) Mär eines angeblich periodisch wiederkehrenden freimaurerischen Logen- oder Ritualmordes analog verhält. Anzutreffen sind hier allegorische Geheimbund-Allusionen und - wie zuvor beim «Evgenij Onegin» (1830) die Verarbeitung abergläubischer Vorstellungen über das Freimaurertum.

Für die Analyse der Erzählung «Grobovščik» (1830) konnte auf eine detailliente Untersuchung der freimaurerischen Elemente in diesem Werk von ELKE NERRE (1986) zurückgegriffen werden. NERRE (1986) versucht zu zeigen, daB das Traumerlebnis Adrijans dessen Abwendung vom Freimaurertum bewirkt habe. Die von der Autorin unterstellte 'Parodierung des Freimaurertums' als geschlossener Bewegung ist jedoch nicht plausibel. Wie in «Prorok» (1826) ist auch in *Grobovscik» (1830) das Motiv des 'Stirb-und-Werde' als BewuBtseinswandlung des Helden im Rahmen des freimaurerischen Meisterrituals verarbeitet (logenähnlicher Charakter des beschriebenen Behau- 
sungsinventars; das sich bewegende und sprechende Skelett als lebendiger Leichnam, freimaurerische Anredeformen). Doch werden diese Geheimbund-Allusionen („Dreimaliges Klopfen“ nach Art der Fremaurer, rituelle Dialogwendung: «Kto tam?») in der Prosa des «Grobovscik» (1830) weiterentwickelt. Das freimaurerische Meisterritual wird hier in ein erzählerisches Geschehen transformiert, wobei die Hauptfigur Adrijan ein bewußtseinserneuerndes 'Stirb-und-Werde' an sich erfâhrt. Diese literarisiente 'freimaurerische Meisterweihe' bildet nicht nur einen Umbruchpunkt für das literarische Geschehen sondern auch eine Folie für das gesamte Werk. Die Erzählung «Grobovšcik» (1830) verbindet unter freimaurerischen Gesichtspunkten mit dem Drama «Mocart i Sal'eri» (1830/31) die thematische Verarbeitung des den Tod begrüßenden, mit ihm „arbeitenden" Handwerks.

«Pikovaja dama* $(1833 / 34)$ ist das dritte Werk, und neben *Grobovšxik» das zweite prosaische, in dem Elemente des Meisterrituals eine hintergründige Rolle spielen. Wie in «Grobovšik» (1830) wird die Hauptfigur mit einem mal lebendigen, mal toten visionären Gegenüber konfrontiert. Neben dieser um das Oxymoron des 'lebendigen Todes' und des 'toten Lebens' entfalteten Beziehung, spielen in diesem Werk zahlreiche Gestalten eine Rolle, die der Geschichte der europäischen wie russischen Männerbünde entliehen sind. Beziige zu Kernelementen des Freimaurertums sind offensichtlich und beziehen sich zum Beispiel auf 'Logenutensilien' (Wendeltreppe, Schlüssel, Sarg, Baldachin, Totenkopf), die 'Rose' als freimaurerisches Wiedergeburtssymbol, auf 'Ziffern' der freimaurerischen Grad- und Zahlensymbolik (Drei - (Fünf) - Sieben) oder auch die Kartenwahrsagekunst und die 'Initiationen' des Freimaurertums. Auch hier ist die hartnäckige These einer 'Parodierung des Freimaurertums' - hier durch WEBER (1968) - als das entscheidende Moment seiner literarischen Einspielung nicht überzeugend. Alle Elemente sind zu stark an den Gang der Erzählung gebunden, als daB eine satirische, kritische oder polemische Absicht Puskins erkennbar wäre. Die Transformationen des freimaurerischen Rituals in das literarische Geschehen spielt in dieser Erzählung die entscheidende Rolle:

Hirams Tod steht im Meister-Ritual der Freimaurer Pate für das Ableben der alten Grăfin, was als Märtyrentod aufzufassen ist. Sie verweiger Hermann die Preisgabe des Kartengeheimnisses und stirbt. Unerheblich bleibt, daB sie nicht durch eine Kugel aus der Pistole Hermanns, sondem vor Schreck den Tod erleidet. Mit ihrem Tod erfüllt sich auch innerhalb des poetischen Geschehens das freimaurerische Meister-Ritual des 'Stirb-undWerde'. Bezeugt wird dies durch die Bewahrung des Geheimnisses und durch das Wiedergeburtssymbol der Rose im Haar der Gräfin. Soweit besteht noch eine Úbereinstimmung zwischen dem Gedicht «Prorok» (1826) und der Erzählung «Grobovšcik» (1830) und zwar hinsichtlich des poetologischen Verfahrens der Uberführung des freimaurerischen Meisterrituals in ein literarisch-poetisches Geschehen. Mit der Erzählung «Pikovaja dama» (1833/34) geht Puskin jedoch darüber hinaus. Denn hier thematisient er die Bewahrung des Geheimnisses bis in den Märtyrertod hinein. Die Weitergabe des Geheimnisses (durch Saint-Germain an die alte Gräfin, wie durch sie an Caplickij) wird zwar nicht an die formelle Zulassung zum freimaurerischen Ritual angebunden, jedoch an 
bestimmte Bedingungen: eine finanzielle Notlage sowie der einmalige Gebrauch des Geheimnisses.

Entfaltet wird dieses Motiv in den drei Visionen Hermanns, nachdem die Gräfin das Geheimnis mit in den Tod genommen hat. Als die Gräfin ihn in seiner ersten Vision aus dem Sarg heraus belustigt angesehen und das Auge zugekniffen hatte, wuBte Hermann das nicht zu deuten. Erst in der zweiten Vision nennt sie ihm die Geheimkarten (Drei - . Sieben - As). Doch in der entscheidenden Situation stellt sich heraus, daB die Einweihung in das Geheimnis nur eine Fiktion Hermanns war. Als es im Spiel um den höchsten Einsatz geht, wartet Hermann vergeblich auf die dritte Gewinnkarte. Statt dessen erscheint ihm die dritte Vision: das Bild der Karte 'Pique Dame' zwinkert mit den Augen und lächelt Hermann höhnisch an. Erst hier wird die Beziehung zur ersten Vision deutlich. Hätte ihm nicht schon damals gewahr werden sollen, daB die 'lebendige Tote' das Geheimnis niemals preisgeben wird? Nach dem verlorenen Spiel weiß er mit der Kartenkombination, in der er das enthüllte Geheimnis gesehen hatte, nichts mehr anzufangen und wird darüber wahnsinnig. Im Wahnsinn kann er die beiden Erlebnisebenen der Vision und des tatsächlichen Spielausgangs (Drei, Sieben, Dame) nicht unterscheiden. Unablässig wiederholt er. „Drei, Sieben, As! Drei, Sieben, Dame!c4s3 Er kann nicht begreifen, da $B$ das Geheimnis für ihn unzugänglich geblieben ist.

Stehen in Puskins Lyrik und Prosa eher das logeninterne Geschehen und die freimaurerische Symbolik im Vordergrund, wird in den Aufsätzen, Tagebüchern und Briefen vor allem sein Interesse am Freimaurertum als historischer Bewegung deutlich. Puškin beschäftigen hier einzelne Schicksale, die für die nicht zu entwirrende Beziehung zwischen offizieller Regierungspolitik und den nichtpolitischen (aber bei den Behörden angemeldeten!) Geheimbünden stehen, wie zum Beispiel das Leben des aufgeklärten Herausgebers und Rosenkreuzers Nikolaj I. Novikov. Dieser wurde inhaftiert, weil Ekaterina II. ihn wegen seiner Zugehörigkeit zu den Rosenkreuzem zu Unrecht als Revolutionär verdächtigte. Puškin zitiert ausführlich eine positive Würdigung des Aufklärers, wenngleich - mutmaßlich mit Rücksicht auf seine strengen Zensoren - ohne sie weiter zu kommentieren. Ein später Plan für einen Aufsatz über Novikovs Bibliothek, die damals in einzigartiger Weise Material zu den Männerbünden speziell in RuBland versammelte, läBt auf Pusklins fortwährendes Interesse an logeninternen Einzelheiten schließen.

Im Falle Radiš̌evs schätzte Puškin den Einfluß der Martinisten auf das für seine Person schicksalhafte Werk «Putešestvie iz Peterburga v Moskvu» (1790) hoch ein. Diese Männerbundbewegung schilderte er in seinem mutmaßlich aus Zensurgründen unveröffentlicht gebliebenen Artikel, det für den «Sovremennik» ${ }^{520}$ bestimmt war. Mit Blick auf das wenige Jahre zuvor geschriebene Drama «Mocart i Sal'erix (1830/31) erscheint der Bezug auf die für ihre Tradition typischen ,zweideutigen Trinksprïche“ der Martinisten besonders interessant. Der Artikel thematisiert vor allem den Irrtum der Zarin Ekaterina 
II., daB die eigentlich unpolitischen Martinisten politisch seien. Die Aufsätze mit ihren Anspielungen zeigen, daB die Männerbünde Puß̌kin auch auBertalb der eigentlichen literarischen Gattungen beschäftigt haben. Und das, obwohl solche Anspielungen immer mit der Gefahr verbunden waren, eine Veröffentlichung zu verhindern. Spärlicher nehmen sich die Ergebnisse der Untersuchung von Pußkins Tagebüchern aus. Doch findet sich hier der entscheidende Hinweis auf Puskins formelles Freimaurertum. Am 4. Mai 1821 verzeichnet er, daB er "bei den Maurem Aufnahme gefunden" habe. Es besteht eine große Diskrepanz zwischen der Hăufigkeit verschlüsselter Verweise auf das Freimaurertum in Puskins literarischen Werken und der Seltenheit von Angaben zu seinen persönlichen freimaurerischen Aktivităten. Deshalb erscheint es wahrscheinlich, daB sich in den autobiographischen Schriften, die Pußkin nach dem Dekabristenaufstand vernichten muBte, noch weitere wichtige Hinweise gefunden hätten. In den Briefen finden sich mehr Hinweise auf seine Mitgliedschaft, doch müssen auch diese stets im Zusammenhang mit Pußkins Schicksal nach Bekanntwerden des Dekabristenaufstandes gelesen werden: Weder korrespondiert er mit den einst KiY̌never 'Logenbrüdern', noch bedient er sich in seinen Briefen zu irgendeinem Zeitpunkt eines stereotypen 'Freimaurer-Codes', der unter Brüdern üblich ist. Erst politische Umstände zwangen ihn, gegenüber dem Zaren zu seiner eigenen Mitgliedschaft Stellung zu beziehen und sich zu offenbaren. Wie später auch der aus dem Ausland zurückkehrende Caadaev, verpflichtet er sich eidesstattlich, von jedet künftigen Mitgliedschaft in einem Geheimbund abzusehen.

Ohne Übertreibung läBt sich sagen, daß die hier untersuchten Werke Pußkins ohne seine Kenntnis freimaurerischer Symbolik und Ritualistik nicht vorstellbar sind. Pußkins freimaurerisch geprägtes Werk sollte aber nicht isoliert betrachtet werden. Die Analyse künstlerischer Texte nach Geheimbund-Allusionen, so wie sie hier vorgenommen wurde, könnte AnstoB sein, das Freimaurertum nicht nur als russisches, sondern als gesamteuropäisches Phänomen literarischen Schaffens zu entdecken. 


\section{LITER A T UR UBER S I CH T}

I. NACHSCHLAGEWERKE ZUM FREIMAURERTUM .................................... I

II. GENESE UND EXPANSION DES FREIMAURERTUMS ............................... II

III. FREMMAUREREI IN GESCHICHTE UND LITERATUR RUBLANDS .................... VIII

IV. MOTIVE DER FREIMAURERLITERATUR

V. MOTIVE DES FREIMAURERTUMS BEI PUSKIN ............................................ XXIX

I. NACHSCHLAGEWERKEZUM FREIMAURERTUM

\section{ALLGEMEINES HANDBUCH DER FREIMAUREREI}

(1900-1901) Verein deutscher Freimaurer (Hrsg.): Lennings Encyklopädie der Freimaurerei, Bde. 1-2, Leipzig.

BAKOUNINE [BAKUNINA], T.

(1967) Répertoire biographique des francs-maçons russes (XVIIle et XIXe siècles), Paris. (=Collection historique de l'institut d'Etudes slaves 19)

(1967) /BOURYCHKINE, P.: La franc-maçonnerie en Russie, Paris/La Hays. (=Etudes sur l'histoire, l'économie et la sociologie des pays slaves 11)

HAWKINS, E. L. A.

(1908)

Concise Cyclopaedia of Freemasonry; or Handbook of Masonic Reference, London.

HUTER, U.

(1981) Bibliotheca okkulta et masonica, München.

LANGLOIS, $P$.

(1983) Les mots de la franc-maçonnerie, Paris.

\section{LEBEDEV, $S$.}

(1994)

Mazurenko, N. V. (Hrsg.): Masony i vokrug nich: masonstvo na stranicach žurnala «More» za 1901-1917 gody. Annotirovannyj bibliografixeskij ukazatel', Sankt-Peterburg/Volgograd.

LENNHOFF, E./POSNER, 0.

(1932) Internationales Freimaurerlexikon, Geschichte, Wesen, Wirken und Geheimnis der königlichen Kunst, Wien. (ND München 1992)

LIGOU, D.

(1987) Dictionnaire de la Franc-Maçonnerie, Paris.

MACKEY, A. G.

A Lexicon of Freemasonry, London. 
MELLOR, A.

(1971) Dictionnaire de la franc-maçonnerie et de franc-maçons, Paris.

MIERS, H. E.

(1976) Lexikon des Geheimwissens, München.

MGZ.

(1995) Schloss Rosenau bei Zwettl. Freimaurer-Museum in Niederösterreich, in: Neue Zürcher Zeitung (IA), 20. April, 45.

RONAYNE, E.

(1955) Handbook of the Freemasonry (1876), Chicago.

SCHAUBERG, J.

(1861-63) Vergleichendes Handbuch der Symbolik der Freimaurerei mit besonderer Rücksicht auf die Mythologien und Mysterien des Alterthums, Bd. $1-3$, Schaffhausen.

SCHNEIDER, H(erbert)

(1977) Deutsche Freimaurer Bibliothek. Verzeichnis der Bibliothek des Deutschen Freimaurer-Museums Bayreuth, Hamburg.

SCHROEDER, W.

(1909) Handbüchlein für die Brr. Meister, Berlin.

(1909) Handbüchlein für die Brr. Lehrlinge, Berlin.

(1910) Handbüchlein für die Brr. Gesellen zum Gebrauch für die unter der Groß-National-Mutterloge , $\mathrm{Zu}$ den drei Weltkugeln" arbeitenden Logen von Wilhelm Schroeder, Berlin.

TROISI, L.

(1985) Dizionario massonico. Esoterismo-Ermitismo-Religioni-Miti-Simboli, Roma.

VALLERY-RADOT, $R$.

(1934) Dictature de la maçonnerie, Paris.

WATTE, A. E.

(1921) A New Encyclopaedia of Freemasonry (Ars Magna Latomorum) and of Cognate Instituted Mysteries: Their Rites, Literature and History, Vol. 1-2, London. (ND New York 1970/1994)

WOLFSTIEG, $A$.

(1911-13) Bibliographie der freimaurerischen Literatur, Bd. 1-4, Burg b. M. (ND Hildesheim 1964) 
II. GENESEUNDEXPANSION DES FREIMAURERTUMS

AGETHEN, $M$.

(1984) Geheimbund und Utopie: Iluminaten, Freimaurer und die deutsche Spätaufklärung, München.

BÄCHTOLD-STÄUBLI, H.

(1927-41) /HOFFMANN-KRAYER, E.: Handwörterbuch des deutschen Aberglaubens, Bd.1-10, Berlin/Leipzig.

BARTELS, A.

(1929) Freimaurerei und deutsche Literatur. Feststellungen und Vermutungen, München.

BAYARD, J.-P.

(1986) La franc-maçonnerie, Paris.

BERTHOLET, $A$.

(1976) Wörterbuch der Religionen, Stuttgart.

BIEDERMANN, $\mathrm{H}$.

(1986) Das verlorene Meisterwort. Bausteine zu einer Kultur- und Geistesgeschichte des Freimaurertums, München.

BINDER, D.

(1988) Die diskrete Gesellschaft. Geschichte und Symbolik der Freimaurer, Graz.

BOOS, $\mathrm{H}$.

(1969) Geschichte der Freimaurerei. Ein Beitrag zur Kultur- und LiteraturGeschichte des 18. Jahrhunderts (1906), Wiesbaden.

BÜHLER, J.

(1919) Freimaurerei und Katholizismus, München.

COIL, H. W.

(1973) A Comprehensive View of Freemasonry, Richmond.

DEITERS, H. G.

(1963) Die Freimaurer. Geheimnis und Enthüllung, München.

EDWARDS, $\mathbf{L}$.

(1956) Rule and teach, a practical handbook of masonic law and custom, London.

FARA

(1937)

Masonstvo i ego dejatel'nost', Charbin. 
FINDEL, G. J. G.

(1900)

(1905) Das freimaurerische Geheimnis als Norm maurerischet Tätigkeit. Eine Johannisfestgabe, Leipzig.

FISCHER, M. W.

(1982) Die Aufklärung und ihr Gegenteil. Die Rolle der Geheimbünde in Wissenschaft und Politik, Berlin. (=Schriften zur Rechtstheorie 97)

FRICK, K. R. H.

Die Erleuchteten: Gnostisch-theosophische und alchemistisch-rosenkreuzerische Geheimgesellschaften bis zum Ende des 18. Jahrlunderts. Ein Beitrag zur Geistesgeschichte der Neuzeit, Graz/Austria.

(1975) Licht und Finsternis: Gnostisch-theosophische und freimaurerischokkulte Geheimgeselischaften bis an die Wende zum 20. Jahthundert, Graz/Austria.

GANTNER, T.

(1983/84) Freimaurer. Schweizerisches Museum für Volkskunde/Basel. Ausstellungskatalog 1983/84, Basel.

GOULD, R. F.

(1951) The History of Freemasonry (1886), Vol. 1-4, London.

HAACK, F.-W.

(1988) Freimaurer, München.

HAMMERMA YER, L.

(1979) Zur Geschichte der europäischen Freimaurerei, in: BÁLAZS, E. H./ WAGNER, H./WOJTOWICZ, J.: Beförderer der Aufklärung̨ in Osteuropa. Freimaurer, Gesellschaften, Clubs, Berlin. (=Studien zur Geschichte der Kulturbeziehungen in Mittel- und Osteuropa 5)

(1980) Der Wilhelmsbader Freimaurer-Konvent von 1792. Ein Hihe- und Wendepunkt in der Geschichte der deutschen und europäiscren Geheimgesellschaften, Heidelberg. (=Wolfenbüttler Studien zur Aufklärung 5/2)

HANNUSCHKA, R.

(1940) Hinter der Maske der Freimaurerei. Mit Anhang: Erstmalige Veröffentlichung eines Rituals für den ersten Grad, Berlin-Schöneberg.

HECKETHORN, C. W.

(1875) The Secret Societies of All Ages and Countries, London. (Dt Leipzig 1900) 
HOLTORF, J.

(1983) Freimaurerlogen, München.

HOLTZ, G.

(1985) Die Faszination der Zwänge. Aberglaube und Okkultismus, Göttingen.

HORN, R.

(1980) Die Masonica der Bayerischen Staatsbibliothek München (-1945), München.

(1980) Studien zur deutschen freimaurerischen Historiographie des 19. Jahrhunderts, Bd. 1-2, München.

HORNEFFER, A.
(1914) Deutsche und ausländische Freimaurerei, München.
(1919) Heilige Arbeit, München. (=Am Bau 2)
(1948) Die Freimaurerei, Stuttgart.

HULTER, C.

(1911) Modeme Arbeitsgebiete der Loge, Lennep.

KERNER, D.

(1971) Mozarts Tod 1791/1971. 180 Jahre Mißbrauch einer Dokumentation, Mainz.

KESSLER, $H$.

(1977) Das offenbare Geheimnis, Freiburg.

KOSELLECK, $R$.

(1959) Kritik und Krise. Ein Beitrag zur Pathogenese der bürgerlichen Welt, Freiburg i. Br.München.

KRAUSE, K. C. F.

(1820) Höhere Vergeistigung der echt überlieferten Grundsymbole der Freimaurerei in zwölf Logenvorträgen von dem Bruder Karl Christian Friedrich Krause, Dresden.

LACHMANN, $\mathrm{H}$.

(1974) /SCHIFFMANN, G. A.: Hochgrade der Freimaurerei, Graz.

LANTOINE, $A$.

(1935) L' histoire de la franc-maçonnerie française: la franc-maçonnerie dans l'état, Paris.

LOBKOWICZ, P. F.

(1971) Die Legende der Freimaurer, Hamburg. 
MELLOR, A.

(1982) Histoire des scandales maçonniques, Paris.

(1985) Logen, Rituale, Hochgrade: Handbuch für Freimaurer, Graz/Wien/ Köln.

MORGAN, W.

(1838)

Ritual und Aufdeckung der Freimaurerei, der Gesellschaften der Ora- nienmänner und seltsamen Gesellen; mit vielen Bildern, einem Schlüssel zu den Phi Beta Kappa so wie auch des an William Morgan, wegen Enthüllung der Geheimnisse der Maurerei begangenen Menschenraubes und Mordes, Leipzig.

NAUDON, P.

(1981) Histoire générale de Franc-Maçonnerie, Paris.

OSLO, A.

(1988) Freimaurer. Humanisten, Häretiker, Hochverräter, Frankfurt am Main.

PEUCKERT, W.-E.

(1928) Die Rosenkreuzer. Zur Geschichte einer Reformation, Jena.

PICK, F. L.

(1983) The Pocket History of Freemasonry, London.

POLICK, A. F.

(1871) Hiram und das Meisterwort, Rostock.

REINALTER, $\mathrm{H}$.

(1983) Freimaurer und Geheimbünde in Mitteleuropa im 18. Jahrhundert, Frankfurt am Main.

RIEGELMANN, $\mathbf{H}$.

(1986) Die europäischen Dynastien in ihrem Verhältnis zur Freimaurerei, Struckum.

RUCKENBORCH, J. v.

(1975) Elementare Philosophie des Rosenkreuzers, Haarlem/NL.

ROBERTS, A. E.

(1974) George Washington - Master Mason, Richmond.

RUNKEL, F.

(1931/32) Geschichte der Freimaurerei in Deutschland, Bd. 1-3, Berlin.

SCHNEIDER, F. J.

(1909) Die Freimaurerei und ihr Einfluß auf die geistige Kultur in Deutschland am Ende des 18. Jahrhunderts. Prolegomena einer Geschichte der deutschen Romantik, Prag. 
SCHNEIDER, $\mathrm{H}$.

(1947) Quest for the Mysteries. The Masonic Background for Literature in Eighteenth-Century Germany, New York.

SCHWAR(T)Z-BOSTUNITSCH [ŠVARC-BOSTUNIČ], G.

(1921) Pravda o Sionskich protokolach, Mitrovica/Sremskaja.

(1922) Masonstvo i russkaja revoljucija, Novi Sad. (ND Novi Sad 1992)

(1928) Die Freimaurerei. Ihr Ursprung, ihre Geheimnisse, ihr Wirken, Weimar. (ND 1933)

SERBANESCO, $\mathbf{G}$.

(1970) Histoire de la franc-maçonnerie universelle, Bd. 1-4, Paris.

SIX, F. A.

(1942) Studien zur Geistesgeschichte der Freimaurerei, Hannover.

STEINER, $G$.

(1985) Freimaurer und Rosenkreuzer - Georg Forsters Weg durch die Geheimbünde. Neue Forschungsergebnisse auf Grund bisher unbekannter Archivalien, Berlin.

STENTZ, T.

(1871) Die Hiram-Sage. Handschrift für Brüder Meister, Berlin.

VALMY, $M$.

(1988) Die Freimaurer. Arbeit am rauhen Stein. Mit Hammer, Zirkel und Winkelmaß, München.

VIBERT, $L$.

(1923)

The Rare Books of Freemasonry, London.

WAGNER, $H$.

(1979)

Die politische und kulturelle Bedeutung der Freimaurer im 18. Jahrhundert, in: BÁLAZS, E. H./HAMMERMAYER, L/WAGNER, H./ WOJTOWICZ, J.: Beförderer der Aufklärung in Osteuropa. Freimaurer, Gesellschaften, Klubs, Berlin, 68-86. (=Studien zur Geschichte der Kulturbeziehungen in Mittel- und Osteuropa 5)

WAITE, A. E.

(1961) The Brotherhood of the Rosy Cross. Being Records of the House of the Holy Spirit in its Unward and Outward History, London.

WEBSTER, N. $\mathbf{H}$.

(1924) Secret Societies and Subversive Movements, London.

WEISS, $A$.

Im Dienste des Ordens. Gesammelte Reden und Aufsätze, Göttingen. 
WELLS, R. A.

(1986) The Rise and Development of Organised Freemasonry, London.

\section{WILSON, C.}

(1982) Das Okkulte, Berlin.

WINKELMÜLLER, 0.

(1967) Les Compagnonnages, eine Wurzel der Freimaurerei, die französischen Gesellenbriderschaften, ihr Beitrag zur Geschichte der Freimaurerei und der Hiram-Legende, Frankfurt am Main.

WOLFSTIEG, $A$.

(1920) Ursprung und Entwicklung der Freimaurerei. Thre geschichtliche, soziale und geistige Wurzel, Berlin.

(1922) Die Philosophie der Freimaurerei, Bd. 1-2, (Bd. 1: Freimaurerische Arbeit und Symbolik, Bd. 2: Die geistigen, sittlichen und aesthetischen Werte in der Freimaurerei und ihre Bedeutung für die Gegenwart, Berlin. (=Werden und Wesen der Freimaurerei 2)

WULF, A.

(1960) Geheimbünde in alter und neuer Zeit, Villingen. (=Quellen zum Ursprung der Freimaurerei 2)

III. FREIMAURER IN RUSSISCHER GESCHICHTE \& LITERATUR

\section{ACTA LATOMORUM}

(1815) Acta lactomorum ou chronologie de l'Histoire de la Franc-Maçonnerie Française et Etrangère, Bd. 1-2, Paris.

ALTŠULER (ALTSHULLER], $M$.

(1982) Masonskie moitvy «Vtorogo toma». Universitetskie studii A. A. Bloka $\mathrm{i}$ ich otraženie v lirike 1904-1905 godov, in: Révue des études slaves 54, 591-607.

AMBURGER, E.

(1961) Geschichte des Protestantismus in Rußland, Stuttgart.

AVRECH, A. Ja.

(1990) Masony i revoljucija, Moskva.

BAEHR, S. L.

(1976)

The Masonic Component in Eighteenth-Century Russian Literature. A Collection of Essays, in: CROSS, A. G.: Russian Literature in the Age 
of Catherine the Great, Oxford, 121-139.

(1987) Freemasonry in Russian Literature: Eighteenth Century, in: The Modem Encyclopedia of Russian and Soviet Literatures 8, 28-36.

BAKUNINA [BAKOUNINE], T. A.

(1935) Znamenitye russkie masony. Vol'nye kamenšciki, Pariž. (ND Moskva 1991 (Mysterium magnum)

BARSKOV, Ja. L.

(1915) Perepiska moskovskich masonov XVIII-go veka (1780-1792gg.), Petrograd.

BAŠILOV, B.

(ca. 1970) Istorija russkogo masonstva, vypusk 9: verstka nevył̌edł̌ego toma, Buènos Ajres.

(1992) Istorija russkogo masonstva, vypusk 1: Moskovskaja Rus' do proniknovenija masonov. Tajna masonstva V. F. Ivanov, vypusk 2: Tỉajsij car' i ego vremja, Moskva. (=B. BAŠILOV (Hrsg.): Istorija russkogo masonstva $1 / 2 ; 3 / 4$ )

(1993) Russkaja Evropija: Rossija pri pervych preemnikach Petra I, nacalo masonstva v Rossii. „Zlatoj vek“ Ekateriny II. (=B. BAS̆LOV (Hrsg.): Istorija russkogo masonstva 5/6)

(1994) Istorija russkogo masonstva, vypusk 9-11: Aleksandr I. i ego vremja, Moskva.

(1995a) Istorija russkogo masonstva, vypusk 12/13: Russkaja Evropija k nałalu carstvovanija Nikolaja I. Religioznye, politiceskie i social'nye rezul'taty 125-letnej evropeizacii Rossii. Vrag masonov No 1. Masonointelligentskie mify o Nikolae I, Moskva.

(1995b) Istorija russkogo masonstva, vypusk 14/15: Masonskie i intelligentskie mify o Peterburgskom periode russkoj istorii, Moskva.

BERBEROVA, $\mathbf{N}$.

(1986) Ljudi i loži. Russkie masony XX stoletija, New York.

BLAGOJ, D. D.

(1960) Istorija russkoj literatury XVIII veka, Moskva.

BOGOLJUBOV, V. A.

(1916) N. I. Novikov i ego vremja, Moskva.

BOŽERJANOV, I. Ch.

(1885) Andrej Nikiforovič Voronichin, stroitel' Kazanskogo sobora v S.Peterburge, in: Russkaja starina 45, 642-52. 
BOURYCHKINE, P.

(1967) /BAKOUNINE, T.: Bibliographie sur la franc-maçonnerie en Russie, Paris/La Haye.

CAMERJAN, I. P.

(1969) Kratko naučno-ateističeskij slovar', Moskva.

CLARKE, J. E.

(1979)

Freemasonry in Russia, in: The Modem Encyclopedia of Russian and Soviet History 12, 14-18.

CROSS, A. G.

(1971)

British Freemasons in Russia during the Reign of Catherine the Great, in: Oxford Slavonic Papers (New Series) 4, 43-72.

DODEL'CEV, R. F.

(1992) (Hrsg.): Énciklopedija okkul'tizma, tom 1-2, Moskva.

DOVNAR-ZAPOL'SKIJ, M. V.

(1915) Pravitel'stvennyja gonenija na masonov, in: MEL'GUNOV, S. P./ SIDOROV, N. I.: Masonstvo $v$ ego proß̌lom i nastojaščem, tom II, Moskva, 118-134. (ND Moskva 1991)

DRUŽININ, N. M.

(1929) Masonskie znaki dekabrista P. I. Pestelja, in: Muzej Revoljucii Sojuza SSR 2, 12-47.

(1983) Erinnerungen und Gedanken eines Historikers. Übersetzt von Beate Eschment, mit Anmerkungen und einem Nachwort von Hans-Heinrich Nolte, Göttingen/Zürich. (=Zur Kritik der Geschichtsschreibung 2)

DÜWEL, W.

(1973) Geschichte der klassischen russischen Literatur, Berlin/Weimar.

EISENBACH, A.

(1979)

Zbratanie polskie wszystkich wyznan religijnych, in: Kwartalnik Historiczny 86/1, 43-66.

ELKNN, B.

(1965/66) Attempts to Revive Freemasonry in Russia, in: Slavonic and East European Review 44, 454-72.

ESEVSKIJ, $S$.

(1870)

Moskovskie masony voz'midesjatych godov prošedక̌ago stoletija, 1780-1789, in: Sobranie sočinenij, tom 3, Moskva. 
FAIVRE, A.

(1979) Friedrich Tiemann und seine deutschen und russischen Freunde, in: BÁLAZS, E. H./HAMMERMAYER, L/WAGNER, H/WOJTOWICZ, J.: Beförderer der Aufklänung in Osteuropa. Freimaurer, Gesellschaften, Klubs, Berlin, 292-330. (=Studien zur Geschichte der Kulturbeziehungen in Mittel- und Osteuropa 5)

FAY, B.

(1935) Revolution and Freemasonry 1680-1800, Boston.

FILATOV, N. F.

(1980) Antip Konstantinov - Kamennych del Podmaster'e XVII v., in: Archiketurnoe nasledstvo $28,65-70$.

FINDEISEN, $\mathrm{H}$.

(1973) Das Ende der Freimaurer, Martinisten und Rosenkreuzer im Bolschewistischen Rußland, in: Quatuor coronati Hefte 86, 53-71.

FISCHER, J. K. A.

(1823) Die Maurerei im Orient von Rußland unter der Regierung der Kaiserin Katharina II (1806), in: Zeitschrift für Freimaurer. Als Manuskript gedruckt für Brüder, Altenburg 1, 1-43.

FRIEDRICHS, E(mst)

(1904) Geschichte der einstigen Maurerei in RuBland - nach dem Quellenmaterial der Großen Landesloge zu Berlin, sowie der Petersburger und Moskauer Bibliotheken, Bertin.

(1907) Die Freimaurerei in Rußland und Polen, Berlin. (=Bücherei für Freimaurer 4)

(1921) Russische Literaturgeschichte, Gotha.

GERSENZON, M. 0.

(1906) K charakteristike P. Ja. Caadaeva. (K 50-letiju so dnja smerti), in: Byloe 1, 243-45.

(1906) Sem'ja Dekabristov, in: Byloe 10/11 (1906), 162-89.

(1910) Otgoloski 14. dekabrja v Moskovskom universitete, in: Russkaja starina $141,333-49$.

GEYER, D.

(1982) Der Aufgeklärte Absolutismus in Rußland. Bemerkungen zur Forschungslage, in: Jahrbücher für die Geschichte Osteuropas 30, 176-89.

GILLEL'SON, M. I.

(1974) Molodoj Puškin i Arzamasskoe bratstvo, Leningrad. 
GUTSCHE, G. J.

(1982) New Perspectives in Nineteeth-Century Prose, Columbus/Ohio.

(1986) Moral Apostasy in Russian Literature, Dekalb/llinois.

HAMMERMA YER, L.

(1979) Zur Geschichte der europäischen Freimaurerei, in: BÁLAZS, E. H./ HAMMERMAYER, L./WAGNER, H./WOJTOWICZ, J.: Beförderer der Aufklärung in Osteuropa. Freimaurer, Gesellschaften, Klubs, Berlin, 13-33. (=Studien zur Geschichte der Kulturbeziehungen in Mittelund Osteuropa 5)

HARDER, H.-B.

(1979)

Nikolaj Karamzin und die philosophisch-literarischen Kreise in Königsberg, Berlin, Weimar und Zürich, in: BÁLAZS, E. H./HAMMERMAYER, L./WAGNER, H/WOJTOWICZ, J.: Beförderer der Aufklärung in Osteuropa. Freimaurer, Gesellschaften, Klubs, Berlin, 304-19. (=Studien zur Geschichte der Kulturbeziehungen in Mittel- und Osteuropa 5)

HARKINS, W. E.

(1956) Dictionary of Russian Literature, New York.

HASS, L.

(1982/84) Wolnomularstwo w Europie Srodkowo-Wschodniej, tom 1: W XVIII i XIX wieku, tom 2: 1905-1928, Ambicje, rachuby, rzeczywistośc, Wrocław.

(1983) The Russian Masonic Movement in the Years 1906-1918, in: Acta Poloniae Historica [Polska Akademia Nauk, Wroclaw, Warszawa/(...)] 48, 95-131.

(1987) Zasady w godzinie proby. Wolnomularstwo w Europie Srodkowowschodniej (1929-1941). Warszawa.

(1993) Masoneria polska XX wieku: losy, loże, ludzie, Warszawa. (ND Warszawa 1996)

HAUMANT, E.

(1910) La culture française en Russie (1700-1900), Paris.

HENNINGS, $P$.

(1965) Zur Geschichte der Freimaurerei im zaristischen Rußland, in: Quatuor coronati Hefte 2, 25-36.

HOLL, M.P.

(1992) Enciklopedičeskoe izloženie masonskoj, germetičeskoj, kabbalističeskoj i rozenkrejcerovskoj simvoličeskoj filosofii, Novosibirsk. 
ISCHREYT, $\mathrm{H}$.

(1974) Die Königsberger Freimaurerloge und die Anfänge des modemen Verlagswesens in Rußland 1760/63, in: LISZKOWSKI, U. (Hrsg.): Rußland und Deutschland. Festschrift für Georg von Rauch, in: Kieler Historische Studien 10, 108-19.

IVANINA, N. S.

(1882) Masonstvo v Rossii v XVIII i XIX vekov, in: Russkaja starina 35, 533-560; 36, 61-76.

IVANOV-RAZUMNIK, V.

(1923) Russkaja literatura ot semidesjatych godov do našich dnej, Berlin.

JENA, K. v.

(1992)

几ENZ, W.: Rußland. Die deutschen Bestände im Sonderarchiv in Moskau, in: Der Archivar [Mitteilungsblatt für deutsches Archivwesen] 45/3 (Juli), 458-67.

JONES, R. E.

(1973) The Emancipation of the Russian Nobility 1762-1785, Princeton.

KIRPIČNIKOV, A. I.

(1899) Novye materialy dlja istorii Arzamasa, in: Russkaja starina 98, 377-81.

KIZEVETTER, A. A.

(1915) Istorið̌eskie otkliki, Moskva.

(1915) Moskovskie rozenkrejcery XVIII stoletija, in: Russkaja mysl' 10, 96124.

KOCETKOVA, N. D.

(1964) Idejno-literatumye pozicii masonov 80-90-x godov XVIII v. i N. M. Karamzin, XVIII vek, Moskva/Leningrad. (=Russkaja literatura XVIII veka: épocha klassicizma 6)

(1987) Masonstvo, in: Literaturnyj éncyklopediceskij slovar', Moskva, 212/13.

KRASNOBAEV, B. I.

(1979) Eine Gesellschaft gelehrter Freunde am Ende des 18. Jahrhunderts. «Družeskoe ucenoe obščestvo», in: BÁLAZS, E. H./HAMMERMAYER, L./WAGNER, H./WOJTOWICZ, J.: Beförderer der Aufklärung in Osteuropa. Freimaurer, Gesellschaften, Klubs, Berlin, 257-70. (=Studien zur Geschichte der Kulturbeziehungen in Mittel- und Osteuropa 5) 
KUKIEL, $M$.

(1960) Lelewel, Mickiewicz and the underground movements of European Revolution (1816-1833), in: The Polish Review 5/3, 59-72.

KUL'MAN, N. K.

(19159 Michail Ivanovið Nevzorov, in: MEL'GUNOV, S. P./SIDOROV, N. I.: Masonstvo v ego prołlom i nastojašcem, tom II, Moskva, 203-25. (ND Moskva 1991)

KUŠELEV, E. A.

(1877)

Uničtoženie masonskich lož v Rossii v 1822 g., in: Russkaja starina $18,455-79,641-64$.

LAUER, $R$.

(1975)

(1979) Russische Freimaurerdichtung im 18. Jahrhundert, in: BÁLAZS, E. H」 HAMMERMAYER, L./WAGNER, H./WOJTOWICZ, J.: Beförderer der Aufklärung in Osteuropa. Freimaurer, Gesellschaften, Klubs, in: Studien zur Geschichte der Kulturbeziehungen in Mittel- und Osteuropa 5, Berlin, 271-91.

LEBEDEV, A. A.

(1912) K zakrytiju masonskich lož v Rossii, in: Russkaja starina 149 (1912), 523-38.

LEHMANN-CARLI, G.

(1991) Karamzins Lavater-Rezeption: Zur Genesis einer Strömung in der russischen Aufklärung, in: Zeitschrift für Slawistik 36/4, 505-17.

LEIGHTON, L. G.

(1982)

(1987) Freemasonry in Russian Literature: Nineteenth Century, in: The Modern Encyclopedia of Russian and Soviet Literatures 8, 36-42.

(1994) The Esoteric Tradition in Russian Romantic Literature: Decembrism and Freemasonry, University Park/Pa.

LEMBERG, $\mathrm{H}$.

(1963) Die nationale Gedankenwelt der Dekabristen, Köln/Graz. (=Kölner Historische Abhandlungen 7) 
LEVICKIJ, A.

(1988) Masonic Elements in Russian 18th Century Religious Poetry, in: BARTLETT, R. P./CROSS, A. G./RASMUSSEN, K. (Hrsg.): Russia and the World of the eighteenth century: proceedings of the third international conference organized by the Study group on EighteenthCentury Russia and held at Indiana University at Bloomington USA, September 1984, Comumbus/Ohio.

LONGINOV, M. N.

(1862) Vospominanie o Caadaeve, in: Russkij vestnik 42, 119-56.

(1867) Novikov i moskovskie martinisty, Moskva.

LOTMAN, Ju. M.

(1963) Socuvstvennik A. N. Radiščeva A. M. Kutuzov i ego pis'ma K I. P. Turgenevu, in: Učenie zapiski Tartusskogo universiteta Trudy po russkoi i slavjanskoj filologii 6, Tartu.

(1966) Masonstvo, in: Sovetskaja istoriceskaja éncikJopedija, tom 9, Moskva, 167-69.

MACARTHUR, G. H.

(1970) Katherine II and the Masonic Circle of N. I. Novikov, in: Canadian Slavic Studies 4, 529-47.

(1980) Freemasonry and Enlightenment in Russia. The Views of N. I. Novikov, in: Canadian Slavic Studies 14, 361-75.

(1989) Riebel-Weckowicz, H.: Catherine the Great and the suppression of Freemasonry: A Russian response to the fear of revolution, 17891792, in: Consortium on Revolutionary Europe 1750-1850: Proceedings 19/2, 607-16.

MAGNICKIJ, $M$.

(1899) Dva donosa v 1831 godu. Vsepoddannejłija pis'ma M. Magnickago imperatoru Nikolaju ob illuminatach, in: Russkaja starina 97, 296-301.

MAKOGONENKO, G. P.

(1951) Nikolaj Novikov i russkoe prosvešcenie XVIII veka, Moskva-Leningrad.

(1976) XVIII Sbomik 11. N. I. Novikov i obšcestvenno-literaturnoe dviženie ego vremeni, Leningrad.

MARTYNOV, I. F.

(1981) Knigoizdatel' N. Novikov, Moskva. 
MEL'GUNOV, S. P.

(1915)

(1923) Dela i ljudi Aleksandrovskago vremeni, Berlin.

MILJUKOV, P. N.

(1903) Ocerki po istorii nusskoj kul'tury, S.-Peterburg.

MINC, I. I.

(1980) Metamorfozy masonskoj legendy (Istoriografija, (...), issledovanija, in: Istorija SSSR [Akademija Nauk SSSR. Institut istorii SSSR, Moskva] 4, 107-22.

MEZIER, A. V.

(1906) V poiskach pravdy i smysla žizni. Ozerk iz istorii russkago masonstva, S.-Peterburg. (=Istorija i obšcestvennye voprosy 112)

MOELLER, $\mathrm{H}$.

(1979) Die Gold- und Rosenkreuzer. Struktur, Zielsetzung und Wirkung einer antiaufklärerischen Geheimgesellschaft, in: Ludz, P. Ch. (Hrsg.): Geheime Gesellschaften, Heidelberg, 153-202. (=Wolfenbütteler Studien zur Aufklärung 5/1)

MYL'NIKOV, A. S.

(1979) Die Rolle nichtoffizieller Vereinigungen im geistigen Leben und in den internationalen Beziehungen RuBlands während der Aufklärungsepoche, in: BÁLAZS, E. H/HAMMERMAYER, L/WAGNER, H./ WOJTOWICZ, J.: Beförderer der Aufklärung in Osteuropa. Freimaurer, Gesellschaften, Klubs, Berlin, 197-212. (=Studien zur Geschichte der Kulturbeziehungen in Mittel- und Osteuropa 5)

N., Z.

(1907) K istorii masonstva v Rossii, in: Russkaja starina 129 (1907), 539-49.

NETTELBLADT, Br. v. (?)

(1835) Geschichte der Freimaurerey in Rußland, in: Kalender für die Provinzialloge von Mecklenburg 1835/37/38, 35-43.

NEZELENOV, A. I.

(1875) Nikolaj I. Novikov, izdatel' žurnalov, 1769-1785, S.-Peterburg.

(1887) Rex̌ o Puškine, S.-Peterburg.

NIKOLAEVSKIJ, B. I.

(1990) Fel'štinskij, Ju. G. (Hrsg.): Russkie masony i revoljucija, Moskva. 
NORTON, B. T.

(1985)

/SMITH, N.: The Constitution of Russian Political Freemasonry (1912), in: Jahrbücher für die Geschichte Osteuropas 34, 498-517.

NOVIKOV, V. I.

(1993) Masonstvo i russkaja kul'tura, Moskva.

PEKARSKU, P. P.

(1870) Dopolnenija $k$ istorii masonstva $v$ Rossii XVIIlago stoletija (17801792gg.), in: Sbornik stat'ej, Citannych $v$ otdelenii russkago jazyka i slovesnosti Imperatoroskoj Akademii nauk 7/4, 1-224.

PFAHL-TRAUGBER, A.

(1991) Die neue/alte Legende vom Komplott der Juden und der Freimaurer. Zur Renaissance des antisemitisch-freimaurerischen Verschwörungsmythos in der Sowjetunion, in: Osteuropa 41, 122-33.

PIKSANOV, N. K.

(1915) I. V. Lopuchin, in: MEL'GUNOV, S. P./SIDOROV, N. P.: Masonstvo $v$ ego prošlom i nastojašcem, tom I, Moskva, 227-55. (ND Moskva 1991)

(1947) Masonskaja literatura, in: Istorija russkoj literatury 4 (Literatura XVIII veka, čast' 2, Moskva/Leningrad, 51-84.

PLATONOV, O. A.

(1995/96) Ternovy venec Rossii, tom 1: Istorija masonstva 1731-1995; tom 2: Zagovor careubijc, tom 3: Nikolaj II. v sekretnoj perepiske, Moskva.

PLIMAK, E. G.

(1957) Masonskaja reakcija protiv materializma v Rossii (70-90-e gody XVIII veka), in: Voprosy filosofii 1, 51-62.

POKROVSKIJ, V. I.

(1913) Nikolaj Ivanovič Novikov, ego žizn' i soxinenija. Sbomik istoriko-literatumych stat'ej, Moskva.

POZDEEV, A. V.

(1962) Rannye masonskie pesni, in: Scando-Slavica 8, 26-64.

PYPIN, A. N.

(1867)

(1868)

(1872)

(1895)
Russkoe masonstvo, in: Vestnik Evropy 12, 42-48.

Russkoe masonstvo do Novikova, in: Vestnik Evropy 6, 546-89.

Materialy dlja istorii masonskich lož, in: Vestnik Evropy 7, janvar', 174-214, fevral', $561-603$.

Vremena Ekateriny II, in: Vestnik Evropy 6, 753-63. 
PYPIN, A. N. [Fortsetzung]

(1896) Quellen und Beiträge der Geschichte der Freimaurerlogen Rußlands, Riga.

(1898) Geschichte der russischen Literatur, S.-Peterburg.

(1902) Materialy dlja istorii gonenija studentov pri Aleksandre II, Leipzig.

(1916) Russkoe masonstvo XVIII i pervaja Cetvert' XIXago veka, Petrograd, (ND Düsseldorf 1970)

(1916) Chronologičeskij ukazatel' russkich lož ot pervago vvedenija masonstva do zaprešcenija ego, 1717-1829, in: PYPIN, A. N.: Russkoe masonstvo XVIII i pervaja cetvert' XIX v., Petrograd, 498-532.

(1918) Obక̌̌estvennoe dviženie v Rossii pri Aleksandre I, Petrograd. (=Izsledovanija i stat'i po èpoche Aleksandra I)

RAEFF, $M$.

(1966)

(1967) Filling the Gap between Radishchev and the Decembrists, in: American Slavic Review 26, 395-413.

RAUCH, G. v.

Origins of the Russian Intelligentsia: The Eighteenth-Century Nobility, London/New York, 159-66.

Slavic Review 26, 395-413.

Johann Georg Schwarz und die Freimaurer in Moskau, in: BÁLAZS. E. H./HAMMERMAYER, L/WAGNER, H./WOJTOWICZ, J.: Beförderer der Aufklärung in Osteuropa. Freimaurer, Gesellschaften, Klubs, Berlin, 212-24. (=Studien zur Geschichte der Kulturbeziehungen in Mittel- und Osteuropa 5)

REINBECK, G.

(1806) Flüchtige Bemerkungen auf einer Reise von St. Petersburg über Moskwa, Grodno, Warschau, Breslau nach Deutschland im Jahre 1805. (In Briefen), Leipzig.

ROGALLA VON BIEBERSTEIN, J.

(1980) Die Bedeutung der Freimaurerei für nationalemanzipatorische Gesellschaften in Polen und Rußland 1815-1825, in: Zeitschrift für Ostforschung 29, 4, 639-53.

ROGOV, I. M.

(1958)

K voprosu o «masonstve» A. N. Radišceva, in: Vestnik Leningradskogo gosudarstvennogo universiteta 20, $153 \mathrm{f}$.

ROTHE, H.

(1978)

Zu Cheraskovs Dichtungsauffassung, in: ROTHE, H./HARDER, H.B. (Hrsg.): Studien zur Literatur und Aufklärung in Osteuropa, in: Bausteine zur Geschichte der Literatur bei den Slawen 13, 94-109. 
ROZANOV, I. N.

(1915) Michail Matveevic Cheraskov, in: MEL'GUNOV, S. P.SIDOROV, N. I.: Masonstvo v ego prołlom i nastojał̌em, tom II, Moskva, 38-51. (ND Moskva 1991)

RYU, In, H. L.

(1973) Moscow Freemasons and the Rosicrucian Order. A Study in Organization and Control, in: GARRARD, J. G. (Hrsg.): The Eighteenth Century in Russia, Oxford, 198-233.

SAKULIN, P. N.

(1914) Novyj trud po istorii masonstva, in: Golos minuvsego 7/8, The Hague /Paris. (=Slavistic printings and reprintings 114/16)

(1928) Masonizm, in: SAKULIN, P. N.: Rusckaja literatura. Sociologo-sintetičeskij obzor literatumych stilej, Cast' 2, Moskva, 337-46.

SČERBATOV, M. M.

(1858) O proizvedenii nravov v Rossii i putešestvie A. Radišceva, London.

SCHALHORN, B.

(1985) Freimaurer (masony), in: TORKE, H.-J. (Hrsg.) Lexikon der Geschichte Rußlands. Von den Anfängen bis zur Oktoberrevolution, München, 127-28.

SEMEKA, A. V.

(1902) Russkie rozenkrejcery i sočinenija imperatricy Ekateriny II protiv masonstva, in: Žumal' Ministerstva narodnago prosvě̉̌čenija 2, 343400.

(1915) Russkoe masonstvo v XVIII v., in: MEL'GUNOV, S. P./SIDOROV, N. P.: Masonstvo $v$ ego prošlom i nastojăšcem, tom I, Moskva, 12474. (ND Moskva 1991)

SEMENNIKOV, V.P.

(1921) Knigoizdatel'skaja dejatel'nost' Novikova i tipograficeskoj kompanii, Petrograd.

SEMEVSKIJ, V. I.

(1908)

Dekabristy-masony, in: Minuvگ̌ie gody I 1/2, in: Žurnal posvjaščennyj istorii i literature; fevral', 1-50; mart, 127-170; maj/ijunja, 379-433.

SETSCHKAREFF, V.

(1984) Die wahre Ironie in Michail Osorgins *Vol'nyj kamenšxik», in: TextSymbol-Weltmodell. Johannes Holthusen zum 60 . Geburtstag. J. R. Döring-Smimov, P. Rehder, W. Schmid (Hrsg.), München, 555-571. 
SMITH, N.

(1968)

(1985) NORTON, B. T.: The Constitution of Russian Political Freemasonry (1912), in: Jahrbuicher für die Geschichte Osteuropas 34, 498-517.

SOKOLOVSKAJA, T. 0 .

(1904) Masonstvo, kak polozitel'noe dviženie russkoj mysli v naxale XIX veka, in: Vsemimyj vestnik 5, 20-36.

(1905) Iz masonskich pesen, in: Russkjj archiv 43, 285-88.

(1905) Podnesenie masonskich perčatok A. E. Labzinoj 1819, in: Russkij archiv 43, 532-35.

(1905) Tajnaja masonskaja instrukcija కotlandskoj masterskoj, in: More i ego žizn' 25/26.

(1906) Brat'ja Zlatorozovogo Kresta. ( $K$ istorii rozenkrejcerstva v Rossii), in: Russkij archiv 44, 89-93.

(1906) Ioannov den' - masonskij prazdnik, in: More i ego žizn' 23/24.

(1906) Masonskaja tajnopis', in: Russkij archiv 44, 399-400.

(1906) Masonskie pesni, in: Russkij archiv 44, 555-60.

(1907)

Iz materialov po istorii masonstva. Sekretnoe otnošenie ministra vnutrennych del' $k$ načal'niku glavnago staba 9 . janvare 1826 g., No. 13, in: Russkaja starina 129, 344-46.

(1907) Russkoe masonstvo i ego značenie $v$ istorii obščestvennago dviženija (XVIII i pervaja cetvert' XIX stoletija), S.-Peterburg.

(1907) Obrjadnost' prežnego russkogo masonstva, in: Russkaja starina 129, 303-07.

(1907) Iz materialov po istorii masonstva, in: Russkaja starina 129, 344-346.

(1907)

K biografii dekabrista kn. S. G. Volkonskogo, in: Russkaja starina $130,480-81$.

(1907) Obrjadnost' prežnego russkogo masonstva, in: Russkaja starina 132, 349-59, 707-17.

(1907) Iz zapiskach knižek masonov grafa M. Ju. Viel'gorskogo i F. N. Glinki, in: Russkij archiv 45, 136-38.

(1907) Predloženie Voennogo Ministra Komandujušcemu Gvardejskim Korpusom, 17-VIII-1822, in: Russkaja starina 130, 270.

(1907) Russkoe masonstvo i ego značenie $v$ istorii obక̌xestvennago značenija XVIII i pervaja cetvert' XIX stoletija, S.-Peterburg.

(1907) Ustav vol'nych kamenšxikov XVIII i XIX veka iz materialov dlja istorii russkogo masonstva, S.-Peterburg.

(1907) Dva portreta Imperatora Pavla I s masonskimi émblemami, in: Russkaja starina 136, 81-95. 
SOKOLOVSKAJA, T. O. [Fortsetzung]

(1907) Dnevnik Simanskogo. V masonskich ložach 1817-1822, in: Vestnik Imperatorskogo obšcestva revnitelej istorii, 159-212.

(1908) Iz donosov na masonstvo. Pis'mo A. B. Korvina k Kn. P. M. Volkonskomu, 3I-V-1820, in: Russkaja starina 136, 683-88.

(1908) O masonskich toržestvach v Cest' Aleksandra I, in: Russkij archiv 46, 99-104.

(1908) Loža trech dobrodetelej i ee cleny - dekabristy, in: Russkij archiv 46, 218-230.

(1909) Novye materialy o masonstve, in: Russkaja starina 137, 386-90.

(1912) Novye dannye dlja istorii nusskogo masonstva po rukopisjam Tverskoj ǔ̌enoj archivnoj komissii, Tver'.

(1915) Masonskija sistemy, in: MEL'GUNOV, S. P./SIDOROV, N. P.: Masonstvo v ego prošlom i nastojašcem, tom II, 52-79. (ND Moskva 1991)

(1915) Vozroždenie masonstva pri imperatore Aleksandre I, in: MEL'GUNOV, S. P./SIDOROV, N. P.: Masonstvo $v$ ego prošlom i nastojascem, tom II, 153-202. (ND Moskva 1991)

(1915) Obrjadnost' vol'nych kamenšcikov, in: MEL'GUNOV, S. P./SIDOROV, N. P.: Masonstvo v ego proß̌lom i nastojašem, tom II, Moskva, 80-117.

(1916) Kapitul Feniksa, vyš̌ee tajnoe masonskoe pravlenie v Rossii, 17781822, Petrograd.

SOLODKIJ, B. S.

(1974) Problema Celoveka v russkom masonstve, in: Problemy gumanizma v russkoj filozofii, Krasnodar, 28-55.

SOLOV'EV, O. F.

(1988) Masonstvo v Rossii, in: Voprosy istorii 10, 3-25.

(1992) Masonstvo dalekoe i blizkoe (Dokumental'nye očerki), in: Novaja i nevejłaja istorija (Rossijskaja Akademija Nauk. Institut vseobక̌cej istorii) 4 (ijul'-avgust), 55-81; 5 (sentjabr'-okjabr'), 136-66.

(1993) Russkoe masonstvo 1730-1917, Moskva.

STARCEV, V. I.

(1989) (Publikacii i soobščenija) Russkoe političeskoe masonstvo 19061918gg. (Dokumenty iz archiva Gurerovskogo instituta vojny, revoljucii i mira), in: Istorija SSSR [Akademija Nauk SSSR. Institut istorii SSSR, Moskva] 6, 119-34. 
STARCEV, V. I. [Fortsetzung]

(1990) (Publikacii i soobšcenija) Russkoe političskoe masonstvo 19061918gg. (Dokumenty iz archiva Gurerovskogo instituta vojny, revoljucii i mira), in: Istorija SSSR [Akademija Nauk SSSR. Institut istorii SSSR, Moskva] 1, 139-55.

STENDER-PETERSEN, A.

(1986) Geschichte der nussischen Literatur, München.

STEPANOV, V.P.

(1968) ISTENNIK, Ju. V.: Istorija russkoj literatury XVIII veka. Bibliograficeskij ukazatel', Leningrad, 72-77.

SUMIGORSKIJ, E. S.

(1915) Imperator Pavel I i masonstvo, in: MEL'GUNOV, S. P./SIDOROV, N. I.: Masonstvo v ego prošlom i nastojaščem, tom II, Moskva, 13552.

\section{TABLEAU GENERAL}

(o. J.) Tableau général de la grande Loge Astrée à L'orient de St. Petersburg et des 23 Loges de sa département, 0.0 .

\section{TAJNYE OBŠ̌ESTVA V ROSSII.}

(1906) Sledstvije, sud, prigovor, amnistija. Official'nye dokumenty, Moskva. (ND Moskva 1926)

TARASOV, E. I.

Novye dannye Novikovskogo knuga, in: lzvestija otdela russkogo jazyka i slovesnosti Imperatorskoj Akademii Nauk 13, S.-Peterburg, 438-55.

(1915) Moskovskoe obščestvo rozenkrejcerov (Vtorostepennye dejateli masonov), in: MEL'GUNOV, S. P./SIDOROV, N. I.: Masonstvo v ego prošlom i nastojaščem, tom II, Moskva, 1-26.

\section{TELEPNEV, B.}

(1922)

(1923)

(1925)

(1926)

(1929)

Freemasonry in Russia, in: Ars Quatuor Coronatorum 35, 261-92. Rosicrusians in Russia, London.

An Oudine of the History of Russian Freemasonry. Some Aspects of Russian Freemasonry during the Reign of the Emperor Alexander I, in: Ars Quatuor Coronatorum (38), 6-66.

A Few Pages from the History of the Swedish Freemasonry in Russia, in: Ars Quatuor Coronatorum (39), 174.

Johann August Starck and his Rite of Spiritual Masonry, in: Ars Quatuor Coronatorum 41, 238-84. 
TOL' (rožd. gr. Tolstaja), S. D.

(1914) Masonskoe dejstvo. Istoriceskij očerk o zagovore dekabristov, in: Golos minuvß̌ego 8, 291-94.

TOLSTOJ, F. P.

(1878) Vozpominanija T. P. Passek, glava XXXVIII, in: Russkaja starina 21, 209-14.

TOLSTOJ, L. N.

(1958) Sobranie socinenij v dvenadcati tomach, Moskva.

TSCHǏ̌EEWSKIJ, D.

(1935) Jacob Böhme in Rußland, in: Evangelium und Osten 8, $175 \mathrm{ff}$.

TUKALEVSKIJ, V. N

(1911) Iskanija russkich masonov, S.-Peterburg.

(1915) N. I. Novikov i I. G. Švarc, in: MEL'GUNOV, S. P./SIDOROV, N.

P.: Masonstvo v ego proßlom i nastojašcem, tom I, Moskva, 175-226.

VERNADSKIJ, G. V.

(1917) Russkoe Masonstvo v Carstvovanie Ekateriny II., Petrograd. (=Zapiski Istoriko-Filologičeskago Fakul'teta Petrogradskago Universiteta 37) (ND Düsseldorf 1970)

(1923) Le césarevitch Paul et les francs-maçons de Moscou, in: Révue des études slaves 3 (1923), 268-86.

(1927) Beiträge zur Geschichte der Freimaurerei und des Mystizismus in RuBland, in: Zeitschrift für Slawische Philologie 4, 162-78.

VJAZEMSKIJ, P. A.

(1878-96) Polnoe sobranie socinenij, tom I-XII, S.-Peterburg.

VOSSTANIE DEKABRISTOV

(1925) Materialy po istorii vosstanija dekabristov, tom 8, Leningrad.

VVEDENSKIJ, S. N.

(1927) $\quad K$ istorii russkogo masonstva pervoj cetverti XIX veka, in: Izvestija Voromežskogo kraevedčeskogo obక̌čestva 3-5, Moskva, 12-14.

WOLFGANG, $U$.

(1997) 1400 Meter Logenarchiv landeten in Moskau. Die materiellen Verluste der deutschen Freimaurerei am Ende des Zweiten Welthrieges, in: Humanität [Zeitschrift für Gesell schaft, Kultur und Geistesleben. Im Auftrage der GroBloge A. F. u. A. M. von Deutschland] 2, 10-13.

ZAMETKI O MASONSTVE

(1928) Kružok russkich masonov v Anglii, London. 
ZAPADOV, A. V.

(1966) Vorwort zu V. I. Majkov, in: Izbrannye proizvedenija, Leningrad.

(1968) Novikov, Moskva.

ZAVALIŠN, D. I.

(1878) Otryvki iz zapisok, in: Drevnjaja i novaja Rossija, Moskva.

(1904) Zapiski dekabrista D. I. ZavaliŠina, Mjunchen.

IV. MOTIVE DER FREIMAURERLITERATUR

AMBELAIN, $R$.

(1965) Scala philosophorum, ou la symbolique des outils dans l'art royal, Pa-

ris.

(1978) Céremonies et rituels de la maçonnerie symbolique, Paris.

ANDRE-GEDALGE, A.

(1987) Manuel interpretatif du symbolisme maçonniques, 1. Grad, 2. Grad, Nice.

ANTONI, 0.

(1968) Der Wortschatz der deutschen Freimaurer-Lyrik des 18. Jahrhunderts in seiner geistesgeschichtlichen Bedeutung, München.

BAYARD, J.-P.

(1974) Le symbolisme maçonnique, Paris.

(1975) Le symbolisme maçonnique des hauts grades, Paris.

(1975) La symbolique de la Rose-Croix, Paris.

(1991) La symbolique du temple, Paris.

(1994) Précis Franc-Maçonnerie, Paris.

BAYLOT, J.

(1968) La voie substitué. Recherche sur la déviation de la franc-maçonnerie en France et en Europe, Liège.

BOKOR, C. v.

(1980) Winkelmaß und Zirkel. Die Geschichte der Freimaurer, Köln.

BONHOFF, C.

(1920) Der Faustische Drang, in: Am Bau, 3-20. (=Freimaurerische Flugschriften 6)

BOUCHER, J.

(1980) La symbolique maçonnique ou l'art royal remis en lumizre a restitue selon les règles de la symbolique ésoterique et traditionelle. Paris. 
BUCK, J. D.

(1908)

Mystische Maurerei oder Symbole der Freimaurerei und die gröBten Mysterien des Altertums, Berlin.

BURGIO, A.

(1985) Dizionario delle superstizioni, Milano.

CHAILLEY-BERT, J.

(1968) La Flûte enchantée, opera maçonnique, musique et ésoterisme, Paris.

DYER, C(olin). F. W.

(1983) Symbolism in Craft Freemasonry, London.

ENDRES, F. $\mathrm{K}$.

(1930) Die Symbole des Freimaurers. Von einem Bruder Meister, Stuttgart. (ND Hamburg 1977)

(1984) ISCHIMMEL, A.: Das Mysterium der Zahl. Zahlensymbolik im Kulturvergleich, Köln.

ERLER, $M$.

(1964) Der moderne Mensch und das Ritual. (Handschr. f. Brr. Frmr.), München.

(1966) Das Symbol des Lebens im Alten Ägypten. Eine symbolgeschichtliche Studie, München.

(1969) Die große Legende vom Tempelbau. (Handschr. f. Brr. Frmr.) Ein Vergleich mit alten Quellen, München.

FARINA, $S$.

(1946) Il libro dei rituali del rito scozzese antico ed accettato, Roma.

FEDDERSEN, K. C. F.

(1982-86) Die Arbeitstafel in der Freimaurerei, Bd. 1-2, Bayreuth.

FINLAYSON, I. F.

(1889) The Symbols and Legends of Freemasonry, London.

FISCHER, R(obert)

(1878) Ritual und Symbol. Unterrichtsvorträge, Leipzig.

(1919) Die Alten Pflichten. Das Grundgesetz der Freimaurerei, Berlin.

GROSSEGGER, E.

(1981) Freimaurerei und Theater 1770-1880. Freimaurerdramen an den k.u.k. privilegierten Theatem in Wien, Wien/Köln/Graz. (=Intemationale Beiträge zur Theaterwissenschaft 4) 
HALL, M. P.

(1951) The Lost Keys of Freemasonry or the Secrets of Hiram Abiff, New York.

HENNE AM RHYN, $O$.

(1906) Kurzgefaßte Symbolik der Freimaurerei, Berlin. (=Bücherei für Freimaurer 11/12)

HIRT, A. L.

(1809) Der Tempel Salomos, Berlin.

HORNE, A.

(1973) King Salomon's Temple in the Masonic Tradition, Wellingborough.

HORNEFFER, A.

(1916) Symbolik der Mysterienbünde, München.

(1923) Das Brauchtum der Freimaurer. Die Loge und ihr symbolischer Hausrat, Hamburg. (=Blaue Reihe 2)

(1950) Die Macht des Symbols. Eine Deutung, Hamburg. (=ZiegeldeckerReihe 4)

(1976) Die Aufnahmehandlung, Hamburg.

HOSER, J.

Swinbumes Klassizismus im Lichte der freimaurerischen Weltanschauung, Regensburg.

JAN, E. v.

(1922) Freimaurerische Versdichtung in der französischen Literatur des 18. Jahrhunderts, Würzburg.

(1925) Der Französische Freimaurerroman im 18. Jahrhundert, in: Germanisch-Romanische Monatsschrift 13, 391-403.

JUNKER, H. Br.

(1929) Die Rose als Wiedergeburtssymbol, Leipzig.

KELLER, L.

(1910) Bibel, Winkelmaß und Zirkel. Studien zur Symbolik der Humanitätslehre, Jena. (=Vorträge und Aufsätze aus der Comeniusgesellschaft 18)

(1918) Die Freimaurerei. Eine Einfuhrung in ihre Anschauungswelt und Geschichte, Leipzig/Berlin.

KILCHER, A.

(1996) Okkulte Sprache und bürgerliche Rationalität. Zur Rezeption der Kabbala in der Freimaurerei, in: Neue Zürcher Zeitung, $1 / 2$. Juni, 53. 
KLODWIG, $\mathbf{R}$.

(1933) Mythologie und Symbolik. Ein Beitrag zur Entwicklung der Symbole in den Mysterienbünden, Lorch/Württemberg.

LINDNER, E. J.

(1976) Königliche Kunst im Bild. Beiträge zur Ikonographie der Freimaurerei, Graz.

LURKER, $M$.

(1988) Freimaurerei; Freimaurerische Symbole, in: LURKER, M. (Hrsg.):

Wörterbuch der Symbolik, Stuttgart, 209-12.

MACKEY, A. G.

(1947) The Symbolism of Freemasonry (1869), Chicago.

MARBACH, $O$.

(1878) Das Freimauret-Gelübde, Leipzig.

NAUDON, $P$.

(1966) Histoire et rituels des hauts grades maçonniques, le rite ecossais ancien et accepté, Paris.

NETTL, $P$.

(1956) Musik und die Freimaurerei. Mozart und die königliche Kunst, Esslingen.

(1956) W. A. Mozart. Als Freimaurer und Mensch, Hamburg. (=Ziegeldekker-Reihe)

OLBRICH, $\mathrm{K}$.

(1930) Die Freimaurer im Dt. Volksglauben, Breslau. (=Wort und Brauch 20)

OLIVER, G.

(1857) Signs and Symbols Illustrated and Explained in a Course of Twelve Lectures on Freemasonry, London.

QUENTIN, C. F.

(1825) Dictionnaire maçonnique ou receuil d'ésquisses de toutes les parties de l'édifice connu sous le nom de maçonnaire, Paris. (ND 1982)

PISEMSKIJ, A. F.

(1912) Masony. Roman, in: Polnoe sobranie soxinenij 15-19, S.-Peterburg/ Moskva.

POLAK, M. S.

(1855) Die Tapis in ihrer historisch-paedagogischen, wissenschaftlichen und moralischen Bedeutung, oder: Geschichte der Urreligion als Basis der Freimaurerei, Amsterdam. 
RUNKEL, F.

(1921) Das salomonische Symbol, Berlin.

RUSSKIJ VOL'NYJ KAMENŠ̌IK

(1946) Franc-maçon russe. Bjulletin russkich lož. Velikaja loža Francii (Hrsg.), Bde. 1-2, Paris.

SCHULZ, G.

(1825) Der Hammer in seiner symbolischen Bedeutung. Für Jedermann insonderheit für Maurer und die es werden wollen, Naumburg.

SCHWAB, F.

(1912) Symbolik. Eine Anleitung zum Verständnis symbolischer Zeichnungen, Lorch.

SCHWARZ-WINKLHOFER, J.

(1972) /BIEDERMANN, H.: Das Buch der Zeichen und Symbole, Graz.

SILVA, $R$.

(1973) Maçonaria Simbólica, São Paulo.

SOKOLOVSKAJA, T. O.

(1915) Obrjadnost' vol'nych kamenšxikov, in: MEL'GUNOV, S.P./SIDOROV, N. I.: Masonstvo v ego prošlom i nastojašem, tom II, Moskva, 80-117.

STEPANOV, A. P.

(1870) Prinjatie v masony v 1815 godu, in: Russkaja starina 1, 221-27.

THOMSON, $\mathrm{K}$.

(1977) The masonic thread in Mozart, London.

TOURNIAC, $\mathrm{J}$.

(1969) Symbolisme maçonnique et tradition chrétienne, Paris.

TRESCASES, J.

(1987) L'étoile flamboyante ou la récherche d' une parole perdue, Paris.

WARD, A. H.

(1923) Masonic Symbolism and the Mystic Way. A Series of Papers on the True Secrets and the Lost Word, London.

WIRTH, 0.

(1909) Le symbolisme hermétique dans ses rapports avec l'alchemie et la franc-maçonnerie, Paris. 
V. MOTIVE DER FREIMAURER(LITERATUR)BEIPUSKIN

ABRAMOVIC, S. L.

(1984) Puskkin v 1836 godu. Predystorija poslednej dueli, Leningrad.

ANNENKOV, P. V.

(1855) Materialy dlja biografii A. S. Puß̌kina, S.-Peterburg.

(1873) A. S. Puškin v Aleksandovskuju épochu, po novym dokumentam, in: Vestnik Evropy 11, 5-69; 12, 457-89.

BARTENEV, P. I.

(1866)

(1925)

A. S. Puškin v južnoj Rossii. Materialy dlja ego biografii (1820-1823), in: Russkij archiv 4, 1089-1214.

Rasskazy o Puškine, zapisannye so slov ego druzej v 1851-1860 godach, in: Zapisi prošlogo 4, 1-140.

BAŠILOV, B.

(o.J.) Puškin i masonstva, Buenos Aires. (=Istorija russkogo masonstva 7)

BLAGOJ, D. D.

(1929) Sociologija tvorčestva Puškina. Etjudy, Moskva.

BAYARD, J.-P.

(1975)

Le symbolisme maçonnique des hauts-grades, Paris.

BAŽANOV, V. G.

(1950) Poéty-Dekabristy. Ryleev, Odoevskij, Kjuchel'beker, Moskva/Leningrad.

BRAUNBEHRENS, $\mathrm{V}$.

(1989) Salieri. Ein Musiker im Schatten Mozarts, München/Zürich.

BRUN-ZEJMIS, J.

(1978) Malen'kie tragedii and «Povesti Belkinas: Western Idolatry and Pushkinian Parodies, in: Russian Language Joumal 32/111, 65-75.

CHAZIN, M.

(1979) «Tvoej molvoj napolnen sej predel...», KiY̌inev.

CJAVLOVSKAJA, T. $O$.

(1975) Otkliki na sud'by dekabristov $v$ tvořxestve Puškina, in: BAŽANOV, V. G./VACURO, V. E.: Literaturnoe nasledie dekabristov, Leningrad, 195-218. 
DALCHOW, J.

(1966) IDUA, G./KERNER, D.: W. A. Mozart. Die Dokumentation seines Todes. Zum 175. Wiederkehr seines gewaltsamen Todes am 5. Dez. 1966, Pähl.

DEUTSCH, O. E.

(1932) Mozart und die Wiener Logen. Zur Geschichte seiner Freimaurer-' Kompositionen, Wien.

DOVNAR-ZAPOL'SKIJ, M. V.

(1907) Idealy dekabristov, Moskva.

DUDA, G.

(1958) "Gewiß man hat mir Gift gegeben“, Pähl/Obb.

EJDEL'MAN, N. Ja.

(1979) Puškin i dekabristy. Iz istorii vzaimootnošenii, Moskva.

(1984) Portrety Dekabristov, Köln.

(1987) Puskkin iz biografii i tvorčestva 1826/1837, Moskva.

FRANK, J. G.

(1947/48) Pushkin and Goethe, in: Slavonic Review 26, $161 \mathrm{f}$.

\section{GERBEL', N. V.}

(1876) Dlja buduš̌ego polnago sobranija sočinenij A. S. Puškina. Stichotvorenija Puskina, in: Russkij archiv 10, 205-44.

GERSENZON, M. O.

(1919) Mudrost' Puškina, Moskva. (ND Ann Arbor/Michigan 1983)

(1926) Stat'i o Puskine, Leningrad.

\section{DIE VEREINIGTE GROSSLOGE}

(1955) (Hrsgg. v. d. Vereinigten Großloge der alten freien und angenommenen Maurer von Deutschland), Frankfurt am Main.

GROSSMAN, L. P.

(1923) Étjudy o Puškine, Moskva/Petrograd.

HASS, L.

(1982)

Wolnomularstwo w Europie srodkowej-wschodniej w XVIII. i XIX. wieku, Wrocław/Warszawa/Krak6w/Gdarisk.

IVANOV, V. F

(1934) Ot Petra do našich dnej, Charbin.

(1940) A. S. Puškin i masonstvo, Charbin.

(1992) Tajny masonstva, vypusk 2, in: BAŠILOV, B.: Istorija russkogo masonstva, Moskva, 77-126. 


\section{KOBILINSKI-ELLIS, L.}

(1948) Puschkin. Der religiöse Genius RuBlands, Olten.

KOCH, R.

(1911) Br. Mozart. Freimaurer und Illuminaten. Nebst einigen freimaurerischen kulturhistorischen Skizzen, Bad Reichenhall.

KONDRACKIJ, A. P.

(1900) Russkij archiv 38, 546.

(1901) Bessarabija v proizvedenijach Puskina, in: Russkij archiv 39, 129-33.

KOŽEVNIKOV, V.

(1988) Sivrovannye క̌trofy «Evgenija Onegina», in: Novyj mir 6, 259-68.

KUL'MAN, N. K.

(1907) K istorii masonstva v Rossii. Kišinevskaja loža, in: Žumal Ministerstva narodnago prosvěščnija, (nov. ser.) 11, 343-73.

LEDNICKI, W.

(1951) Puskin, Tjutchev, Mieckiewicz and the Decembrists. Legend and Facts, in: Slavonic Review 29, 375-401.

LEIGHTON, L. G.

(1977)

(1982)

(1983) Pushkin and Marlinskij. Decembrist Allusions, in: Russian literature 14/15, 351-82.

(1994) The Esoteric Tradition in Russian Romantic Literature. Decembrism and Freemasonry, Pennsylvania. [IV]

LERNER, N. $O$.

(1909)

Zametka o Puškine, in: Russkaja starina 140, 192-210.

(1910)

LIPRANDI, I. P.

(1866)

Iz dnevnika i vospominanij, in: Russkij archiv 4 (1866), 1213-84, bes. $1240 / 01$.

LOTMAN, Ju. M.

(1983)

(1983)
Aleksandr Sergeevið Puškin, biografija pisatelja, Leningrad.

Roman A. S. Puškina. „Evgenij Onegin“. Kommentarij. Posobie dlja čtenija, Leningrad. 
LOTMAN, Ju. M. [Fortsetzung]

Besedy o russkoj literature. Byt i tradicii russkogo dvorjanstva (XVIIInačalo XIX veka), Sankt-Peterburg. (Dt. Köln/Weimar/Wien 1997)

(1997) Kagan, Gennadij: Rußlands Adel. Eine Kulturgeschichte von Peter I. bis Nikolaus I., Köln/Weimar/Wien. (=Bausteine zur Slavischen Philologie und Kulturgeschichte N.F. Reihe A: Slavistische Forschungen , 21)men

MAKOGONENKO, G. P.

(1982) Tvorłestvo A. S. Puskkina v 1830-e gody, tom 1-2, Leningrad.

MEYER, H. V.

(1994) Romantische Orientierung. Wandermodelle der romantischen Bewegung (Rußland): Kjuchel'beker - Puškin - Vel'tman, München. (=Slavistische Beiträge 333)

MJAKOTIN, V. A.

(1923)

A. S. Puskin i dekabristy, Berlin.

NABOKOV, V. V.

(1964) Eugene Onegin. Vols. I-IV, New York. (=Bollinger series 72)

NEČKINA, M. B.

(1949) Puškin i dekabristy. Vsesojuznoe obščestvo po rasprostraneniju politǐ̌eskich i naučnych znanii, Moskva.

NERRE, E.

(1986) Puškins «Grobovščik» als Parodie auf das Freimaurertum, in: Wiener Slavistischer Almanach 17, 5-32.

NEVELEV, G. A.

(1985) «Istina sil'nee Carja». (A. S. Puskin v rabote nad istoriej dekabristov), Moskva.

NIEPEL, $M$.

(1986) Die narrative Perspektivierung in Puškins Erzählungen. Ansätze zu einer kommunikationsorientierten Erzähleranalyse, Erlangen/Nürmberg.

NOVIKOV, I. A.

(1949) Pułkin v izgnanii, Moskva.

OFENBACH, $\mathrm{H}$.

(1986) Briefmarken erzählen Freimaurergeschichte, Münster.

OSORGIN, M. A.

(1937) Puškin - vol'nyj kamenščik, in: Poslednyja novosti, (sreda) 10. fevr., no. $5801,4,1-6$. 
PIKSANOV, N. K.

(1922) Puškinskaja studija, Petrograd.

PUGACEV, V. V.

(1977) Iz vzaimootnošenii Puškina i dekabristov, in: Studia Slavica Academiae Scientarum Hungaricae 23, 97-108.

PUSKKIN, A. S.

(1956-58) Polnoe sobranie sočinenij v desjati tomach, Moskva.

(1870) Novye pis'ma Puškina k V. A. Žukovskomu, in: Russkij archiv 8, 1169-83.

(1986) Tajnye zapiski 1836-1837 godov, Minneapolis.

PYPIN, A. N.

(1887) Istorija teksta sočinenij Puskkina, in: Vestnik Evropy 22, fevral', 780802.

(1887) Radiščev i Puškin B. Jakuškina, in: Vestnik Evropy 23, 870-79.

ROSEN, $\mathbf{N}$.

(1975) The Magic Cards in the "Queen of Spades“, in: The Slavic and East European Journal 19, 255-75.

SACHOVSKOJ, A. J.

(1941) Betrachtung über die Religiösität Puschkins, Berlin.

SAKULIN, P. N.

(1920) Puškin. Istoriko-literatumye éskizy. Puškin i Radiš̌ev. Novoe rešenie starogo voprosa, Moskva.

SCEGOLEV, P. E.

(1908) K istorii Puškinskoj masonskoj ložy, in: Minuvšie gody 5/6 [=Žumal posvjaščennyj istorii i literature), (=Slavistic Printings and reprintings 120 (Bd. 1-3), The Hague 1973], 517-20.

SCHMID, W.

(1997)

„Pique Dame“ als poetologische Novelle, in: Die Welt der Slawen [Internationale Halbjahresschrift für Slavistik, München] 42/1, 1-33.

(1998) Sen-Žermen, Kazanova, Tomskij, Puß̌kin: magi rasskazyvaija, in: Die Welt der Slawen [Internationale Halbjahresschrift für Slavistik, München] $43,153-60$.

SCHRAMM, G.

(1973) Puškins politisches Dilemma, in: Das Vergangene und die Geschichte, Thadden, R. v/Pistohlkors, G. v/Weiss, H. (Hrsg.): (Festschrift für Reinhard Wittram), Göttingen, 312-36. 
SEMEVSKIJ, V. I.

(1909) Masonskaja loža v Kiłineve, in: SEMEVSKIJ, V. I.: Politiðeskaja i obక̌cestvennyja idei dekabristov, S.-Peterburg, 313-21. (davor in: Minuvsie gody $1 / 3,162-70$ )

SETSCHKAREFF, V.

(1963) Alexander Puschkin. Sein Leben und Werk, Wiesbaden.

SHAW, J. T.

(1962) The 'Conclusion' of Puskin's Queen of Spades, in: Studies in Russian and Polish Literature, $119 f$.

(1985) Pushkin. A concordance to the Poetry, vols. 1-2, Columbus/Ohio.

SLOVAR' JAZYKA PUŠKINA

(1946-59) Slovar' jazyka Puškina, tom 1-4, Moskva. (=Akademija Nauk SSSR, institut jazykoznanija)

SOBOLEVSKIJ, S. A.

(1870) Tainstvennyja primety v žizni Puškina, in: Russkij archiv 8, 1377-88.

SOKOLOVSKAJA, T. $O$.

(1907) Dvadcat' pjataja masonskaja loža sojuza Astrei, in: Russkaja starina 129,642 .

STEN, S. .

(1931) Puškin mistik. Istoriko-literaturnyj ǒ̌erk, Riga.

STÖCKL, E.

(1962) Puškin und die Musik. (Die Bedeutung der Werke A. S.Puškins für die Tonkunst). Mit einer annotierenden Bibliographie der Puškinvertonungen (1815-1960), Bde. 1-2, Jena.

STOJUNIN, V. Ja.

(1880) Aleksandr Sergeevic Pußkin, biografija, in: Istoriceskij vestnik 6-8, I, 6, 217-54; I, 7, 435-53; I, 8, 615-66.

ŠUL'C, R.

(19885) Puškin i knidskij mif, München.

TOMAŠEVSKU, B.

(1925) Puskin. Sovremennye problemy istoriko-literaturnogo izuð̌enija, Leningrad.

TRUBECKOJ, B. A.

(1973) «Tvoej molvoj napol'nen sej predel...» (Stranicy žızni Puškina v Moldavii), Kiß̌inev. 
TYMČIŠN, V. V.

(1979) Puškin yn Moldova, Kisinèu.

TYRKOVA-VIL'JAMS, A.

(1929-48) Žizn' Puškina, Pariž.

VENGEROV, S. A.

(1908) Pußkin, tom 1-2, S.-Peterburg.

VERESAEV, V. V.

(1932) Puškin v žizni. Sistematǐeskij svod podlinnych svidetel'stv sovremennikov, Moskva/Leningrad.

(1937) Sputniki Puškina, tom I-II, Moskva.

VERNADSKIJ, G. V.

(1937) Pushkin and the Decembrists, in: CROSS, S. H./SIMMONS, E. J.: Centennial essays for Pushkin, Cambridge.

VINOGRADOV, V. V.

(1941) Stil' Puškina, Moskva.

VJAZEMSKIJ, P. A.

(1877) Charakteristiki, zametki, vospominanija, in: Russkij archiv 15, 66-78.

(1878-86) Polnoe sobranie sočinenij, S.-Peterburg.

(1892) Pis'ma, in: Russkaja starina 74 (1892), 658.

VOLKOV, G.

(1978) Puškin i Čaadaev. Vysokoe prednaznað̌nie Rossii, in: Novyj mir 6, 250-66.

WEBER, H. B.

(1968)

"Pikovaja dama»: A Case of Freemasonry in Russian Literature, in: The Slavic and East European Journal 12, 435-47.

WOLF, M. [Wolfmark@cip.ub.uni-muenchen de]

(1992) Aspekte der Symbolik und Historie des Freimaurertums bei A. S. PuSkin, in: Arion [Jahrbuch der deutschen Puschkin-Gesellschaft] 2, 273302.

WOLL, J.

(1976) „Mozart and Salieri" and the Concept of Tragedy, in: Canadian-American Slavic Studies 10, 250-63. 


\section{Personenverzeichnis}

$\therefore$ Dem Nachnamen vorangestellt markiert dieses Zeichen als maurerisches Abkürzungssymbol hier die unbestrittene Mitgliedschaft in einer Freimaurer-Loge.

Fettgedruckte Ziffern stehen für Stellen der Verarbeitung freimaurerischer Motive und Rituale in Puškins Werk.

Literarische Gestaltennamen stehen kursiv. 


\section{- A -}

Abramovix, S. L. XXIX.

Agethen, $M$. III.

Aischylos 18.

Aleksandr I. (car') $12,42,52,54,60, I X, X V$, XXI, XXVIII.

Aleksandr II. (car') 12, XVII.

Alekseev, N. S. 59, 107, 110.

Altsuler, M. VIII.

Ambelain, R. XXIV.

Amburger, E. VIII.

$\therefore$ Anderson, J. (Reverend) 22 (.,Alte Pflichten", "Constitutions of the Free-Masons"), 23 (..Alte Pflichten"), 32, 52, 92.

Andre-Gódalge, A. XXIV.

Anna Ioanovna (carica) 42.

Annenkov, P. V. 12, XXIX.

Antoni, O. 65, XXIV (Wortschatz der Freimaurerlyrik).

A.S.P. 94 (Initialen von Adrijan Semenovič Prochorov in Grobovszik. 1830 wie von seinem Schöpfer Aleksandr Sergeevix Puškin) 108.

Avrech, A. Ja. VIII.

$\therefore$ Aude-de-Sion, K. I. 55.

$$
\text { - B - }
$$

Bächtold-Stäubli, H. 11, 88, III.

Baedocker, K. 41, 53.

Baehr, S. L. 1, 65, VIII.

$\therefore$ Bagrjanskij, M. I. 48.

Bakounine [Bakunina], T. A. siehe Bakunina.

Bakunina, T. A. 13, 48/49, 53/54, 57, 71/72, $76,1, I X / X$.

$\therefore$ Balasov, A. D. 55/56.

Bálazs, E. H. 10, 27, 41, 48/49, 52, 64, VII, XI-XIV, XVI, XVIII.

Bal'mont, K. 77.

Balsamo, J. siehe Cagliostro.

$\therefore$ Barooci (Barozi/Barozzi) A. I. (General) 59 (Mitglied der Loge «Ovidij»).

Barruel, A. 50.

Barskov, Ja. L. S1, IX.

$\therefore$ Bartek, A. III.

Bartenev, P. Ju. 95, XXIX.

Bartiett, R. P. XV.

Bašilov, B. F. 14 («Puškin i masonstvo» o.J.), IX, XXIX.

$\therefore$ Batenkov, G. S. 62 .

Bayard, J.-P. III, XXIV, XXIX.

Baylot, J. XXIV.

$\therefore$ Bazanov/Bazenov, V. I. 48, XXIX.

$\therefore$ Beaumarchais, P.-A. 86/87, 112 .
Begemann, W. 22 (EinfluB von Revered J. ADderson af dos Freimaurertum/Fribles Freimaurertum in England).

$\therefore$ Benkeodorff, A. Ch. 55 .

Berberova, N. N. 13, DX.

$\therefore$ Bernarda, M. 59 (Mitbegrinder der loge avidijo, dritter Grad).

Bertholet, A. 24 (onAtandisziplin". Prüfung für den Initisnten), III.

$\therefore$ Bestuzev-Marlinslij, A. A. 62, 102, XXXI.

( $\therefore$ ) Bezuchov, Pierre (Held in Tolstojs *Vojna i mirs 1868/69) 12.

Biedemann, H. 19 (Faszination der Freimaurerei. Kultur des ,höchsten Wissens"), III. XXVII.

Binder, D. 32-35 („Die diskrete Gesellschaft"), (Meister-Aufnahme), III.

Blagoj, D. D. IX, XXIX.

Blok, A. A. VIII.

$\therefore$ B(e/oe/e)ber, I. V. 55, 57 .

Böhme, J. 47, 51, XXII.

$\therefore$ Bogdanovic, I. F. 44.

Bogoljubov, V. A. 49, IX.

Bokor, C. v. XXIV.

Bonhoff, C. XXIV.

Boos, H. 9, III.

$\therefore$ Borozdin, N. M. 55 .

Bostunic [Švarc-Bostunið], G. siehe Schwar(t)zBostunitsch.

Boucher, J. XXIV.

Bourychkine, P. 13, 49, 53, 1, X.

Bozerjanov, I. Ch. IX.

$\therefore$ Brankoviz, I. 59 (Gründungsmitglied der La ge «Ovidij»).

Braunbehrens, V. 83-85, 112, XXIX.

Brun-Zejmis, J. XXIX.

Buck, J. D. XXV.

Bühler, J. III.

Burgio, A. XXV.

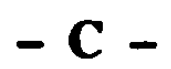

Cagliostro, A. 50/51.

Camerjan, I. P. X.

$\therefore$ Casanova, J. 51, 96, XXXIII.

Chailley-Bert, J. XXV.

Chazin, M. XXIX.

$\therefore$ Chernnicer, 1. I. 49.

$\therefore$ Cheraskov, M. M. 23 (,Proischoždenie masonstva i ego razvitie $v$ Anglii XVIII i XIX v."), 44, 48/49, 53, 61, 65, XVIII (, $\mathrm{Zu} \mathrm{Ch}-\mathrm{s}$ Dichlungsauffassung" von $\mathrm{H}$. Rothe), XIX, (*Masonstvo v ego pros$\operatorname{lom}(. .) \times.(1915)$.

Cjavlovskaja, T. G. 70-73, XXIX. 
Clarke, J. E. 58, X.

Clemens (Papst) 10.

Coil, H. W. III.

Cross, A. G. VIII, X.

Cross, A. K. XV.

Cross, S. H. XXXIV.

$\therefore$ Casdaev, P. Ja 70, 74775, 79, 80 (Meistergrad), 115, XI, XV, XXXIV.

Caplix, E. I. (=Caplickij) 96, 113.

Cebotarev, Ch. A. 48.

Cekalinskij, P. P. 96.

Cerkasskij, A. A. 48.

$\therefore$ Culkov V. V. 48.

\section{- D -}

Dalchow, J. XXX.

$\therefore$ Deiters, H. G. 30, III.

Derzavin, G. R. $42,49$.

$\therefore$ Desaguliers, J. T. 38.

Deutsch, O. E. XXX.

$\therefore$ Dmitriev, I. I. 81 .

$\therefore$ Dmitriev-Mamonov, M. A. 62.

Dodel'cev, R. F. X.

Döring-Smirnov, J. R. XIX.

$\therefore$ Dolgorukij, Ju. M. 47.

Dostoevskij, F. M. 81 («Selo Stepanxikogo i ego obitateli» (1859)).

Dovnar-Zapol'skij, M. V. 13, 52, 58, X, XXX.

$\therefore$ Dragusevix, M. 59 (Gründungsmitglied der Loge rOvidijw).

Družinin, N. M. 38, X.

Duda, G. XXX.

Duwel, W. $X$.

Dyer, C(olin). F. W. 20, XXV.

$$
-\mathbf{E}-
$$

Edwands, L. III.

Eisenbach, A. X.

Ekaterina II. (carica) 12, 41, 45-47, 50-52 (Komödien mit Parodien auf Cagliostro, C. als Illuminat), 54, 61/62,105/06, 114, IX/X, XV, XVII, XIX, XXII/XXIII.

$\therefore$ Elagin, I. P. 46, 53, 78.

Elisabeth siche Elizaveta

Elizaveta (carica) 41/42, 44/45.

Elkin, B. X.

Ellisen, E. E. (G. H.) $55,57,96$.

$\therefore$ Endres, F. C. $20,37,39, \mathrm{XXV}$.

Erier, M. 25 (Moderner Mensch und das Ritud), 27/28 (rituelles Diktum, freimaurerische Ritual-Ästhetik. Frage-und-Antwort-Spiel, Schema zum Ritusverlauf,
Aufnahmo-Zeremoniell, Meister-Erhebung), $32, X X V$.

Esevskij, S. $X$.

Euripides 18.

Evgenij Onegin 79 ( $\mathrm{OOn}$ farmazon in $\times \mathrm{Ev}$ seall Oregins 1823-30).

$$
-\dot{\mathbf{E}}-
$$

Ejdel'man, N. Ja. 14, XXX.

El'kin/Elkin E. 13, X.

$$
-\mathbf{F}-
$$

Faivre, A. XI.

Fara III (Pseudonym).

Farina, S. 39, XXV.

Faust XXIV (,Faustischer Drang" (1920)).

Fay, B. XI.

Foddersen, K. C. F. XXV.

Fel'štinskij, Ju. G. XVI.

$\therefore$ Fessler, I. A. 25 (Eleusinien des 19. Jhs.), $55,56$.

Filatov, N. F. XI.

Findeisen, H. XI.

$\therefore$ Findel, G. J. G. III.

Finlayson, I. F. XXV.

$\therefore$ Fischer, J. K. A. 44, 48, XI.

Fischer, M. W. IV.

Fischer, R. 23 ("Alie Pllichten", "Grundgeset. der Freimaurerei"), 29 (,Ritual und Symbol $\left.{ }^{*}\right), X X V$.

$\therefore$ Fleri [Fleury], P. 59 (Gríndungsmitglied der Loge rOvidijw).

$\therefore$ Forster, E. Ch. (J. G.) VIl.

Frank, J. G. XXX.

$\therefore$ Frenkel', I. I. 48.

$\therefore$ Frick, K. R. H. 69, IV.

$\therefore$ Friedrich der Grobe 38, 42.

$\therefore$ Friedrichs, E. 9, 14, 42, 44-47, 50-58, 60-62, XI.

$$
-\mathbf{G} \text { - }
$$

$\therefore$ Gagarin, G. P. 47.

$\therefore$ Gamaleja, S. I. 48, 50, 55 .

Gantner, T. IV.

Garrard, J. G. XVIII.

Gerbel, N. V. XXX.

Gercen, A. 81 (KZapiski odnogo molodogo Celovekan 1840/41).

Gersenzon, M. O. XI, XXX.

Geyer, D. 9, 13, 45, 49, 52, XI. 
Gillel'son, M. I. XI.

$\therefore$ Girljanda, R. 59 (Grindungsmitglied und Zo remonienmeister der Loge kOvidij»).

$\therefore$ Glinka, F. N. 14, 62, XX. («lz zapiskach knizek masonov grafa M. Ju. Viel'gorskogo i F. N. G-i).

$\therefore$ Goethe, J. W. v. 18 (,Maximen und Reflektionea"), 32, 51 (,Grobkophta"), 66, 81, 88, 93, XXIV (Goethes Faust; der ,Faustische Drang"), XXX.

$\therefore$ Golenistev-Kutuzov (Ehrentitel: Smolenskij), M. I. 55 (Russischer Feldmarschall).

Golicyna, N. P. siehe «Grafinja staraja*** *

$\therefore$ Gordon, P. I. (J. P.) 42.

Gorkij, M. 81 («V ljudjach» (1918), 7).

$\therefore$ Gould, R. F. IV.

Gräfin siehe «Grafinja staraja****

«Grafinja staraja**** (Gestalt in *Pikovaja damax 1833/34, mutmaBlich stilisierte Golicyna, N. P.) 95, 97-102, 113/14.

$\therefore$ Griboedov, A. S. 82 (G. war 1816/17 Mitglied der Loge aLes Amis reunisw und gehörte 1817 mit zu den Gründern der Loge „Du Bien“).

$\therefore$ Grobegger, E. 11, XXV.

Grossman, L. P. XXX.

Gutsche, G. J. 94, XII, XXXI.$$
\text { - H - }
$$

$\therefore$ Haack. F.-W. 33 (PaBwort und Griff), IV.

Hall, M. P. XXV.

Hammermayer, L. 9, 10, 17, 19, 22 (nichtpolitischer vs. politischer Geheimbund), 48, IV, VII, XI-XIV, XVI, XVIII.

Hannuschka, R. IV.

Hansen-Löve, A. A. 77.

Hander, H.-B. XII, XVIII.

Harkins, W. E. XII.

Hass, L. XII, XXX.

$\therefore$ Haugwitz (Chaugvic), C. A. H. 60.

Haumant, E. XII.

Hawkins, E. L. A. I.

Heckethorn, C. W. IV.

Hegel, G. F. W. Vorwortseite.

Heine, H. Vorwortseite.

$\therefore$ Heane am Rhyn, O. 20 (Systematischer Zugang zur freimaurerischen Symbolik. Personenkreisbezogenheit), 25 (wider die "Hochgrade", , Johannismaurerei", „blave Maurerei", Farbe „Blau“, englische Barhuitenbriderschafien), 28 (verdunkelte. nicherarteitende Loge), 29 (Ostung der Kultbsuten und Gräber), 30-32 (,diustere Umgebung des Lichtsuchenden $\%$,.An-
die-TL-Kopfen" $/$, Hochgrade v8. Schottisches System" ${ }^{\omega}$ ), 35/36, 39, XXVI.

Hennings, P. 42, 45, XII.

Hermann 95-102, 113 (Held in *Pikovaja daman 1833/34).

Herzen, A. siche Gercen, A.

Hielscher, Korla 80.

Hirt, A. L. XXVI.

Hoffmann-Krayer, E. 11.

Holl, M. P. XII.

Holthusen, J. XIX.

Holtorf, J. V.

Holtz, G. V.

Hom, R. 9 (Freimaurerische Historiographie in Deutschland), V.

Horne, A. XXVI.

$\therefore$ Horneffer, A. 20, V, XXVI. (Aufnahmehandlung).

Hoser, J. XXVI.

$\therefore$ Hülter, C. V.

Hume, D. 49.

Huter, U. I.

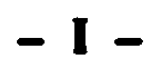

In-Ho, L. Ryu 49.

$\therefore$ Inzov, I. N. (General) 61, 75, 107, 109.

$\therefore$ Ipsilanti (Ypsilanti) A. 56.

Ipsilanti (Ypsilanti) D. 56.

Ischreyt $\mathrm{H}$. XIII.

Ivanina, N. S. 42, XIII.

Ivanov, V. F. 14 («Puskin i masonstvo» 1940), $38 / 39$ („O Petra pervago do našich dnej.

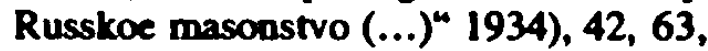
76, XXX.

Ivanov-Razumnik, V. (I.) 51, XIII.

$$
-\mathbf{J}-
$$

Jakuškin, B. XXXIII.

Jan, E. v. XXVI.

Jena, K. v. XIII.

Jensen A. E. 24 (.Beschneidung und Reifezeremonien bei Naturvölkern" ${ }^{\omega}$ ).

Jones, R. E. XIII.

$\therefore$ Junker, H. 33, XXVI.

$$
-\mathbf{K}-
$$

Kagan, Gennadij XXXII.

$\therefore$ Kapoist, A. V. 49.

$\therefore$ Karamzin, N. M. 48, 105, XII-XIV.

Katharina die Grobe siche Ekaterina II. 
Keil, R.-D. 80.

$\therefore$ Keith, J. 42, 46.

Keller, L. XXVI.

Kerner, D. V, XXIX.

$\therefore$ Kessler, H. V.

Kilcter, A. XXVI.

Kireevskij, I. V. 105.

Kirpicnikov, A. I. XIII.

Kizevetter, A. A. XIII.

$\therefore$ Kjurto (Curtot), P. 59 (Oberstleutnant, Grimdungsmitglied der Loge «Ovidij»).

Kjuchel'beker, V. K. XXIX, XXXII.

Klodwig, R. XXVII.

Kobilinskij-Ellis, L. XXXI.

$\therefore$ Koch, R. XXXI.

Kocetkova, N. D. 13, 44, 49, XIII.

$\therefore$ Koüubej, V. P. 62.

Kolokol'nikov, V. Ja 48.

Koodrackij, A. P. XXXI.

Konstantinov, A. XI.

$\therefore$ Konstantin Pavlovic (Velikjj knjaz.) 55.

$\therefore$ Korff, H. Baron v. 58.

Korvin, A. B. XXI.

Koselleck, R. 26/27 (,Pathogenese“ in: „Kritik und Krise“ 1959), V.

Koževnikov, V. XXXI.

Krasnobaev, B. I. 49, XIII.

$\therefore$ Krause, K. C. F. V.

Kuess, G. G. 22 (Einflub von Reverend James Anderson auf das Freimaurertum).

Kukiel, M. XIV.

Kul'man, N. K. 16 (Veröffentlichte Akten ïber die Loge *Ovidij» von 1907) 57, 59. 60, XIV, XXXI.

$\therefore$ Kurakin, A. B. 47, 53.

$\therefore$ Kušlev, E. A. $12,58,59,62,74$, XIV.

$\therefore$ Kutuzov, A. M. 48, XV.

$\therefore$ Kutuzov, M. I. (Russischer Feldmarschall) siche Golenižcev-Kutuzov, M. I.)

\section{$-\mathbf{L}-$}

$\therefore$ Labzin, A. F. 55.

Labzing, A. E. XIX.

Lachmann, H. V.

Langlois, P. I.

$\therefore$ Lantoine, A. V.

Laver, R. 64-66, 68, 73, 85, XIV.

$\therefore$ Lavater, J. K. XIV.

Lebedev, A. A. 63, XIV.

Lebedev, S. I.

Lednicki, W. XXXI.

$\therefore$ Lefort [Le Fort], F. Ja. 42.

Lehmann-Carli, G. XIV.
Leighton, L. G. 14, 39, 41, 49, 58, 69, 97, 100,101, XIV, XXXI.

Lemberg, H. XIV.

$\therefore$ Leanhoff, E. 9-11, 13/14 (Symbolbegriff), 17-19 GKonstitutionenbuch", "Alte Pflichten", "Grundgesetz der Freimaurerospekulative vs. operative Freimaurerei), 20-26, 29 (Osten als freimaurerisches Symbol), 31 46, 49, 51-53, 64, $66,69,71,72,74,81,82,84 / 85,87$. 93. 95/96, 98-101, 105, 110, 1 .

$\therefore$ Lenning/Buchhöndler Hesse 1 (,Enzyklopädie dor Freimurerei...").

Lenz, J. M. R. 48.

Lenz, W. XIII.

Lerner, N. O. 58, XXXI.

Levickij, A. XV.

Liebel-Weckowicz, H. XV.

Ligou, D. I.

Lindner, E. J. XXVII.

Liprandi, I. P. XXXI.

$\therefore$ Lobanov-Rostovskij, I. A. 58.

Lobkowicz, P. K. V.

$\therefore$ Lodyżenskjj [Ladyženskij], A. F. 48.

Longinov, M. N. 12, 42, 48/49, 51, 54, XV.

Lopuchin, P. V. 48.

$\therefore$ Lopuchin, I. V. 46, XVII.

Lotman, Ju. M. 13 (Artikel «masonstvo* in «Sovetskaja istoriceskaja enciklopedija» (1966)), 44, 52 (Artikel kmasonstvo* in «SIE* (1966)), 71, 80, 81, XV, XXXV XXXII.

Ludz, P. Ch. XVI.

Lurker, M. 18 (Freimaurerischer und allgemeiner Symbolbegriff), 23 (f. S.), 19 (Geheimbundwesen), 29 (Osten als freimaurerisches Symbol), 33, 34, 36/37, XXVII.

$\therefore$ L'vov, N. A. 49.

$$
-\mathbf{M}-
$$

MacArthur, G. H. 49, XV.

$\therefore$ Mackey, A. G. 101, 1, XXVII.

Magnickij, M. XV.

$\therefore$ Majkov, V. I. XXIV.

Makogonenko, G. P. 13, 49, XV, XXXI XXXII.

$\therefore$ Maksimovix, M. (Major) 59 (Grindungsmitglied der Loge «Ovidij», dritter Grad).

Marbach, O. XXVII.

$\therefore$ Marlinskij, A. A. siehe $\therefore$ Bestužev-Marinskij, A. A.

Martynov, I. F. 49, XV.

$\therefore$ Majkov, V. I. 44. 
$\therefore$ Mel'gunov, S. P. 12, 18 (Cheraskov-Artikel in: «Masonstvo (...) 1915)», 21 (Sokobovskaja-Artikel in: «Masonstvow (...) 1915), 29, (Sokolovskaja-Artikel in: xMasonstvo» (...) 1915), 33, 34, 39, X, XII. XV, XVII-XXII.

$\therefore$ Melissino, P. I. 45.

$\therefore$ Mellor, A. II, VI.

Meyer, H. V. XXXII.

Mezier, A. V.XV.

Mieckiewicz, A. XIII, XXX.

Miers, H. E. 27 ("Wortaut des Rituals", ,Erkemoungszeichen", "sakrale Zeremonie", "ritueller Duktus", in: Lexikon des Go heimwissens 1979), II.

$\therefore$ Miljukov, P. N. XVI.

$\therefore$ Minc, I. I. XV.

Mjakotin, V. A. 14, XXXII.

$\therefore$ Mogal'cev, K. 47.

Moeller, H. XVI.

$\therefore$ Montesqieu, Ch. de S. 47.

Morgan, W. VI.

$\therefore$ Mozart, W. A. 11 (Gauberflöte", "Hoheslied"s), 67, 83-90 (.Zauberflöte"), 115 , XXVIIXXVIII, XXX.

$\therefore$ Murav'ev, A. N. 62.

$\therefore$ Murav'ev, N. M. 62.

$\therefore$ Murav'ev-Apostol', S. 1.61.

$\therefore$ Musin-Puskkin-Brjus' (-Bruce), V. V. 56, 61.

Myl'nikov, A. S. 50, XVI.$$
-\mathbf{N}-
$$

Nabokov, V. V. 80, XXXII.

Napoleon 70.

$\therefore$ Naryskin, I. A. 54, 58.

Našcokin, P. W. 95.

Naudon, P. VI, XXVII.

Nexkina, M. B. 14, XXXII.

Nerre, E. 14 (Beitrag über das Freimaurertum in «Grobovscik»), 27 (über A. N. Pypin), 89, 90-94, 103, 112, XXXII.

$\therefore$ Nettelbladt, Br. v. 43, 45, XVI.

Nettl, P. 11, 84, XXVII.

Nevelev, G. A. 107, XXXII.

Nevzorov, M. 1. 48, XIII.

Nezelenov, A. I. 12, 49, 52, XVI.

Niepel, M. XXXII.

Nikolsevskij, B. I. XVI.

Nikolaus I. siehe Nikolaj I. oder Nikolaj II.

Nikolaj I. 55, 61, 110, IX, XV, XXXI.

Nikolaj II. XVII.

Norton, B. T. XVII, XX.

$\therefore$ Novikov, A. 1.48. $\therefore$ Novikov, N. I. 12, 42, 43, 47-52, 54, 60/61, 65, 105/06, 114, IX, XV-XVIII, XIX, XXIIIXXIV.

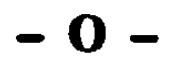

$\therefore$ Ochomikov, K. A. 59 (Mitglied der Loge avidijo).

$\therefore$ Odoevskij, A. I. XXIX.

Ofenbach, H. XXXII.

Olbrich, K. XXVII.

Oliver, G. 23 (,osigns and Symbols"), XXVII.

Orleans, P. v. 96.

$\therefore$ Orlov, M. F. (General) $59-61$ (Mitglied der Loge «Ovidij»), 75, $107 / 08$.

Osorgin, M. A. 12, XIX, XXXII.

Oslo, A. VI.

$\therefore$ Ostermann-Tolstoj, A. I. 55.

Ovidius, Publius Ovidius Naso 74.

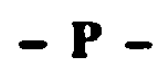

$\therefore$ Panin, N. I. 43, 46, 53.

Pape, W. 9.

Passek, T. P. XXII.

Paul I. siehe Pavel I.

Pavel I. (car') 18, $52-54$ (P. auf einem in Stockholm aushängenden Porträt mit freimaurerischen Emblemen abgebilet, $X X$ («Dva portreta Imeratora Pavla I. s masonskimi émblemami» (1907)), XXII. («Pavel I. i masonstvo 1915x), XXIII.

Pekarskij, P. P. 12, 42, 44, XVII.

$\therefore$ Pestel', P. (P.-M.) I. (Dekabristenfuihrer, Oberst) $14,16,38,55,62,107, X$.

Peter der Grobe siehe Petr I.

Petr I. 42, 44, 49, 53, 107, XXX/XXXI.

Petr III. 44, 53.

Peuckert, W. E. VI.

Pfahl-Traugber, A. XVII.

Pick, F. L. VI.

Piksanov, N. K. 13, 43, 48, XVII, XXXIII.

Pindar 18.

Pisemskij, A. F. XXVII («Masony. Roman» 1912).

Pistohlkors, G. v. XXXIII.

$\therefore$ Philipps, J. (Captain) 42.

Platon 18 (Dialog «Symposion/Gastmahl»).

Platon, Metropolit 52.

Platonov, O. A. XVII.

Pletnev, P. A. 108.

Plimak, E. G. 13, 52, XVII.

Plutarch 32 (Osiris-Legeode P.s).

Pokrovskij, V. I. XVII. 
Polsk, M. S. 36, XXVII.

Polick, A. F. VI.

$\therefore$ Posner, O. 9-11, 13/14 (Symbolbegriff), 1719 („Konstitutionenbuch", "Alte Pflichten", "Gruodgesetz der Freimaurer"/ spekulative vs. operative Freimaurerei), 20-26, 29 (Osten als freimaurerisches Symbol), 31-46, 49, 51-53, 64, 66, 69. $71-74,81,82,84 / 85,87,93,95 / 96$, 98-101, 105, 110, 1 .

$\therefore$ Potockjj, S. K. 55 .

$\therefore$ Pozdoev, O. A. 49, 55, 65, XVII.

Prochorov, Adrijan Semenovic 89-95 (Held in Puskins aGrobovisik» 1830; seine Initialen sind mit denen seines Schöpfers Aleksandr Sergeevit Puskin (A.S.P.) identisch und wird von Golt'lib Sul'c nach Art der Freimaverer mit drei Tirklopfer besucht) 112/13.

Pugacev, V. V. XXXIII.

Puscin, I. I. 59.

$\therefore$ Puscin, P. S. (Begriunder und Stuhlmeister der Loge wOvidij») 14 («Generalu Pusxinu= 1821), 59-61, 68, 70-74, 75, 78, 107 («Generalu Pusxinu* 1821)

$\therefore$ Puskia, A. S. WerkeverzejChNIS (KerneEREIOHE) 16, 107 («Kisinevskij dnevoikw 1821); 56 («Kirdzalix); 68/69 ((,Stances" (1814), «Knjazju A. G. GorZakovu» (1814), «K Batjuškovu» (1814). «K N. G. Lomonosovu» (1814), «Batjusłovu» (1815), «K Pusxtinu» (1815), «K Galicu» (1815), «Vospominanie (K Puscinu)» (1815), «Poslanie k Galiču» (1815), «K Del'vigu» (1815), «Aleksandru» (1815), «Poslanie $k$ Judinu* (1815), «K Zukovskomu» (1816), «Š i̧kovu» (1816), «Djade, nazvavšemu soxinitelja bratom* $(1816) \propto V$. L. Puskinu» (1817)); 70, 74775 («Caadaevu» 1821); 70T. («Generalu Puscinu. 1821); 75f. (AProrol- 1826); 78 ( $\alpha$ Literatumoe izvestie» (1829); «Moja rodoslovnaja» (1830)); 79-82 (aEvgenij Onegin. 1823-30); 82-88 wocart I Sal'eri(1834/31); («Grobovšikw 1830); 94 101 («Pikovaja dama» (1833/34); 104 («Boris Godunov» 1824/25); 108/09 (aPis'maso).

$\therefore$ Puskin, S. L. (Vater) 16, 55, 108.

$\therefore$ Puxkin, V. L. (Onkel) 16, 55, 68, 108.

Pylaev, M. I. 26 («znak», «slovo», «parol'»).

Pypin, A. N. 9, 12, 13, 22-32, 36-38, 42-49, $51-63,68,72,78,91,96,100$, XVIIXVIII, XXXIII.

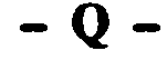

Quentin, C. F. XXVII.

Quiroga A. 71.

$\therefore$ Radizcev, A. N. 48, 51/53, 105/06, 114 , («Puterestvie iz Peterburga v Moskvu* 1790), XV, XVII-XIX, XXXIII.

Raeff, M. XVIII.

$\therefore$ Raevskij, (Major) V. F. (Mitglied der Loge rOvidije) 14, 59/60, 109.

Rasmussen, K. XV.

Rauch, G. v. 41, XVIII.

$\therefore$ Razurnovskij, A. K. 47, 56.

Rehder, P. XIX.

$\therefore$ Reichel(I), P. B. Baron v. 45/46.

Reinalter, H. VI.

$\therefore$ Reinbeck, G. 50, XVIII.

$\therefore$ Repain, N. V. 53.

Riegelmann, $H$. VI.

Rijckenborch, J. v. VI.

Ritter, J. 104.

Roberts, A. E. VI.

Robinson, J. SO.

Rogalla von Bieberstein, J. 63, XVIII.

Rogov, I. M. S2, XVIII.

Ronayoe, E. II.

Rosen, N. XXXIII.

Rothe, H. 48, XVIII.

Rozanov, I. N. 48, XIX.

Rousseau, J. J. 49.

Runkel, F. VI, XXVIII.

$\therefore$ Ryleev, K. F 100-03, XXIX.

Ryu, In H. G. XIX.

$\therefore$ Rževskij, A. A. 47.

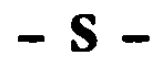

$\therefore$ Saint-Martin, L. C. (Marquis de) 47, 51.

$\therefore$ Saint-Germain, Gr v. 50/51, 95/96, 113, XXXIII.

Sakulin, P. N. 13, XIX, XXXIII.

Salieri, A. XXIX.

Saussure, F. de 20. (Arbitrares Moment zwischen Symbolen und inrem jeweiligen Bedeutungsinhalt)

Schalhorn, B. XIX.

Schauberg. J. 20, 25, 29 (Osten), 30 (Grablegung), 32 (Hand in rechien Winkel al 
bewegen), 33 (Stellenwert der Bibel) 34 37, II.

Schiffmand, G. A. V.

$\therefore$ Schiller, F. 81.

Schimmel, A. 39, XXIV.

Schmid, W(olf) 51, 94, 103, XIX, XXXIII.

$\therefore$ Schneider, F. J. VI.

Schneider, H. VII.

$\therefore$ Schneider, H(erbert). II.

Schranm, G. XXXIII.

$\therefore$ Schroeder, W. 20 , II.

$\therefore$ Schulz, G. 36, XXVIII.

Schurtz, H. 25.

Schwab, F. XXVIII.

Schwartz, J. G. siehe Švarc, J. G.

Schwar(t)z-Bostunitsch, G. 30 (Meisterschrith, Steigen úber den Sarg), $33 / 34$ (Wiedergabe des Meisteraufnahme-Rituals), 91. VII.

Schwarz-Winkelhofer, J. XXVIII.

$\therefore$ Scott, W. L. 81, 90.

Semeka, A. V. 41-43, 50, 52, 81, 90, XIX.

Semevskij, V. I. 13, 58-61, XIX, XXXIV.

Serbanesco, G. VII.

$\therefore$ Sergeev, A. S. 55.

Setschkareff, V. XIX, XXXIV.

Shakespeare, W. 89.

Shaw, J. T. 73/74, 97, XXXIV.

Sidorov, N. P. 23 (Cheraskov-Artikel in $\alpha \mathrm{Ma}$ sonstvo (...) w 1915), 26 (SokolovskajaArtikel in: «Masonstvo* (...) 1915), 33 (Sokolovskaja-Artikel in: *Masonstvo* (...) 1915), 41, 48, 52, X, XIII, XV, XVII-XXII.

Silva, R. XXVIII.

Simmons, E. J. XXXIV.

Six, F. A. VII.

Smith, N. XVII, XX.

Sobolevskij, S. A. XXXIV.

Sokołovskaja, T. O. 13, 26 («UKenik, «tovarisč («diakon») «mastero/«prikosnoveniex), 31 (Nekaman", Zeichen und Borihrungen), 33 (.Masonskija systemy“). $36 / 37,42,54-56,58,77, X X / X X I$. XXXIV.

Solodkij, B. S. 13, XXI.

Sologub, F. 77.

Solov'ev, O. F. 41, XXI (Rossijskaja Akademija nauk).

Sophokles 18.

$\therefore$ Speranskij, M. M. 56.

$\therefore$ Starcev, V. I. XXVXXII. (Akademija nauk SSSR)

$\therefore$ Star(c)k, J. A. Baron v. 47, 57, XXII.

Steiner, G. VII.

Stender-Petersen, A. XXII.
Stennik, Ju. V. XXI.

Stentz, T. 32 (Die Hiram-Sage. Handschrift für Brider), VII.

$\therefore$ Stepanov, A. P. 30, 31, 38, XXII, XXVIII.

Stöckd, E. XXXIV.

Stojunin, V. Ja. XXXIV.

$\therefore$ Stroganov, A. S. 46.

$\therefore$ Sumarokov, A. P. 43.

$\therefore$ Swedenborg, E 51, 96 .

Swinburne, A. Ch. XXVI.

$$
-\mathbf{S}-
$$

Sachovskoj, A. J. XXXIII.

$\therefore$ Sambono, S. 59 (Mitglied in der loge (Ovidij»).

$\therefore$ Sregolev, P. E. 59 (Uber die Geschichte dex Loge * Ovidij»), XXXIII.

$\therefore$ Scerbatov, M. M. 47, XIX.

Simanskij, ?. ?. XXI («Dnevnik \$-ogo» 1970).

Štejn, S. f. XXXIV.

Sul'c, Gotlib 89-93 (Deutscher Held, Handwerker und mutmaBlicher Freimaurer in Puskins «Grobovšcik» 1830).

Sul'c, R. XXXIV.

Sumigorskij, E. S. 53, XXI (*Imperator Pavel I. i masonstion (1915))

$\therefore$ Švarc, (Schwartz) J. G. 47-50, XVIII, XXIII.

Švarc-BostumiZ siehe Schwar(t)z-Bostunitsch

$$
-\mathbf{T} \text { - }
$$

Tarasov, E. I. 49, XXII.

$\therefore$ Tarden, L. S. (Grúndungsmitglied der Loge rOvidij») 59.

$\therefore$ Telepnev, B. 13, 44, 47, 63, XXII.

Thadden, R. v. XXXIII.

Thomson, K. XXVIII.

Tiemann, F. XI.

TjutZev, F. I. XXX.

Tol" (rožd. gr. Tolstaja), S. D. 62, XXII («Istorixeskij ocerk o zagovore dekabristov» (1914)).

$\therefore$ Tolstoj, F. P. 58, XXII.

Tolstoj, L. N. 12 («Vojna i mirw 1868/69, hiet Anm. 19: T-s persöaliche Einstellung zum Freimaurerturn), 39 (das für seinen Roman benutzte Material zum Freimaurerturm), XXII.

Tomasevskij, B. XXXIV.

Tomskij 97, XXXIII.

Torke, H.-J. XIX.

Tourniac, J. XXVIII.

Trescases, J. XXVIII. Markus Wolf - 9783954790715 Downloaded from PubFactory at 01/10/2019 02:51:59AM 
$\therefore$ Tresta, L. Baron v. 58 (Gribdungsmitglied der Loge Ovidijw und Inhaber des (dritvea) Meistergrades).

$\therefore$ Troisi, L. II.

Trubeckoj, B. A. XXXIV.

$\therefore$ Trubeckoj, Ju. N. 48.

$\therefore$ Trubeckoj, N. N. 46, 48, 61 .

Tschizevskij, D. 13, 42, 44, XXII (,Jakob Böh$m e$ in RuBland" (1935)).

$\therefore$ Tuckov, S. A. (Generalmajor, Gritndungsmitglied und Kassenwart der Loge nOvidijo), 59, 61, 109.

Tukalevskij, V. N. 47-50, XXII.

Turgenev, A. I. 68/69, 70.

$\therefore$ Turgenev, I. P. 48, 53, XV.

Turgenev, N. N. 46.

$\therefore$ Turgenev, N. I. 62.

Turgenev, P. P. 48.

Tymcisin, V. V. XXXV.

Tyrkova-Vil'jams, A. XXXV.

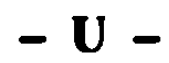

$\therefore$ Ulubyšev, A. D. 84.

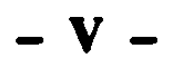

Vacuro, V. E. 69, XXIX.

Vallery-Radot, R. II.

Valmy, M. VII.

Vasjutinskij, A. M. 52.

Vel'oman, A. F. XXXII.

Vengerov, S. A. XXXV.

Veresaev, V. V. 71, 73, XXXV.

Verevkin, A. 48.

Vernadskij, G. V. 13, 41-44, 46-48, 53, 63, 104, XXIII, XXXIV.

$\therefore$ Vibert L. VII.

$\therefore$ Viel'gorskj (Wielhorsky) M. Ju. 56, 83/84, XX. ( $\mathbf{L I}$ zapiskach knižek masonov grafa M. Ju. V-ogo i F. N. Glinki).

Vinogradov, V. V. XXXV.

Vjazemskij, P. A. 69, XXIII, XXXV.

Volkonskij, P. M. 69, XX.

$\therefore$ Volkonskij, S. G. (Dekabrist) 61/62, 109 XX.

Volkov, G. XXXV.

$\therefore$ Voltaire, F. M. 49, 104.

$\therefore$ Voronichin, A. N. IX.

Vvedenskij, S. N. XXIII.
Wagnex, H. 27 (DDie politische und kulturelle Bedeutung der Freimaurer im 18. Jahrhundert, "Arkandisziplin" ${ }^{\text {") }}$, VII, XIXIV, XVI, XVIII.

$\therefore$ Waite, A. E. II, VII.

Ward, A. H. XXVIII.

$\therefore$ Washington, G. VI.

Weber, H. B. 14, 94, 96-100, 102/03, 113, XXXV.

Webster, N. A. VII.

Weishauph, Adam 52.

$\therefore$ WeiB, A. VII.

WeiB, H. XXXIII.

Wells, R. A. VIII.

Wilson, C. VIII.

Winkelmüller, $O$. VIII.

Wirth, O. XXVIII.

Wittram, R. XXXIII.

Wojtowicz, J. VII, XI-XIV, XVI, XVIII.

Wolf, M. XXXV.

Wolfgang, U. XXIII $(, 1.400$ Meter Logenarchive landeten in Moskau. Die materiellen Verluste der dt. Freimaurerei (...) (1997)).

$\therefore$ Wolfstieg, A. 20, II, VIII.

Woll, J. XXXV.

$\therefore$ Wren, C. 42.

$\therefore$ Wuintemberg, A. v. 55 .

Wulf, A. VIII.

$$
-\mathbf{Z}-
$$

Zapadov, A. V. 49, XXIII.

Zavališin, D. I. (Dekabrist) XXIV.

$\therefore$ Zinnendorf, J. W. K. v. 45, 57.

$$
-2
$$

$\therefore$ Zerebcov, A. A. 55/56.

Zukovskij, V. A. 12, 16, 60, 68, 73, 108/09. XXXII. 


\section{Deutsches Motiv- und Sachregister freimaurerischer Symbolik und Allegorik}




\section{- A -}

Abendmahlsfeiem (A. der Kirche) 24.

Aberglauben 9, 21 (deutscher), 81, 87/88, XXVII.

Abgrenzung, gegenüber Nichtmitgliedem 19.

"Ablauf des schematischen "Initiationsritus" 29. "Absicherung der Loge" siehe "Deckung"

Absolutismus, aufgeklärter 9, 13, 45, XI

"Absteigender Ritus" 35.

Abstreifen, menschlicher Gebrechen und Irrtiimet 33.

Abstufung der Arkandisziplinen 26.

.Abzeichen", freimaurerische 35.

"Adam und Eva" 38.

Adel, russischer XXXII (Lotman).

Ägypien 24/25, 32, 36, 38, 51, XXV.

Ästhetik, rivelle 27.

"Akazie" 39 (.A-zweig").

Akademija Nauk XXI (Solov'ev, O. F. veröffentlicht in der Reihe $\alpha$ Rossijskaja Akademija Nauk. Institut istorii»).

Akademija Nauk SSSR XXI (Starcev, V. I. veröffentlicht in der Reihe *Akademija Nauk SSSR»).

Akademie der Wissenschaften siehe Rossijskaja Akademija Nauk).

„Akt der Einweihung"“ 11, 24, 88, 108, 114.

Alchemie 20, 58, XXVII.

Allegorie/Allegorik 19, 23, 28, 31 (freimaurerische A.), 35/37 (,Behawen des Steines" $), 40,67,70,87,88$, $111 / 12$.

Allusionen auf Freimaurer in einzelnen Werken (Anspielungen/«nameki», oder bei Puškin frz. "allusions") 9, 17 (Geheimbund-Allusionen als systematisierender Oberbegriff), 21 , $45,64,67-70,73 / 74,78-82,90$, 94, 96, 100, 103, 104 (Bei Puskin: (frz.) “allusions"), 106, 108, 111-13, XXXI.

.Altar 34-36 (Der Lehrling ersteigt mit 3, der Geselle mit 5 und der Meister mit 7 Stufen den Altar).

"Alte Pflichten" siehe Constitutions

Altertum XXV (Mysterium des A-s).

Altes Testament siehe Bibel

Altersklasse(n) 24 (Tradition det A.), 25/26 (Jingling-Mann-Greis").

.Altschottischer Ritus“ 39.

Anagramm(atik) 101.

An-die-Tir-Klopfen, dreimaliges 30, 65, 113.

Andreasonden, schottischer 42.

Androgynensage (Platon) 18.
Anfeindungen gegeniber der Freimaurerei 10.

Angelegenheiten, innere 18.

Anspielungen siehe unter Allusionen.

.Anstecknadeln" 38 (A. des Dekabristenführers Pavel Pestel').

"Antike" 24, 29, 32, 36, 74.

Aphorismus 106 (A. Puskins iber Freimaurer). "arbeitet", "Loge" 29, 54-56, 72.

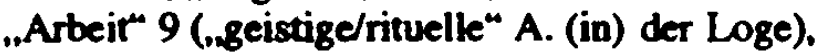
11-13, 16, 25 (Eröffnung der .A. $\left.{ }^{\infty}\right), 26,28$ (nicht arbeitende Loge ist dunkel), 30 (кTrudy/krabotax), ("Schliessung der eigentlichen A. ${ }^{\infty}$ ), 33, 35 (,Saubere Hände bei der $A$. durch weiße Handschute ${ }^{\circ}$ ), 59, 72, 84, 96, 107.

„Arbeitsanweisung/en" 18, 29 (für Brüder Meistex).

„Arbeitsplaa“ 28 (Bruder legt (...) A. auf).

"Arbeitstafel" XXV.

Arbitrarität 20 (des Symbols nach Saussure). . arcana" siehe Arkandisziplinen

Archivdokumente 41 (bis 1917 bekannte A.), 42, 44,52,54,56,59, XXI (Tver'), XIII (Bestände deutscher Freimaurerlogen im Moskauer Sonderarchiv), XXIII.

„Arkandisziplinen“ (,arcana“) 24, 26 (Abstufung der , $a^{\left.2-a^{\circ}\right), ~} 52$ (freimaurerische A-praxis Novikovs), 61, 88.

«Arzamas* s. Dichterkreis «Arzamas».

Atheismus IX.

"Aufheben/aufrichten" 34 (,Der Meister vom Stuhl tritt dazu, faBt den Liegenden mit der linken Hand hinter die rechte Schulter, mit der Rechten die rechte Hand, die der zweite Aufseher unterdessen freigegeben hat macht den Meistergriff, drickt sein rechtes Knie auf das linke des Liegenden und sagt: ,So will ich versuchen, ihn aufzurichten'. Dann hebt ex ihn auf"), 77 ( $*$ Vosstan'* in Prorokx 1826), 91 («Grobovsxik» 1830).

Aufklänung 10, 27, 41, 48, 94, 104-06, 111 , 114.

.Aufnahme" 12, 16 (,Ritual der A." ), 24 (,A. in den Bund $\left.{ }^{\circ}\right), 27$ (,A-ritual $\%$, Azeremoniell"), 29, (, A. in den Bund"), 32.36, 67, 70, 74, $76777,91,93,111,115, \mathrm{XXV1}$ (Aufnahmehandlung), XXVIII («Prinjatie $\vee$ masony $\vee 1815$ godu» (1870)). 
"Aufrichtigkeit" 37 (,Senkblei"\% als das Symbol für "A.", "Geradheir" und die "Offenherzigkeit für das .ganze Leben"), 86 (,Aufrichtige Freundschaft" («Iskrennyj sojuz») in Mocart i Sal'erio 1830/31).

"Aufsagen des Eidesformel" 31.

Aufseher 27 (,erster/zweiter A. ${ }^{*}$ ), 33/34 (,WinkelmaB auf der Brust des Meisters oder des Aufsehers"), 36/37, 42 (Gordon), 72, 92.

"Aufsteigen" 26 (Bedirfnis aufzusteigen/ Aufsteigender Ritus), 32, 100.

"Aufzunetrmender" siehe "Initiant".

„Ausruf" 34 (,Fäulnis" als erster A. des Erstaunens, „Benac" im Scheine).

„Aussto8" 34 (Symbolisient „A." aus der ,alten "Geselleogemeinschaft).

"AuBenweld AuBenraum" 27.

Autobiographie, a. Literatur Puškins 14, 16/17, $47,63,75,107,111,115$.

$$
-\mathbf{B}-
$$

„Baldachin“ 37 („vielfarbiger B.“ symbolisiert bei den Freimaurem die "Jakobskiter","B." verkörpert den ,Himmel", 99/100 («Pikovaja dama» $1833 / 34), 113$.

"Bänder", .,Farbenordnung der B.“ 38.

"Bauart des Salomonischen Tempels“ 29.

Bauhüttenbruderschaften 9, 23, 25.

„Baumeister" 29 (,.Tod des B-s"), 35 (,Geselle erlebt Identifikation mit Baumeister Hiram").

"Baumeister aller Welten", siche „Grober Baumeister aller Welten".

Bausagentradition 32.

„BAW", siehe „Grober Baumeister aller Welten".

"Beamte“ 38, 46, 61, 70.

"Bedecken" 33 (Sarg wird bei Meistererhebung mit Leinwand bedeckt).

Bedeutung, kulturelle 21.

Bedeutung, metaphysische 38.

Bedeutung, politische 21.

"Bedeutung", „symbolische“ 11.

"Bedeutungsebenen", verschiedene 26 (der Johannisgrade).

„Befördenung" 23 (B. zum Gesellen), 27 (Requisit der B.), 32 (zu befiordernde Geselkn), 39 (B. zum Gesellen), 92 (B. zurm Meister).

"Befugnis" 36 (Bei Freimaurern versinnbildlicht det "Steinmetzschlegel“/,Ham- mer auch die ,Macht", den "Willen", die "B.", und auch die materielle Gewalt des operativen Maurers).

„Begräbnis" 32 (symbolisches B.), 39 (des irdischeo Menschen), 95 (Hemann nimmt an Begräbnis teil in -Pilovaja damas 1833/34).

"Begräbnisprozession" 37 (freimaurerische B.).

"Behaven des Steines" 37, 65.

"Bekleidung" siebe Kleidung.

"Beleuchumg" 26 (ausschlieblich künstlich in det Loge, selbst bei hellstem Tag), 92 (,Spärliche Beleachung" in aGrobovscits 1830)

„Benac" siche, Mac-Benac".

Berlin XII.

Berührung 26, 33, 92 . (zwischenkörperliche B.). Bessarabien XXX (B. im Werk Puskins).

"Bestimmung der Zeit" 35.

"Besuch, briderlicher" 26, 89 (Gotlib Sul'c in Grobovšxilt- 1830)

"Beweglich" 37 (weil keinen festen Platz in de Loge, 2. B. die „Kheinodien“), 98 (bewegliches Skelett in arobovsciks 1830).

Beteuerungen der Freimaurer 10, 26, 51 .

Bezeichnendes (signifiant) 20.

Bezeichnetes (signifie) 20.

„Bibel“ 36 (,aufgeschlagene B. “), XXVI. (B. als freimaurerisches Symbol), 38/39, 77.

Bibelstelken 32 (1Könige 4, 6; 1Könige 5, 15 32; 2Chronik 2, 13/14), 32 (1Könige 7, 15-22), 35 (1Mose 28, 12f.), 63 (AT/NT), 74 (Jesaja 6 , 2-10), 77, 100 (1Mose 28, 12f.).

„Biene“ 39.

"Bienenkorb" 39.

Bilder der Freimaurerei siehe Ikonogaphie der Freimaurerei XXV

Bildhaver 32 (altägyptische StatuenbildhaverRituale).

"Bijou“ 38.

„Blau“ 25, 38 (.Farbe des Himmels und der Johannismaurer").

"Blutbedecktes Handtuch" 77.

"Boas" siehe ,Jachin und B.").

Bodenteppich siehe Teppich.

"Brauchtur" 11 (,freimaurerisches/symbolisches").

„Brauchtum-Utensilien" 11.

„Brennende Kerzen“ 33 (drei kleine Lichter).

Briefmarken XXXII (B. erzählen Freimaurergeschichte).

Briefwechsel, Puskins 14, 17. 
.Bronzemedaille" 31 (Symbol für die "Ruhmsuche").

„Brr." (freimaurerische Abbreviatur) siehe Bruder.

, Ander $\%$, Bribder 20 (allgemeine Bundaugehörigkeitsbezeichnung), $22, \quad 28$ (Brivder werden in den Tempel gefuihrt; Bruder legt Aubeitsplan auf), 29 (, never B." ), 30 (drei Rosen" werden einem „B." mit ins "Grab" gegebea), 31 (Verschwiegenheit gegenuiber Br-a niedrigerer Grade), 34, 89.

Bruderschafien, geistliche 20, 23 .

Bruderschaften, klösterliche 20.

„Brust, entblöBte“ 27, 30 (B. gegen B. als einen der fünf Punkte der Meisterschaft), 34, 37 (.WinkelmaB auf der B. des Meisters oder der Aufseher), 76 («Prorok- 1826).

Bulle(n), Päpstliche 10 (Erste 28.4.1738), 69.

„Bund" 9 (Anhänger des B-es), 11-13 (Ideen des B.), $27,30,36,41,42,44,49$, $61,65,68,70,84,87,90,95$.

.Bundeskleider" 35 (,w. Bundeskleider"/ .Schurzfelle"s).

\section{$-\mathbf{C}-$}

Chlysten 69.

"Choral" 33.

Christentum, frithes 20.

Code 17, 21, 78, 115.

Comeoiusgesellschafi XXV.

"Constitutions" (1723) 17, 22, 32 (Andersons Konstitutionenbuch), 38, 4), 42$44,46 / 47,69,92, X X V$.

$$
\text { - D - }
$$

.Danksagung 35.

.David" 32 (.,Tod König D-s").

.Deckung" 28 (,D." mach außen und nach innen, steht für gesichert vor dem Eintritt Unbefugter), 35 (..Absicherung der Loge").

Dockmantel für die Dekabristen siehe Dekabristen.

.Degen“ 37 (als zeremonielles Utensil Hochgrad-Freimaurerei), 74.

Dekabristen(aufstand) 12 (emeuertes Verbot der Freimaurerei 1821), 7 (Biinde der D.), 16, 36, 61/62 (Freimaurerei als Deckmantel für die D.), 66 ,
$77,82 / 83,103,10607,110-13$, $120 / 21, X I, X I V, X V I I, X I X / X X$, XXII-XXXIV.

Deutsche Handwerker siehe Handwerker "Diakoo" 26.

Dialog 11 (rituell-stereotyper D. in der Loge), 18, 21, 28, 45 (Dialog der Freimairet zuerst mit Ekaterina II.), S6 (Kurzer D. det zaristischen Behörden mit den Freimaurem nach 1810), 70 (rituelle D.-Wendungen), $111,113$.

Dichterkreis *Arzamass 12, 16, 62, 69, 70, 108. XI, XIII.

Dichtung siehe Literatur.

"Diplome", "freimaurerische" 41.

disciplina arcani siche Arkandisziplinen.

Dogmatik 38, 41 (fehlende D. bei der wahren Freimaurerei).

"Dokch" 31, 37 (,D." als zeremonielles Utensil), 82, (rätselhafie Strophe $D X$ im «vgenij Onegin» 1823-30 mit der Verszeile: «Kinžal L, ten' $B(\ldots) \times)$.

Drama 11, XXV, XXXV (Freimaurentramalen, in Österreich (1770-1880)).

„Drei/dreimalig" 14 (D. Elemente des Freimaurerturns als Quelle in literarischen Text), 16 (D. Johannisgrade), 25, 33/34 (d. Reisen um den "Tolen"/d. Rosen werden einem Bruder mit ins Grab gegeben), 36 (,d. Reisen $\%, D$. Kleine Lichter brennen als Kerzeo auf d. Säulen $\left.{ }^{\infty}\right), 37$ (.d. Hauptesprossen dex Jakobsleiter"), 57/58 (Licht, Klopien, Schieben als freimaurerische Spezifik), 72 (.oD-maliges Klopien an die Tïr nach Freimauretart in aGrobovsciks 1830), 79 (Caadaev/Onegin in Evgenij Ooegin* 1823-30), 83 (D. Punkte als freimaurerisches Sigel mit Abkürzung), 95 (Drei unfehtbare Karten in aPikovaja dama. 1833/34) 97, $100-05$ (×Pikovaja damas 1833), 115.

.Dreieck“ 37 (rechtwinkliges D., der Lehrling ersteigt mit 3, der Geselle mit 5 und der Meister mit 7 Stufen den Altar. Für das Ritual ist entscheidend, daB der Maurer alle in der geraden Linie nach Muster eines rechtwinkligen D-s abschreiret. Auch die Hand soll der Mau- 
re im rechien Winkel bewegen), 64.

"DreiBig" 35 (.DreiBigster (30.) Grad)".

Duelltod 14 (Angeblicher D. Puskins im Zusammenhang mit der Freimaurerei).

Dunkel 28 (nichtarbeitende Loge heiBt d-e Lo ge), 29 (,dunkle Kammer des stillen Nachdenkens" $\left.{ }^{4}\right), 46,65,73$ (Distere Stadt Kixinev in aeneralu Puxxinu» 1821), 85 (Jànes Dunkel in Mocart I Sol'erio 183931 ), 98 (,Verdunkelter Vorraum in Pikovaja dama* $1833 / 34), 102$.

Duktus, ritueller 27.

$$
-\mathbf{E}-
$$

„Ebene" 28 (..Ubertragung auf die höhere E.“), 35 (.,profane E.").

„Eid" 18, 27 (,freimaurerische E-esformel\% "Aufsagen der E-esformel"/umstrittener Bestandteil des Ritualtextes), 31, 33 (,E-esformer"), 76 (Bezug zur frm. ,E-esformel" in Prorok. 1826), 102 (E-formel der Neophyten in «Pikovaja dama 1833/34), 111.

"Einführung" 27 (Einweihung), 28 (E. des Bumdes in den Tempel).

"Eingeweiht(er)" 9 (nichte. Forschung), 10, 13, $16 / 17,19,24,38,40,42,51$, $53,54,60 / 61,70,81,88,91$, 94, 95, 98, 102.

Einweihung, freimaurerische siehe Initiation.

.Eintritt 28 (Sicherung vor E. Unbefugter/E. in den Ritus), 32 (,E." in ein neves Leben), 58, 77, 100.

„Eintritt in den Bund" (,E. i. d. B." Pierre Bezuchovs in Tolstojs *Vojna i mir 1868/69) 12.

"Elite“, als Menschheit" 26.

"Elite", ,neve" 26.

Embleme 38, XX (Zwei Porträts des Caren Pavel I. unit freimaurerischen Emblemen).

Empfehlung 18, 43 (freimaurerische E-briefe in RuBland), 53 (E. Panins).

Emigration 14 (Veröffentlichungen über \&Puskin i masonstrox).

Engel Gortes 37.

England siehe Grobbritannien.
"Entdockung des Geheimnisses" 65 GAAuseinderzichen des Vothangs").

"Enthüllung" 10 (freimaurerisches "Geheimnis" $), 25$ (.E." und Geheimnis" ${ }^{\text {"N }}$ ), 114.

Entstehung (Auftreten/Aufkommen der Freimourerei) 10, 11 (erstmalig 1730, puletzt 1822/26), 20 (Hammer. mayer zur regulisen Freimaurerei), 25, 36, 41 (E. in RuBland).

Entzinden der Lichter siehe "Hereinnufen des Lichies".

"Er 35 (".Er lebe im Sohn").

"Erde" 37 (Verbindung zwischen Himmel und Ende als Jakobsche Himmelsleiter).

.Ergebnis" 35 (Ubertragung des E-s auf die profane Ebene).

"Enhebung" 34 (als wichtigstes Ereignis der Meisteraufnahme), 77, 93.

.Erkenne Dich selbst* 26 («Gnoti seauton»), 52 (Novikov: Posnanie samogo sebja), 64.

.Erkenntnisstufen“ 17.

.Erkennungszeichen" 10, 18 (,freimaurerisches E.), 19, 28, 29 («mak»).

.Erlebnis" 10 (persönliches E.), 26.

.Eröffnung der Vorloge" 28.

.Eröffnung der Arbeit" 28 (Hoch und Hauptritus in der Freimaurerloge), 29.

Erz 32.

Esoterik 19 (e. Traditionen aller Epochen), 24, 96, 98, XXIV.

"Etappen des Lebens" 25, $91,93$.

"Ethik" 26 (Freimaurerische Symbole weisen auf den breiten Rahmen der E.)

.Eva und Adam" 38.

"Ewig(es)/Ewigkeir" 33 (.Maßstab des Ewigen ${ }^{\text {to }}$, 77 (e. Fever des Todes). 95 (Saint-Germain als 'Ewiger Jude').

$$
-\mathbf{F}-
$$

"Fäulnis" 34 (als erster Ausruf des Erstaunens des Neuaufgenommenen).

Farbe 100, 102 (Farbe der Karten in «Pikovaja damar 1833/34).

"Farbe", „blauce" 38 (freimaurerische F./Blau als ${ }^{\circ}$ F. des Himmels ${ }^{\text {(4) }}$ ).

"Farbe", .ngelbe" 29, 36, 93 (leuchiende Farben der Töchter Adrijans (ateltye Slapki»)).

"Farbe", "schwarze" siehe Schwarz.

"Farbe", "weike" siche WeiB. 
"Farbenordoung" 38 (,F. der Bänder").

Faust, Heinrich Dr. XXIV.

Februnrevolution siehe Revolution.

Feiertag, freimaurerische XIX.

"Feigenblatu" (,biblisches" von "Adam und

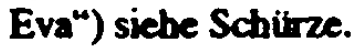

"Feind(efin)" des „Ordens" 27, 40.

"Feste", "höchste freimaurerische" 28.

Festlegung des rituellen Ortes siehe "Ubertragung auf die höhere Ebene".

Feststellung der Zeit 28, 100 (Frage nach der Uhrzeit in aPlkovaja damaw 1833/34)

„Feversalve" 31 (Freimaurerische Alegorie für das "Gastmahl").

"Finger", F. des Meisters 34 (Meister ergreift die rechte Hand des im Sarge liegenden am Zeige- und Mittelfinger).

"Fleisch" 34 („die Haut verläBt das F." "das F. veriäBt die Knochen" als rituelle Spriche), 91 (Fleisch hat sich vom Skelett gelöst im aGrobovgxik- 1830).

„Flüstern" 34 (Meister flüstert erstem Aufseher das Meisterwort), 95 (Saint Germain hatte det Gräfin drei Go winnkarten geflüstert in «PikovaJa daman 1833/34).

"Formeln" 19 (symbolische F.), 31, 102 (Eidesformel des Neophyten in -Pikovaja damas 1833/34), 111

(Freimaurerische Lehrformel).

Forscherloge, 45.

Forschung, Exil 13.

Forschung, historische 19 (historische F.),

Forschung, nichleingeweihte 9.

Forschung, nichtsowjetische 13.

"Forschung", .profane" 9.

Forschung, russische Geschichte 9.

Forschung, russische Literatur des 18 . und 19. Jahrhunderts 9.

Forschung, sowjetische 49,71.

Forschung, vorrevolutionäre 14, 49, 53.

Forschung, westliche 49.

Forschungslucken, (Freimaurerei als gesamteuropäisches Phänomen) 9.

"Frack" 38. (in der Loge nur im F.).

"Frage" 28 (.F.: Warum nenden wir uns Freimaure?"), 28 (.,F.: Wo hat (...) seinen Platz?), 29 (,Wanum nennen wir uns Freimaurer?").

„Frage-und-Antwort-Spiel” 11, 17, 21, 27, 66 , 121.

Franc-maxon-russe 31.
Frau(en) siche "Schwestern".

"Freie Klinste" 37 Goiebeo Sprossen der Jakobeleiter" haben sieben Namen der nf. K." ).

Freidenker(um) 80 (vol'nodumec), 104-06, 109.

"Freiheit" 34 (Eriangung der g. F. für den künftigen Meister), 52 (Novikov bekam auf GeheiB Pavels I. Freiheit arick), 72/73 (Und wird ausnufen: F. F." (al vozzoves': ssvoboda!) in) in aceneralu Puscinu» $1821)$.

Freimaurer XXIII ( $\times$ Kruzok nusskich masonov v Anglii» (1928)).

Freimaurerbund 9 (.,Institution des F-s." $), 12$, $14,16,17,53,76,92,108$.

Freimaurerdichtung siche Freimaurerliteratur.

Freimaurendrama siche Drama.

Freimaurerei 14 (Angeblich zarenfeindlicher Verschwörungsbund gegen Puskin), S0 (Verschwönungstheorie seit der Französischen Revolu(jon).

„Freimaurerei, blause" 25.

Freimaurerei, deutsche XXIII.

„Freimaurerei, europäische" 10, XI.

Freimaurerei, Experten (russische) 13.

Freimaurerei, Geschichtstheorien der 9.

„Freimaurerei, „nicht eingeweiht in die F. “ 10. .Freimaurerei", "operative vs. spekulative" 23.

"Freimaurerei", orthodoxale" 22.

„Freimaurerei", "nichtpolitisch-spekulativ" 17. 22 (Beteuerungen).

Freimaurerei, politische XVI (Verfassung einer angeblich 'Russischen Politischeo Freimaurerei').

„Freimaurerei", „reguläre“" 10, 14, 20, 22.

Freimaurer-Gelübde siehe Gelöbais XXV.

Freimaurergeschichte/F-historie 16, 25, 40, XXXII, XXXV.

„Freimaurerische Eidesformel" siehe Eid.

Freimaurerkonvent, Wilhelmsbader von 1782 48.

Freimaurertehrling 29.

"Freimaurerlieder" siehe Lieder

.Freimauretliteratur" 10, 20, 41, 49, 64, (thematische Eingrenzung unmöglich), 67, 115, XIV, XVII, XX, XXIV (..Wortschatz der dt. Freimaurerlyrik des 18 . Jahrhunderts 1968)), XXVI „Freimaurerische Versdichtung in der französischen Literatur des 18 . Jahrhunderts (Freimauretroman)). 
"Freimaurerlogen“ 10 (Geheimgesellschaften 12 (offiziell angerneldet in Rußland), 14, 39 (erste in St: Petersburg), 61 (Abschaffung in RuBland 1822),

Freimaurerlyrik siehe Freimaurerliteratur.

Freimaurerroman" XXVI (französischer F.).

"Freimaurentemper" 29.

Freimaurertum zu viele Einträge.

Freimaurerverzeichnis 13 (nussisches F.).

Freudealied siehe Lieder.

„Fünf” 34 (in allen Logen stehen fuinf Säulen), 37, 10901, 113 («Pikovaja da$\operatorname{man} 183334$ ).

"FuB" 33 G,linker/rochter F.“/dem Neumeister streckt man die linke Hand dor Länge nach der Seite aus, die reche Hand wird mit dem Schurzfell umwickelt und der rechte F. auf das linke Knie gestellt, um ein WinkelmaB zu formieren) 34 (,F. gegen F." als einer der "fünf Punkte der Meisterschaft").

$$
-\mathbf{G}-
$$

„Gastmahl" 31 (,Feuersalve" als Allegorie für das freimaurerische G.).

Gattung, prosaische 17 (als Hilfsbegriff).

GBAW siehe „Grober Baumeister aller Welten”. "Geber 29.

"Gebrauchtur" 10, 52.

„Gebrechen" 33 (.Abstreifen menschlicher Gobrechen und Intuimer").

"Geburt-Leben-Tod" 25.

„Gebur", „zweite" 32 (Neuaufnahme wie eine $z$. G.), 35 (G. des neuen Menschen), 77 (spirituelle G.).

„Gedeckte Loge" 38.

Gedenktage, vaterländische 31 .

Gegensatupaare, stereoxype 66 (s. G. der Freimaurer(literatur)).

Geheimbund-Allusion 21 (Begriff der G.-A.), $23,49,64,68,73 / 74,111-13$, 115.

Geheimbund-Mitteilungen 21.

Geheimbund/Geheimbuinde, größter (intemationaler) 9, 10, 16 (Verbol det Geheimbiinde), 82.

Geheimgesellschaft-en 9, 10 (nicht alle sind Freimaureriogen), 12/13 (Verbot aller Gen in RuBland durch Aleksandr I. 1822), 17, 21, 22 ,
$41,48,60,62,69,77,82,110$, 111, XVI, XXII.

"Geheimnis" 10 (freimaurerisches G. wurde unzöhlige Male verrateo), 11, 14, 19, 20, 22 (als HerrschaftsinstrumentTeilnahme am „G.“), 26 (Preisgabe des „G-es"), 30-33, 37 (mschilissel" als SymbolNAllegorie fir die Zunge, die des f. G. bewahnt"), 57, 65 (Enideckung des $\mathrm{G}-\mathrm{es}^{\mathrm{N}}$ ), 81, 88, 92 (Geheimnisvolles Mondlicht in Grobovitil 1830), 95 (Kartengeheimnis in Pilsovaja damas 1833 34) XXVII, XXX.

Geisteswissenschaften 9.

"Gelb" 32 (.ngelbe Seide"), 38.

„Gelöbais" 10 (G-worte), 30 (G-worte), XXV (Freimauret-Gelöbnis).

Gematria siehe Kabbalah.

„Gemeinschaft" 27 (ständevereinende G.), 33 (,unauflösliche G.") 37 (,sittliche G."), 43 (Gesinnungsg.).

"Gentleman" 29.

"Gerechtigkeit" 36 (WinkelmaB als Symbol da "Gerechtigkeir" und des Gewissens), 65, 105.

Geriuchte 10, 83 (Mordgericht beim Tode Mozarts)

Gesang 30 (Chora), 42, 49.

Geschehen, logenintern-rituelles 11, 33, 67.

Geschichte der Freimaurerei 9 (in RuBland), 11 (allgemein), 40 (Anfänge), 44, $67,78,103,111-14$.

„Geselle/n" 25, 27 (,zugelassener G."), 30 (zu befördernde G-n/Während da Ubergabe wird dem G-n gesagt: .Der, dessen Schädel du trägst, mein Bruder, war einst ein Mensch wie du!" ), 32 (verbrecherische G-n/Der Lehrling asteigt unit 3, der G-n. mit 5 und der Meister mit 7 Stufen den Altar. Für das Ritual ist entscheidend, daB der Maurer alle in der geraden Linie nach Muster eines rechtwinkligen Dreiecks abschreitet. Auch die Hand soll der Maurer im rechten Winkel bewegen), 33-35, 39 (.G-grad"), 66, 81, 92, aGrobovscils- 1830), 100, 102.

„Gesellenschurz"KG-schürzen" 33/34 (wird dem Geselken abgerissen).

"Gesellschaft gelehrter Freunde" 48, XIII. .gesichert 28 (.ng. vor dem Eintritt Unbefug(en). 
Gesinnung 13 (Tolstoj bezeichnete sich in einem Brief an einen Freimaurer, det ihm geschrieben hatte, dor Gesinnung nach als Freimaurer), 24, 43 (G-gemeinschaft), 68 (freimaurerische $G$. des Onkels von Puskin)

„Gewalt 36 (Bei Freimaurern versinnbildlicht der Steinmetzschlegel/Hammer auch die Macht, den Willen, die Befugnis, und auch die materielle Gewalt des operativen Maurers).

"Gewisseo" 27 (,besseres G. der Politik“), 36 (WinkelmaB als Symbol des "Gewissens ${ }^{*}$ ), 89.

„Glauben“ 37 (eine der drei „Hauptsprossen der Jakobsleiter").

Glaubensgemeinschaft 19,69 (jede Glaubensgemeinschaft soll nach dem Konstitutionenbuch James Andersons in den Logen Platz finden).

"Gleichheit" 37 (,Lineal" als Symbol für die „G."), 72 (Ideale der französischen Revolution).

„Gleichgewicht" 36 (Gleichgewicht zwischen Recht und Pflicht).

Glossar 22 (freimaurerisches G. für den russischen Logenbetrieb).

.Gold* 30, 32, 45, 47, 61, 65, 85.

Goldkreuzer 10, 101, XVI.

"Goldnuinze" 30 (Symbol für „Habsucht").

„Grab/ „Gräber"/,Grablegung“ 25, 30 (Rose als Symbol für die Grablegung/drei Rosen werden einem Bruder mit ins Grab gegeben), 31, 35 (lette Ruhestätteläuterung effolgt im Grabe), 39 (..G-hügel"), 85 (aMocart I Sal'erio 1830/31), 91 («Grobovszik-1830).

"Grad/e"/G-bezeichungen "Grad(us)y" 23, 25/26 (*Novye g-y»), 32-34, 36$38,46,48,50,57,62,70,71$, $73,76,94,113$.

.Gradheir" 37 (,Senkblei" "Lor" als das Symbol für "Aufrichtigkeit", ,G." und die "Offenherzigkeit für das "ganze Leben").

.Grenzen" 22.

"Griff" 33 (als zwischenkörperliche Berührung).

Grobbritannien 22, 23, 29, 43, 45 (Grobloge von England), 46, 57.

"Grobe Provinzialloge" 56.

Grober Baumeister aller Welten (GBAW) 29 (.02. Incantatio"), 69.

"Grobloge" 22/23 (englische), 31, $42 / 43$ (London), 45, 48 (G. «Astraea», Mit- glioderzahlen), 62, 69, 70, 74, XIV, XXI, XXIX (Vereinigte G. von Deutschland), 88, 96, XXXIII (xAstracas).

"Gro8meister" 22, 31, 42, 46, 99, 53, 58, 70.

"Grundgesetz der Freimaurerei" siehe Pflichten, Alte.

"Grundpfeilex" der Humanität siehe „Säulen".

$$
-\mathbf{H}-
$$

„Habsucht" (8. beim Symbol: „Goldmünze“). .Hammer" 33 (,.H. wind auf den „Kopf" gelegt), 34, 36 (,Recht H. zu fuihren") "Form des Steinmetzschlegels"), $78,111, X X V I I I$, Der $H$. in seiDer symbolischen Bedeutung" (1825)).

„Hand, linke $\%$,rechte H.“ 33 (dem Neumeister streckt man die linke $H$. der Länge nach der Seite aus, die rechte H. wird mit dem Schurzfell umwickelt und der rechte FuB auf das linke Knie gestellt, um ein WinkelmaB zu formieren), 34 (niedergelassene He/der Meister vom Stuhl tritt hinzu, faBt den Liegenden mit der linken $H$. hinter die rechte Schulter, mit der Rechten die rechte $H$., die der zweite Aufseher unterdessen freigegeben hat (...) Harmmer in $\mathrm{H}$. als einer der fünf Punkte der Meisterschafulinke $H$. um den Nakken)/Der Lehrling ersteigt mit 3 , der Geselle mit 5 und der Meister mil 7 Stufen den Altar. Für das Ritual ist entscheidend, dab der Maurer alle in der geraden Linie nach Muster eines rechtwinkligen Dreiecks abschreitet. Auch die $\mathrm{H}$. soll der Maurer im rechien Winkel bewegen,,blutbedecktes $H$ wuch"), 35 (,Saubere H. bei der A. durch weibe H-schuhe"), 46, 102, 111.

.Handbuchlein fir Brider Lehrlinge", "Brider Gesellen", "Brider Meister" 20, II.

.Handschuhe" 38 (,WeiBe H." ).

"Handtuch", ",blubbedecktes" 77.

"Handwerk/er" 20 (Lehrzeiten der H.), 35 (Arbeit der H.), 8489 ( 4 Mocart i Sal'eri- 1830/31), 99 (Grobovsxik= 1830). 
„Harmonie" 86 (6,Zwei Söhne der Harmonie" in aMocart i Sal'erib 1830/31).

"Harmonisierung der Steinform" 37.

„Hauptrunst" 35 (,geistige H. ").

"Haupuriturs", siehe "Hochritus".

"Hauptsprossen der Jakobsleiter" siehe „Spros$\operatorname{sen}^{\circ}$.

.Haut" 34, 91 (,die H. verläBt das Fleisch“ $/$ das Fleisch verläße die Knochen" als rituelle Spritche).

„Hereinnufeo des Lichtes" 28 6.H. d. L." steht symbolisch fur das "Anzünden" der Lichter in der gedeckten Loge).

Hermetik XII, XXVIII (symbolisme hermétique).

Herz 65, 93, 96.

.Herz des Aufzumehmenden" 36.

.Herz" 65.

Hieroglyphen 25 (h-e Bilder).

"Himmel" 37 (,Baldachin" verkörpert den .H. $\left.{ }^{\circ}\right)$, ogatom katafal ke nod barchatnym baldachinom 100 ( Grob stojal na bBaldachin als Symbol des $\mathrm{H}-\mathrm{s}$ in aPikovaja dama* 1833/34).

„Himmelsleiter" 37 (Jakobs H.), 93 («Grobovscik= 1830).

„Himmelsrichtung/en” 29 (symbolische Beckuttung der H-en im Tempel), 26 (Wandenungen nach $H),$. (Osten, Norden, Süden, Westen).

"Hiram-Legende"\%,-Sage $\%$."-Mysterien" 17 (H. als Meister der Steinmetze), 29 (H-mysterien), 39, 9297 (aGrobovsxik- 1830), 102/03 («Pikovaja damax 1833/34), 113, XXV ("Lost secrets of HiramAbiff" (1951)).

Historiker 9 (Beiträge über Freimaurertum in RuBland), 12, 13 (sowjetische), 20 (Freimaurerische $\mathrm{H}$.).

„Hochgrade" 25/26, 32, 37 (,arcana“), 46, 48, $50,56,58,62$.

.Hochgrad-Freimaurerei“ 37 („Degen" als Utensil der H.).

"Hochmittag“" 28.

„Hochmitternachr" 28.

"Hochritus", siehe „Hauptritus“ 28.

Hochstapelei 51.

"Höhle(n)" 29.

.Hoffnung"s 37 (eine der drei Tugenden und "Hauptsprossen der Jakobskei(10").

"Hohestiod" (Mozart) 11.

Holz 32.
„Humanitz̈re Grundidec\%/,H-r" 36 G.Tempel der H. $\left.{ }^{\infty}\right), 93$, XXV.

"Hymne/o" siche "Lieder"

$$
\text { - I - }
$$

"Identifikation mit Baumeister Hiram 35 (erlebr Geselle).

Ikonogaphie 30 (zertez), XXV (I. der Freimaurerei), XXVII (freimaurerische Zeichnugen).

Iluminaten 10, S0-52, 57, XV, XXX.

"Incantatio, 1." 28.

"Incantatio, 2." 29 (GroBer BAW).

Initialengleichheil 98 (bei Adrijan Semenovič Prochorov Held in GrobovSxik. 1830 und Alcksandr Sergeevic Puskin), 113.

"Initiant" siehe Neuaufzunehmender.

.Initiation" 11, 17 (I.-ritual), 24, 26, 27 6,I.-ritus $^{\text {*) }}$ ), 29 (schematischer Ablauf des "I-ritus" nach Pypin), 30, 32, 34, 37 (I-rituale), 39, 77 (*Vosstan' in aProrok" 1826), 91 (Teile des I-srituals in aGrobov3xik- 1830) 117-21.

Innenminister siche Ministerstvo vautrennych del.

Innenraum, moralischer 27 (Koselleck).

Insekt 39 (,.Biene ${ }^{\text {we }}$.

Intelligentsia XVIII (Russian I.).

"Irdisches" 31 (im "Norden" wird der Neuaufgenommene auf die Vergänglichkeit alks I-n hingewiesen), 34 (Uberirdisches).

Ironie 90 (Ironie in aGrobovszik» 1830), XIX (Uber die wahre Ironie in $M$. Osorgins «Vol'nyj kamensxik* 1940 von V. Setschkareff (1984)).

$$
-J-
$$

.Jachin und Boas“ 32 (Säulen des „J. U. B.“), 36.

.Jakobskiter" 37 (der vielfarbige "Bachdachin" symbolisien bei Freimaurern die .J."), 100 (*Pikovaja dama 1833).

"Jakobs Himmelsleiter" siehe .Jakobsleiter".

Jahresopfer 11.

'Jehova' 39, 51 (Spitzname Cagliostro6).

Jesuiten 52, 57, 68, 69, 81 .

.Johannes der Evangelist* 32. 
"Johannes der Täufer" 32.

"Johannisfest" 28, 33 (J. als Rosenfest).

"Johanisgrade" 25 (Lehrling-Geselle-Meister)

26 (Bedeutungsebenen der J.), 32.

$57 / 58$.

Juden 95 (Saint-Germain als 'Ewiger Jude'), XVII.

Jüngling-Mann-Greis 25/26.

\section{$-\mathbf{K}-$}

Kabbala(h) 20, 45, 48, 50/51, 63, 94, 100, 10203, 104, XIl, XXVI (KRezeption in det Freimaurerei (1996), XXXI.

„Kadosch" (,Ritter Kadosch") siehe „DreiBigster Grad".

"Kammer" 29 (,dunkle K. des stillen Nachdenkens $\left.^{*}\right), 102$.

"Kandidat" 10, 27, 29-31 (Meister-Kandidat), $34,76,91 / 92$.

„Kandinaltugenden” 37.

Karten 95 (Kartengeheimnis), 96-98, 100. XXXII (magische K.).

Katafalk siche Sarg.

Kazaner Kathegrale siehe Kathedrale, Kazaner.

Kategorien, freimaurerische 26.

Kathedrale, Kazaner IX.

Katholische Kirche/Katholik 10 (keine Vermischung mit Freimaurerei), 39, 53, 62.

.Kenozeichen" 18.

"Kerzen" 36 ("Drei kleine Lichter brennen als „Kerzen auf drei Säulen“), 98 («Pikovaja dama- 1833/34).

„Kette(nbildung) 31, 32 (Darstellung der vollendeten K-nbildung), 65, 101 (Anagramm).

"Kettenlieder" siche Lieder.

"King" siche "König".

Kirche 25 (Bräuche der), 39, 99, 105 (orthodoxe Kinche).

Kisinev siche Loge «Ovidij».

Klassizismus XXV.

.Kleidung" 33, 38.

.Klein/e 36 (,Drei kleine Lichter brennen als Kerzeo").

"Kleinodien" 37 (,bewegliche und unbewegliche $\left.K-\mathrm{n}^{\omega}\right), 38$.

"Klerikst der Tempelherreo" 47.

"Klopfen“" . „dreimaliges an die Tür K.“ 26, 65, 72 ( Fehit das Klopfen (die Loge ist noch nicht gedeckt in $\mathrm{Gen}$ ralu Puscinu» 1821), 90 (aGro bovtetis- 1830).
"Klopfzeichen" 19, 34, 72 (gradspezifische K.). "Knie", "rechtes/linkes" 27, 30 (dem Neumeister streckt man die linke Hand der Länge nach det Seite aus, die rechte Hand wird mit dem Schurzfell urnwickelt und da rechte FuB auf das linke Knie gestellh, um ein WinkelmaB w formieren), 33/34 (,Der Meister vom Stuhl tritt hinzu, fabt den Liegenden mit der linken Hand hinter die rechte Schulter, mit der Rechten die rechte Hand, die der zweite Aufseher unterdessen freigegeben hat, macht den Meistergriff, driickt sein rechtes Knie auf das linke des Liegenden und sagt: "So will ich versuchen, ihn aufzurichten". Dann hebt ex inn auf $\%$,Knie gegen Knie" als einer der fünf Punkte der Meisterschaft).

„Knochen" 34 (.die Haut verläßt das Fleisch"/"das Fleisch verläbt die Knochen" als riturelle Spriiche), 91 («Grobovstik» 1830).

König/King, Trinken auf den siehe Trinkspriche.

„Könige“, „Buch der K. Siehe Bibel.

Königsberg XII (K-er Freimaurerloge).

Kolonie 43 (deutsche K. in St. Petersburg).

„Konfessio" 29 (Frage: „Warum nennen wir uns Freimaurer").

Konfessionen 39.

„Konstitutionenbuch" s. Constitutions (1723). „Kopf" 77 (.,blutbedocktes Handtuch über dem K.“).

Kryptokatholizismus 46 (Vendacht des K.).

Kryptonym/K-gramm(atik) 100-03, 106, (K. Kondratij F. Ryleevs in aPikovaja dama 1833/34).

„Kulmination“ 27, 102.

Kulthandlung 10.

„Kultur(en)"* 9/10, 13, 18 (,antike K.“), 41, 52, $64,65,97$.

„Kunst" des Einzelnen 17.

"Kunst" 11 (, königliche K.“), 23, 28 (,königliche $\left.\mathrm{K} .{ }^{*}\right), \mathrm{XXV} / \mathrm{XXVI}$.

"Kinstler" 4.

Kunstwerke, EinfluB der frm. Bewegung auf 9. .Läutenung" 35 (,L. erfolgt im Grabe*), 94.

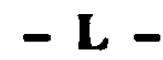

Landesloge 45/46, 56.

Markus Wolf - 9783954790715 
"Leben 32 (,Eintritt in ein vollkormmenes L. $\left.{ }^{*}\right), 33$ (vergängliches L.), 34 (der Westen erinnert den Meisterkandidaten daran, daB der Tod eine Herausfordering fuir das $L$. ist), 35 ("Erhebung zu nevern L." I,profanes L."), 37 (,Senkblei“" I .Lox" als Symbol für "Aufrichtigkeit", "Gradheit" und die „Offenherzigkeit" fir das ,ganze L."), 93 («Grobovisikw 1830), 102 (lebendiget T. vs. totes Leben).

Lebensalter 24 (Jüngling-Mann-Greis).

Legende, Petrinische 42.

Legende $32 / 33$ (L. Hirams) alte / neue XVII. (v. Komplott der Freimaurer und Juden).

"Lehrart", "Berlinische" 46.

"Lehrat", "schottische" 34, 35, 46, 65.

.Lehrling" 10, 25 (Maurerlehrling), 37 (Der Lehrling ersteigt mit 3 , der Go selle mit 5 und der Meister mit 7 Stufen den Altar. Für das Ritual ist entscheidend, daB der Mauret alk in der geraden Linie nach Muster eines rechtwinkligen Dreiecks abschreitet. Auch die Hand soll der Maurer in rechten Winkel bewegen), 65 (roher/rauher Stein des L-s), 100.

.Lehrling"-.,Geselle"-,., Meister" 25.

"Lehrtafer" 36.

"Leiche/Leichnam" 77 («Prorok 1826»), 85 (Lebendige Graberscheinung in Mocart i Sal'eri 1830/31), 92 (,Trinken auf das Wohl von $L-n "$,

Grobovšik= 1830).

"Leinentuch" 34.

"Leinwand" 32 (rosennote), 33 (Sarg wird bei Meistererhebung mit einer $L$. be dockt).

"Leitspriche" siche Lieder.

"Leuchier" 39 (siebenarmiger Leuchter).

"Lichr" 28 (das L. erleuchte diesen Tempel), 29

(.maurerisches L."), 30, 35

(,Entlassen des L-es"), 33 (.Drei kleine Lichter brennen als Kerzen auf drei Säulen“), 34 (geistiges L.), 65 (Licht und FinstemisDualismus der Freimaurer), 69. 71, 73, 85.

"Liebe" 36/37 (eine der drei „Hauptsprossen der Jakobsleiter"), 64, 66 (Freundschaft - L.-Dualismus), 73, 77 (Liebestod vs. Todesliebe im
Symbolismus) 95 (L. zum Tod in aGrobovšxilk 1830).

Lied/er, passeode/s 28, 35 (Freudenlied bei Aufnahme zum Meister), 32, 6465 (L. und Leitspriiche), XVII («Russkie masonskie pesni»).

"Lineal" 37.

"Linie", „gerade" 35 (Der Lehrling ersteigt mit 3, der Geselle mit 5 und der Meister mit 7 Stufen den Altar. Für das Ritual ist entscheidend, daB der Maurer alle in der geraden $\mathrm{Li}$ nie nach Muster eines rechtwinkligen Dreiecks abschreitet. Auch die Hand soll der Maurer im rechten Winkel bewegen).

"Links"/rechts" 33 (dem Neumeister streckt man die linke Hand der Länge nach der Seite aus, die rechte Hand wird mit dem Schurzfell umwickelt und der rechte FuB auf das linke Knie gestellh, um ein WinkelmaB zu formieren), 34 (te Hand/Der Meister vom Stuhl tritt hinzu, faßt den Liegenden mit der linken Hand hinter die rechte Schulter, mit der Rechten die rechte Hand, die der zweite Aufseher unterdessen freigegeben hat, macht den Meistergriff, drück sein rechtes Knie auf das linke des Liegenden und sagt: "So will ich versuchen, ihn aufzurichten". Dann hebe er ihn auf.), 34 (Wert in linkes Ohr).

Literarisierung der Freimaurerei 12, 21 (Zur Zeit Puskkins ein Tabu), 89, 103.

Literatur XV (Freimaurerische Elemente in der russischen religiösen Literatur).

Literaturgeschichte, des 18. und 19. Jhs. 9.

Literaturubersicht (L. als bibliographisch erweitertes Literaturverzeichnis dieser Arbeit) Iff.

Literaturwissenschaft 13/14 (sowjetische).

"Lodge" 22, 41.

"Löschen det Lichter" 35.

"Loge“ 27 (,erleuchtete L.“) 27, 34 (,.Licht der L. $\left.{ }^{\infty}\right)$.

"Loge, Apollo"w 45.

"Loge ,Alexandre (du Lion d' Or) ${ }^{\cdots *} 16$.

"Loge ,Astrte a L'Orient de St. Petersburg XXII.

„Loge Elizabeth a la Vertu et Chercheurs de la Manne"s 16.

„Loge ,Harpolkrates“" 41. 
"Loge ,Les Amis Réunis"., Petersburg (Mitglied war Dekabrist P. I. Pestel') 16, 54/55, 57, 68, 70 (und Ca2 deev), 81 (sowie Griboedov und auch der Stuhlmeister der Loge (Ovidij» General P. 1. Pušxin), 98.

"Loge Neptuma" 55.

"Loge Ovidij," in Kixinev 14, 16 (Puskin gesteht Zugehörigkeit Zukovskij). $14,16,45,58-60,67,70,73-75$, 82, 90, 107-11, 115/16, XXX, XXXII.

"Loge $\mathbf{Z u}$ den drei Weltkugeln`” 20.

"Loge ¿Zu den drei Wohltätern" XXI (,Loge" Ru den drei Wohltätern* und ihre Mitglieder - die Dekabristen).

"Loge Zu den drei Degens" 74.

"Loge Zu den goldenen Schlüsseln" " 45.

.Loge Zur Beständigkeit)" 44.

"Logenarbeit" 23, 23, 26, 50, 53, 59, 72, 84.

.Logenbetrieb" 27 (.Ablehnung der Politik beim L." $\left.{ }^{-}\right), 72$ (Voraussetzungen des L.).

Logenmord siehe Ritualmord.

Logennamen, Entwicklung der 74 (*Ovidij»).

Loge/n, russische/n 29, 56 (Wiedereröffnung der T-n L-n 1810).

.Loge" 9, 12, 19, 23, 26 C"L. ist vor Sonnenlicht grundsätzlich geschlossen zu halten"), 31 (,SchlieBung der L. “), 33 (,Requisiten der L.), 35 (Absicherung der Loge), 36, 45, $54,56,58 / 59,60,62,65,67$. $70,72-74,82,92,96,98,107$. 109-11.

.Logensystem" 25.

Logentod siehe Ritualmord.

,Logos" 36.

"Lossagung" 30 (. L. eigensichtiger Prinzipien" des Gesellen).

Losung 19 (freimaurerische L.), 74, 121.

"Lot siehe "Senkblei".

Lyrik 9 (Puskins), 16 (1. Gattungen), 63-68, $70,72,75,79,108$.

$$
-\mathbf{M}-
$$

.Mac-Benac" 34 (Meisterwort, Benac im Scheine).

"Mac-Putrefaktion" siche, Mac-Benac".

.Mache 36 (,Bei Freimaurern versinnbildlicht der Steinmetzschlegel Hammer auch die $M$., den Willen, die Be fugnis, und auch die materielle Gewalt des operativen Maurers").

„Mächte", .ngeistliche" 22, 69 (ABAW).

Männerbund/Männerbilnde, Wesen des Mysterien-M. 9 (Tradition des M-s) 11, 13/14 (Tradition des M-s), 23/24, 26 Tradition des M-s/Brauchtum/politische M-e/sbendländische M-e), 36, 120.

Märtyre 98, 49, 81, 94, $102 / 103,107 / 08$, $111 / 12,114$

Malteserarden 53.

Martinist/eo 5 (Moskauer M.), 56 (Ekaterina II. hielt Radiszev fuir einen M-en), $55,62,105 / 06,114$, XIV.

.MaBstab" 33 (,M. des Ewigen").

"Materielle Gewalr" 36 (Bei Freimaurern versinnbildlicht der SteinmetzschlegeVHammer auch die Macht, den Willen, die Befugnis, und auch die m. G. des operativen Maurers).

.Mavern am Tempel der Menschheit" 65.

"Maurerlehrling" "Einführung des $\mathrm{M}-\mathrm{s}^{\text {"N }}$ siehe Freimaurerlehrling.

"Maurerlieder" siehe Freimaurerlieder.

"Maurer", "operativer" (Steinmetumaurer) vs. .spekulativer (Freimaurer') 36 (Bei Freimaurern versinnbildlicht der "Steinmetzschlegel"/,Hammer" auch die "Machr", den „Willen", die „B.", und auch die materielle Gewalt des 0. M-s).

"Maurertempel"s siche ,Freimaurertemper".

Maurerzinfie, handwerkliche 37 (Anlehnung an die h. M.").

Medailk, siche Bronzemodaille.

,Meister" 25, 27 (Grundlage der "Arbeit" /gibt seiden Toast bei Neuaufnahme eines Bruders), 32 (nur Stand der M. bei der M-aufnahme anwesend), 31-33 (Reisen der M./ MKandida/dem Neum. streckt man die linke Hand der Länge mach der Seite aus, die rechie Hand wird mit dem Schurzfell umwickelt und der rechic FuB wof das linke Knie gestellh, um ein WinkelmaB zu formieren), 34-39 (Der Lehrling ersteigt mit 3, dex Geselle mit 5 und der M- mit 7 Stufen den Altar), 33, 94 ( $\mathrm{kMa-}$ stery i podmastery" Grobovsxiks 1830), XXIV.

"Meisteraufnahme" $/ \mu$ Meistererhebung" 23, 28, 31 (Ein Ereignis der Meisterauf- 
nahme ist die Meistererhebung) 32 (Fünf Schritte der Meistererhebung), 32 (Untergliederung der M.), 76-78 (Bezug zu freimaurerischer ,E-formel ${ }^{\mathrm{N}}$ in «Prorok* 1826), 84, 91-95, 98/99, 100, $112,113$.

"Meistergelöbnis" 33.

"Meistergrad" 32, 70, 93 («Mastery i podmastery in aGrobovzilk 1830).

"Meistergriff" 34 (Der Meister vom Stuhl tritt hinzu, faßt den Liegenden mit der linken Hand hinter die rochte Schulter, mit der Rechten die rechte Hand, die der zweite Aufseher unterdessen freigegeben hat, macht den Meistergriff, driickt sein rechies Knie auf das linke des Liegenden und sagt: "So will ich versuchen, ihn aufzurichten". Dann hebt er ihn auf), 36.

"Meistergrub" 34.

"Meisterkandidat“ 30, 31 (vier Himmelsrichtungen vier Erinnerungsmomente), 99 (Hermann steht vor Gräfin wie ein Meisterkandidat in aPikovaja dama. 1833/34), 112.

"Meisterreisen“, „drei" 34.

"Meisterritual" 29, 31 (Ende der Wiedergabe des Meisteraufnahme-Rituals), 84.

„Meisterschrita“ 33.

"Meistertisch“ 34.

"Meister vom Stuhl“ 10, 25, 29 (als Primus inter pares), 33/34, 36, 56, 77 (aProrokw 1826).

"Meisterweihe“ 29, 95 («Grobovšcik» 1830).

"Meisterworr" 34 (,Mac-Benac").

.Mensch"Menschheit 13, 18-20, 26 ('Elite als Menschheit' (Koselleck)) 30 (,Während der Ubergabe wird dem Gesellen gesagt: .Der, dessen Schädel du trägst, mein Bntder, war einst ein Mensch wie du!'”), 32-35 (Tod des, alten Menschen"), 35 (Geburt des neuen M-en), 65 (, Mauem am Tempel der Menschheir"), 75, 77, 80, 99. 106.

„Meta noeite! 35.

Metaphysische Bedeutung 19, 23, 26, 35.

Ministerium für Volksaufklänung siehe Ministerstvo nanodnago prosvešcenija.

Ministerstvo narodnago prosvescenija 16, 52. $57,59, X I X, X X X$.

Ministerstvo vautrennych del $\mathrm{XX}$.
Mitglieder 10, 19, (Zulauf der), 20, 22 (Grade der Mitglieder), 26, 28 (,M-verzeichnis" ${ }^{\circ}$, 31 („M." beglilckwinschen den neuen ,Bruder"), 38, $43,48,53,55,58-60,62,67$, $7778,109 / 10$.

,Mitgliedschaft" 16, 21, 69, 70, 81, 108, 110 . 115.

Mithras-kuly-höhlen 24, 29.

"Mittelfinger" siche "Finger".

,Mitwisserschaft" 26 (,Uberlegenheitsgefüh" durch $M$.$) .$

Moldawien XXXIV.

„Mond" 36, 39 (als Symbol der "Nache"), 92

(Geheimnisvolles M-licht \&Grobovšik* 1830).

"Musik" 34 (,einsetzende" M. bei Erhebung des jungen Bruder Meister), 84 (Schaffen Mozarts), 88, XXIV/ XXV, XXXIII.

Musikwissenschafuer 11.

Mysterien, ägyptische 11, 24.

Mysterien 24 (antike Hiram-M.), 25, 26 (Verbindung zu freimaurerischen Ritualen), 29 (antike M-bünde), 31/32, XXIV/ XXV.

Mysterien, höchste 29.

Mysterien, Orphische 24.

Mysterien, Eleusinische 24.

Mystik/Mystizismus, freimaurerische/r 11, 48, SO/51 (Spott über den f. $M$. durch Radišcev 1790), 57, 64, 81, 95 (Mystiker Saint-Germain bei Puskin), 96, 105, 112, XXIII (Vernadskij: Geschichte der Freimaurerei und des $M$. in RuBland (1927).

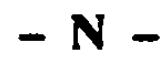

.Nachdenken", „stilles" 29 (,dunkle Karmmet des stillen Nachdenkens").

"Nachr" 36 (,Mond" als Symbol der „Nacht“).

"Nacken" 34 (,dinke Hand um den N.").

Namen 37, 69.

Nationalhymne 31 .

Naturvölker 24.

.Nekaman! 28 (.gegebenes Wort" furr den Neuaufgenommenen).

"Neophyt" siche Neuaufgenommener.

.Neu“ 31 (n-er .junger Bruder Meister"), 32

(Geburt des n. Menschen), 33/34 (Neumeister). 
Neuaufgenommener 20, 25-28, 30 (Uber den Sarg zu steigen veranlabt den $\mathbf{N}$ en an den Tod zu denken), 105.

Neuaufamehmender siehe Initiant.

Neues Testament siehe Bibel.

Neugierige 19.

"Neumeister" siehe "Meister".

Niederlande 42 (Aufenthalt Petrs I.).

Niedrigwasser 31 .

.Nichteingeweihter" 81, 94.

Nichufreimaurer 10 (Literanr für $\left.{ }_{\text {"N. N. }}{ }^{\circ}\right), 3$ (ztgängliche Literaur über Freimaurerei fir , $\left.{ }^{N}{ }^{\infty}{ }^{\infty}\right), 94$.

"Norden" 34 (im N. wird der Neuaufgenommene auf die Vergänglichkeit alles Irdischen hingewiesen).

Nullpunkt 34.

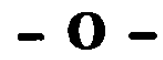

Österreich, Freimaurerdramen 83.

Obskurantismus 50.

„Offenherzigkeir" 37 („Senkblei"/,Low" als das Symbol für "Aufrichtigkeit", "Gradheit" und die „O. für das .ganze Leben").

„Ohre 34 (.,ins Ohr flüstern"), 77.

Okkultismus XXVI (o. Sprache).

Oper 11 (Mozart), XXIV.

Orakel von Delphi 65.

"Ordnung, kosmische" 36, 38.

"Organisation", „innere“ (Mittel der) 14.

Organisationsformen, bürgeriich-adelige des 18. Jhs. 9, 19, 41, 46, 48, 63, 73.

Originalitä, (mangelnde $O$. des freimaurerischen Ostens) 25.

"Oriene" siehe "Osten".

"On, ritueller" 24, 26 (,dunkle O-e").

Osiris-Legende 29 (O. Plutarchs).

"Osten", freimaurerischer 29 (.,von O. aus leitet der ,Meister vom Stuhl' die Lo-

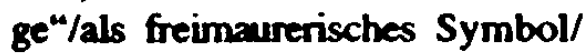
iber dem Osten leuchtet in vielen Freimaurerlogen die ,strahlende Sonne $\%$,maurerisches Licht" "Ont einer Loge ist im $O$. oder Orient"), 31 (,im O. erhält ex $\mathrm{Zu}$ spruch"), 36 (Schürze" als Symbol fir das ,orientalische Urkleid der Menschheir"), 46, 50, 65.

"Ostung" der .Kulurbeuten"/der Gräber/Wendung Richtung Osten 29.

Ovidij» siehe Loge avidij».

$$
\text { - P - }
$$

Papst/um 10, 47.

Paradigma 11 (P. einer freimaurerischen Symbolik und eines f. Brauchturms), $77,85$.

Parodie/p-e Stilisierungen in $14,69,89,93 / 94$, (aGrobovšcikw 1830), $102 / 03$ (APikovaja damax 1833/34), 112.

„Parole" 18, 26.

"Pabwort" 33 (das vom Gesellen soeben erlernte Pabwort).

Pathogenese (R. Koselleck) 26.

"Pentagramm" 39.

Personenkreisbezogenheit (der Symbole) 20, 94.

Petersburger Logen 44, 84.

Planzen 30 (,.,Rose"), 37 (".Akazie" /Rose).

"Pflichten", .Alte" 10, 22 (.,Old Charges"), 23, 26 (besondere P.), 36 (,Gleichgewicht" zwischen "Recht" und "Pflicht"), 88, (aMocart I Sal'. erio 1830/31), 93.

Philosophie, freimaurerische XII.

Philosophie, hermetische XII.

Philosophie, kabbalistische XII.

Philosophie, rosenkreuzerische XII.

Philosophie, symbolische XII.

„Platz" 28 (,Wo hat (...) seinen P. . (,keinen festen $P$. hat das WinKelmaB in der Loge).

Poetisierung der Freimaurerei 21 (P. d. F. war nach 1821 ein Tabu).

Polen XI, XVIII.

Politik 26 (.,unpolitisch“), 107.

Porträts XX (Zwei Bilder mit Pavel I. und freimaurerischen Emblemen).

„Portikus“ siehe „Säule/n“.

aPoslednyja novosti» (Pariser Emigrantenzeitung) 12.

PorträtP-malerei 38, 52/53 (Pavel I. mit freimaurerischer Emblemen auf $P$. in Stockholmer Poträrt-Galeric), 59.

Primus inter pares 33 (,.Meister vom Stuhl ${ }^{\text {"N }}$ als p. i. p.).

„Profan/e“ 10/11 (p-e Welt), 21-23 (Abgrenzung von p-e Welt), 29, 34 (Freudenlied gegen P-e), 35.

Publikationen 9, 10-14, 48.

Puskinvertonungen XXXIV. 
Rachsuche 30 (6.Dolch" als freimaurerisches Symbol für die "R." $)$.

"Rangstufe" 25/26, 31 (,erster Rang"), 45.

(R.C.) siche Rosenkreuzer.

Recht(e), besondere 24, 31 (,Zur Rechien des Meisters"), 33, 36 (,Recht, den Hammer zu fithred").

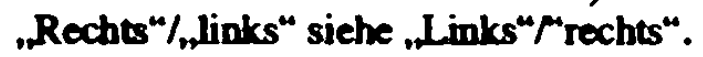

"Redewendungen," "stereotype“ 27/28.

"Regulations" 22.

"Reinigung" (,Stufe I") 28.

Reisebedingungen, erleichterte 27.

„Reise/n" 24, 33 (,R. der Meister/drei R. um den "Toten"), 34 (.Vorbereitung auf den Tod während drei R-n $\left.{ }^{\omega}\right)$.

"ReiBbreta des Meisters" 37.

Religion/en/Religiösität 10, 24, 36, 39/40, XXXII.

Revolution XX (Rolle der russischen Freimaurer in der Februarrevolution).

"Rites de passage" 24.

"Ritter Kadosch" siehe "DreiBigster Grad"

"Ritual, freimaurerisches" $10,25,28,29,31$, $32,35,39,44,47,52,69,72$, $78,87,88,92$.

„Ritus" 27 (,abfallender R.“), 28 (,aufsteigender R. $\left.{ }^{*}\right), 29,32,35,58,100$.

„Roher Stein" 37.

Romantik VI, XXXI.

"Rose 30 (als freimaurerisches Symbol bei Johannisfest und bei der Grablegung/drei R-en werden einem Bruder mit ins Grab gegeben), 39, 67/68, 100-103, 105 (\&Pikovaja damaw 1833); 113, 121 , XXV (R. als Wiedergeburtssymbol).

"Rosenfest" siche "Johannisfest".

Rosenloreuzer 10, 33, 45, 47-54, 56, 61, 64, 88, 90, 99.104 («Pikovaja damav 1833/34); 120, XII $X I I I$, XVI, XVIII XIX, XXII (*Moskovskoe obšcestvo rozenkrejoerovm), XXIV ("Symbolique du Rose-Croix" (1975)).

.Rosensor 32 (,r-e Leinwand").

"Rot" 38, 79.

"Ruhestätte, letzte" siehe Grab

"Ruhmsucht" (,Bronzemedaille" als Symbol fir ,R.“) 30.

"Runde" 34 ("die Runde machen").

RuBland/Sow jetunion 6, 12, 16, 21, 40-47, 50 , $53,56,60,61,65,68,81,105$, 109, 111, 114, XI (Bolschewistisches R-d), XVI.

$$
\text { - S - }
$$

"Sabmo" siehe „Tempel Salomos".

"Säule/n" 32 (Jachin und Boss"), 36 (Drei kleine Lichter breanen als Kerzen ouf drei S." $\left.{ }^{\mu}\right), 36$ (in allen Logen steben finf S-n), 100 (Baldachin als Himmel wird voo den beiden Sïnlen getragen).

Salomon/S-ischer Tempel 29 (Baurt des), 32, 38 (Betreten des „S. T-s" mit besonderer Kleidung), 65, 98-101 («ikovaja dama 1833).

"Sarg" 30 (S. wird bei Meistererhebung mit Leinwand bedeckt/ber den Sarg zu steigen veranlabe den Neuaufgenommenen an deo Tod w denken), 31, 33/34, 89-93 (aGrobovscik» 1830), 102, 105 («Pikovaja damaw 1833), 100 , 102, $113 / 14$.

"Sauber bei der Arbeir" 35.

"Schädel" $/$ "Totenschädel“ 32, (U'bergabe des T-s an den Gesellen), 91 (,.lebeodiges Skektt" in «Grobovsxik» 1830), 117.

Scharlach 32.

"Scharlatanerie" SO.

"Schenkel des Zirkels" siehe Zirkel.

"SchieBen" 65.

"Schliebung" 19, 32 (,S.“ der eigentlichen ,Arbeit $\left.{ }^{\circ}\right), 60$ ("S. der Loge in RuBland").

"Schlüssel“ 37 (.,S.“ als Symbol für die ,Zunge"/und wegen deren ännlicher Form auch der "Verschwiegenheit $\left.{ }^{\circ}\right), 45,99,102,113$ (Hermano bekommt von Liza deo Schlüssel in Pikovaja damav 1833/34).

„Schönheit" 33, 36, 87 (.,S." als geistige Kraft der Freimaurer).

.Schottische (Frei)-Maurerei“" 30, $36 / 37$ (,sch. Lehrart" d. Freimaurerei), 42, 44, $46,48,57,99$, XIX.

„Schritt/e" 9, 33 (,.Meisters.), 34 (drei S-e/stufenweise gelehrte S-e).

"Schulter", "rechte" 34.

.Schürze(o)/Schurzfell" 31 (..S." als Symbol der .sittlichen Arbeir"), 33 (Gesellenschurze/dem Neumeister streckt man die linke Hand der Lönge nach der Seite aus, die rechic Hand wird mit dem S-fell umwickelt und der rechte FuB anf 
das linke Knie gestellt, um ein WinkelmaB zu formieren), 35 (,weibe S-e"), 38 (,Schürze" steht als Symbol fir das ,orientalische Urkleid der Menschheit"). Sie auch "Adam und Eva"

"Schutupatrone", ", heilige" 31 .

"Schwarz(e)" Farbe (bei Aufnahme in den Bund) 30, 87 (Schwarz gekleideter Mann in Mocart i Sal'eri. $1839 / 31$ ).

"Schwedisches System" 46, 65, XXII ("History of Swedish Freemasonry in Russia" (1926).

"Schwelle/n" 65 (., Oberschreiteo der S." ), 92 (Unbekante Schwelle in aGrobovixik- 1830).

"Schwert" 37 (,gezogenes Schwert"/Gravuren und Stiche mit Abbildungen von freimaurerischeo Schwertern), 7476 (Bezug zur freimaurerischen "E-formel" in eProroks 1826).

"Schwester/s" 28, 30 (rituelle Symbolik ar Vermeidung der Aufnahme von Fraven in die Logen), 95 (SaintGermain nahm auch Fraven in seine Logen auf; Gräfin als Parallele in Pikovaja dama. 1833/34).

Seestrand 31.

"Seide", "gelbe" 32.

"Selbstbeherrschung", Schulung der 30.

.Selbsterzichung 37 (,soziale S.” des Menschen).

Selbstverständnis, freimaurerisches 11,81 .

"Senkblei" "Lor" 37 (Symbol fuir "Aufrichtigkeit", "Gradineit" und die „Offenberzigkeit für das ,ganze Leben“), 64.

Sensationsbedürfnis der Zeit 10.

.sicherung (,Stufe I') 28 (S. vor Eintritt Unbefugter), 35.

opieben" 38 (,Jakobsleiter" hat s. "Sprossen“), 37 ("heilige Zahl fuir Meister"), 57, 95-100 (aPikovaja damax 1833), 102, 103, $113 / 14$.

"Silber" 32.

"Simn" 31 (, ibertragener $/$ "wörtlicher").

.Sinnbildor 18-20, 23, 30, 36, 38, 99.

"Sittichkeir" 19/20, 37 (WinkelmaB als Symbol der Befördenung der S./s. Mabstäbe).

Skelett siche Schödel.

Skopzen 69.

"Sohn" 35 (.Er lebt im Sohn").

Sonderarchiv siche Archiv.
„Sonne" 29 (Gstrahlende"), 36 (drei Lichier auf drei kleinen Säulen), 34, 39, 65 (S-strahl).

Sorge 26 (Koselleck: S. vor Verrat).

Sowjetunion siche RuBland.

"Soziale Selbsterzichung" des Menschen 37.

Spekulation 11 (S-n über die Freimaurer), 81.

"Spiegel" 38/39, 79, 98/99 («Pikovajo damsw. $1833 \sqrt{34}), 112$.

„Sprossen" 37 GJakobsleiter" hat ,sieben „S.“ drei "Hauptsprossen der Jakobsbiter).

"Spruch" 35, 64.

Staatsgefährlichkeit der Freimaurerei 10.

"Stärke“ 36, 87.

"Stand", ,eigener" 32. (der Meister).

„Stein" 36/37 ("Behaven des S-8/ „Harmonisierung der S-form "/,Tempel könne nicht aus rohem S. bestehen"\% ,rauher S. des Lehrlings"/,kubischer/vollendeter S.), 39, 65 (roher/rauher S. des Lehrlings), 81.

Steinmetzbruderschaften, kirchenbavende 2, 23, 33 (Werkzeuge der Steinmezen).

Steinmetzgilde 28.

Steinmetzschlegel (Form des S-s) siehe Hammer.

Steinmetzzunftbrauchtum 10.

"Stellung beibehalten" 33 (.,Neumeister muB S. b. bis er das verlorene Wort wiederfindet).

Stern, flammender XXVII.

„Stewards" 38 (S-s tragen rotes Band).

"Stirb-und-Werde-Gedanke" 32 (Goethes), 66, $77,93,95,98,102,112 / 13$.

"Strafe" 31 (verbale Androhung von „S."

"Strikte Observanž («strogaja nabjjudenijan) 46.

„Stufen" 24-26, 34 (Der Lehrling ersteigt mit 3, der Geselle mit 5 und der Meister mit 7 Stufen den Altar. Für das Ritual ist entscheidend, daB de Maurer alles in der geraden Linie nach Muster eines rochtwinkligen Dreiecks abschreitet. Auch die Hand soll der Maure in rechien Winkel bewegen), 65, 99 (Wendeltreppe in ePikovaja daman 183334).

"Stuhlmeister" siehe ,Meister vom Stuhr".

"Sïden" 33 (im S. als der letzten Hirnmelsrichtung wird der Neuaufgenommene aufgefordert, ein Leben in steter Rücksicht auf das Ende zu führen).

„Symbol(e/ik) zu viele Einträge. 
"System/e" 9 (,Entwicklung der verschiedenen S-e), 19, 23 (reigenes S."), 26 (,schottisches S."), 35 (orthodoxales S.), 39, 44/45, 48, $50,55-58,65,100$.

$$
-\mathbf{T}-
$$

Tabuisienng (der Freimaurerei) 12.

"Tag" 34 (,Sonne" als Symbol des T-es), 95.

Tagebuch 16 39, 59 (Kixinev, 1821), 107-11.

"Tapis" siehe "Teppich".

Teilhabe 26.

"Temper" 23, 28 6,T." als Symbol des „Weltalls ${ }^{\circ)}$ ), 29 (,Einführung der Brüder in den T. $\%$, Licht erleuchte diesen T."), 29 (.Himmelsrichtungea haben symbolische Bedeutung im T. $\%$, T. ist selbst am hellsten $\mathrm{Ta}$ ge künstlich beleuchtet), Bauart des Salomonischen T-s), 29 (Legende vom Groben T-bau), 32/33, 35-37 (.,T. könne nicht einfach aus rohem Stein bestehen"1 "T. der Humanität"), „Tempetherren" 46 G.Klerikat der T. herren" ${ }^{40}$. 65, 100, 103, XXIV (,T-bau"), XXV (,T. Salomos" (1809)), XXVIII (T als Salomonisches Symbol).

"Teppich“ 36, 46, 76, 91/92, XXVII (Tapis)

ressera hospitalis 18.

"Testament Salomonis“ 32.

Theater siche Drama.

Theater (wissenschaften) 4.

Theosoph/ie 50-52, 65, 69, 96.

"Thron der Wahtreit" 65.

Tier siehe Biene.

"Toast" 31 (,Meister" gibr seinen T. bei Netaufnahrne eines Bruders).

„Tod" 29 (T. des Baumeisters), 30 (Uber den Sarg zu steigen veranlaBt den Neuaufgenommenen, an den $T$. zu denken), 31 (der Westen erionert den Meisterkandidaten daran. das der T. eine Herausforderung fir das Leben ist), 32-34 (.Vorbereitung auf den $T$. wäh rend der drei Reisen“), 73, 77 (AProrok- 1826), 82/83, 87-91, 93 («Grobovšik» 1830), 98 (Geheimnis-Verweigerungs-Tod der Gräfin in Pikovaja dama 1833/34), 113 (Das den Tod be gribeade Handwerk in arobovExito 1830)

"Todeserlebais" 34 (Vorwegnahme des T-es).

"Tontäfelchea" 33.

"Totedr" 33 (drei Reisen um den .T-a*), 31

(Hilfestellung, darnit der T. nicht wieder zusammenbricht), 89 (Lo beodiger Tod und boles Leben in Grobovsxik 1830), 95 (Tole Gröfin blinzeh Hermann w in Provaja damav 1833/34), 99 , $102,113-115$.

"Totenschïdel" siche „Schäder".

Tragödie siche Drama.

Travergesandtschaft 29.

Trinksitten, freimaurerische siehe Trinkspriche

Trinkspriche, freimaurerische 31, 92 .

„Tir", "dreimaliges An-die-Tür-Klopfen" 30 (Dreimailges Klopfen nach Art der Freimaurer in aGrobovseilk. 1830),

"Tugenden", ,freimaurerische 10, 20, 55, 57 , 102.$$
-\mathbf{U}-
$$

Ubereinkunft 18.

"Uberintisches" 33 (wird dem Neuaufgenommenen im Osten als Zuspruch prophezcit).

Uberiegenheitsgefüh 26 (der ,Mitwisserschafi").

„Umgebung, düstere" 26 („für den Lichtsuchendenc).

„Umwickeln“ 33 (dem Neumeister strockt man die linke Hand der Länge mach der Seite aus, die rechic Hand wird mit dem Schurzfell u-t und der rechte FuB auf das linke Knie gestellt, um ein WinkelmaB au formieren).

„Unauflöslich 20 (U-e Verbindung/Gemeinschaff").

„Unbefugr" 28, 35 (,u-e Einblicke in die La ge).

.Unbeweglich" 37 (heiBt mit festem Platz in der Loge, z.B. sind bestimmte "KJeinodien" u.).

„Unschuld“ 38, 106, 109.

„Unterondnung" 26.

Urreligion XXVII (.,U. als Basis der Freimaurerei" (1855)).

Utensil, zeremonielles $17,19,21,37,111$. 


\section{$-\mathbf{V}$ -}

"Vaterunser" 39.

Verbot 13, 15 (erstes Verbot 1822), 48, 52, 571 $58,60-62,67,73,81 / 82,94,96$, $100,108,110$, XVII.

„Vendunkelt(e)", Loge 33, 65, 98 (Verdunkelter Vorraum in aPitovaja dama 1833/34).

"Verginglichkeit/vergängliches Leben" 33 (im "Nordea" wird der Neuaufgenornmede auf die Vergänglichkeit alles Irtischen hingewiesen).

Verlagswesen XII (Anfäge des modernen V-s in Rubland).

"Verloreses Wort 33, XXVII.

Veröffentlichung/en, freimaurerische 33.

"Verrar 10, 26 (orSorge vor V.").

Verrïierschriften 10, 33.

"Verschwiegenheit" 10 (.,voverbrichliche V."), 30, 34 (Verschwiegenheit gegeniber Bridern niedrigerer Grade), 88.

Volksglauben siehe Aberglauben.

Voltairianer/Voltairianismus 104-106 (Pußkin in seinem Aphorismus Zameki i aforizmy raznych godov» 1829).

"Vorbereitung" 34 (aur den Tod).

"Vorbereitungszimme" 29 (.dunkles V. des Neuaufzumehrneaden").

"Vorhang" 65 (Auseianderzichen des Vorhangs als Entdeckung des Geheimnisses).

„Vorloge“ 28 (,Eröffnung der V.").

Vorsicht 26 (V. gegenüber den AuBenstehenden von seiten der Freimaurer nach Kosellek).

Vorstellung, aberglüubische 11, 81, 87.

Vorwissen 26, 104 (Vorausgesetztes V. in be zug auf die Freimaurer in Puskins Aphorismus Rametki i aforizmy raznych godov" 1829).

$$
-W
$$

"Wahrheir" 65 ("Throo der W.").

"Wandel" 35 ("Vorbereitung auf den Wandel").

"Wanderumgen", rituclle 28, 30.

Weimer XII.

"Weisheit" 36.

"Weiß/e 38 (,w. Handschuhe" der Freimaurer, "w. Bundeskleider" und $w$. Schurdfelle).

Welt der Zeichen siche Zeichen.

„Wehtall 28 (T. als Symbol des Weltalls).
"Welt", ,alte" 18, 22.

"Welt", "birgerliche" 26.

"Welt", newe" 26.

"Wele", "profane" 11.

"Welt", „verborgene" 22.

Weltanschaung XXVI (freimaurerische W.).

Weltmaurerei 40.

"WerkabeitWerkmaurerei" 23.

"Workseuge" 23 (W. der Baukunst), 35, $37^{\circ}$ (owichtigste W. des Maurers").

Wendungen, stereotype 17, 27/28.

„Westen 43 (dex W. erinnert den Meisterkandidaten daran, daB der Tod eine Herausforderung für das Leben ist).

„Wiedererkennungszeichen" 18.

"Wiederfinden des veriorenen Wortes" 33.

"Wiodergeburtssymbol" 102 (Rose als Wiedergeburtssymbol in aPikovaja damax 1833/34), 113, XXV (Rose als W.).

Wilhelmsbader Freimaurerkonvent 48.

„Willen" 36 (Bei Freimaurern versinnbildlicht der Steinmetzschlegel/Hammer auch die Macht, den Willen, die Befugnis, und auch die materielle Gewalt des operativeo Maurers).

Winkel/W.-maB 33 (dem Neumeister streckt man die linke Hand der Länge nach der Seite aus, die rechie Hand wird mit dem Schurzfell umwickelt und der rechte FuB auf das linke Knie gestelle, um ein W. zu formieren), 35 (Für das Ritual ist entscheidend, dab der Maurer alle in der geraden Linie nach Muster eines rochtwinkligen Dreiocks abschreitet. Auch die Hand soll der Maure im rechten Winkel bewegen), 37, (.W. auf der Brust des Meisters oder dex Aufseher"), 39 XXVI (W. neben Bibel und Zirkel als freimaurerisches Symbol).

Wissen un die eigene Teilhabe 26.

"Wissensstufen", ,ethische" 24.

"Wo" siehe Frage.

"Wohlwollen" 36 (.,Gerechtigkeir" und „W.").

"Wor" 26 (",besonderes W."), 31 (gegebenes W." für den Neuaufgeoormmenen), 33 (,Neumeister muB verlorenes $W$. wiederfinden), $34,101$.

„Wortlaut des Rituals“ 27.

Wortschatz 65/66 (W. der Freimaurer sei nicht originär), XXIII (W. der deutschen Freimaurerlyrik). 
Wörtlich nehmen 31.

"Winde" 36 (Zeichen der "Wuirde").

$$
-\mathbf{Z}-
$$

,ZahVen“ 38, 46 (,freimaurerische Z-ensymbolik*), 79, 95 (Zahlen in aGrobovisxik- 1830), 100-103 (Zahlen in Pikovaja daman 1833/34) 113, XXV.

,Zauberföte" (Mozart) 11.

"Zeichen" 17, 26 (eigenes Z.), 30, 31, 35/36, $68,82,91$.

Zeichnungen, freimaurerische siehe Ikonographic.

Zeigefinger siehe Finger.

"Zeit" 28 (.Feststellung der Zeit" (=Bestimmung der Z.)), 35.

Zensur 12, 14, 47, 53, 55, 71, 106, 109.

,Zeremonien" $/$ "Zeremoniell" 10, 19, 24/25, 27 , $30,32,43,37,93$.

Ziele, keine politischen 26, 94, 111.

,Zirkel" 35 (Z. symbolisiert die Liebe zu den Menschen und zur MenschlichkeiUSpizze/Schenkel), XXIV, XXVI (Z. ist neben der Bibel und dem WinkelmaB das typische freimaurerische Symbol).

Zunftwappen 38 (,altes Z. der englischen Maur rereic).

Zünfte, mittelalterliche 23, 37, 92.

Ziirich XII.

.Zunge" 31 (rituelles Herausreißen der ,Z. Vergraben der ,Z.") 27, 37 ("Schlüssel" als Symbol/Allegorie für die Z., da sie die Geheimnisse gut bewahren kann"), 75/76 (RiB Zunge aus dem Mund in -Proroks 1826), 99.

.Zuspruch 33 (,im Osten erhält der Neuaufgenommene Z.").

Zwecke, parteipolitische 10.

Zwecke, religionspolitische 10 .

,Zylinder" 38. 


\section{Russischer Motivindex freimaurerischer Symbolik und Allegorik}




\section{- A -}

*AS.P.» 90, 94, 98, 108 (lnitialen von Adrijan

Semenovic Prochorov, dem Sargmacher-

Held in a-Groboviziks 1830, sind iden-

tisch mit denen seines Schöpfers und

Freimaurers Aleksandr S. Puskin).

«Akacija» 39 («vetv" akaciix).

Aljuzija/alljuzii/namek/i"allusions"(frz.) 9.

14, 17 (Geheimbund-Allusionen als

systematisierender Oberbegriff), 21, $45,64,67-70,73 / 74,78-82,90,94$,

$96,100,103,104$ (bei Puskikin frz.

"allusions") 106, 108, 111-13, XXXI.

*Altar' 34, 36 (masonskij «a.x).

"Allusions" (Genre- oder Subgenre-Begriff bei

Puskin) siehe alljuzija.

Astreja siehe Lozyy (Astreja.

$$
\text { - B - }
$$

«Baldachin» 37 («mnogocvetnyj b.»), 99 ( Grob stojal na bogatom katafalke pod barchatnym b-orn in a Grobov. sxik» 1830), 100, 113.

„Benac" 34 (Meisterwort ins linke Ohr).

«Belyj/ye» 38 («b-ye percatkix).

«Biblija» 30 («b. otkryta na evangelii ot Ioannax), 31 («Kandidat kladet pravuju nku na evangelie, razvernutoe na čtenii ot sv. loanna, i pri étom proiznosit za masterom prisjaguw), 36 ( $\mathrm{kv}$ lože $\mathrm{ma}$ ster stoit na vostoke, na grudi visit u nego naugol'nik; $b$. otkryta na evangelii of loanna, i tri gorjasija svexi stavjatsja v certežre na polu, v vide treugol'nika (...)শ), 38/39, 75-77.

„Bijou" («Bižnw) 38.

«Bol'Sinstvo» 29 (aJa zaprešcaju vsjakuju bran', kljatvy ili sopot, i vse profannye razgovory, kakogo by roda ni bylo, pod nemen'sim strafom, cem kakoj polozit' b.»).

«Bran'/oranit' 29 («Ja zaprešcaju vsjakuju b., kljatvy i sopot, i vse profannye ragovory, kakogo by roda ni bylo, pod nemen'šim strafom, cem kakoj položit' bol'Sinstvo.n), 59, 72 («skoro smolknet b. sred' rabskogo narodan, in «Generalu Puscianx 1821), 104.

«Brav'jar 23, 25, 28-30, 35 («Master udarjaet tri raza o stol derevjannym molotkom $i$ nadevaet sljapux/rostal'nye brat'ja ostretsja bez sljapw), 53 (Pavel I. k delegaciju russkich masonov: episite mne po-b-ski bez vsjakich komplimentovw).
68 (Pis'mo k V. L. Puskkin in aDjade, anveviemu soxinitella bratom. (1816), 7071 ( $\propto 0$ veruyj bratw in «Gemerale Puscinu» (1821)), 72, 86 ( $\alpha$ Slusaj, brat Sal'erix in alocart 1 Sal'ert 1830/31), 91, 108 (Pis'mo k V. L. Pưkin in aDjade, nazvavemu soxthitielia bratom* (1816)), XX (\&Bra'ja Zlatorozovogo Krestax).

*Bratstvas 23 (uremestennye b-av/ \&b-a kamenotescovis).

«Byt'budets 29 (ximeet-li on istinnoe telanie byt' prinjatym?x), 31 («Pust' mne budet pererezana Seja, jazyk vyrvan s kornem i zaryt $v$ morskom peske pri nizkoj vode za kabel'tov razstojanija ot berega. gde priliv $i$ otliv prochodjat dvaždy v dvadcat' zetyre casar).

\section{$-\mathbf{C}$ -}

«Cep' 34/35.

«Ceremonija priema» 27, 30, 32, 34, 55, 87.

*Chram* 23 («vnutrennyj ch.»), 28, 33, 35, 38

(«ch. gumannostiw/ «ch. Solomonovas).

«Chranit'» 31 («chranit' i ne vydaval' ni pod kakim vidom nikakoj iz tajnych misteii svobodnago kamen(')šcicestvar).

«Cilindro 38.

"Cirkul'» 30 («emu rastegivajuk zilet $i k$ obnažennoj levoj grudi pristavljajut ostrie c-ja, kotoryj on sam deržjt v levoj nukex), 35.

$$
-\grave{C}-
$$

«Cerepw 30, 91 («(..) cerep ego laskogo ulybalsja grobovšxiku» in aGrobovšstik» 1830))

«čentež. 30 («tri gorjazija sveči stavjatsja v teže na polu, v vide treugol'nika (...)» IaPosle togo kandidata podvodjat, tremja masonskimi క̌agami, $k$ skamejke, stojascej pered upomjanutym $z$-emw),

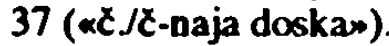

$$
\text { - D - }
$$

«Dejstvon 62 («masonskoe d.»).

(Dekabristy-masony, XIX.

«Den $\$ 28$ (akak soloce zachodit na zapade, cto-

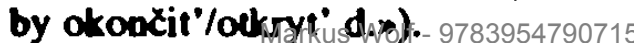


«Derevjanyjo 29 (xMaster udarjact tri raza o stol derevjannym molotkom»).

«Dertat' 30 («(...) emu rastegivajut zilet i $k$ obartennoj levoj grudi pristavljajut ostrie cirkulja, kotoryj on sam d-zit v levoj rukex).

«Diakon/y* 26, 28 («maldxij d.w/«d. donosit ob ètom masterux), 32, 33.

$\alpha$ Dialog 18, 21, 28, 45, 56, 111, 113.

«Dikij» 37 («dikij kameo' dlja ucenika»).

«Dolzoost'* 28 («Ispolnite svoju d.»).

DDososit'* 28.

«Docka 37 («tertežnaja d.»).

«Dostopočtennyj» 28 («d., loža otkryta») 71

( O kamensxik poctennyj» in «Gene.

ralu Pexxinu* 1821), 91.

¿Drugaja komnata siehe komnata.

«Druzeskoe urenoe obstestvo* 49, XIII.

«Dvadcat' cetyre casa* 31 («dvaždy v d. c. c.»).

«Dvazdy 31 («d. v dvadcax' cetyre casas).

«Dver' 28 («udarjat' tri raca v d.», «stojat' na s-e u dverej»), 30 (xstuxit' tri raea v d. loži), 90 («Grobovszik» 1830), 101.

«Dient'men* 29 («Master sprasivaet potom, gotov-li k prinjadju d., predlozennyj v prosloj raz?x).

$$
-\mathbf{E}-
$$

«Evangelija» siche «Biblija» kak masonskij simvol.

$$
-\mathbf{P}-
$$

«Frakw 38 («otdetyj prosto vo f.»).

*(Frank-)mason/y /stvow/«franmason-/ «farma20a* 13, 22, 24, 79/80 (xfarmazon* als Verballhornung von xfrank-mason* in Evgenif Onegin. 1823-30), 90 (arobovidik- 1830), 104 (xfanmasony* in Zametki I aforizmy raznych godov. (1829)).

$$
-\mathbf{G}-
$$

«Garmonijaw 46, 86/87 ( Dvuch sinovej g-ii» in aMocart i Sal'eris 1830/31).

aGlazar 29 («zavjazyvajut plakatom g. i predostavljajut ego na neskod'ko vremeni ego rasmyšlenijamn).

*Gorjasija svexi» 30 («tri g. s. stavjatsja v centeze na polu, $v$ vide treugol'nika (...) $)$.
«Gotov-li» 29 («Master sprasivaet potom, 8.-1. $k$ prinjatiju džentl'men, predložennyj $v$ prosboj raz?»).

«Grad(us)ys 16, 24/25 (*Novye g-y»), 30, 32 $34,36-38,46,48,50,57,62,70,71$, $73,76,94,113$.

*Gravirovat' " siche *Ni g.».

«Greక̌nyj moj jazyku 76 (Bezug zur freimaurerischen "Eidesformel" in AProrok" 1826).

«Grob/ovoj 34, 85 (*Viden'e grobovoe in Mocart I Sal'erib 1830/31), SOIf. (Grobovidik- 1830).

Grobovzitu (Adrijan Semeonovič Prochorov) seit.

«Grud' 30 («na grudi visit u mastera naugol'nikw/kemu rastegivajut zilet $i k$ obnaZennoj levoj g-i pristavljajut ostrie cirkulja, kotoryj on sam derzit v levoj nukex), 76/77 (Bezug 2ur freimaurerischen "Eidesformel" in aProrotw" 1826).

«Gumannost' 38 («chram g-iw/«chram Solomonovar).

\section{- I-}

«Iakov/as 37 («lestnica I-as).

«Illjuminaty XV.

«Imja» 29 («vo i. sv. Ioannaw/«sprasivajut ego imja i zvaniex).

«loannaw 29 («vo i. sv. I.»), 30 («loža po6vjascennoj sv. I-y, (...) w/ «na evangelii ot Ioannaw/ $\times$ Kandiat kladet pravuju mku na evangelie, razvernutioe na ctenii ot sv. Ioanna, i pri etom proiznosit za masterom prisjagu $)$, XX ( $\mathrm{Il}$-ov den' masonskij prazdniks).

«Iskusstvo* 22/23, 31, 39, 84 («Rodilsja ja s ljuboviju $k$ iskusstvus in Mocart $i$ Sal'erio 1830/31), 86/87, 98, 100, $102,111,113$.

«Ispolnit' 28 («I. svoju «dolžnost'»), 75 («I. voleju moej» in «Prorok» 1826).

«Istinnoe Zelaniew 29 (ximeet-li on i. z. byt' prinjatym?w).

$$
-\mathbf{J} \mathbf{J} \mathbf{u} \text { - }
$$

«Jazyk» 31 («Pust' mne budet pererezana seja, ja vyrvan s kornem i zaryt $v$ morskom peske pri nizkoj vode $2 a$ kabel'tov razstojanija of berega, gde priliv i otliv prochodjat dvazdy $v$ dvadcat' betyre 
Casar), 76 («Greßnyj moj jazyk» als Bezug zur freimauretischen "Eidesfor$\mathrm{mel}^{*}$ in \&Prorols 1826 ).

«ug* 28 («Otvet: Pozadi startago nadziratelja na ju-e/na zapade/na vostokex).$$
-\mathbf{K}-
$$

«Kabel'tov» 31 ( ZZa k. razstojanija of beregax). «Kamen' 37 («dikij k. dlja ứenikaw/«soversennyj, kubickskij k.»), 75, 81.

*Kamenotesy» 23 («rabota kov»), 36.

«Kamenscik/ix 17, 22, 24 («vol'nyj/ex/*svobodnyj/yew/xOrden svobodnych kov»), 31 («chranit' i ne vydavat' ni pod kakim vidom nikakoj iz tajnych mysterii svobodnago k-scickestvar), 69 ( 0 k. poxtenyjw in aGeneraln Puszinow 1821), $71 / 73$ («farmazon» als Verballhornung von kfrank-mason* im Evgenif Oregin- 1823-30).

*Kandidat» 10, 24, 27 («K. ostavljaetsja ( $v$ osoboj komnate) odinx), 29 («K. (nauCaemyj provozatym) otvexaet: Celovek, kotoryj ielaet imet' i prosit' u'astija v blagach étoj dosopoxtennoj lož, posvjasčennoj sv. loannu, kak èlo sdelali do menja mnogie brat'ja i tovariscisw) 30 («K. kladet pravuju ruku na evangelie, razvernutoe na ctenii of sv. loanna, i pri etom proiznosit za ma sterom prisjaguw), 32-34, 76, $91-93$ («Grobovšik» 1830) 98, 99, 112.

Kapitul feniksa XXI.

Kazanskjj Sobor IX.

«Kinzal» 37, 82 («K. L, ten' B (...)» als rätselhafte, immerhin freimaurerisch-assozijetbare Strophe IX im 10. Kapitel des «Evgenij Onegin» 1823-30).

«Klejnod/y* $37 / 38$ («tri podvižnych i tri nepodvižnych klejoody»).

«Kljarva 29 («Ja zaprešlaju vsjakuju bran', k-y ili sopotw i vse profannye razgovory, kakogo by roda ni bylo, pod nemen'sim strafom, čto kakoj položit' bol'sinstvow.), 31 («k.w/<prisjagar).

«KJjue' * 38, 74, 91.

«Kolebaniex 31 («bez vsjakago k-jaw).

«Kolenow 29 («potom obnazajut emu pravoe $k$. na levuju obutuju nogu nadevajut tuflju, zavjazyvajut plakatom glaza i predostavljajut ego ma neskol'ko vremeni ego razmy (lenijamx).

*Komnata* 29/30 («Kandidat ostavljaetsja (v ocoboj $k-e$ ) odin. Ortuda ego privodjat v druguju komnatu, soversenno temnujux), 98 («po vsem komnatam casy» in aPilcovaja damax 1833).

«Korea'» 31 («Pust' mne budet pererezana seja, jazyk vyrvan s k-nem i zaryt $v$ morskom peske pri aizkoj vode za kabel'tov razstojanija of berega, gde priliv i otliv prochodjal dvazdy $v$ dvadcat' cetyre casen).

«Kotoryj ¿as? 100.

«Kniga konstiuxcii» 22.

\&Krasit' * siebe $\alpha$ Ni larasit' $*$.

«Krasotan 36, 69 (*Deva k-y»).

*Krest' * siehe *Brat'ja Zlatorozovogo Kresta*.

«Kruglaja sljapa* 38.

«Kto tam? 30 («mladXij nadziratel' sprasivact: Sto tam? sw), 90/91, 113 (freimaurerische Frage in «Grobov3xilk 1830), 121.

«Kubizeskij» 37 («soveršennyj, k. kamen' «).

«Kul'ty» 24 («tajnye t.»).

$$
-\mathbf{L}-
$$

*Lestnica lakovas 37.

*Levyj» 30 («emu rastegivajut tilet $i k$ obnaŻennoj 1-oj grudi pristavljajut ostrie cirkulja, kotoryj on sam deržt v l-voj nukex).

«Linejka» 37.

«Ljudy» 28/29 («platit' 1-jam ich zarabotok»/ «Master postavit 1-ej na rabotun).

«Loža 28 (ksmotret' ctoby l. byla pokrytaol «skažite, gde mesto mladsago diakona/starsago nadziratelja/mastera $v$ l-e?), 29 ( Zatem master snimaet sljapu i ob"javljaet 1-u otkrytoj, sledujuscimi slovamix/xeto loža otkryta vo imja sv. loannan), 30 («master stoit v bž ma vostokex/kv dver' loži»), 31 (kspisok lozw), 32-35.

«Loża (Trech Dobrodetelej)» XXI («L. «T. D.) i ce cleny - dekabristy ().

«Ložy (Astreja) 54, 74 (1. *Petra $k$ istine», 2. *Palestiny», 3. «lzida», 4. «Neptun $k$ Nadezdex, 5. «lzbrannago Michailax, 6. «Akeksandra Koronovannago k Pelikanu», 7. «londana», 8. «Soedinennych Druzej», 9. «Plamenejuscej zvezdej», 10. «Voennaja, Georgija Pobedonosca», 11. «Razsejannago Mraka», 12. *Trech Sekir», 13. *Aleksandra $k$ Trojstvennomu Blagu», 14. *Trex Koronovannych Merej», 15. «Kljux' k Dabro detelejw, 16. *Otla Rossijskagom, 17. 
«Lumaw 34.

«Soodinennych Slavjan», 18. «Ljubov $k$ istine», 19. «Severnych Druzej», 20. «Belago Orla», 21. «Oolotago Kol'ca», 22. «Aleksandr k PZel», 23. «Vostoxnago Svetilax, 24. rOzirisa k Plamenejux (zvezdex).$$
-\mathbf{M}-
$$

., Mace 34 (Meisterwort ins rechte Ohr).

Martinisty 51, 56, 62, 105/06, 114.

«Mason/y» 16, 24 (xpervaja objazannost' ma sonaw), 30/31, 35, 56, 62, 90, 104, 107, 199, XXVII («Prinjatie $v$ ma sony v 1815 godus (1870)).

Masonskaja instrukcija XX. (Tajnaja masonskaja instrukcija sotlandskoj masterskoj).

*Masonskaja tajna* 30 (*Master sprasivaet ego: Obexxat li on nikomu i nikakim obrazom de vydava' masonskoj tajnys?x).

«Masonskaja tajoopis' » siche «tajnopis'».

«Masonskie pesni» siche pesni.

«Masonskie znaki 38.

*Mascoskjj prazdnik siebe prazdnik.

*Masonskija systemy* 29.

*Masconskoe dejstvo» 62.

*Masonstvow 13, 22/23, 33, 36 (*Tri menకjel velikje svetil'nika $\mathrm{m}$-ax), 41 (russkoe «m.»), XX (m. kak položitel'noe dvizenie russkoj mysli $v$ naxale XIX veka (1904)), 37, 41, 44, 46, 80, 104.

«Master/y" 25, 26, 28 (*M. sprasivaet mladsego diakonam/adiakon donosit ob étom masteruw/aM. sprasivaet: SkaZive, gde mesto mladsego diakonal Mladsego nadziratelja/starsago nadziratelja/m. v loze?w/kM. stoit na vostokew/xM. postavit ljudej na rabotu» /aM. udarjaet tri raza o stol derevjannym molotkom»/^M. nadevaet sjlapux/\&Master sprasivaet potom, gotovli k prinjatiju dłentl'men, predložennyj $v$ prołloj raz? $), 30$ ( $\alpha v$ loze $m$. stoit na vostoke, na grudi visit u nego natgol'nik; biblija otkryta na evangelii or loanna, i tri gorjałija svexi stavjatsja v Centeze na polu, $v$ vide treugol'nika (...) $w / \propto M$. orvexact tremja udarami molotkan/kPosle voprosa mastera $k$ kandidon, on prikazalw/ $\times$ Slovo $m$-a $k$ kandjdatuw: Pokazite emu sveton), 31 (xKandidat kladet pravuju ruku na evangelie, razvernutoe na ctenii of sv. loanna, i pri étom proiznosit za masterom prisjagu»), 32/33, 92 (cedorov'e masterov i podmasterov in $\times$ Grobovizik- 1830).

*Masterskij stol 34.

«Masterskij sag* 33.

«Master stulaw 33/34, 36.

*Master velikij» 30 ( $\propto v$ prisutstvii v-ago masteran).

«MeX 37 (mobnatennyj m.*), 75 (Bezug aur freimminerischen "Eidesformel ${ }^{\circ}$ in Proralo 1826).

«Mensijie» 36 (*Tri menŠie /velikie svetil'nika masonstvan).

*Minister voutrennych del» XX.

«Misterii» 24 («starye m.»), 31 («chranit' i ne vydavat' ni pod kakim vidom nikakoj iz tajnych $\mathrm{m}$-ii svobodnago ka men'scixestvax).

*Mladłij diakon* siehe «diakon».

«MladXij nadziratel' siehe «nadziratel' $\%$.

«Mnogocvetnyj baldachin* 37.

«Molotok* 29 («Master udarjact tri raza o stol derevjannym m-tkom»), 30 («Master otvexact tremja udarami m-tkan), 33, 36, 71/72, 115 («Generala Pustinu» 1821)

«Morskij» 31 («Pust' mne budet pererezana ja, jazyk vyrvan $s$ kornem i zaryt $v \mathrm{~m}$ kom peske pri nizkoj vode za kabel'tov razstojanija of berega, gde priliv $i$ otliv prochodjat dvaždy $v$ dvadcat' cetyre casax), 75.

«Mudrost' $\$ 36$.

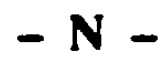

«Nabljud/at'/enie» 28 («čtoby lučse n. solnce»), 46.

«Nadevat' 29 («Master n.et Sjlapuw).

«Nadziratel'/i», «vtoroj»/«pervyj n.» 27, 30. 34.

«Nadziratel" 27/28 («mladsij n.w/«peredavat' pontenija of starక̌ago nadziratelja mladXemux), 30 ( $\mathrm{km}$. n. spraxivaet: (Kto tam?? ) , 33, 36, 72, 91.

«Nactiratel', starsij n.» 28/29 (*Otvet: P. starSago nadziratelja na juge/na zapade/na vostokex/«peredaval' porucenija of starsago $n$-ja mladsemum/atak i starsij n. stoit na zapade, ctoby okonxit' den'. ctoby zakryvat' ložu, platit' ljudjam ix zarabotok i otpuskat' ich s rabotyx).

«Nakazaniex 31 («pod strachom takogo n-jaw). Nameki siche alljuzija 
*NauXaconyj 30 (*D. provozatymm).

*Naugol'nik» 30 ( n.»), 33, 36, 37.

.Neksman" 31 (kslovo prinjatija novoprinjatogo»).

«Nemensij» 29 («Ja zaprežaju vsjakuju bran', $k-y$ ili sopotw i vse profannye razgovory, kakogo by roda ni bylo, pod nim straforn, cto kakoj polozit' bol'sinstvo.»), 72.

«Nepodvižnaja/nij» 31 (xpodvižnaja vexx'»), 37 («tri podvižnych i tri nepodvižnych klejoodyx).

«Nezakonno* 31.

«Ne vydaval' 30/31 («Master sprasivaet ego: Obectace li on nikomu i nikakim obrazom ne vydavat' masonskoj tojny>x).

«Ni gravirovat'» 31 («novoprinjatyj ne budet izobrazat' (...) i ....).

«Ni krasit'» 31 («novoprinjatyj ne budet izobražat' (...) i ...x).

«Ni poxatat' 31 («novoprinjatyj ne budet izobrazat' (...) i ....).

«Ni pisat'» 31 («novoprinjaryj ne budet izobražat' (...) i ...»).

«Ni podavat' 31 («novoprinjatyj ne budet izobrazat' (...) i ...x).

«Ni risovat' 31 («novoprinjatyj ne budet izobrazat' (...) i ...»).

«Ni vyrezyvat'» 31 («novoprinjatyj ne budet izobrazat" (...) i ....).

«Nizkoj» 31 («Pust' mne budet pererezana seja, jazyk vyrvan s komem i zaryt $v$ moskom peske pri $\mathrm{n}$. vode za kabel'tov razstojanija of berega, gde priliv i otliv prochodjat dvazdy $v$ dvadcat' cetyre casan).

«Nogar 30 («na levuju obutuju n-gu nadevajut tuflju»).

«Novoprinjatyj» 31 («ne izobrazat' ètoj tajny nikakim voobrazimym sposoboms).

«Nravstven(nosti)/nyj/najas 20, 23 (nravstvennaja rabotax), 25, 27 (nravstvennaja rabotax).

$$
-\mathbf{0}-
$$

«Obesza/nie/-t'» 30 («Master sprałivaet ego: Obescat li on nikomu i nikakim obrazom ne vydavat' masonskoj tajny >w), 31 (obescanie kljatvy).

«Objazannost'/i» 23 («starye 0.»), 27 («pervaja o. masterar), 28 ( $\propto V$ cem sostoit vasa o.»).
*Obnazat' 29 («potom o-ajut emu pravoe koleno, an levuju obutuju nogu nadevajut tuflju, zavjozyvajut plakatom glaza $i$ predostavljajut ego na Deskol'ko vremeni ego razmyslenijamo), 30 (kemu rastegivajut zilet i k o-eanoj levoj grudi pristavljajut ostrie cirkulja, kotoryj on sam deržt v levoj rukew).

*Obrjadnost' vol'uych kamenxxikov» 26, 29, 31, 36, XX (кo. prežnego russkogo maconstvan).

rObrjady prieman 24, 29.

Obscestrolan, anjp(oe/ye)»22, 24, 26, 62 , 110, XXII («t. o. v Rossii» 0. J.).

*Obskurantizm* 50.

«Ob" javljat' 28 ( 2 Zatem master snimaet sljapu i o-et ložu otkrytoj, sledujušximi slovamix).

*Ochranjat' \$ 30 («Komnata o. brat'jami»).

*Odin» 28, 29 ( $\times$ Kandidat ostavljactsja ( $v$ coboj komnate) odinx).

«Okontanie raboty/truda* 35.

*Okon'it' 28 («kak solnce zachodit na zapad, Ctoby 0. den' $\left.^{\prime}\right), 46,48$.

*Orden 22 («o. svobodnych kamensxikov»).

*Ostat'sja bez 8ljap* 29 (*Master udarjaet tri ran o stol derevjannym molotkom i nadevaet sljapu; o-nye brat'ja o-jutsja b. §..»).

«Ostavat'sja» 29 ( $\times$ Kandidal o. (v osoboj komnate) odin $x)$.

*Ostrij» 30 (xemu rastegivajut zilet $i k$ obnazennoj kevoj grudi pristavljajut o-ie cirkulja kotoryj on sam derzit v levoj nukex).

ardetyj 36 («otdetyj prosto vo frakw).

*Otkryt' 28/29 («dostopožtennyj, loža o-anl akak master o-vaet ložuw/«Kak solnce vschodit na vostoke, ctoby 0 . den' hožux), 30.

«Otpuskat' 28 («O. ich s raboty»).

«Otvexat' 30 («Master o-aet tremja udarami molotkax).

«Otves'» 37.

«Otvet» 28 («O.: Pozadi starłago nadziratelja na jugex).

\section{- P -}

«Pal'ba* 31.

«Parol'» 18, 26.

«PCela» 39, 74 («Loťa Aleksandr k PCelex).

«Pecatat' $₫$ siche «ni p.». 
«Percatkiø 36 («belye p.»), XX («Podnesenie masonkich p-tok A. E. Labzinoj» (1819)).

«Pereduvat' 28 («p. poruðenija ot starsago nadziratelja mladsemux).

«Perednito/<zapon* 31, 33, 34, 38.

«Pererean'» 31 («Pust' mne budel p-zana seja, jazyk vyrvan s kornem i zaryt $v$ morskom peske pri nizkoj vode $2 \mathrm{a} \mathrm{ka}$ bel'tov razstojanija of berega, gde priliv i otliv prochodjat dvatdy $v$ dvadcat' Cetyre casas).

«Pesni» XVII («Rannie masonskie p.»), XX (kmasonskie pesni»).

«Pesok» 31 («Pust' mne budet pererezana Seja, jazyk vyrvan $s$ kornem i zaryt $v$ moskom p-ke pri nizkoj vode za ka bel'tov razstojanija of berega, gde priliv i otliv prochodjat dvazdy $v$ dvadcat' Cetyre Casan).

«Pir 31 («masonskij p.»).

«Pisat' siehe «ni p.».

«Plakatr 29 (kzavjazyvajut p-om glaza i predo stavljajut ego ma neskol'ko vremeni ego rasmysllenijams).

«Ptatit' 28 («p. ljudjam ich zarabotok $i$ otpuskat' ich 8 raboty").

«Poctennyj» siehe «dostopoctennyj.

«Podavat'» siehe «ni p.»

«Podvižnaja/nij» 28 («p. vešc»), 31 (кtri pnych $i$ tri nep-nych klejnody»), 38.

«Pokałite emu svet» 30 (xslovo mastera k kandidatux).

«Polorov'» 63.

«Pokryvat' 28 («smotret' ctoby loža byla ptan).

«Pokryvatel'» 28.

«Pol» 30 («tri gorjaxija svexi stavjatsja v certeZe na p-u, $v$ vide treugol'nika (...)x).

«Položit' 29 («Ja zaprescaju vsjakuju bran', kjatvy ili sopot, i vse profannye razgovory, kakogo by roda ni bylo, pod nemen'Kim \$-om, cem kakoj p. bol'Sinstvon).

«Ponucenijao 29 («peredavat' p. ol staršago nadziratelja mladsemux).

«Postavit' " 28/29 (*Master p-it ljudej na rabotux).

«Posvescenie* 24.

«Pozadio 28 («Otvet: P. starsago nadziratelja na juge/na zapade/oa vostokex).

«Pozannie samogo sebjan 52 (Novikov).

«Pravyj/oe/aja 29/30 («polom obnatajut emu p-e koleno, na levuju obutuju nogu nadevajut tufju, zavjazyvajut plakatom glaza i predostavljajut ego na neskol'. ko vremeni ego razmyšlenijamw/ «Kandidx kladet p-uju nuku na evangelie, razvernutoe na ctenii ot sv. Ioanna, i pri clom proiznosit za masterom prisjaguo).

«Prazdnik» XX (loannov den' - masonskij p.e).

«Predlagajuscij» 30 ( $\alpha$ Kogda vse prigotovlenija kookeny, p. stučcit tri raza v dver' loiiv).

«redlotennyj 29 («Master sprałivaet potom, gotov-li k prinjatiju džentl'men, p-yj v prosbj raz? $x$ ).

«Predostavljat'» 29 («potom obnazajut emu pravoe koleno, na levuju obutuju nogu nadevajuk tuflju, zavjazyvajut plakatom glaza i p-jut ego na neskol'ko vremeni ego raumy కlenijamx).

«Prigotovlenie» 30 (xkogda vse p-ja konceny....).

«Priem 24, 27 (xceremonija p-as), 29 («Obrjady p-an).

«Prikazal * 30 ( Posle voprosa mastera $k$ kandidatu, on p-lx).

«Prikosnovenie» 26, 31.

«Prinadleźnosti 35.

*Prinjat'/ie» 16 ( 4 . maja ja byl prinjat $v$ masony in aKisinevskif dnevaik 1821), 29, 30, 31, 38, («p. $v$ masonyw/aZelanie, istinnoe byt' p-ym* I «Master sprasivaet potom, gotov-li k p-ju dzentl'men, predlozennyj $v$ prosloj raz? $x), 60$ («4. maja ja byl prinjat $v$ masony in aKisinevskij daevnik» 1821), 72, 78, 107 («4. maja ja byl prinjat $v$ masony $*$ in $\alpha$ Kisinevskij deevalk» 1821), XXVIII (*Prinjatie $v$ masony v 1815 godu. (1870)).

«Prisjaga» 30/31 («Kandiat kladet pravuju ruku ma evangelie, razvernutoe ma ctenii ot sv. Joanna, i pri ctorn p-t za masterom p-un).

«Privodit' 29 («Kandidat ostavljaetsja (v osoboj komnate) odinx. Ortuda ego privodjat v druguju komnatu, soversenno temnujux).

«Profannyj/yex 10, 11, 19, 21, 23, 29 (אJa mprestaju vsjakuju bran', kljatvy ili sopotw i vse p-ye razgovory, kakogo by roda ni bylo, pod nemen'sim straform, two kakoj položit' bol'sinstvow), 34, 35.

*Proiznosit' * 30 («Kandiat kladet pravuju ruku na evangelie, razvernutoe na ctenii of sv. loanna, i pri etom p-t za masterom prisjagux). 
«Proßloj raz» 29 («Master sprasivaet potom, gotov-li $k$ prinjatiju džentl'men, predložennyj v p. r.?x).

«Putešestvija masterov» 33.

«Puti s vostoka na zapad 30.

$$
-\mathbf{R} \text { - }
$$

«Rabota" 19, 23 (knravstvennaja t.»), 27/28 («Opuskat' ich s rabotyo/xMaster postavit ljudej $n$. r-uw), 33, 35 (kokoncanie raboty"), 101.

«Raz 28 (*Master udarjact tri r-a o stol derovjannym molotkom*), 29 (xstuxit' tri r-a v dver' ložix), 30.

«Razgovory* 29 («Ja zaprešaju vsjakuju bran', kljatvy ili sopotw $i$ vse profannye $r-$ $y \times)$.

«Razmyšlenie» 29 («potom obnazajut emu p-oe koleno, na levuju obutuju nogu nadevajut tuflju, z-jut plakatom glaza i pjut ego na neskol'ko vremeni ego rjam*), 90 («Sii razmyšlenija byli prervany nečajanno tremja franmasonskimi udarami $v$ dver'* in aGrobovszik» 1830).

«Remeslo/ennik/i» 18 («korolevskoe r-O»), 23 ( $\alpha$-yj toud v ložew/akorolevskoe r.»), 36. 8486 («Mocart i Sal'erix 1830/31), 90 (aNrav nasego grobovsxika soveršenno sootvetstvoval mraxnomu ego $\left.r-u_{x}\right)$ in eGrobovscik* 1830).

«Risoval' * siehe «ni risovat' *

«Roza* 67 («Roza* 1815), 99 («Drugoj - molodoju krasavicu s orlinym nosom, s zacesannymi viskami i s r-ju $v$ pudrenych volosach in aPikovaja damax 1833/34).

«Rozen'urejcet/y/stvow 45, 47-50,52,54, 56, $60,62,65,68,88,99, \mathrm{XIX} / \mathrm{XX}$ (istorija r-stva v Rossii).

«Ruka» 30 (kemu rastegivajut żilet i $k$ obnaZennoj levoj grudi pristavljajut ostrie cirkulja, kotoryj on sam derzit $v$ levoj rukeo/kKandiat kladet pravuju ruku na evangelie, razvernutce na ctenii ot sv. loanna, i pri étom proiznosit za masterom prisjagu»).

«Russkjj vol'nyj kamenscik» 31.

$$
-\mathbf{S}-
$$

«Silaw 36, 87 ( $\times$ S. garmonii in aMocart i Sal'eris 1830/31).

«Skamejka 30 («Posle togo kandidata podvodjat, tremja masonskimi kagami, $k$ s-e, stojaxcej pered upomjanutym reteZemp).

«Slovow 26, 29 (xZatem master snimaet sljapu i ob"javljaet ložu otkytoj, sledujusčimi s-amix), 31 (ks. ubenikas).

«Smotret'» 28 (as. Cuoby loža byla pokrytan).

«Snimat' - 28 (aZatem master s-et sljapu i ob" javljact ložu otkrytoj, sledujuscimi slovamix).

«Sobratstvo* 23.

«Solnce» 29 («čtoby luž̌e nabljucat' s.w/xkak s. zachodit na zapad, ctoby okonxit' den'w/akak solnce vschodit na vostoke, ctoby otkryt' den' $x), 36$.

«Solomon» 38 (xchram gumannostiw/xchram S-ovas).

«Soveršennyj» 29 («\$-o temnaja komnata»), 37 («sover'̌ennyj, kubix̌skij kamen'»).

«Spisok loz» 31.

«Sprasivat' 28 («Master sprałivaet mladł̌go diakonas), 29 («Master s-et potom, gotov-li $k$ prinjatiju džentl'men, predložennyj v prołloj raz? $\rightsquigarrow$ ), 30 (Kedes'v temnoj komnate s. egow/ks-jut ego imja i zvaniew/crmladsij nadziratel' s-aet: Kto tam?»»), 72.

«Starsij nadziratel'» siche nadziratel'.

«Stepeni» 25 («simvolixeski-nravstvennye si»), 26 ( «juannovskie $s-i=$ pervyja tri $s-i \nsim / \alpha v y s s_{i j a}$ s. $\left.\infty\right)$.

«Stoit' $\nsim 28$ («mladsij diakon stojaszij na straže u dverejw), 29 («Kak solnce vschodit na vostoke, ctoby otkryt' den', tak master stoit na vostoke, ctoby otkryt' svoju bžu i postavit' ljudej na rabotux), 30 (kmaster stoit $v$ lože na vostokex).

«Stol» 29 («masterskij s.»), 33/34, 72.

«Storonas 28 (notverat's drugoj s-y talze tremja udaramix).

«Strach» 31 («pod strachom takogo nakazanijax).

«Straž 28 («stojat' na s-e u dverej»).

«Strogaja nabljudenija» (=Strikte Observanz) 46.

«Stucit' * 30/31 («predlagajušcij s. tri raa v dver' bžis).

«Svexi» 30 («tri gorjaxija sveči stavjatsja v teze na polu, $v$ vide treugol'nika (...) $)$. 
«Svetw 26 (*Slovo mastera $k$ kandidatux: Poknzite emu svetox), 47, 49 (*Utreonij svetw Novikova).

«Svetil'nil/iø 36 (*Tri mensie/velikie s-a masonstvan).

*Sv. Ioann* 29 ( «èto loźa otkryta vo imja sv. Iax), 30 («na evangelii I-ax).

«Svobodanij» 22, 31 («chrenit' i ne vydavat' ni pod kakim vidom nikakoj iz tajnych misterii s-ago komea'scixestvar), 70 73, 111 ( $\alpha$ I vozaoves' 8." in aGeneraI. Puxxinn 1821).

«Simvolixeski-nravstvennye atepeni 25.

«Sistemy» 29 («Masonskjja s.»), 33, 36.

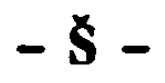

«Sag* 30 (*Posle togo kandidata podvodjat, tremja masonskimi $\$$-ami, k skamejke, stojasxej pered upomjanutym certeZem*), 33 («masterskij $Z_{.} »$ ).

*Sarlacanstvo* SO.

«Sej» 31 («Pust' mne budet pererezana $\zeta-j a, j a-$ zyk vyrvan s kornem i zaryt $v$ morskom peske pri nizkoj vode za kabel'tov razstojanija of berega, gde priliv i otliv prochodjat dvazdy v dvadcat' cetyre san).

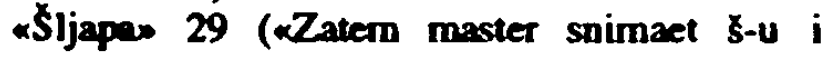
ob" 'javljact ložu otkrytoj, sledujuszimi slovami $\gg$ Master nadevact $\$-u$ / kostal'nye brat'ja ostajutsja bez sljap»), 38 (xkruglaja sljapax).

«Sopot» 29 («Ja zaprestaju vsjakuju bran', kjarvy ili $8 . \infty$ i vse profannye razgovory, kakogo by roda ni bylo, pod nemen'sim straforn, cto kakoj položit' bol'sinstvo.»).

«Spaga» 37 (Symbol der Hochgrad-Freimaurereix).

«Straf 29 ( (Ja zapresčaju vsjakuju bran', kljatvy ili sopot, i vse profannye razgovory, kakogo by roda ni bylo, pod nomen'క̌in $s$-om, đem kakoj položit' bol'sinstvox).

$$
-\mathbf{T}-
$$

«Tajoaw 31 (masonskajan) («Master sprasivaet ego: Obexzact li on nikomu i nikakim obrazom ne vydavat' masonskoj t-ysw) «chranit' i ne vydavat' ni pod kakim vidom nikakoj iz tajaych misterii svo- bodnago kamen'sciðestvan), 84, (wMocart I Sal'eri- 1830/31).

*Tajnopis'* XX (*masonskaja t.x).

«Tapii* 36.

*Temnaja komnata* 30 («Kandidat ostavljaetsja \{v osoboj komnate\} odinw. Ottuda ego privodjat $v$ druguju komnatu, soversenno kemnujux), 98 (xtemnyj kabinet in Pikovaja damam 1833/34)

«Ten'* 82 («Kinzal L, t. B (...)* rätselhafte Strophe IX im 10. Kapitel des avgeaif Oregino 1820-30).

*Tost» 31, 22 (*Grobovšciko 1830).

*Tovaris $x$ /i/Cestvo* 19, 22, 25/26, 30-33, 92 ( $*$ Skelet $=$ tovaris $x *$ in $*$ Grabovsxit $*$ 1830)

*Treugol'nik 30 (*tri gorjaxija svexi stavjatsja $v$ certeže na polu, $v$ vide $t-a(. .) w$.$) .$

*Tri» 28 («udarjar' tri raza v dver' *), 29 (*Master udarjact tri raza o stol derevjannym molotkon i nadevaet sljapux), 30 (*tri gorjasija svexi stavjatsja v certeze na polu, $v$ vide treugol'nika (...)w/ustucit' tri raga $v$ dver' ložiw/kM. otvetaet tremja udarami molotkan/«Posle togo kandidata podvodjat, tremja masonskimi కagami, k skamejke, stojašej pered upomjanutym certežems), 36 («Tri mensie /velikie svetil'nika masonstvaw), 37 (ktri podvižnych i tri oepodvižnych klejnody"), 79, 86, («Mocort i Sal'eri- 1830/31), 90/91 (eGrobovexik» 1830), 97 («tri vernye karty» in aPikovaja dama* 1833/34)

*Trud» 30, 32 (*okoncanie raboty/t-ax), 75, 84. «Trup 75, 77 («Kak t. v pustyne ja ležal» in Proroks 1830), 84 («Muzyku ja raz"jal kak t. in aMccart i Sal'erio 1830/31).

*Tuflja* 29 (*levuju obutuju nogu nadevajut tjux).

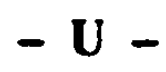

«UČenik» 25, 26, 31, 37 («dikij kamen' dija uas).

«Udarjat' * 28 ( (U. tri raza v dver' $*)$.

«Udr'» 28 (xtremja u-ami otvetat'w/xMaster udarjact tri raza o stol derevjannym molokkom i nadevaet sljapu; ostal'nye brat'ja ostaetsja bez Sljapw), 30 ( $\mathrm{kMa}$ ster ofvecaet tremja u-ami molotkas), 72. sars1 (*Grobovzxik $=1830$ ).

«Ukej» 39.

Markus Wolf - 9783954790715 
*Umolkaniex 31 (*bez vautrennogo u-jas). «Ustav vol'nych kamenscikov» XX.

«Uvertki 31 («ni bylo U.»).

$$
-\mathbf{V}-
$$

*Velikij/ie» 36 (*Tri mensie/v-ie svetil'nika masonstvax).

*Vetv'» 39 («v. akacii»).

«Vid/enie» 30 («tri gorjaxija svexi stavjatsja v Certeze na polu, $v$ vide treugol'nika (...) x), $85(x V$. grobovoex in a Mocart i Sal'erio 1830/31)

«Vnutrennij» 23 («v. chramx), 31 («bez v-ogo urmolcanijas).

*Vnutrennost' loži 37.

*Voda* 31 («Pust' moe budet pererezana Seja, jazyk vyrvan s kornem i zaryt $v$ moskom peske pri nizkoj vode za kabel'tov razstojanija ot berega, gde priliv i otliv prochodjat dvazdy $v$ dvadcat' cetyre casas).

*Vol'nyj kamensxik» 80.

Vol'nodumec 80.

Volter'janec 10405.

«Vo imja* 29 («vo imja sv. loannas).

*Vopros* 30 («Posle v-a mastera $k$ kandidatux).

«Vostok» 25 («na v-ke/kak solnce vschodit na v-kex), 28 («Puti s v-ka na zapadx), 29 («Kak solnce vschodit na v-ke, ctoby otkyt' den', tak master stoit na i-ke, ctoby otkryt' svoju ložu i postavit' ljudej na rabotu»), 30 («master stoit $v$ loZe na v-ex).

*Vremjar 29 («zavjazyvajut plakatom glaza $i$ predostavljajut ego na neskol'ko vremeni ego rasmyšlenijamm).

«Vsjakij» 29 ( (Ja zaprešaju v-uju bran'*).

*Vstan' 77 (Bezug zum Meistererhebungsritual in *Prorok\$ 1826).

*Vydavat'* 30/31 («ne v. masonskoj tajny»/ «chranit' i ne vydavat' ni pod kakim vidom nikakoj iz tajnych misterii svobodnago kamenscicestvax).

«Vyrezyvat'* siehe *ni v.».

«Vyrva'* 31 («Pust' mne budet pererezana beja, jazyk v-van s kornem i zaryt v morskom peske pri nizkoj vode za kabel'tov razstojanija of berega, gde priliv i otliv prochodjat dvazdy $v$ dvadcat' Cetyre casar), 75/76 ( $\propto V$-val gresnyj moj jazyk» Bezug zur freimaureri- schen "Eidesformel" in Proroks 1820).

$$
-\mathbf{Z}-
$$

Zachodit' 28 (aksls solnce z. na zapad, ctoby okonkit' den'y).

«zakryva' 28 («tak i starłij nadziratel' stoit na zapede, ctoby okonxit' den', ctoby 2. ložu, pletit' ljudjam ich zarabotok i otpuskat" ich s rabotyy).

¿Zapad 28 (*Otvet: Pozadi starsago nactairatelja na juge/na 2 -de/na vostokew) 29 (akak solnce zachodit na z-e, ctoby ckoaxit' den'»), 30 («Puti s vostoka na 2.x).

×Zapon»/кperednik» 31, 33/34, 38.

¿Zaprescat'» 28 ( $\mathrm{Ja}$ zaprescaju vsjakuju bran' $x)$.

«Zarabotki» 29 («platit' ljudjam ich 2-ok i otpuskat' ich s raboty").

¿Zaryt' * 31 («Pust' mne budet pererezana seja, jazyk vyrvan s kormem i zaryt v morskom peske pri nizkoj vode za kabel'tov razstojanija of berega, gde priliv i otliv prochodjat dvażdy v dvadcat' cetyre $c_{\text {a }}$ san).

«Zavjazyva'» 29 («potom obnazajut emu p-oe koleno, na levuju obutuju nogu nadevajut tuflju, z-jut plakatom glaza i predostavljajut ego na neskol'ko vremeni ego razmyslenijamm).

ZZak» 31, 38 («masonskie Z-i»).

¿Zvanie» 29 (ku nego sprasivajut ego imja i 2.x)

«Želaniex 29 («imeet-li on istinnoe Ż. byt' prinjatym?x).

$$
-\mathbf{2}-
$$

*Žilet» 30 («emu rastegivajut z. i k obnažennoj levoj grudi pristavljajut ostrie cirkulja kotoryj on sam deržit v levoj nukex).

¿telanie» 26 («istinnoe $z$. byt' prinjatym*), 61 («Otnositel'no ze zanjatija ego po masonskoj lożi, to ne po otkrytiju takovoj, te možet byt' onym, chotja by $i$ z. ego k tomu bylow), so General Inzov an Volkonskij iber Puskins Loge «Ovidij» 1821). 


\section{SLAVISTISChE BEITRÄGE}

(1995-1997)

Herausgegeben von Peter Rehder

323. Tchouboukov-Pianca. Florence: Dic Konzeptualisicrung der Graphomanic in der russischsprachigen postmodernen Literatur. 1995. 140 S. 34.- DM. (3-8769()-594-X)

324. Lehfeldt. Werner: Eintührung in die Sprachwissenschali lür Slavisten. 1995. 2. verb. und crg. Aul1. 1996. 182 S. 30.- DM. (3-87690)-6()6-7) (Studienhillien. 3.)

325. Bonola, Anna: Osip Mandel štams ..Eg̣ipetskaja marka”. Einc Reckonstruklion der Motivsemimtik. 1995. 286 S. 46.- DM. (3-87690)-607-5)

326. Бирих, Александр: Метонимия в современном русском языке. (Семантический и грамматический аспекты). 1995. 11. 191 S. 40.- DM. (3-87690-608-3)

327. Schuster, Rudolf: Synonymitait im Text. Eine Untersuchung an russischen Textheispielen. 1995. 232 S. 44.- DM. (3-87690-6(09-1)

328. Miszewski. Brigitta: New-Age-Diskurs in der polnischen Literaturwissenschaft. Literaturk ritik und Lyrik der 7ker und 80er Jahre. Rekonstruklion cines Weltbildes. 1995. 2.36 S. 44.- DM. (3-8760)-611-3)

329. Pülsch. Anja: Emigration als literarisches Vertiahren bei Zinovij Zinik. 1995. 2()2 S. 40.- DM. $(3-8769)-612-1)$

3.30. Богатырев, Константин К.: Акиентуашия северолехитских говоров с историческої точки зрения. 1905. VI. 169 S. $4(0 .-$ DM. $(3-87690)-61.3-X)$

331. Mielke. Tomas M.: Der homosexuclle Wortschatz im Russischen. Einvernchumliche und Lagersexualitit swischen Miinnern. 1995. 1.39 S. 32.- DM. (3-8769)-621-())

332. Slavistische I.inguistik 1994. Referalle des $X X$. Konstanzer Slivistischen Arbeilstreffens. Zürich 2().-22.9.1994. Herausgegelenn von Danicl Weiss. 1995. 11. 39.3 S. 52.- D.11. 1.3-8769)6.2-9)

33.3. Meyer, Holt: Romantixche Orienticrung. Wandermodelle der romantinchen Bewegung (Rubland): Kjuchel boker - Puskin - Velomam. 1905. 542 S. 58. DM. (3-8769)-623-7)

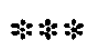

3.34. Schmaus, Alois: Lchrbuch der serbischen Sprache. Band II. Vollstiandig new bearbeilet von Vera Bojic: 1906. 252 S. 36.- DM. (3-8760)-624-5) (Studienhilfien. 4.)

33.5. Lauersdort, Mark Richard: The question of 'Cullural Languige" and interdialectal norm in IGh century Slovalkia. A phonological analysis of I 6 h century Slovilk administrative-legal (cxis. 1996. 267 S. 44.- DM. (3-876)()-(3+1)-7)

3.36. Huelmann. Magdalene: Die litauischen und kellischen Arheitslieder. Ein Vergleich. 1\%96. 318 S. 48.- DM. $(3-8760)-641-5)$

3.37. Drews, Peler: Deutsch-slavische Lilcrallurbezichungen im I8. Jahrhundert. 1996. 4.30 S. 52.DM. $(3-876(x)-6+2-3)$

3.38. Mendoza. Imke: Zur Koordination im Russixchen: u, $a$ und da als pragmattische Konnckloren. 1006. 248 S. H.- DM. (3-8760()-648-2)

3.39. liggers, Martin: Das Ersbistum dev Method. Lage. Wirkung und Nalchleben der hyrillomethodianischen Mission. 1906. 18.5 S. 40.- DM. (3-8760()-(240-(1)) 
340. Maurice. Florence: Der modale Infinitiv in der modernen russischen Standardsprache. 1996 3.37 S. 48. - D.M. 1.3-8760)-6.50-4)

341. Willich. Heide: Lev. L. Kobylinskij-Ellis: Vom Symbolismus zur ars sacra. Eine Sudic üher Lethen und Werk. 1996. 299 S. 48.- D.M. (3-87690-6.51-2)

342. Slavistische Linguistik 1995. Referate des XXI. Konstanzer Slavistischen Arbeitstreffens. Mainz 26.-29.9.1995. Herausgegeben von Wollgang Girke. 1996. 11. 456 S. 56.- DM. (3$87690-662-8)$

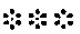

343. Федор Сo.nогуб: Собрание сочинений. Том второй: Рассказы (1909-1921). Составите.7ь У.тьрих IIIте.льтнер. 1997. VIII. 4.34 S. 54.- DM. (3-8769)-66.3-6)

344. Fvans-Romaine, Karen: Boris Pasternak and the tradition of German romanticism. 1997.329 S. 48.- DM. (3-8769)-6(24-4)

345. Kluge. Rohert: Der sowjetische Traum vom Fliegen. Analyseversuch eines gesellschaftlichen Phiinomens. 1997. I1. 246 S. 44. - DM. (3-87690-66.5-2)

346. Oppermann. Hans И.а.: Частное неофициальное письмо и тексты-рассуждения. Persönlicher Bricfwechsel und Erörlerungen auf Russisch. Ein Lehr- und (̈bungshefi für Fortgexchrittene. 1997. 12.3 S. 20.- DM1. 13-87690-666-(0) (Studienhilfen. 5.)

347. Sippl. Carmen: Reiselexte der russischen Meslerne. Andrej Belyj und Osip Mandel"stam im Kaluhilusus. 1997. 28.3 S. 46.- DM. (3-87690)-667-9)

348. Birnbaum. Henrik. Jos Schacken: Dass alth archenslavische Wort. Bildung - Bedeutung Herlentung. Altkirchenslativche Studien 1. 1997. 190) S. 36.- DM. (3-87690-668-7)

34). Israteli. Alina: Semantics and pragmattics of the "rellexive" verbs in Russian. 1997. 226 S. 42.D.M. $(3-87(6)(0)-6(6)-5)$

350. Ylli. Xlelal: Dan slavixche L.ehngut im Alhanischen. I. Teil: Lehnwörter. 1907. 344 S. 48.D.M. $1.3-87(60)(0)-(07(1)-9)$ )

3.51. Irei. Bohumil Jiri: Tschechusch grundlich und systemalisch. Ein Lehrbuch. Band 1. 1997. 360) S. 36. D.M. (3-876)()-671-7) (Studicnhillion. 6.)

352. Semjatova. Batrbel: Sologubs Schopenhatlerredeptoon und ihre Bedeutung lïr dic Motivgeviallumg in seinen Erzihlungen. 1997. 4.51 S. 54.- DM. (3-8760)-672-5)

35.3. За.лизняк. Аина А.. А.тексей Д. ШІмелев: Лекиши по русской аспектологип. 1997. 151 S. 26.- DM1. (3-8760)()-67.3-3) (Siudienhillen. 7.)

354. Slas istische I, inguistik 1996. Relerate den $\lambda \times 11$. Konstanzer Slatislischen Arheitstreflens. Potodam 17.-20.9.1906. Heramegegeten von Peler Kowlal und Elke .Mann. 1997. 368 S. 50.DM. $(3-87(0)()-(6) 1-1)$

\section{Verlag Otto Sagner \\ D)-8(1).328 München \\ e-mail: postmaster@kubon-sagner.de}




\section{Sagners Slavistische Sammlung}

Herausgegeben von Peter Rehder

Band 7: Erzpriester V. M. Metallov:

Russische Semeiographie. Zur Archäologie und Paläographie des Kirchengesangs. Paläographischer Atlas der altrussischen linienlosen Gesangsnotationen. Kommentier und herausgegeben von Johann von Gardner. Nach der Ausgabe des Kais. Archäolog. Instituts „Kaiser Nikolaus II.“, Moskau 1912. 1984. Ln. 260 S. 98.- DM. (ISBN 3-87690-290-8).

Band 11: Velimir Chlebnikov 1885-1985.

Herausgegeben von Johannes Holthusen $t$, Johanna Renate Döring-Smirnov, Walter Koschmal. Peter Stobbe. 1986. Ln. 278 S. 48.- DM. (ISBN 3-87690-330-0).

Band 14: Петр Андреевнч Гильтебрандт:

Справочный и объяснительный Словарь к Новому Завету. Nachdruck besorgt von Helmut Keipert und František Václav Mares. Mit einer Einleitung .Zur Geschichte der kirchenslavischen Bibelkonkordanzen“ (I. Band) und einer Einführung in .Die neukirchenslavische Sprache des russischen Typus und ihr Schriftsystem" (II. Band). Bd. I-VI (in 5 Büchern). 1988-1989. Ln. 2538 S. 860.- DM. (ISBN 3-87690-389-0).

Band 18: Maurice L. Hébert:

Hesychasm, Word-Weaving, and Slavic Hagiography: The Literary School of Patriarch Euthymius. 1992. Ln. VIII, 533 S. 120.- DM. (ISBN 3-87690-530-3).

Band 19, I+II: Wolfgang Hock:

Der Flexionsakzent im mittelbulgarischen Evangelie 1139 (NBKM). I. Akzentgrammatik. - Il. Akzentwörterbuch. 1992. Ln. 304; XIl, 642 S. 146.- DM. (ISBN 3-87690-531-1 und -532-X).

Band 20: Петр Андреевич Гильтебрандт:

Справочный и объяснительный Словарь к Псалтири. Nachdruck der Ausgabe St. Petersburg 1898 mit einer Einleitung von Helmut Keipert. 1993. Ln. 16. VIII, 552 S. 160.- DM. (ISBN 387690-553-2).

Band 21: Sebastian Kempgen:

Die Kirchen und Klöster Moskaus - ein landeskundliches Handbuch.

1994. Ln. 698, C S. 135.- DM. (ISBN 3-87690-566-4).

Band 23: Ulrich Schwcier:

Paradigmatische Aspekte der Textstruktur. Textlinguistische Untersuchungen zu der intraund der intertextuellen funktionalen Belastung von Strukturelementen der frühen ostslavischen Chroniken. 1995. Ln. X, 322 S. 98.- DM. (ISBN 3-87690-614-8).

Band 24: Ein Leben zwischen Laibach und Tübingen. Primus Truber und seine Zeit. Intentionen. Verlauf und Folgen der Reformation in Würtemberg und Innerösterreich. Herausgegeben von Rolf-Dieter Kluge. 1995. Ln. 586 S. 140.- DM. (ISBN 3-87690-620-2).

\section{Verlag Otto Sagner D.80328 München}

Telefon (089) 54218.0 - Telefax (089) 54218 -218 - email: postmaster @ kubon-sagner.de 